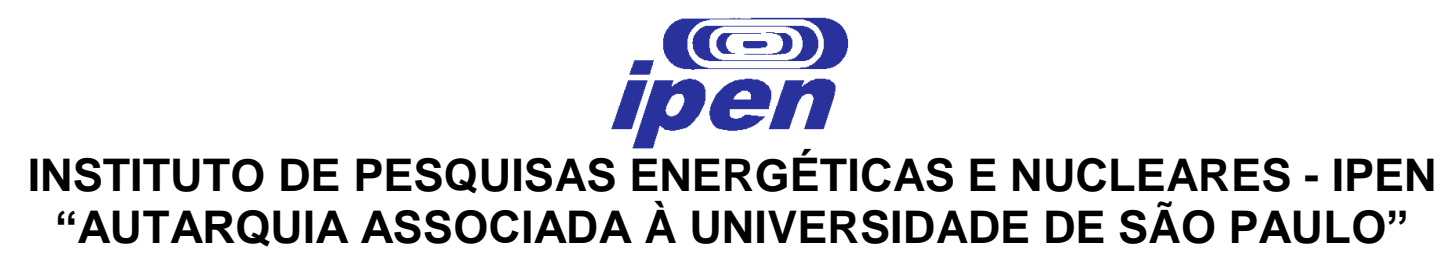

\title{
PROGRAMA DE REABILITAÇÃO DA ÁREA CENTRAL DE SÃO PAULO (PROCENTRO) E SUA INFLUÊNCIA NA FORMAÇÃO DA ILHA DE CALOR
}

\author{
WALDIR MACHO LA RUBBIA
}

Dissertação apresentada como parte dos requisitos para obtenção do Grau de Mestre em Ciências na Área de Tecnologia Nuclear - Materiais.

Orientador: Prof. Dr. Afonso Rodrigues de Aquino

São Paulo

2010 


\section{DEDICATÓRIA}

Dedico este trabalho à minha família, especialmente à minha esposa, pelo apoio e paciência durante todo o período de elaboração desta pesquisa e, aos meus netos (trigêmeos e os que ainda virão) para que recebam um planeta melhor. 


\section{AGRADECIMENTOS}

Agradeço a todos que contribuíram direta e indiretamente para a realização deste trabalho e principalmente:

- ao Instituto de Astronomia, Geofísica e Ciências Atmosféricas (IAG) da Universidade de São Paulo (USP) pelo gentil atendimento e fornecimento dos registros de temperatura e umidade do Parque Fontes do Ipiranga;

- $\quad$ à SP Urbanismo que possibilitou a minha participação neste Mestrado;

- $\quad$ à Arqa Luciana Loureiro pelas informações ambientais e do Procentro;

- $\quad$ aos professores do Programa de Tecnologia Nuclear do Instituto de Pesquisas Energéticas e Nucleares (Ipen) pela atenção e dedicação;

- ao Prof. Dr. Afonso Rodrigues de Aquino, orientador deste projeto, cujo apoio, conhecimento, contribuição e incentivo foram fundamentais para atingir esta meta. 


\title{
PROGRAMA DE REABILITAÇÃO DA ÁREA CENTRAL DE SÃO PAULO (PROCENTRO) E SUA INFLUÊNCIA NA FORMAÇÃO DA ILHA DE CALOR
}

\author{
Waldir Macho La Rubbia
}

\section{RESUMO}

A cidade de São Paulo passou por cinco grandes reurbanizações desde 1825 até os dias atuais que intensificaram o uso do solo em detrimento do clima urbano. A partir de 1960 a região central entra em um processo de decadência e, em 2002, é lançado o Programa de Reabilitação da Área Central de São Paulo (Procentro) para reverter esta situação por meio de intervenções distribuídas pelos distritos da Sé e da República que, levando em consideração as questões ambientais, reduzirão a intensidade da ilha de calor paulistana.

Palavras-chave: reurbanizações, uso do solo, ilha de calor 


\title{
REHABILITATION PROGRAM OF THE CENTRAL AREA OF SÃO PAULO (Procentro) AND ITS INFLUENCE ON THE FORMATION OF HEAT ISLAND
}

\author{
Waldir Macho La Rubbia
}

\begin{abstract}
The city of São Paulo passed through five major urbanizations since 1825 until today that intensified land use over urban climate. Since 1960 the central region goes into a process of decay, and in 2002 is being launched Rehabilitation Program of the Central Area of São Paulo (Procentro) to reverse this situation through assistance distributed by the Districts of the República and Sé and that taking into consideration environmental issues, reduce the intensity of the heat island of São Paulo.
\end{abstract}

Keywords: urbanizations, land use, heat island. 


\section{SUMÁRIO}

Página

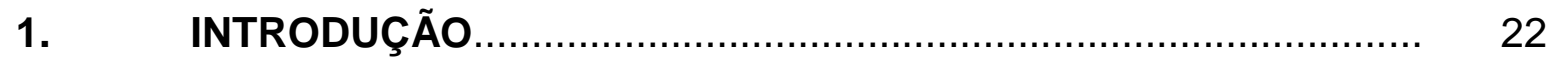

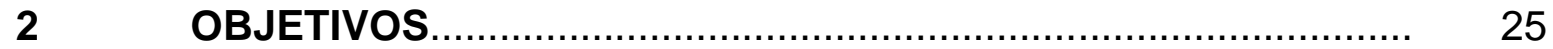

3. PROCESSO DE URBANIZAÇÃO DO MUNICÍPIO DE SÃO 26 PAULO

3.1 Primeira reurbanização.......................................................... 28

3.2 Segunda reurbanização.......................................................... 32

3.3 Terceira reurbanização.......................................................... 33

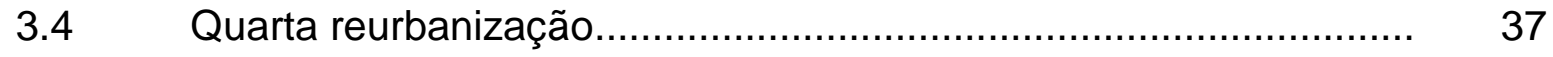

3.5 Quinta reurbanização............................................................... 41

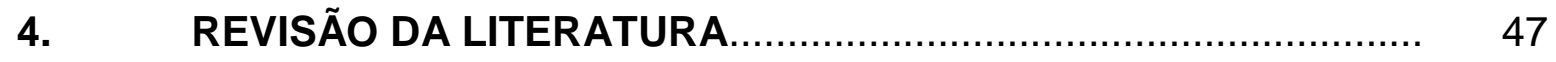

4.1 Considerações preliminares.................................................... 47

4.2 Densidade vertical................................................................... 48

$4.3 \quad$ Impermeabilização do solo......................................................... 49

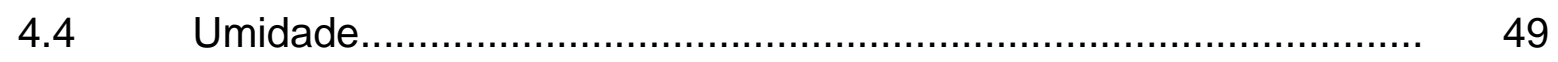

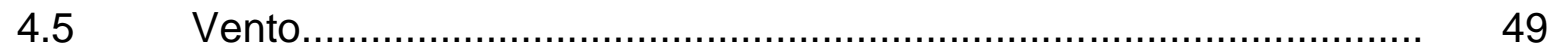

4.6 Poluição do ar.................................................................... 50

4.6.1 Padrões de qualidade do ar ...................................................... 51

4.6.2 Efeito estufa .............................................................................. 54

4.6.3 Dióxido de carbono ………................................................... 55

4.6.4 Umidade ........................................................................... 55

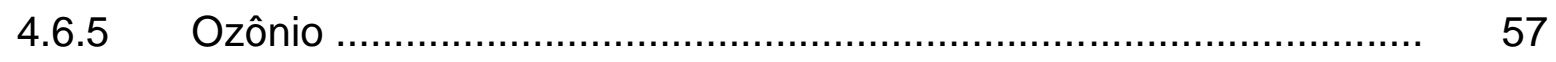

4.6.6 Clororofluorcarbonados ............................................................ 58

$4.7 \quad$ Ilha de calor....................................................................... 58 


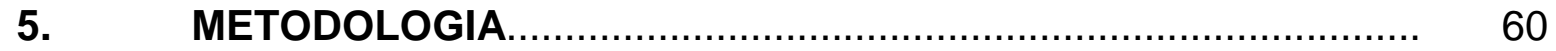

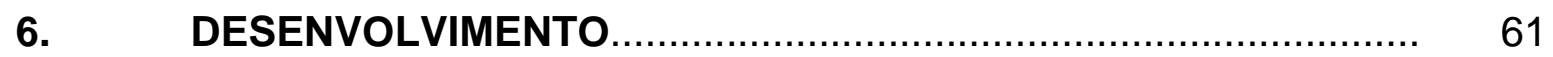

6.1 Temperatura e umidade relativa do ar....................................... 61

6.2 Poluição atmosférica................................................................... 63

6.3 Densidade demográfica................................................................ 66

6.4 Cobertura vegetal.............................................................. 67

6.5 Resíduos sólidos......................................................................... 67

6.6 Adensamento vertical............................................................ 67

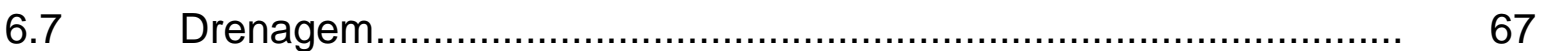

$6.8 \quad$ Programa Procentro............................................................... 68

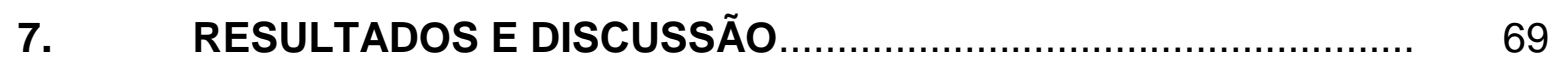

7.1 A ilha de calor na Subprefeitura da Sé.......................................... 69

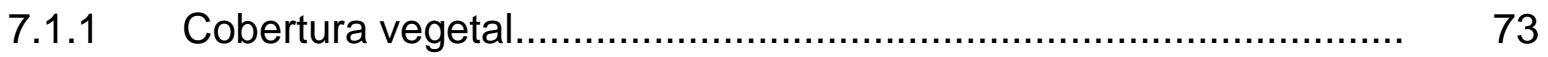

7.1.2 Adensamento vertical............................................................ 76

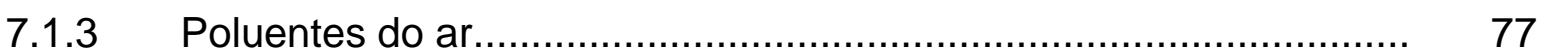

7.1.3.1 Teores de fumaça ................................................................. 77

7.1.3.2 Partículas inaláveis ............................................................... 77

7.1.3.3 Partículas totais em suspensão ……….......................................... 77

7.1.3.4 Dióxido de carbono ...................................................................... 78

7.1.3.5 Dióxido de nitrogênio .......................................................... 80

7.1.3.6 Monóxido de nitrogênio ............................................................ 80

7.1.3.7 Ozônio......................................................................................... 80

7.1.4 Temperatura do ar........................................................... 81

7.1.5 Umidade relativa...................................................................... 84

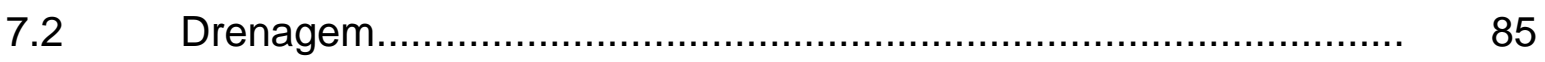

7.3 Resíduos sólidos no Município de São Paulo.................................. 86

7.4 Ações do Procentro ............................................................... 88 
7.4.1 Ações de revitalização ............................................................. 89

7.4.2 Ações de drenagem ............................................................. 90

7.4.3 Ações de controle da poluição do ar ............................................... 91

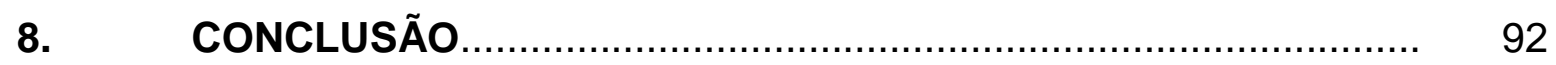

APÊNDICE A - Gráficos e tabelas de concentrações de poluentes do ar..... 95

APÊNDICE B - Gráficos e tabelas de temperatura do ar.............................. 101

APÊNDICE C - Gráficos e tabelas de umidade relativa do ar....................... 149

APÊNDICE D - Ações de revitalização do Procentro...................................... 197

APÊNDICE E - Ações de drenagem do Procentro......................................... 212

APÊNDICE F - Ações de controle da poluição do ar do Procentro................ 215

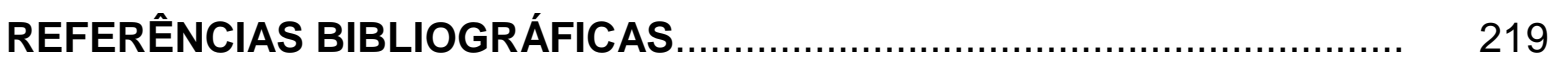




\section{LISTA DE TABELAS}

Página

TABELA 1. Densidade demográfica por distrito da Subprefeitura da Sé... 46

TABELA 2 Padrões de qualidade do ar................................................ 53

TABELA 3. Parâmetros e métodos nas estações automáticas................... 65

TABELA 4. Parâmetros e métodos nas estações manuais......................... 66

TABELA 5. Cobertura vegetal por distrito da Subprefeitura da Sé............. 75

TABELA 6. Índice de cobertura vegetal por área dos distritos da Subprefeitura da Sé.

TABELA 7. Frequência das máximas intensidades da ilha de calor registradas nos anos de 1981, 1983, 1988, 1993, 1998 e 2003.

TABELA 8. Frequências dos horários em que ocorreram as máximas intensidades da ilha de calor registradas nos anos de 1981, 1983, 1988, 1993, 1998 e 2003.

TABELA 9. Máximos teores anuais de fumaça nas estações de monitoramento da CETESB da Subprefeitura da Sé de 1989 a 2008........

TABELA 10. Concentrações máximas anuais de partículas inaláveis nas estações de monitoramento da Subprefeitura da Sé de 1998 a $2008 .$.

TABELA 11. PTS máximas anuais nas estações de monitoramento da CETESB da Subprefeitura da Sé de 1989 a 2008

TABELA 12. Máximas anuais de $\mathrm{NO}_{2}$ nas estações de monitoramento da CETESB da Subprefeitura da Sé de 1998 a 2008.

TABELA 13. Máximas anuais de NO nas estações de monitoramento da CETESB da Subprefeitura da Sé de 1998 a 2008.

TABELA 14. Máximas anuais de $\mathrm{O}_{3}$ nas estações de monitoramento da CETESB da Subprefeitura da Sé de 1998 a 2008.

TABELA 15. Registros horários das temperaturas $\left({ }^{\circ} \mathrm{C}\right)$ nos dias 4 de janeiro, 9 de fevereiro e 21 de março de 1981

TABELA 16. Registros horários das temperaturas $\left({ }^{\circ} \mathrm{C}\right)$ nos dias 21 de abril, 26 de maio e 26 de junho de 1981.

TABELA 17. Registros horários das temperaturas $\left({ }^{\circ} \mathrm{C}\right)$ nos dias 13 de julho, 26 de agosto e 21 de setembro de 1981

TABELA 18. Registros horários das temperaturas $\left({ }^{\circ} \mathrm{C}\right)$ nos dias 7 de outubro, 2 de novembro e 26 de dezembro de 1981 . 
TABELA 19. Registros horários das temperaturas $\left({ }^{\circ} \mathrm{C}\right)$ nos dias $1^{\circ}$ de janeiro, 16 de fevereiro e 20 de março de 1983.

TABELA 20. Registros horários das temperaturas $\left({ }^{\circ} \mathrm{C}\right)$ nos dias 14 de abril, 17 de maio e 15 de junho de 1983

TABELA 21. Registros horários das temperaturas $\left({ }^{\circ} \mathrm{C}\right)$ nos dias 16 de julho, 12 de agosto e 22 de setembro de 1983.

TABELA 22. Registros horários das temperaturas $\left({ }^{\circ} \mathrm{C}\right)$ nos dias 8 de outubro, 17 de novembro e 21 de dezembro de 1983

TABELA 23. Registros horários das temperaturas $\left({ }^{\circ} \mathrm{C}\right)$ nos dias 13 de janeiro, 7 de fevereiro e 3 de março de 1988

TABELA 24. Registros horários das temperaturas $\left({ }^{\circ} \mathrm{C}\right)$ nos dias 23 de abril, 19 de maio e 16 de junho de 1988.

TABELA 25. Registros horários das temperaturas $\left({ }^{\circ} \mathrm{C}\right)$ nos dias 7 de julho, 3 de agosto e 2 de setembro de 1988.

122

TABELA 26. Registros horários das temperaturas $\left({ }^{\circ} \mathrm{C}\right)$ nos dias 16 de outubro, 19 de novembro e 19 de dezembro de 1988

TABELA 27. Registros horários das temperaturas $\left({ }^{\circ} \mathrm{C}\right)$ nos dias 9 de janeiro, 10 de fevereiro e 23 de março de 1993.

126

TABELA 28. Registros horários das temperaturas $\left({ }^{\circ} \mathrm{C}\right)$ nos dias 15 de abril, 21 de maio e 13 de junho de 1993

TABELA 29. Registros horários das temperaturas $\left({ }^{\circ} \mathrm{C}\right)$ nos dias 19 de julho, 9 de agosto e 7 de setembro de 1993

TABELA 30. Registros horários das temperaturas $\left({ }^{\circ} \mathrm{C}\right)$ nos dias 14 de outubro, 15 de novembro e 14 de dezembro de 1993

TABELA 31. Registros horários das temperaturas $\left({ }^{\circ} \mathrm{C}\right)$ nos dias 27 de janeiro, 27 de fevereiro e 25 de março de 1998.

TABELA 32. Registros horários das temperaturas $\left({ }^{\circ} \mathrm{C}\right)$ nos dias 25 de abril, 27 de maio e 26 de junho de 1998

TABELA 33. Registros horários das temperaturas $\left({ }^{\circ} \mathrm{C}\right)$ nos dias 28 de julho, 26 de agosto e 12 de setembro de 1998.

TABELA 34. Registros horários das temperaturas $\left({ }^{\circ} \mathrm{C}\right)$ nos dias 23 de outubro, 28 de novembro e 29 de dezembro de 1998.

TABELA 35. Registros horários das temperaturas $\left({ }^{\circ} \mathrm{C}\right)$ nos dias 23 de janeiro, 23 de fevereiro e 14 de março de 2003

TABELA 36. Registros horários das temperaturas $\left({ }^{\circ} \mathrm{C}\right)$ nos dias 25 de abril, 15 de maio e 15 de junho de 2003 
TABELA 37. Registros horários das temperaturas $\left({ }^{\circ} \mathrm{C}\right)$ nos dias 2 de julho, 20 de agosto e 16 de setembro de 2003.

TABELA 38. Registros horários das temperaturas $\left({ }^{\circ} \mathrm{C}\right)$ nos dias 22 de outubro, 20 de novembro e 23 de dezembro de 2003.

TABELA 39. Registros horários da umidade relativa nos dias 9 de janeiro, 9 de fevereiro e 21 de março de 1981 .

150

TABELA 40. Registros horários da umidade relativa nos dias 21 de abril, 26 de maio e 26 de junho de 1981

152

TABELA 41. Registros horários da umidade relativa nos dias 13 de julho, 26 de agosto e 21 de setembro de 1981

TABELA 42. Registros horários da umidade relativa nos dias 2 de outubro, 2 de novembro e 26 de dezembro de 1981

TABELA 43. Registros horários da umidade relativa nos dias $1^{\circ}$ de janeiro, 16 de fevereiro e 20 de março de 1983

TABELA 44. Registros horários da umidade relativa nos dias 14 de abril, 17 de maio e 15 de junho de 1983.

TABELA 45. Registros horários da umidade relativa nos dias 16 de julho,12 de agosto e 23 de setembro de 1983.

162

TABELA 46. Registros horários da umidade relativa nos dias 8 de outubro, 17 de novembro e 21 de dezembro de 1983

TABELA 47. Registros horários da umidade relativa nos dias 13 de janeiro, 7 de fevereiro e 3 de março de 1988

TABELA 48. Registros horários da umidade relativa nos dias 23 de abril, 19 de maio e 16 de junho de 1988.

TABELA 49. Registros horários da umidade relativa nos dias 7 de julho, 3 de agosto e 2 de setembro de 1988

TABELA 50. Registros horários da umidade relativa nos dias 16 de outubro, 19 de novembro e 19 de dezembro de 1988

TABELA 51. Registros horários da umidade relativa nos dias 9 de janeiro, 10 de fevereiro e 23 de março de 1993.

TABELA 52. Registros horários da umidade relativa nos dias 15 de abril, 21 de maio e 16 de junho de 1993.

TABELA 53. Registros horários da umidade relativa nos dias 19 de julho, 9 de agosto e 7 de setembro de 1993

TABELA 54. Registros horários da umidade relativa nos dias 14 de outubro, 15 de novembro e 14 de dezembro de 1993 
TABELA 55. Registros horários da umidade relativa nos dias 27 de janeiro, 27 de fevereiro e 25 de março de 1998.

TABELA 56. Registros horários da umidade relativa nos dias 25 de abril, 27 de maio e 25 de junho de 1998.

TABELA 57. Registros horários da umidade relativa nos dias 28 de julho, 26 de agosto e 12 de setembro de 1998.

TABELA 58. Registros horários da umidade relativa nos dias 23 de outubro, 28 novembro e 29 de dezembro de 1998

TABELA 59. Registros horários da umidade relativa nos dias 23 de janeiro, 23 de fevereiro e 14 de março de 2003

TABELA 60. Registros horários da umidade relativa nos dias 25 de abril, 15 de maio e 15 de junho de 2003

TABELA 61. Registros horários da umidade relativa nos dias 27 de julho, 20 de agosto e 16 de setembro de 2003.

TABELA 62. Registros horários da umidade relativa nos dias 22 de outubro, 20 de novembro e 23 de dezembro de 2003 


\section{LISTA DE FIGURAS}

Página

FIGURA 1. Distritos do município de São Paulo e localização da área central da cidade.

22

FIGURA 2. Planta da cidade de São Paulo de 1810................................ 27

FIGURA 3. Panorama da cidade de São Paulo, 1821 ............................. 27

FIGURA 4. Ponte de Santa Ifigênia, 1827............................................ 28

FIGURA 5. Rua São Bento em 1862 ............................................... 28

FIGURA 6. Rua do Rosário, 1862.................................................... 29

FIGURA 7. Rua Direita em 1862........................................................... 29

FIGURA 8. Rua Florêncio de Abreu, 1862 e 1887..................................... 30

FIGURA 9. Largo de São Francisco, 1862 e 1887.................................. 31

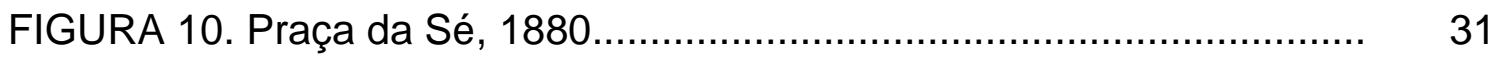

FIGURA 11. Planta da expansão urbana de São Paulo de 1897............... 32

FIGURA 12. Cruzamento da Rua Direita com São Bento, 1900................ 33

FIGURA 13. Detalhe de planta de Affonso A. de Freitas. Leito original do Rio Tamanduateí, o trecho menor retificado em 1848 e o novo leito

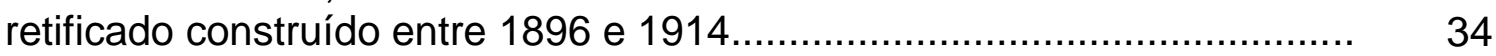

FIGURA 14. Foto da Rua Direita.......................................................... 34

FIGURA 15. Foto da Rua São Bento................................................... 35

FIGURA 16. Foto da Rua XV de Novembro........................................... 35

FIGURA 17. Parque Anhangabaú, 1914, com os Palacetes Prates........... 33

FIGURA 18. Parque Anhangabaú, 1923, com Theatro Municipal e Hotel Esplanada.

FIGURA 19. Largo de São Bento/Viaduto Santa Ifigênia, 1920................. 37

FIGURA 20. Anhangabaú/Viaduto do Chá/Praça do Patriarca, 1925........ 38

FIGURA 21. Praça do Patriarca/viaduto do Chá/Anhangabaú, 1927.......... 38

FIGURA 22. Rua São Bento, 1929.................................................. 39

FIGURA 23. Edifício Martinelli, 1929................................................. 39

FIGURA 24. Esquema técnico de São Paulo, parte Plano de Avenidas..... 40 
FIGURA 25. Foto das obras da Avenida Duque de Caxias, antes e durante as obras de alargamento.

FIGURA 26. Viaduto do Chá, 1920 e 1940.

FIGURA 27. Vale do Anhangabaú, Edifícios Martinelli e Altino Arantes entre 1940 e 1946.

FIGURA 28. Vale do Anhangabaú, 1957.

FIGURA 29. Vista dos galpões industriais no bairro do Bom Retiro.

FIGURA 30. Densidade demográfica por distrito da região central..

FIGURA 31. As diferentes áreas e a relação entre altura e velocidade do vento.

FIGURA 32. Efeito estufa.

FIGURA 33. Localização das estações de monitoramento Centro e Parque D. Pedro II

62

FIGURA 34. Localização das estações de monitoramento do ar

FIGURA 35. Evolução da área com ocupação urbana na região metropolitana de São Paulo de 1930 a 1995.

FIGURA 36. Evolução mensal e anual das médias diárias de temperatura de 1936 a 2005.

FIGURA 37. Evolução anual e mensal das médias diárias da umidade relativa do ar de 1936 a 2005.

FIGURA 38. Mapa das temperaturas de superfície da cidade de São Paulo em 3 de setembro de 1999 às 9h57.

FIGURA 39. Detalhe da situação da Subprefeitura da Sé no mapa das temperaturas de superfície da cidade de São Paulo.

FIGURA 40: Mapa das isotermas no centro de São Paulo

FIGURA 41. Número de edifícios com mais de cinco pavimentos por $\mathrm{km}^{2}$, por distrito da região central, 2007.

FIGURA 42. Áreas verdes por distrito no centro de São Paulo.

FIGURA 43. Fatores médios de emissão de $\mathrm{CO}_{2}$ para veículos leves novos no período de 2002 a 2008.

FIGURA 44. Valores típicos de emissão de $\mathrm{CO}_{2}$ para veículos em uso, movidos a gasolina convertidos para gás natural veicular, no período de 2002 a 2008

FIGURA 45. Evolução da frota de veículos automotores leves da região metropolitana de São Paulo. 
FIGURA 46. Gráfico horário das temperaturas e da intensidade da ilha de calor, no dia 3 de março de 1988, na Estação de Monitoramento Centro e Estação Meteorológica do Parque Estadual Fontes do Ipiranga..

FIGURA 47. Gráfico horário das temperaturas e da intensidade da ilha de calor, no dia 12 de setembro de 1998, na Estação de Monitoramento do Parque D. Pedro II, Estação Meteorológica do Parque Estadual Fontes do Ipiranga

FIGURA 48. Composição do lixo no Município de São Paulo.................... 86

FIGURA 49. Distribuição do lixo no Município de São Paulo...................... 87

FIGURA 50. Área de intervenção e área de impacto do Procentro............. 88

FIGURA 51. Concentrações máximas anuais dos teores de fumaça na Subprefeitura da Sé de 1989 a 2008

FIGURA 52. Concentrações máximas anuais de partículas inaláveis na Subprefeitura da Sé de 1998 a 2008.

FIGURA 53. Concentrações máximas anuais de partículas totais em suspensão na Subprefeitura da Sé de 1989 a 2008

FIGURA 54. Concentrações máximas anuais de dióxido de nitrogênio na Subprefeitura da Sé de 1998 a 2008

FIGURA 55. Concentrações máximas anuais de monóxido de nitrogênio na Subprefeitura da Sé de 1998 a 2008.

FIGURA 56. Concentrações máximas anuais de ozônio na Subprefeitura da Sé de 1998 a 2008.

FIGURA 57. Gráficos horários das temperaturas e da intensidade da ilha de calor nos dias 4 de janeiro, 9 de fevereiro e 21 de março de 1981, na Estação de Monitoramento Centro, Estação Meteorológica do Parque Estadual Fontes do Ipiranga

FIGURA 58. Gráficos horários das temperaturas e da intensidade da ilha de calor nos dias 21 de abril, 26 de maio e 26 de junho de 1981, na Estação de Monitoramento Centro, Estação Meteorológica do Parque Estadual Fontes do Ipiranga

FIGURA 59. Gráficos horários das temperaturas e da intensidade da ilha de calor nos dias 13 de julho, 26 de agosto e 21 de setembro de 1981, na Estação de Monitoramento Centro, Estação Meteorológica do Parque Estadual Fontes do Ipiranga

FIGURA 60. Gráficos horários das temperaturas e da intensidade da ilha de calor, nos dias 7 outubro, 2 de novembro e 26 de dezembro de 1981, na Estação de Monitoramento Centro, Estação Meteorológica do Parque Estadual Fontes do Ipiranga 
FIGURA 61. Gráficos horários das temperaturas e da intensidade da ilha de calor, nos dias $1^{\circ}$ de janeiro, 16 de fevereiro e 20 de março de 1983, na Estação de Monitoramento Centro, Estação Meteorológica do Parque Estadual Fontes do Ipiranga

FIGURA 62. Gráficos horários das temperaturas e da intensidade da ilha de calor, nos dias 14 de abril, 17 de maio e 15 de junho de 1983, na Estação de Monitoramento Centro, Estação Meteorológica do Parque Estadual Fontes do Ipiranga.

FIGURA 63. Gráficos horários das temperaturas e da intensidade da ilha de calor, nos dias 16 de julho, 12 de agosto e 13 de setembro de 1983, na Estação de Monitoramento Centro, Estação Meteorológica do Parque Estadual Fontes do Ipiranga

FIGURA 64. Gráficos horários das temperaturas e da intensidade da ilha de calor, nos dias 8 outubro, 17 de novembro e 21 de dezembro de 1983, na Estação de Monitoramento Centro, Estação Meteorológica do Parque Estadual Fontes do Ipiranga.

FIGURA 65. Gráficos horários das temperaturas, nos dias 13 de janeiro, 7 de fevereiro e 3 de março de 1988, na Estação de Monitoramento Centro, Estação Meteorológica do Parque Estadual Fontes do Ipiranga e da Intensidade da llha de Calor.

FIGURA 66. Gráficos horários das temperaturas, nos dias 23 abril, 19 de maio e 16 de junho de 1988, na Estação de Monitoramento Centro, Estação Meteorológica do Parque Estadual Fontes do Ipiranga e da Intensidade da llha de Calor.

FIGURA 67. Gráficos horários das temperaturas e da intensidade da ilha de calor, nos dias 7 de julho, 3 de agosto e 2 de setembro de 1988, na Estação de Monitoramento Centro, Estação Meteorológica do Parque Estadual Fontes do Ipiranga

FIGURA 68. Gráficos horários das temperaturas e da intensidade da ilha de calor, nos dias 16 de outubro, 19 de novembro e 19 de dezembro de 1988, na Estação de Monitoramento Centro, Estação Meteorológica do Parque Estadual Fontes do Ipiranga.

FIGURA 69. Gráficos horários das temperaturas e da intensidade da ilha de calor, nos dias 9 de janeiro, 10 de fevereiro e 23 de março de 1993, na Estação de Monitoramento do Pq. D. Pedro II, Estação Meteorológica do Parque Estadual Fontes do Ipiranga

FIGURA 70. Gráficos horários das temperaturas e da intensidade da ilha de calor, nos dias 15 de abril, 21 de maio e 13 de junho de 1993, na Estação de Monitoramento do Pq. D. Pedro II, Estação Meteorológica do Parque Estadual Fontes do Ipiranga 
FIGURA 71. Gráficos horários das temperaturas e da intensidade da ilha de calor, nos dias 19 de julho, 9 de agosto e 7 de setembro de 1993, na Estação de Monitoramento do Pq. D. Pedro II, Estação Meteorológica do Parque Estadual Fontes do Ipiranga.

FIGURA 72. Gráficos horários das temperaturas e da intensidade da ilha de calor, nos dias 14 de outubro, 15 de novembro e 14 de dezembro de 1993, na Estação de Monitoramento do Pq. D. Pedro II, Estação Meteorológica do Parque Estadual Fontes do Ipiranga

FIGURA 73. Gráficos horários das temperaturas e da intensidade da ilha de calor, nos dias 27 de janeiro, 27 de fevereiro e 25 de março de 1998, na Estação de Monitoramento do Pq. D. Pedro II, Estação Meteorológica do Parque Estadual Fontes do Ipiranga.

FIGURA 74. Gráficos horários das temperaturas e da intensidade da ilha de calor, nos dias 25 de abril, 27 de maio e 26 de junho de 1998, na Estação de Monitoramento do Pq. D. Pedro II, Estação Meteorológica do Parque Estadual Fontes do Ipiranga....

FIGURA 75. Gráficos horários das temperaturas, nos dias 28 de julho, 26 de agosto e 12 de setembro de 1998, na Estação de Monitoramento do Pq. D. Pedro II, Estação Meteorológica do Parque Estadual Fontes do Ipiranga e da Intensidade da llha de Calor.

FIGURA 76. Gráficos horários das temperaturas e da intensidade da ilha de calor, nos dias 23 de outubro, 28 de novembro e 29 de dezembro de 1998, na Estação de Monitoramento do Pq. D. Pedro II, Estação Meteorológica do Parque Estadual Fontes do Ipiranga

FIGURA 77. Gráficos horários das temperaturas e da intensidade da ilha de calor, nos dias 23 de janeiro, 23 de fevereiro e 14 de março de 2003, na Estação de Monitoramento do Pq. D. Pedro II, Estação Meteorológica do Parque Estadual Fontes do Ipiranga.

FIGURA 78. Gráficos horários das temperaturas e da intensidade da ilha de calor, nos dias 25 de abril, 15 de maio e 15 de junho de 2003, na Estação de Monitoramento do Pq. D. Pedro II, Estação Meteorológica do Parque Estadual Fontes do Ipiranga.

FIGURA 79. Gráficos horários das temperaturas e da intensidade da ilha de calor, nos dias 2 de julho, 20 de agosto e 16 de setembro de 2003, na Estação de Monitoramento do Pq. D. Pedro II, Estação Meteorológica do Parque Estadual Fontes do Ipiranga.

FIGURA 80. Gráficos horários das temperaturas e da intensidade da ilha de calor, nos dias 22 de outubro, 20 de novembro e 23 de dezembro de 2003, na Estação de Monitoramento do Pq. D. Pedro II, Estação Meteorológica do Parque Estadual Fontes do Ipiranga 
FIGURA 81. Gráficos horários da umidade relativa e do diferencial de umidade, dias 4 de janeiro, 9 de fevereiro e 21 de março de 1981, na Estação de Monitoramento Centro, Estação Meteorológica do Parque Estadual Fontes do Ipiranga.....

FIGURA 82. Gráficos horários da umidade relativa e do diferencial de umidade, dias 21 de abril, 26 de maio e 26 de junho de 1981, na Estação de Monitoramento Centro, Estação Meteorológica do Parque Estadual Fontes do Ipiranga

FIGURA 83. Gráficos horários da umidade relativa e do diferencial de umidade, dias 13 de julho, 26 de agosto e 21 de setembro de 1981, na Estação de Monitoramento Centro, Estação Meteorológica do Parque Estadual Fontes do Ipiranga

FIGURA 84. Gráficos horários da umidade relativa e do diferencial de umidade, dias 7 de outubro, 2 de novembro e 26 de dezembro de 1981, na Estação de Monitoramento Centro, Estação Meteorológica do Parque Estadual Fontes do Ipiranga

FIGURA 85. Gráficos horários da umidade relativa e do diferencial de umidade, dias $1^{\circ}$ de janeiro, 16 de fevereiro e 20 de março de 1983, na Estação de Monitoramento Centro, Estação Meteorológica do Parque Estadual Fontes do Ipiranga

FIGURA 86. Gráficos horários da umidade relativa e do diferencial de umidade, dias 14 de abril, 17 de maio e 15 de junho de 1983, na Estação de Monitoramento Centro, Estação Meteorológica do Parque Estadual Fontes do Ipiranga

FIGURA 87. Gráficos horários da umidade relativa e do diferencial de umidade, dias 16 de julho, 12 de agosto e 23 de setembro de 1983, na Estação de Monitoramento Centro, Estação Meteorológica do Parque Estadual Fontes do Ipiranga

FIGURA 88. Gráficos horários da umidade relativa, dias 8 de outubro, 17 de novembro e 21 de dezembro de 1983, na Estação de Monitoramento Centro, Estação Meteorológica do Parque Estadual Fontes do Ipiranga e do diferencial de umidade relativa.

FIGURA 89. Gráficos horários da umidade relativa, dias 13 de janeiro, 7 de fevereiro e 3 de março de 1988, na Estação de Monitoramento Centro, Estação Meteorológica do Parque Estadual Fontes do Ipiranga e do diferencial de umidade relativa.

FIGURA 90. Gráficos horários da umidade relativa e do diferencial de umidade, dias 23 de abril, 19 de maio e 16 de junho de 1988, na Estação de Monitoramento Centro, Estação Meteorológica do Parque Estadual Fontes do Ipiranga 
FIGURA 91. Gráficos horários da umidade relativa e do diferencial de umidade, dias 7 de julho, 3 de agosto e 2 de setembro de 1988, na Estação de Monitoramento Centro, Estação Meteorológica do Parque Estadual Fontes do Ipiranga

FIGURA 92. Gráficos horários da umidade relativa e do diferencial de umidade, dias 16 de outubro, 19 de novembro e 19 de dezembro de 1988, na Estação de Monitoramento Centro, Estação Meteorológica do Parque Estadual Fontes do Ipiranga.

FIGURA 93. Gráficos horários da umidade relativa, dias 9 de janeiro, 10 de fevereiro e 23 de março de 1993, na Estação de Monitoramento Pq. D. Pedro II, Estação Meteorológica do Parque Estadual Fontes do Ipiranga e do diferencial de umidade.

FIGURA 94. Gráficos horários da umidade relativa e do diferencial de umidade, dias 15 de abril, 21 de maio e 13 de junho de 1993, na Estação de Monitoramento Pq. D. Pedro II, Estação Meteorológica do Parque Estadual Fontes do Ipiranga

FIGURA 95. Gráficos horários da umidade relativa e do diferencial de umidade, dias 19 de julho, 9 de agosto e 7 de setembro de 1993, na Estação de Monitoramento P. D. Pedro II, Estação Meteorológica do Parque Estadual Fontes do Ipiranga.

FIGURA 96. Gráficos horários da umidade relativa e do diferencial de umidade, dias 14 de outubro, 15 de novembro e 14 de dezembro de 1993, na Estação de Monitoramento Pq. D. Pedro II, Estação Meteorológica do Parque Estadual Fontes do Ipiranga

FIGURA 97. Gráficos horários da umidade relativa e do diferencial de umidade, dias 27 de janeiro, 27 de fevereiro e 25 de março de 1998, na Estação de Monitoramento Pq. D. Pedro II, Estação Meteorológica do Parque Estadual Fontes do Ipiranga

FIGURA 98. Gráficos horários da umidade relativa, dias 25 de abril, 27 de maio e 26 de junho de 1998, na Estação de Monitoramento Pq. D. Pedro II, Estação Meteorológica do Parque Estadual Fontes do Ipiranga e do diferencial de umidade relativa.

FIGURA 99. Gráficos horários da umidade relativa e do diferencial de umidade, dias 28 de julho, 26 de agosto e 12 de setembro de 1998, na Estação de Monitoramento Pq. D. Pedro II, Estação Meteorológica do Parque Estadual Fontes do Ipiranga.

FIGURA 100. Gráficos horários da umidade relativa e do diferencial de umidade, dias 23 de outubro, 28 de novembro e 29 de dezembro de 1998, na Estação de Monitoramento Pq. D. Pedro II, Estação Meteorológica do Parque Estadual Fontes do Ipiranga 
FIGURA 101. Gráficos horários da umidade relativa e do diferencial de umidade, dias 23 de janeiro, 23 de fevereiro e 14 de março de 2003, na Estação de Monitoramento Pq. D. Pedro II, Estação Meteorológica do Parque Estadual Fontes do Ipiranga.

FIGURA 102. Gráficos horários da umidade relativa e do diferencial de umidade, dias 25 de abril, 15 de maio e 15 de junho de 2003, na Estação de Monitoramento Pq. D. Pedro II, Estação Meteorológica do Parque Estadual Fontes do Ipiranga.

FIGURA 103. Gráficos horários da umidade relativa e do diferencial de umidade, dias 27 de julho, 20 de agosto e 16 de setembro de 2003, na Estação de Monitoramento Pq. D. Pedro II, Estação Meteorológica do Parque Estadual Fontes do Ipiranga.

FIGURA 104. Gráficos horários da umidade relativa e do diferencial de umidade, dias 22 de outubro, 20 de novembro e 23 de dezembro de 2003, na Estação de Monitoramento Pq. D. Pedro II, Estação Meteorológica do Parque Estadual Fontes do Ipiranga

FIGURA 105. Áreas com baixo potencial de transformação dentro do perímetro do Programa Nova Luz.

FIGURA 106. Áreas com possibilidade de transformação imediata dentro do perímetro do Programa Nova Luz....

FIGURA 107. Volumetria máxima proposta na Quadra 19........................ 199

FIGURA 108. Conjunto Residencial da Rua Riachuelo.............................. 200

FIGURA 109. Favela do Gato e Conjunto Residencial Parque do Gato.... 201

FIGURA 110. Reurbanização da Praça Roosevelt................................... 201

FIGURA 111. Praça da Sé - Análise e diagnóstico - Requalificação e instalação de ponte sobre o espelho d'água.

202

FIGURA 112. Resgate das características originais dos canteiros, remoção de muretas, reconstituição das orlas, sarjetas e substituição do pavimento por elemento cerâmico

203

FIGURA 113. Resgate do eixo da Rua do Arouche com a 7 de Abril......... 203

FIGURA 114. Reurbanização da Praça da República............................... 203

FIGURA 115. Reurbanização da Praça Dom José Gaspar, aumento da área permeável do solo, novo traçado dos passeios e nova paginação do piso.

FIGURA 116. Requalificação do Mercado Municipal................................ 205

FIGURA 117. Recuperação do Theatro Municipal..................................... 206 
FIGURA 118. Recuperação da Casa no1 e do Beco do Pinto..................... 206

FIGURA 119. Recuperação da Biblioteca Mario de Andrade..................... 207

FIGURA 120. Incorporação do antigo prédio do IPESP como anexo da

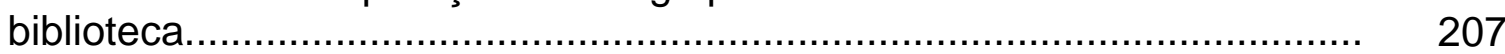

FIGURA 121. Recuperação do Solar da Marquesa................................... 208

FIGURA 122. Fachadas do Vale do Anhangabaú e Avenida São João referentes período de início das obras da Praça das artes

209

FIGURA 123. Maquetes do projeto da Praça das Artes com vistas do Vale do Anhangabaú e Avenida São João.

209

FIGURA 124. Edifícios S. Vito, Mercúrio e Francisco Herrerias................. 210

FIGURA 125. Inundações do Vale do Anhangabaú 1929 e 1999............... 213

FIGURA 126. Inundações da Avenida Nove de Julho.............................. 213

FIGURA 127. Reservatórios de retenção de enchentes na Praça da Bandeira e Praça 14 Bis.

FIGURA 128. Córregos. Saracura, Itororó, Bixiga, Moringuinho e Anhangabaú, Intervenções no Córrego Moringuinho e Saracura, reservatórios de retenção de enchentes na Praça da Bandeira e Praça 14 Bis 214

FIGURA 129. Requalificação das Ruas da Nova Luz.............................. 215

FIGURA 130. Requalificação dos espaços públicos................................. 216

FIGURA 131. Circuitos da Rótula e da Contrarrótula na Região Central da cidade de São Paulo. 


\section{INTRODUÇÃO}

O tema deste trabalho trata da análise do Programa de Reabilitação da Área Central da Cidade de São Paulo (Procentro), com referência à sua influência na mudança da temperatura nesta região.

A área central da cidade de São Paulo é constituída pelos distritos da Sé, República, Bom Retiro, Santa Cecília, Consolação, Bela Vista, Liberdade e Cambuci, formando a Subprefeitura da Sé (FIG. 1) (COMIN, 2004).

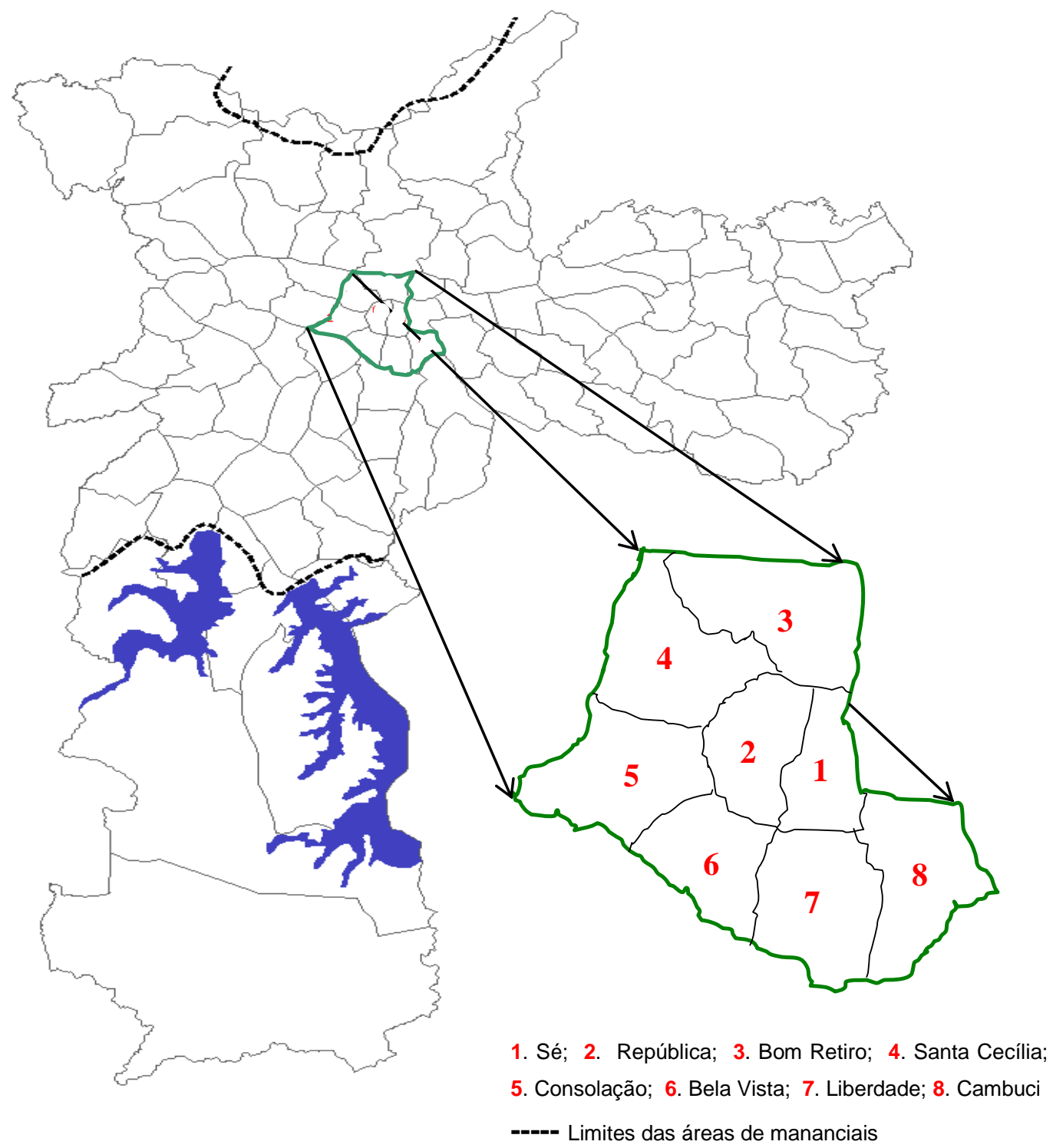

FIGURA 1. Distritos do Município de São Paulo e localização da área central da cidade.

Fonte: Adaptação de Município de São Paulo, Novos distritos. 
O Procentro é constituído por um conjunto de ações que tem como área de intervenção os distritos da Sé e da República (Centro Histórico), região mais deteriorada do centro, e, como área de influência, a região formada pelos demais distritos da Subprefeitura da Sé (VESPUCCI, 2004).

A relevância deste tema está em trazer um assunto que não vem sendo discutido com a magnitude que merece, pela importância da área como polo econômico, histórico, cultural e pela amplitude do Procentro.

Além disso, muito se discute sobre o aquecimento global e sua influência no clima, mas o que pretendemos é discutir a nossa participação neste processo.

O centro da cidade de São Paulo apresenta as consequências das intervenções que sofreu ao longo da sua história, principalmente aquelas ocorridas durante o século $X X$, que lhe deram importância econômica, patrimônio histórico e forte dinamismo (GARAY, 2002).

É uma região que reúne atrativos como: transporte coletivo, dinâmica comercial, baixo custo imobiliário, farta disponibilidade de imóveis, variada rede de serviços, infraestrutura de cabeamento ótico, rede elétrica subterrânea, rede de telefonia, serviços públicos de educação, saúde e cultura (COMIN, 2004).

Pelos últimos dados, atualizados em 2003, a região central oferece 380 mil empregos formais, além dos empregos públicos, 17 estações de metrô, duas estações ferroviárias, 250 linhas de ônibus, 31 hospitais com 8.467 leitos, 12 Unidades Básicas de Saúde, 115 escolas de educação infantil, 96 escolas de ensino fundamental, 53 escolas de ensino médio, 39 escolas de nível superior, cinco bibliotecas públicas, três bibliotecas infanto-juvenis, 60 salas de cinema, 76 salas de teatro, 25 salas de shows e concertos, 19 museus e 15 estabelecimentos da área de comunicação (jornais e emissoras de rádio) (BIDONE, 2003).

Região detentora de pujante rede comercial, também possui agressivo comércio informal. Além de executivos, comerciantes, funcionários públicos, bancários, possui uma legião de dependentes químicos e moradores de rua. Ao lado de edifícios de grande valor histórico e arquitetônico, apresenta edifícios abandonados e deteriorados (BIDONE, 2003). 
Durante a segunda metade do século $X X$, o centro da cidade de São Paulo passou por um processo de degradação, resultado da descentralização de 1950, que provocou a retirada dos moradores do centro para a região da Avenida Paulista. Da desindustrialização do centro, que se iniciou em 1960, provocando perda de inúmeros postos de trabalho. Da descentralização de 1970, deslocando os moradores do centro para a região da Avenida Berrini. Das transformações econômicas e sociais ocorridas de 1980 até o final do século XX (TASCHNER; BÓGUS, 2001).

Em outubro de 2002, a Empresa Municipal de Urbanização (Emurb), atual SP Urbanismo, apresentou o Procentro com o objetivo de dinamizar a região, criando atrações que compatibilizassem a estrutura existente, através de reabilitação urbanística, ambiental e social (SÃO PAULO [Cidade] - EMURB, 2007).

Este programa relaciona a má qualidade ambiental do centro a seis fatores principais: qualidade do ar, drenagem, diminuição da vegetação, dificuldades de limpeza, destinação dos resíduos sólidos e baixos investimentos em zeladoria.

Destes fatores, pelo menos três (qualidade do ar, drenagem e diminuição da vegetação) têm influência sobre o meio ambiente, podendo provocar aumento de temperatura.

Esta pesquisa, considerando que a ocupação do espaço urbano tem influência preponderante sobre o aumento das temperaturas, analisa a variação da temperatura ao longo do século XX no centro da cidade de São Paulo e as relaciona com variáveis ligadas às ações antrópicas no centro.

A justificativa para a realização deste trabalho se dá pela abrangência do programa, importância da região e pela influência que a ilha de calor exerce social e culturalmente e sobre a saúde da população (RIBEIRO, 1996). 


\section{OBJETIVOS}

Alterações microclimáticas, confirmadas a partir de análises das temperaturas médias anuais de 1885 até 1995, apresentaram aumento entre 1,05 e $2,59^{\circ} \mathrm{C}$ na cidade de São Paulo, mudanças estas intimamente relacionadas com a poluição atmosférica, redução da cobertura vegetal, impermeabilização do solo e a verticalização dos imóveis (SÃO PAULO [Cidade] - SVMA, 2004).

A maciça utilização do concreto nas construções, a deficiência de vegetação, as áreas impermeabilizadas e a poluição contribuem para a diferença de temperatura entre o centro e a periferia de $3^{\circ} \mathrm{C}$ até $11^{\circ} \mathrm{C}$ (RIBEIRO, 1996).

No centro de São Paulo, a temperatura média é equivalente à média do município. Entretanto, o Centro Histórico tem temperatura mais elevada em função do maior volume de construção e pela maior escassez de vegetação, sendo que estes períodos de calor são amenizados pelas grandes áreas de sombreamento prolongado, geradas pelas elevadas construções (BIDONE, 2003).

Como a ocupação do espaço urbano tem maior influência sobre o aumento das temperaturas do que os aspectos naturais do relevo, os objetivos deste trabalho foram: pesquisar séries históricas de variação de temperatura no centro da cidade de São Paulo; conhecer as principais causas dessas variações; relacioná-las com as demais variáveis, como verticalização e áreas verdes; analisar as ações do Procentro que poderiam interferir nas temperaturas; promover a setorização dos dados a fim de contribuir para futuras análises da variação temporal da temperatura na cidade de São Paulo; e determinar as ações que poderiam ser tomadas, em caráter local, para melhorar a gestão ambiental e contribuir para o bem-estar humano. 


\section{PROCESSO DE URBANIZAÇÃO DA REGIÃO CENTRAL DE SÃO PAULO}

O ser humano, na busca de soluções para melhorar as condições climáticas e garantir o abastecimento de água, compromete a sustentabilidade dos recursos naturais por ações que não possuem a compreensão necessária da potencialidade da natureza local. Tais ações não são capazes de fornecer qualidade ambiental, estandardizam as paisagens, reduzem as cidades a construções amontoadas e introduzem vegetação exótica (SCHUTZER, 2005).

$\mathrm{Na}$ região onde se localiza a cidade de São Paulo, originalmente encontravam-se a Mata Atlântica e a Floresta das Araucárias. A Mata Atlântica constituía a formação principal desta área até a chegada da colonização. O clima tropical úmido alimentava o lençol d'água subterrâneo durante o período de chuvas, que alimentava permanentemente os cursos d'água, inclusive nos meses de estiagem. O clima mais frio de altitude não permitia o desenvolvimento de árvores altas, o que formava uma floresta menos densa e fechada, favorecendo o desenvolvimento das araucárias que emergiam acima da floresta tropical (SCHUTZER, 2005).

Em 1554, o conhecimento da existência de ouro no Brasil, nas regiões do Jaraguá e de Santana do Parnaíba, proporcionou a fundação da cidade de São Paulo, elevada à categoria de cidade em 1711, época em que apresentava intenso movimento das expedições de entradas e bandeiras. Até o final do século XVIII a cidade mantém os seus limites definidos pelo sítio original e a vida social é limitada pelo Triângulo, localizado na colina histórica, entre os rios Anhangabaú e Tamanduateí, formado pelas ruas Direita, São Bento e 15 de Novembro (SÃO PAULO [Cidade] - SEMPLA, 2008).

A partir do começo de 1825, inicia-se a expansão da cidade e sua população passa a se distribuir além dos limites do Rio Tamanduateí e do Córrego Anhangabaú (FIG. 2 a 4) (SÃO PAULO [Cidade] - SEMPLA, 2008). 


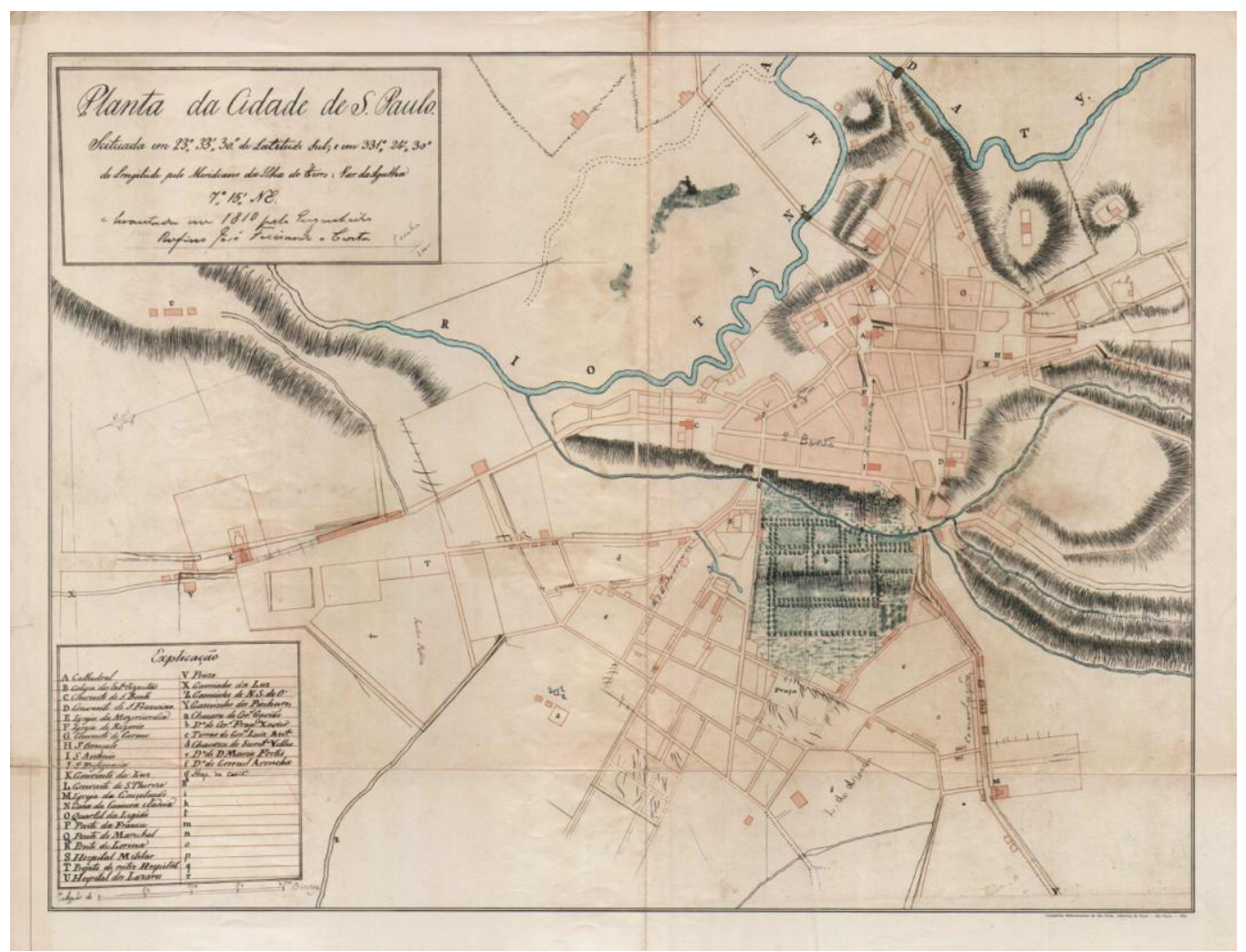

FIGURA 2. Planta da cidade de São Paulo de 1810. Disponível em http://www.bibliotecadigital.puccampinas.edu.br/tde busca/arquivo.php?codArquivo=179. Acesso em: 22 set. 2010.

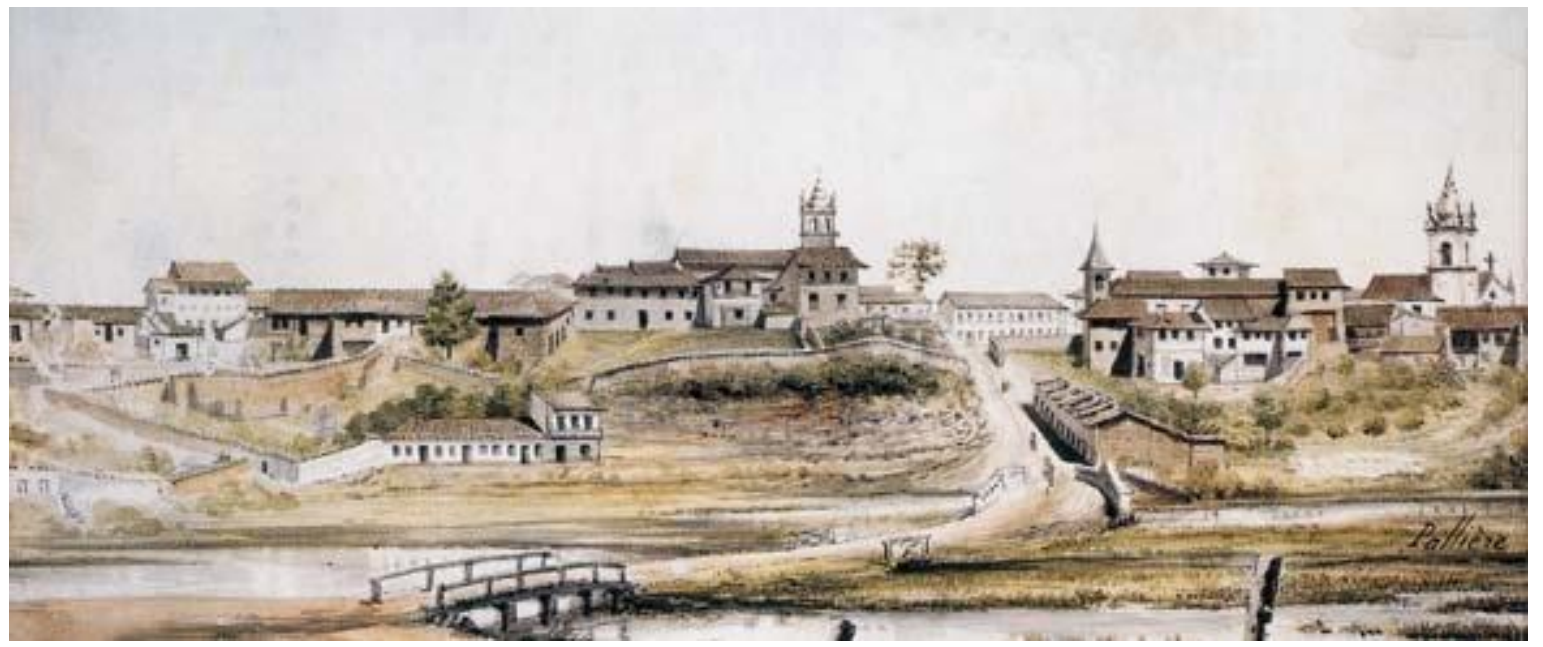

FIGURA 3. Panorama da cidade de São Paulo, 1821. Autor: Arnaud Julien Pallière. Disponível em: $<$ http://sitededicas.uol.com.br/clip sp0.htm>. Acesso em: 20 set. 2010. 


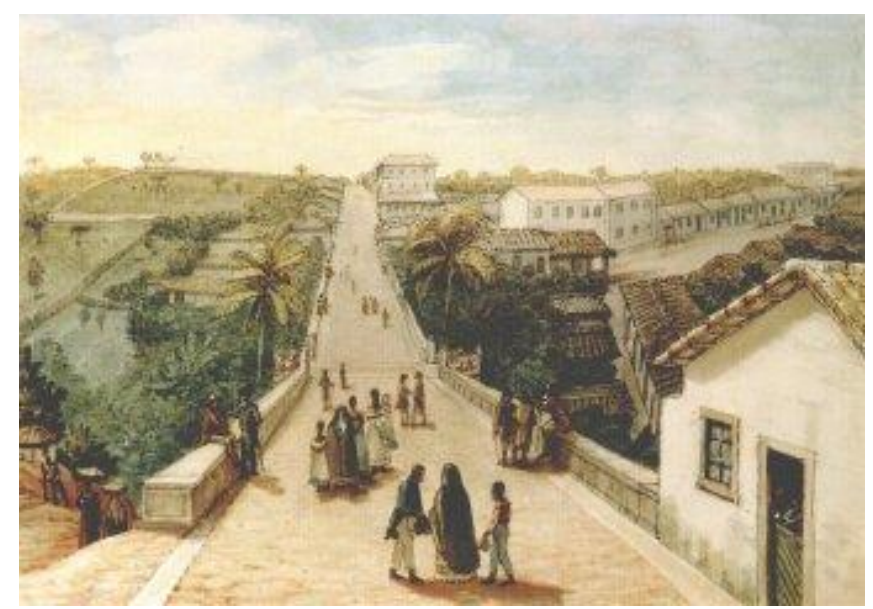

FIGURA 4. Ponte de Santa Ifigênia, 1827. Autor: Jean Baptiste Debret. Disponível em: $<$ http://www.klepsidra.net/klepsidra15/rev1842-2htm>. Acesso em: 20 set. 2010.

\subsection{Primeira reurbanização}

No início do Império, São Paulo apresenta uma sociedade reclusa e casas acanhadas (CAMPOS et al, 2004).

Em 1825, abre-se o primeiro jardim público da cidade, o Jardim da Luz, e, em 1827, é criada a Faculdade de Direito do Largo São Francisco (SÃO PAULO [Cidade] - SEMPLA, 2008).

Em 1829 é implantada a iluminação pública com lampiões a azeite, e em 1865, ainda com características coloniais (FIG. 5 a 7), tem início a primeira mudança urbanística pela chegada da estrada de ferro (CAMPOS et al, 2004).

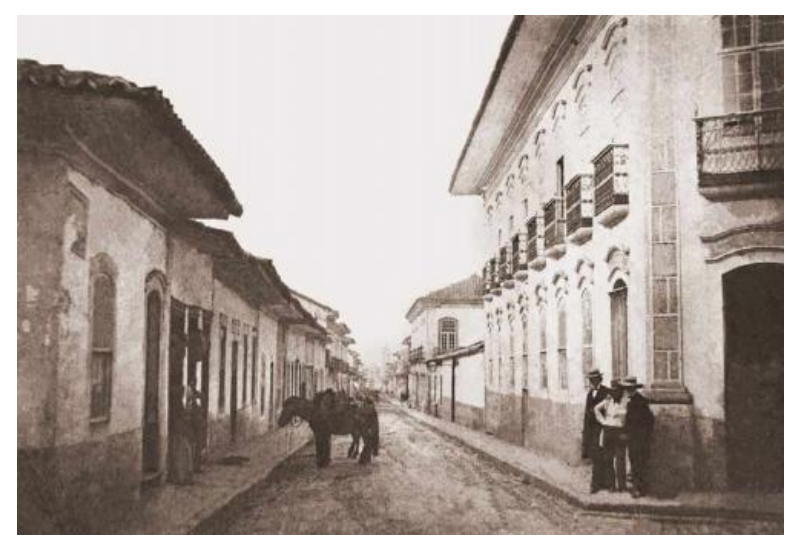

FIGURA 5. Rua São Bento em 1862. Foto de Militão A. Azevedo. Fonte: Plataforma Superior. Disponível em: http://plataformasuperior.com/fotos mundo/americas/america sul/anhangabau-e-saobento.html. Acesso em: 23 set. 2010. 


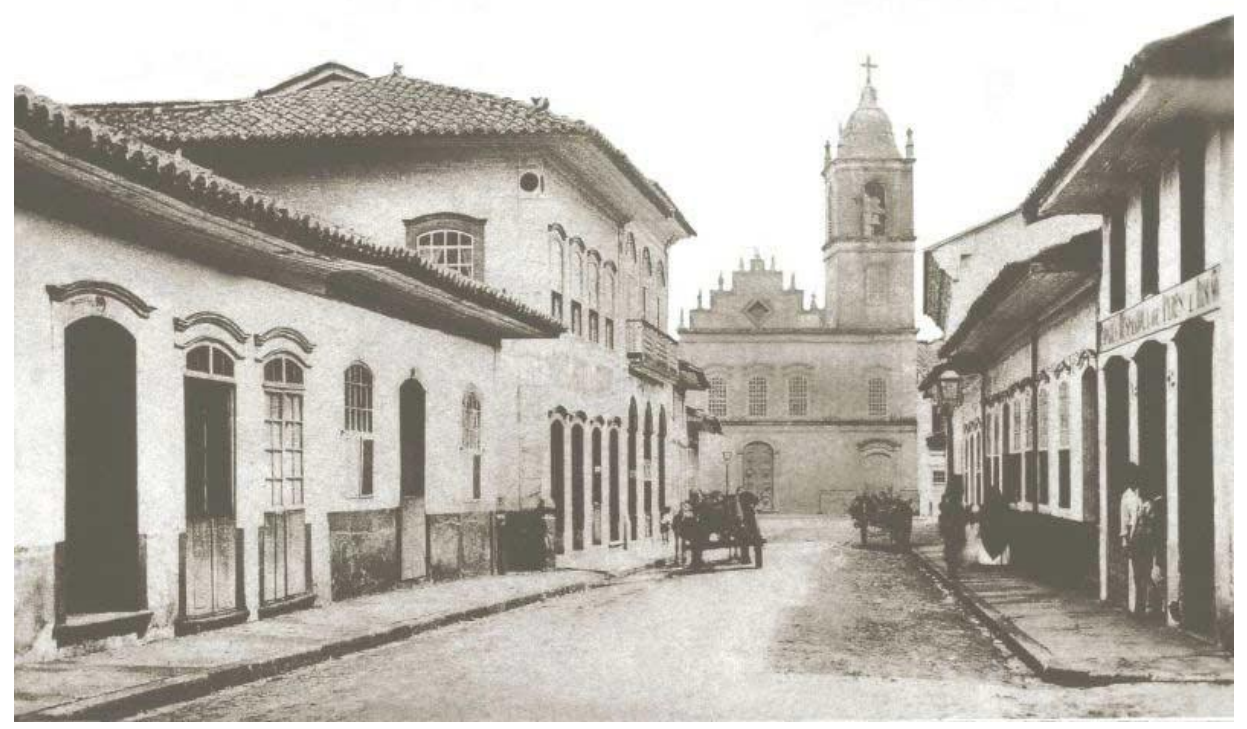

FIGURA 6. Rua do Rosário em 1862 (depois denominada Rua da Imperatriz e atual XV de Novembro). Fonte: Panoramio. Disponível em: <http://www.panoramio.com/photo/4687435>. Acesso em: 20 set. 2010.

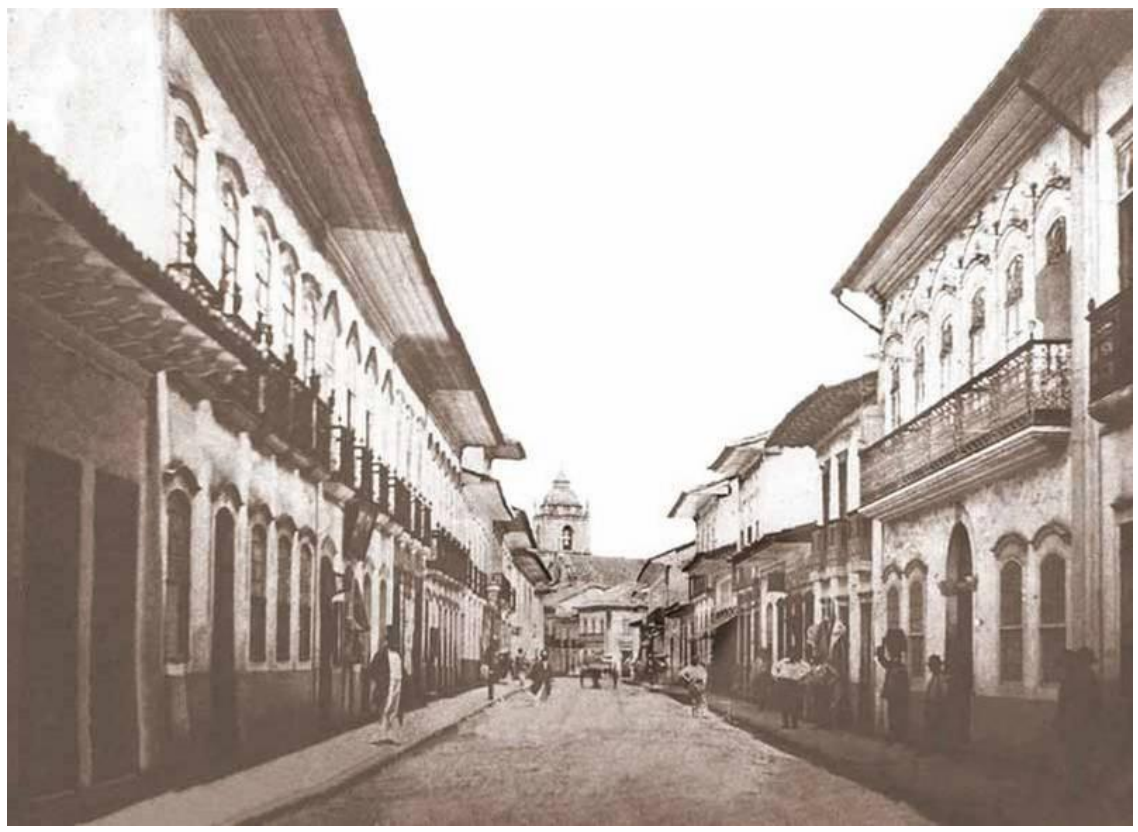

FIGURA 7. Rua Direita em 1862. Disponível em: <http://www.skyscraperlife.com/brazil/6877-saopaulo-ontem-e-hoje-fotos-de-1862-2007-a.html>. Acesso em: 20 set. 2010.

No governo de João Teodoro (1872 a 1875) ocorre grande parte dessa mudança e se abre o caminho para o crescimento (CAMPOS et al, 2004). 
Em 1872, com 30 mil habitantes, a elite cafeeira estabelecida na cidade e a vinda de imigrantes europeus, iniciam-se as transformações urbanas que tornam São Paulo a metrópole do café. No último quartel do século, o Triângulo é reurbanizado, suas ruas recebem arborização, iluminação com lampiões de gás (1872), pavimentação com paralelepípedo (FIG. 8 a 10) e a região se transforma em setor de comércio e serviços. Além das obras no Triângulo, são melhorados os acessos para a Luz e Santa Ifigênia, reformados o Jardim Público e o Largo 7 de Abril (atual Praça da República), e em 1872 é implantada a primeira linha de bondes com tração animal ligando a Estação da Luz aos Campos Elísios (SÃO PAULO [Cidade] - SEMPLA, 2008).
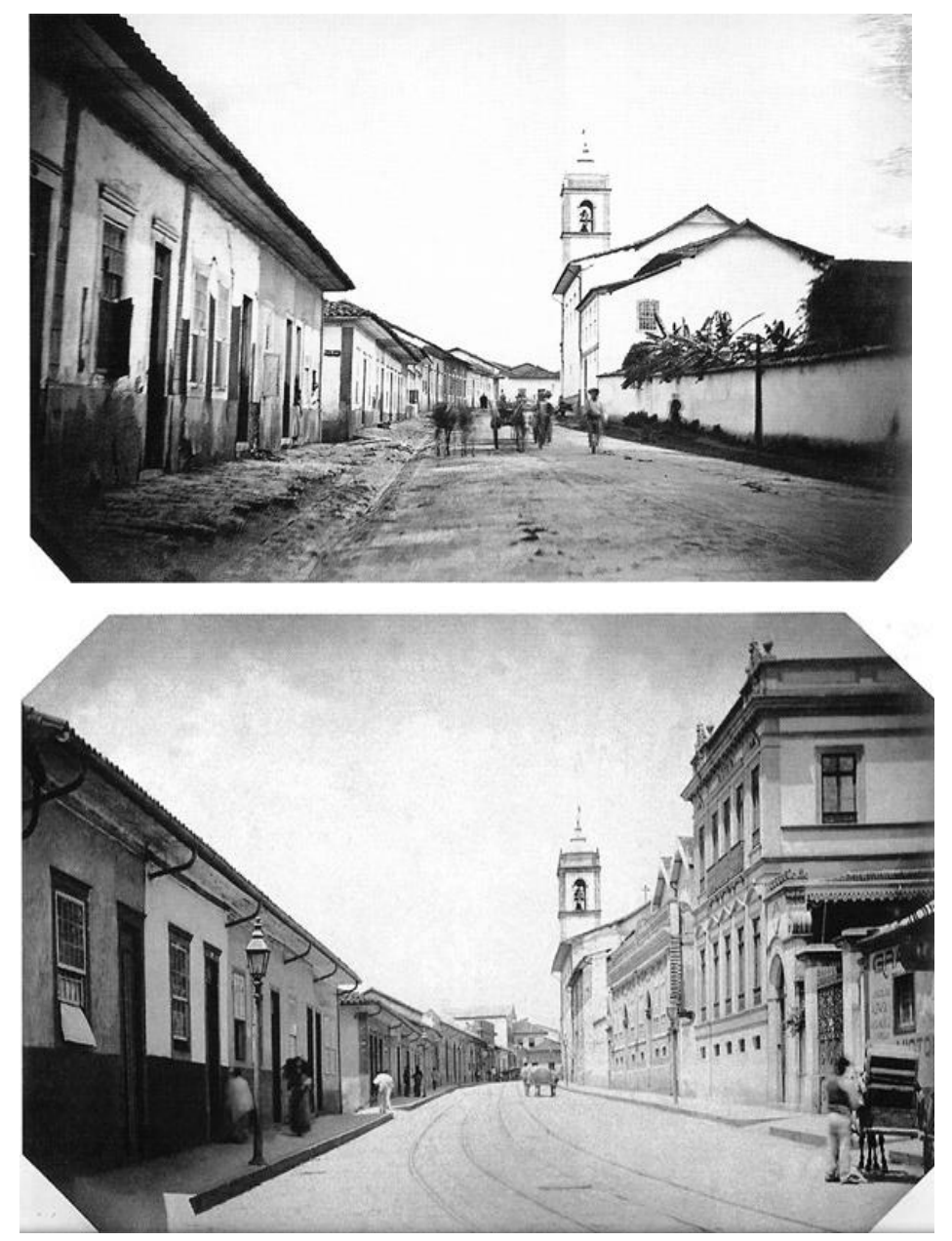

FIGURA 8. Rua Florêncio de Abreu, 1862 e 1887. Fonte: Caderno de Fotografia Brasileira, Instituto Moreira Salles. Disponível em: <http://www.skyscrapercity.com/showthread.php?t=332942>. Acesso em: 20 set. 2010. 

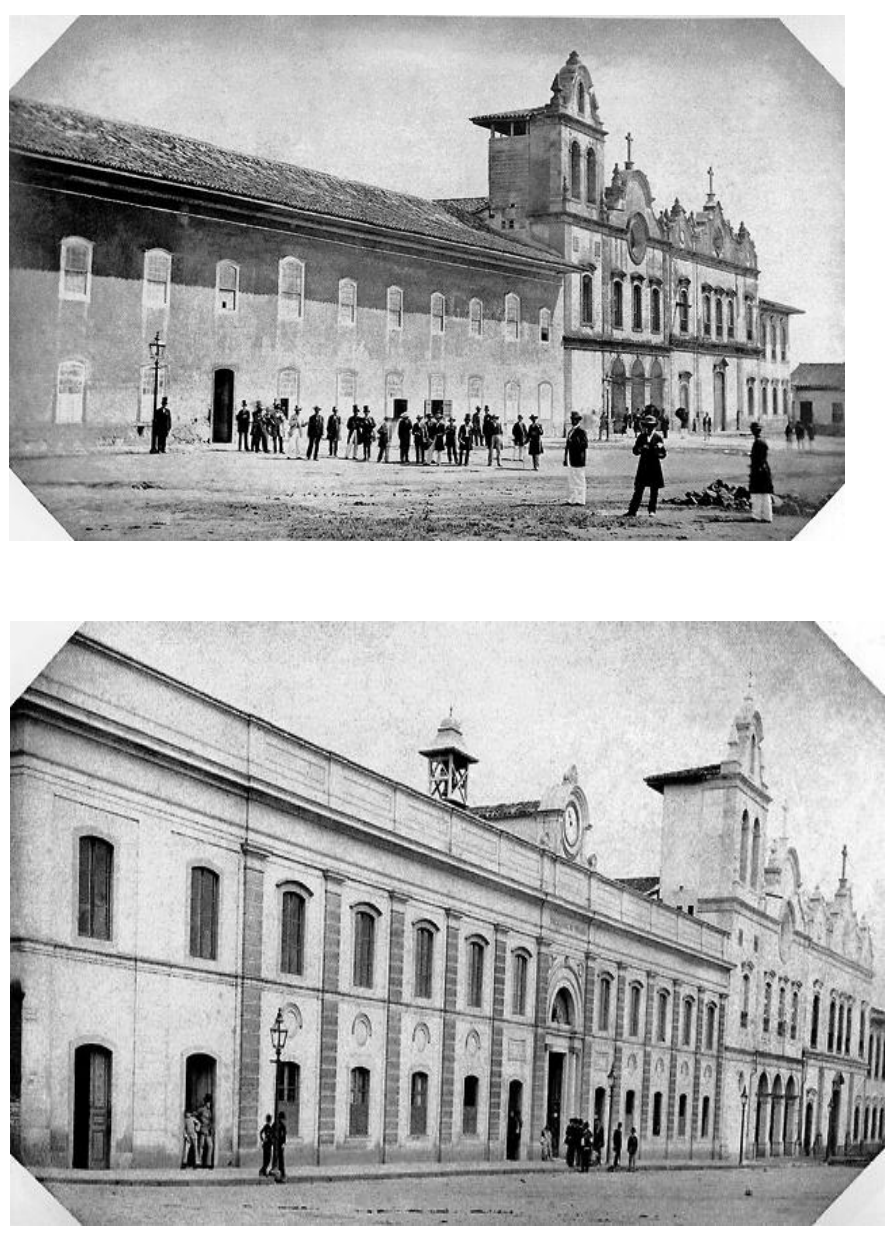

FIGURA 9. Largo de São Francisco, 1862 e 1887. Fonte: Caderno de Fotografia Brasileira, Instituto Moreira Salles. Disponível em: http://www.skyscrapercity.com/showthread.php?t=332942. Acesso em: 20 set. 2010.

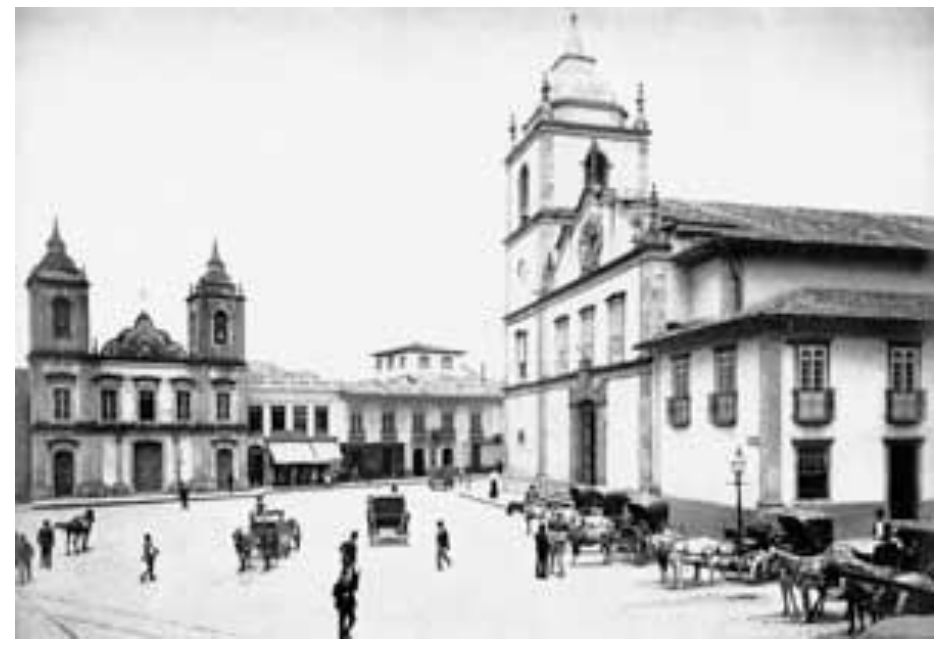

FIGURA 10: Praça da Sé, 1880. Disponível em: http://www.aprenda450anos.com.br/450anos/vila metropole/2-1 matriz saopaulo.asp. Acesso em: 20 set. 2010. 
Em 1885, com o crescimento acelerado da população que chega aos 65 mil habitantes, surgem problemas de transporte coletivo e a população se concentra nos arredores do Triângulo, como na Rua Líbero Badaró, onde surgem cortiços, focos de doenças transmissíveis (IACOCCA, 1998).

Em 1886 é criada a primeira legislação urbanística da cidade, com objetivo voltado para a estética e a higiene, estabelecendo a largura mínima das vias de circulação, a localização de teatros, hospitais, indústrias e seus horários de funcionamento (SÃO PAULO [Cidade] - SEMPLA, 2008).

\subsection{Segunda reurbanização}

Em 1889, quando mudanças políticas e sociais acontecem no país, tem início a segunda urbanização com a reformulação do Serviço Sanitário. Os cortiços do Triângulo são demolidos e as ruas, alargadas. A cidade se expande para terras mais afastadas, em todas as direções (FIG. 11). Os locais altos se valorizam, ocupados pelas classes sociais mais abastadas, as terras mais baixas e úmidas são ocupadas pelos menos favorecidos e por indústrias (IACOCCA, 1998).

Em 1892 é inaugurado o Viaduto do Chá (CAMPOS et al, 2004).

Inicia-se a mudança da elite do Centro Histórico para as demais colinas (CAMPOS et al, 2004).

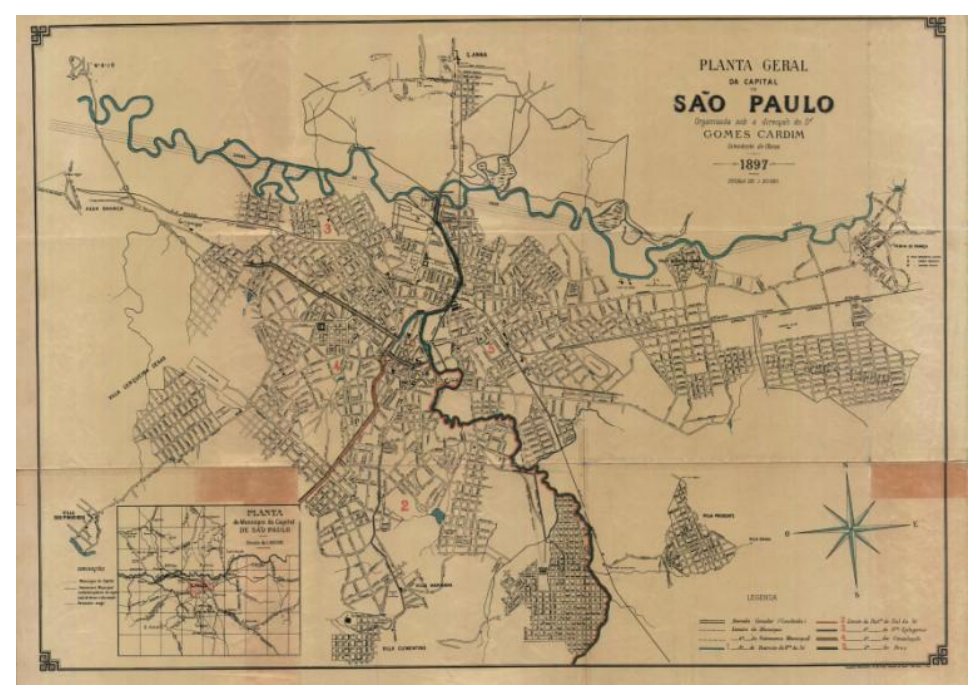

FIGURA 11. Planta da expansão urbana de São Paulo de 1897. Fonte: Lucia Noemia Simoni. Disponível em: http://www.ufmg.br/rededemuseus/crch/simoni a-planta-da-cidade-de-sao-paulo-de1897.pdf. Acesso em: 23 set. 2010. 


\subsection{Terceira reurbanização}

Em 1900, a população da cidade atinge 240 mil habitantes e as obras realizadas resultaram numa cidade diferente daquela que existia na primeira metade do século XIX. Mas no início do século XX a transformação continua. Entre 1900 e 1912 são implantados os bondes elétricos, viabilizando a comunicação do Centro Histórico com a parte nova da cidade, localizada além do Anhangabaú (FIG. 12) (SÃO PAULO [Cidade] - SEMPLA, 2008).

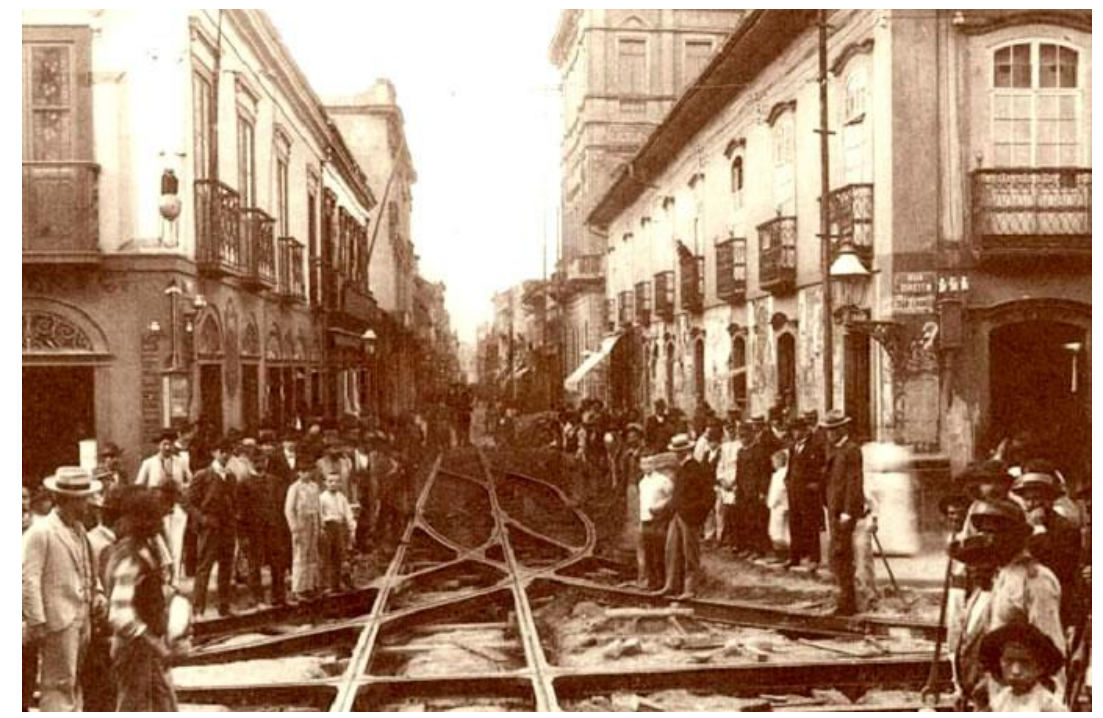

FIGURA 12: Cruzamento da Rua Direita com São Bento 1900. Foto do Censo Demográfico do Município de São Paulo de 1900 a 1919. Disponível em:

http://sempla.prefeitura.sp.gov.br/historico/1900.php. Acesso em: 23 set. 2010.

As epidemias já não acontecem mais, graças ao saneamento promovido desde 1890. Canalizam-se rios e ribeirões, garante-se o fornecimento e melhora-se a qualidade da água potável, a retificação do Rio Tamanduateí é concluída em 1914 (FIG. 13) (CAMPOS et al, 2004).

Nos primeiros anos do século $\mathrm{XX}$ a cidade assiste à substituição das casas e igrejas com arquitetura colonial por construções com arquitetura européia. Em 1910, a iluminação pública com lampiões de gás é substituída pela iluminação elétrica. Na Praça da Sé são demolidas a igreja de São Pedro dos Clérigos e a antiga Catedral, tendo início a construção da atual Catedral em 1913 (SÃO PAULO [Cidade] - SEMPLA, 2008). 


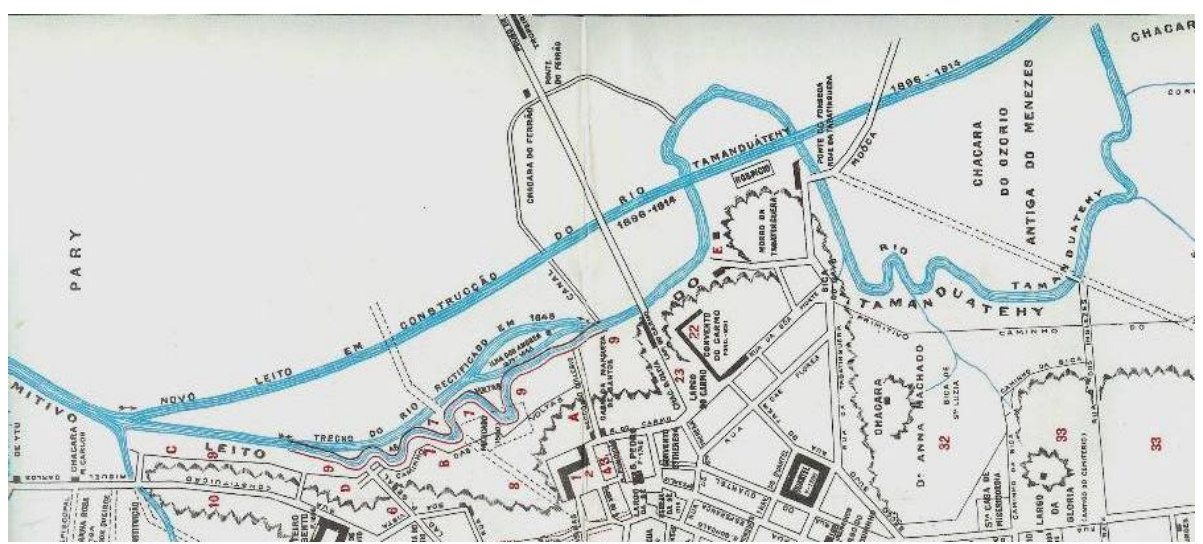

FIGURA 13: Detalhe de planta de Affonso A. de Freitas, mostrando o leito original do Rio Tamanduateí, o trecho menor retificado em 1848, e o novo leito retificado construído entre 1896 e 1914. Fonte: Informativo do Arquivo Histórico Municipal. Disponível em: http://www.arquiamigos.org.br/info/info05/index.html. Acesso em: 23 set. 2010.

Durante as primeiras décadas do século XX, a colina histórica, que anteriormente abrigava toda a cidade, passa a comandar a cidade em expansão, ter um perfil elitizado, comercial e residencial, preterindo as necessidades da produção industrial e da população trabalhadora. A cidade, já considerada moderna para os padrões da época, assiste à construção da Estação da Luz e de grandes edifícios públicos para abrigar as instituições republicanas, como o Palácio da Justiça, Liceu de Artes e Ofícios (atual Pinacoteca do Estado), o Quartel da Luz e outros (FIG. 14 a 16) (CAMPOS et al, 2004).

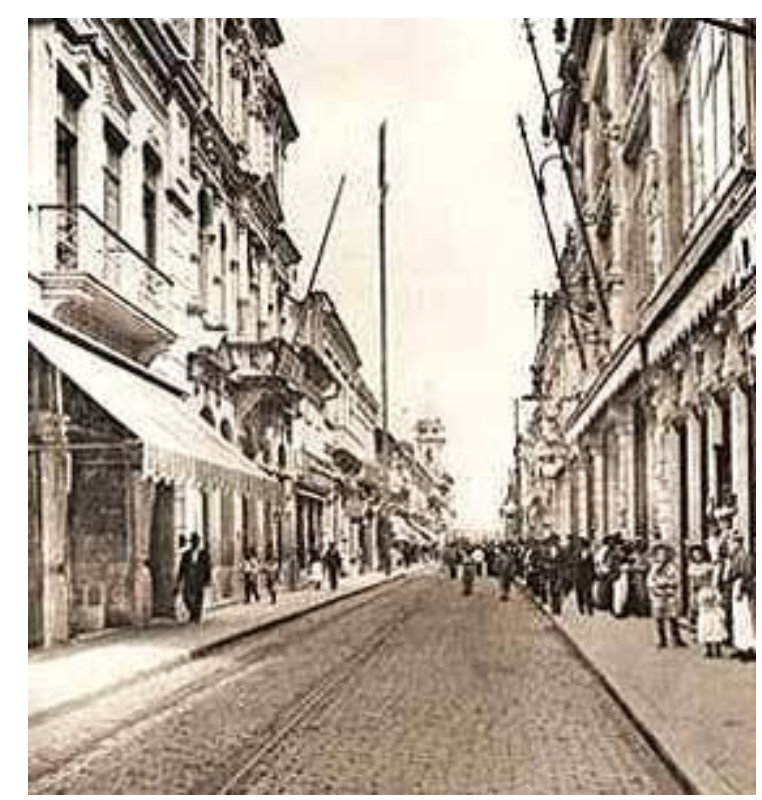

FIGURA 14. Foto da Rua Direita. Fonte: Atlas ambiental do município de São Paulo. Disponível em: <http://atlasambiental.prefeitura.sp.gov.br>. Acesso em: 19 jul.2008. 


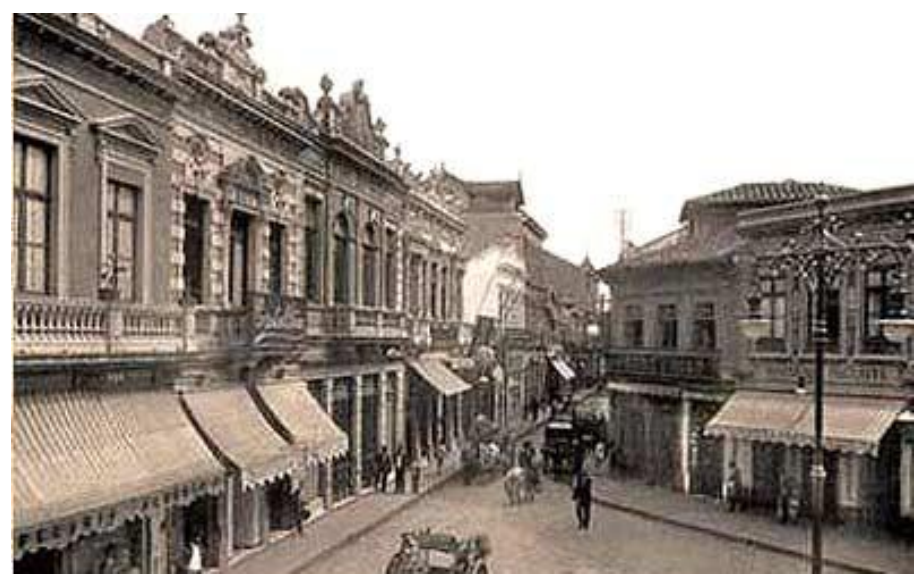

FIGURA 15. Foto da Rua São Bento. Fonte: Atlas ambiental do município de São Paulo. Disponível em: <http://atlasambiental.prefeitura.sp.gov.br>. Acesso: em 19 jul. 2008.

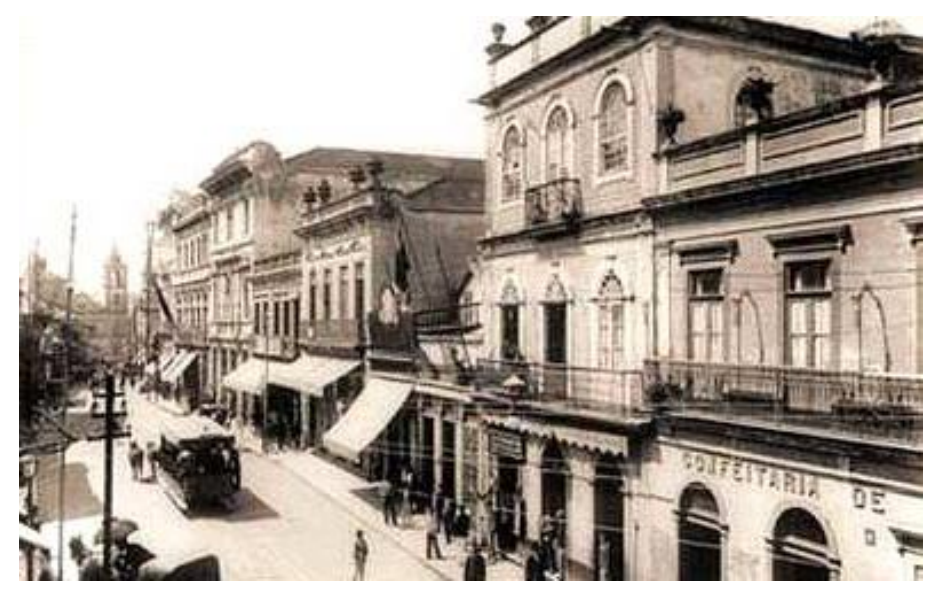

FIGURA 16. Foto da Rua XV de Novembro. Fonte: Atlas ambiental do município de São Paulo. Disponível em: <http://atlasambiental.prefeitura.sp.gov.br>. Acesso em: 19 jul. 2008.

Em 1911 é inaugurado o Theatro Municipal, referência arquitetônica da cidade (LUZ, 1999) e, em 1913, o novo Viaduto Santa Ifigênia (SÃO PAULO [Cidade] - SEMPLA, 2008).

A partir de 1911, J. A. Bouvard integra um lado da Rua Líbero Badaró ao parque construído no Vale do Anhangabaú, ladeado por volumes controlados, tornando-se um cartão-postal de rara beleza. Implantou a Praça Ramos de Azevedo (1912) na encosta do Theatro Municipal, construiu os blocos gêmeos dos palacetes Prates enquadrados por um belvedere (1914) (FIG. 17), o Monumento a Carlos Gomes (1922), o Hotel Esplanada (1923) (FIG. 18), a sede da Light (1924), o Clube Comercial (1929) (CAMPOS et al, 2004). 


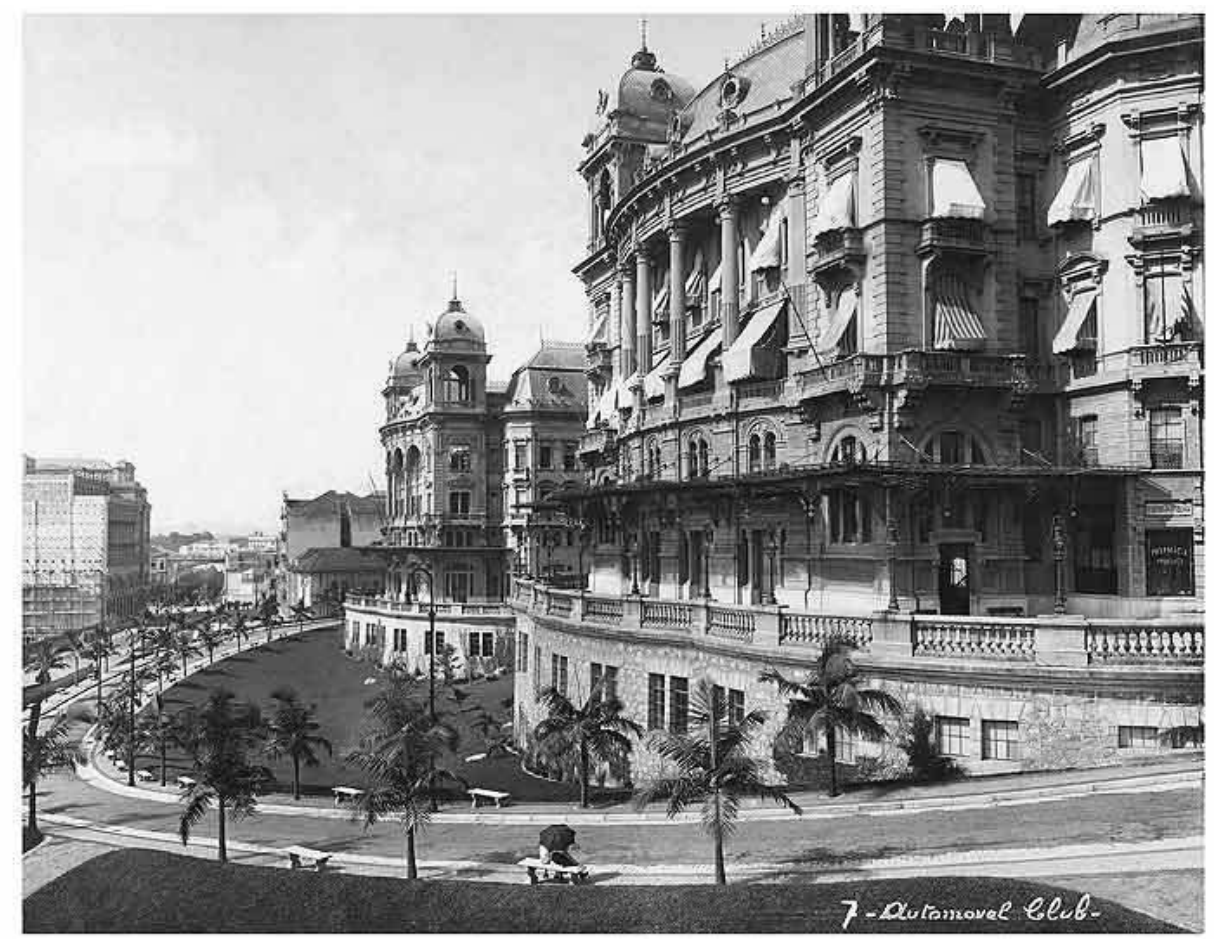

FIGURA 17: Parque Anhangabaú, 1914, com os Palacetes Prates. Fonte: Guilherme Gaensly. Disponível em: <http://cafehistoria.ning.com/photo/palacetes-prates-sp $>$. Acesso em: 20 set. 2010.

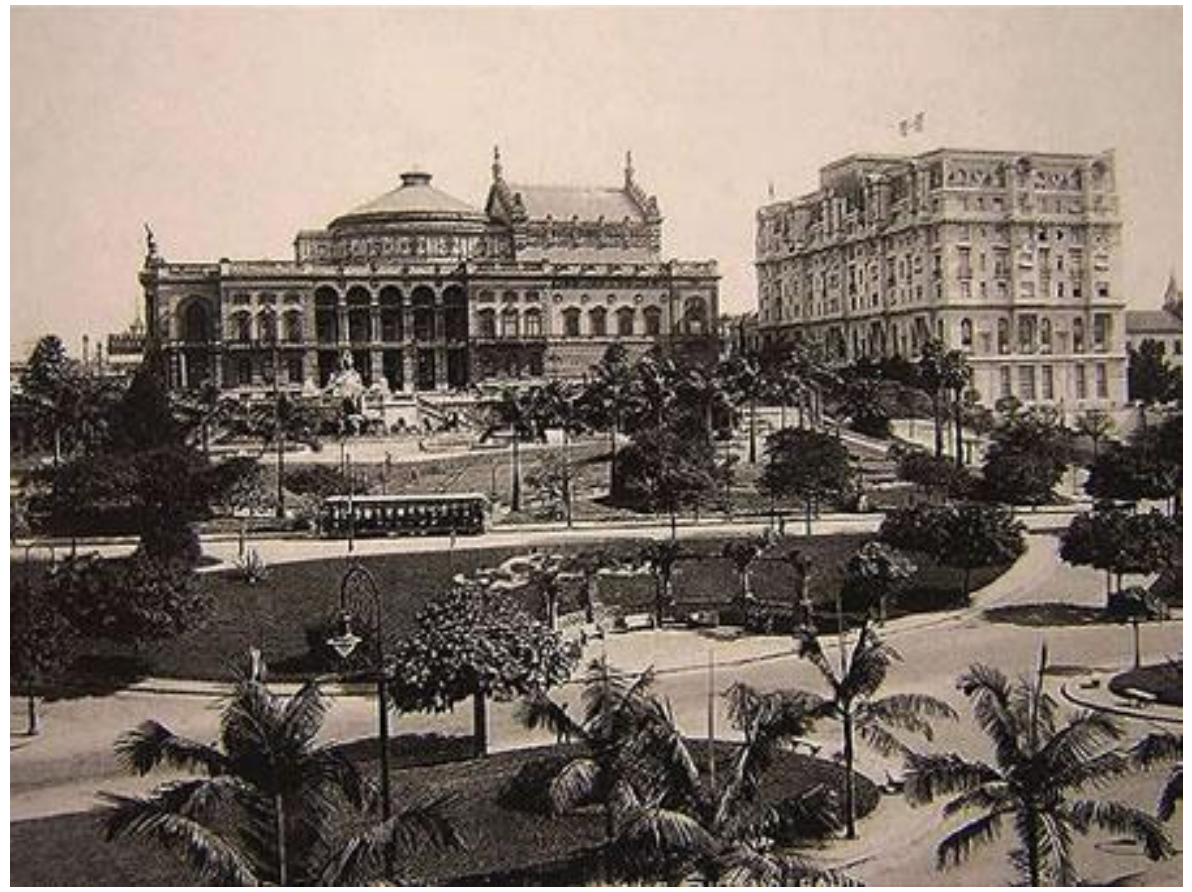

FIGURA 18: Parque Anhangabaú, 1923, com Theatro Municipal e Hotel Esplanada. Disponível em: <http://sempla.prefeitura.sp.gov.br/histórico/1900.php>. Acesso em: 20 set. 2010. 


\subsection{Quarta reurbanização}

Em 1920, após a Primeira Guerra Mundial (1914-1918), São Paulo surge como o maior produtor industrial do país, responsável por 32\% da produção nacional. O transporte coletivo, constituído pelos bondes elétricos, não atende mais à demanda e implanta-se a rede de transporte coletivo urbano com o sistema de ônibus (1924). É nesta mesma época que começa a crescer a frota de automóveis particulares da cidade (FIG. 19) (SÃO PAULO [Cidade] - SEMPLA, 2008).

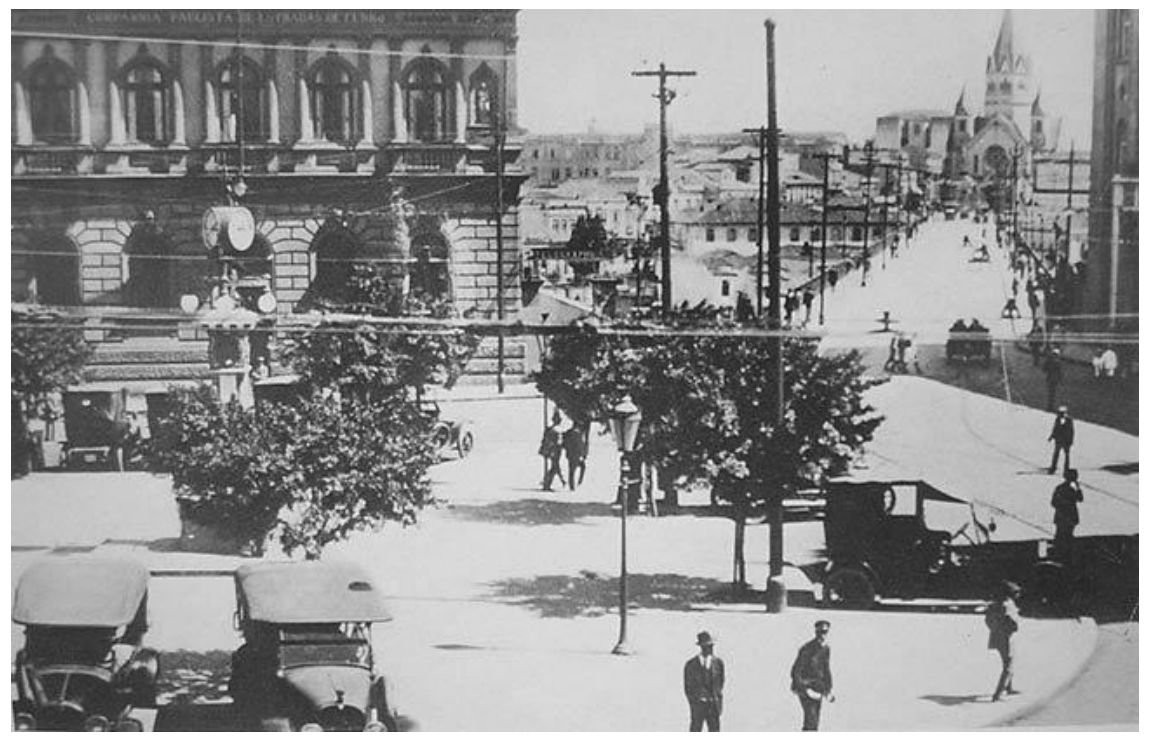

FIGURA 19: Largo de São Bento e Viaduto Santa Ifigênia, 1920. Fonte: Censo Demográfico do Município de São Paulo de 1900 a 1919. Disponível em:

http://sempla.prefeitura.sp.gov.br/historico/1900.php. Acesso em: 23 set. 2010.

Ainda em 1920 foi alterado o Código de Obras, permitindo a construção de edifícios altos, o que, futuramente, quebraria a harmonia estabelecida em diversos pontos da cidade, como no Anhangabaú. Até 1929 a cidade dispunha de pouco mais de 50 edifícios com mais de quatro andares, concentrados principalmente no centro (FIG. 20 a 22) (CAMPOS et al, 2004). 


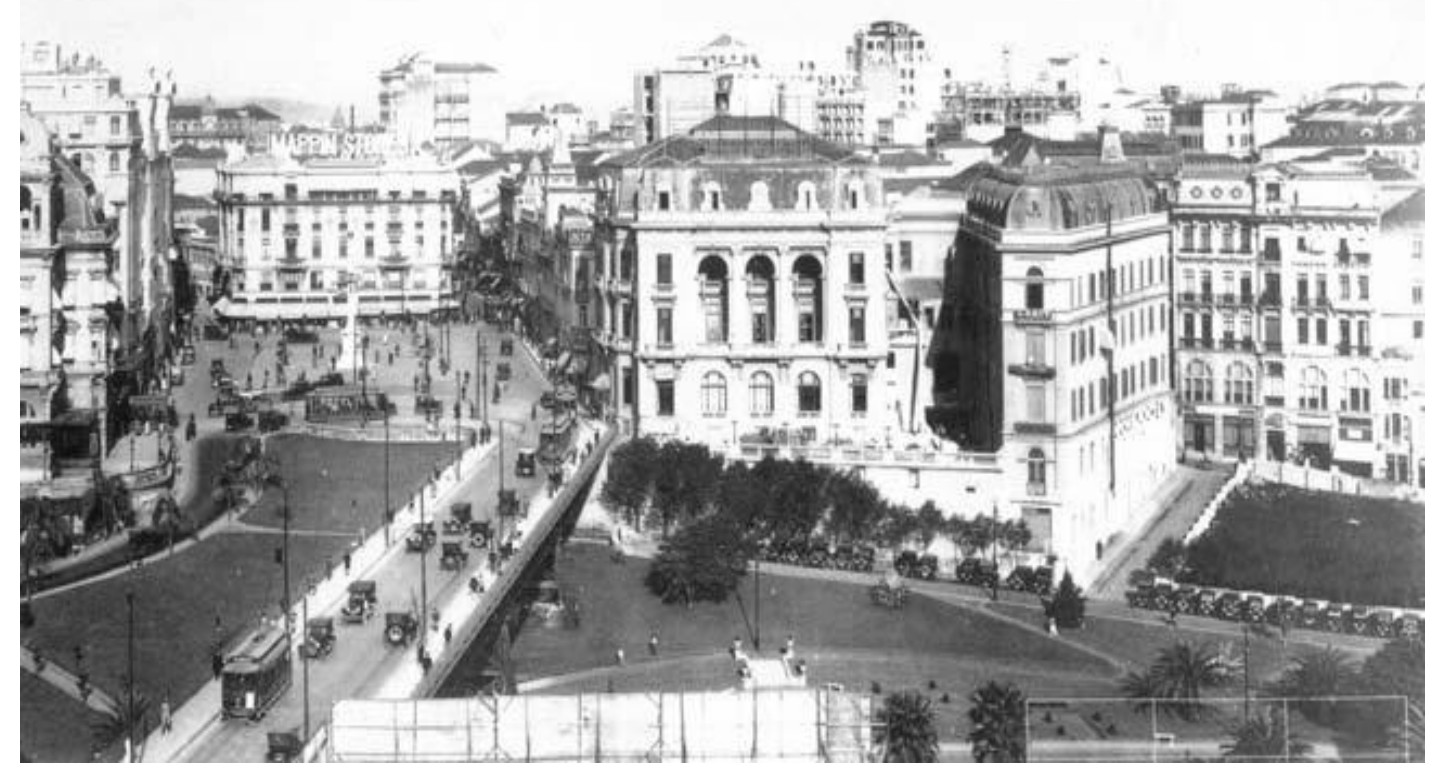

FIGURA 20: Anhangabaú/Viaduto do Chá/Praça do Patriarca 1925. Fonte: Censo Demográfico do Município de São Paulo de 1920 a 1929. Disponível em:

http://sempla.prefeitura.sp.gov.br/historico/1920.php. Acesso em: 23 set. 2010.

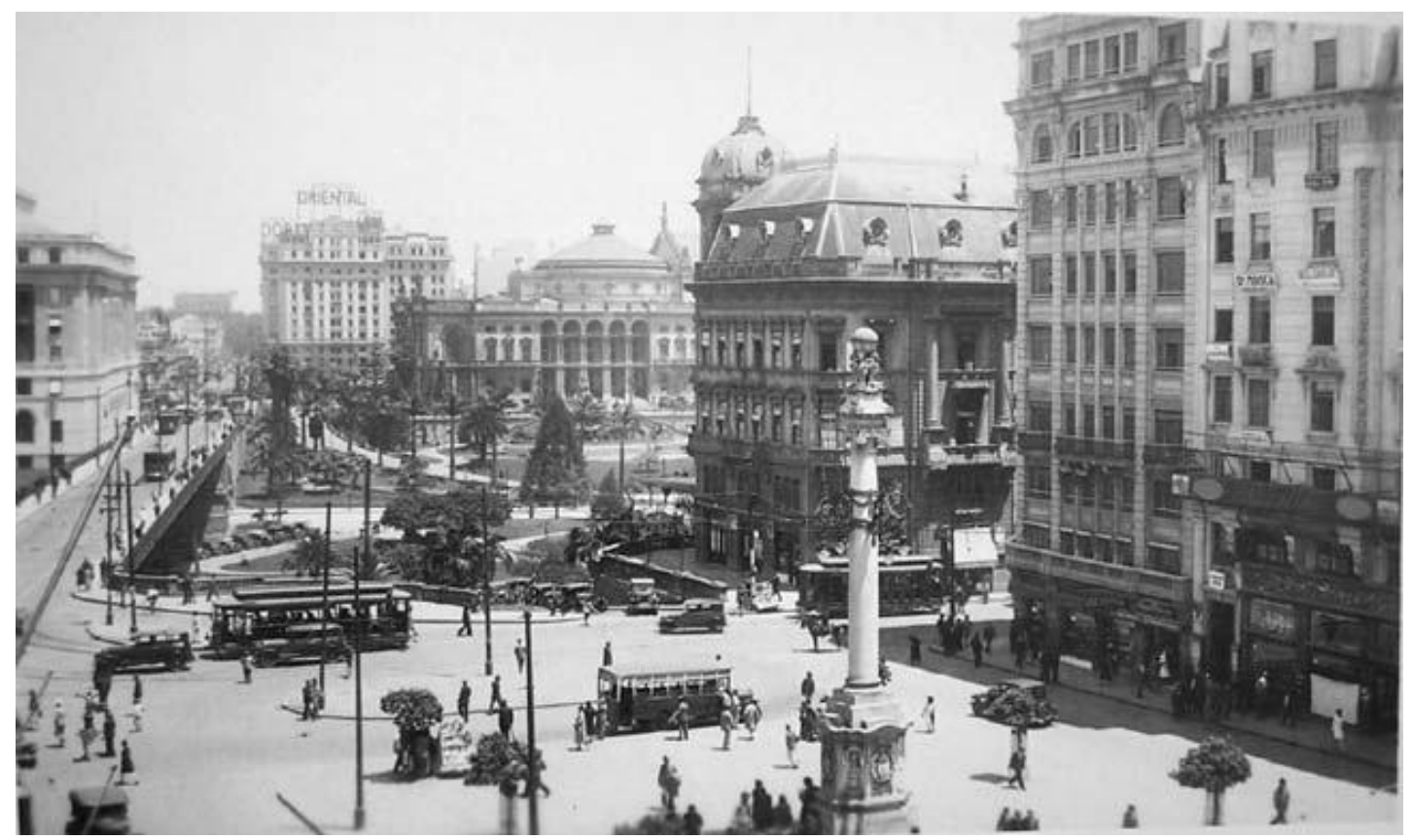

FIGURA 21: Praça do Patriarca/viaduto do Chá/Anhangabaú, 1927. Fonte: São Paulo, 3 cidades em um século. Benedito Lima de Toledo. Disponível em:

http://books.google.com.br/books?id=GWEHamfPog8C\&pg=PA153\&lpg=PA153\&dq=pra\%C3\%A7a+d o+patriarca+sp+1927\&source=bl\&ots=rbDvYD6YzG\&sig=3nSqhK-IOvTvyi2bl0ml8PSzok\#v=onepage\&q\&f=false. Acesso em: 23 set. 2010. 


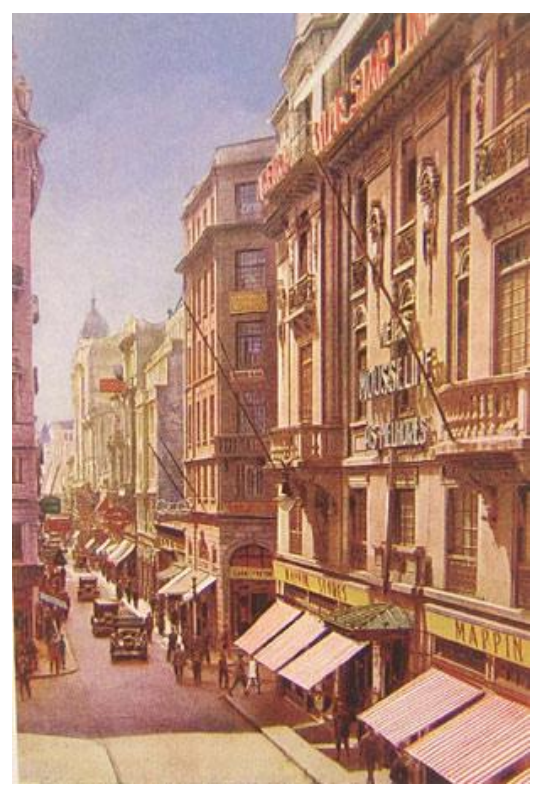

FIGURA 22: Rua São Bento 1929. Fonte: Censo Demográfico do Município de São Paulo de 1920 a 1929. Disponível em: http://sempla.prefeitura.sp.gov.br/historico/1920.php. Acesso em: 23 set. 2010.

Em 1929 ocorre a grande enchente e é lançado o Código de Obras Arthur Saboya, com o objetivo de controlar a estética, higiene e segurança das construções. Criada a Comissão de Melhoramentos do Rio Tietê, chefiada por Ulhôa Cintra, propondo aprofundamento do canal, urbanização da várzea e construção das avenidas marginais (SÃO PAULO [Cidade] - SEMPLA, 2008).

Entre 1925 e 1929 é construído o Edifício Martinelli, com 26 andares, marco da verticalização com elevados arranha-céus (FIG. 23) (LUZ, 1999).

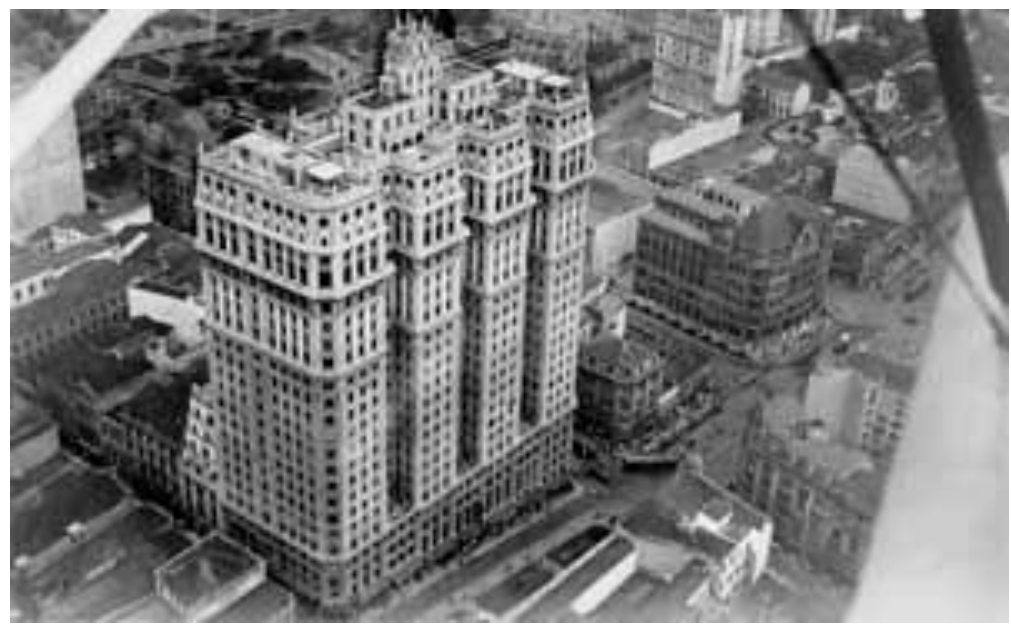

FIGURA 23: Edifício Martinelli, 1929, autor desconhecido. Fonte: São Paulo 450 anos. Disponível em: <http://www.aprenda450anos.com.br/450anos/galeria/showfoto.asp?url=ANF02_C>. Acesso em: 20 set. 2010. 
$\mathrm{Na}$ década de 1930, protagonizada pela iniciativa privada e associada à ideia de modernização, progresso e êxito econômico da metrópole, a verticalização em São Paulo transforma a área central da cidade. O comércio de luxo passa a se instalar no Centro Novo, na Rua Barão de Itapetininga (CAMPOS et al, 2004).

Em 1930 é lançado o Plano de Avenidas de Prestes Maia, com as primeiras diretrizes de zoneamento, soluções viárias, localização de edifícios públicos, criação de novas áreas verdes para corrigir o índice existente na época, de $0,71 \mathrm{~m}^{2}$ de área verde/habitante (FIG. 24) (SÃO PAULO [Cidade] - SEMPLA, 2008).

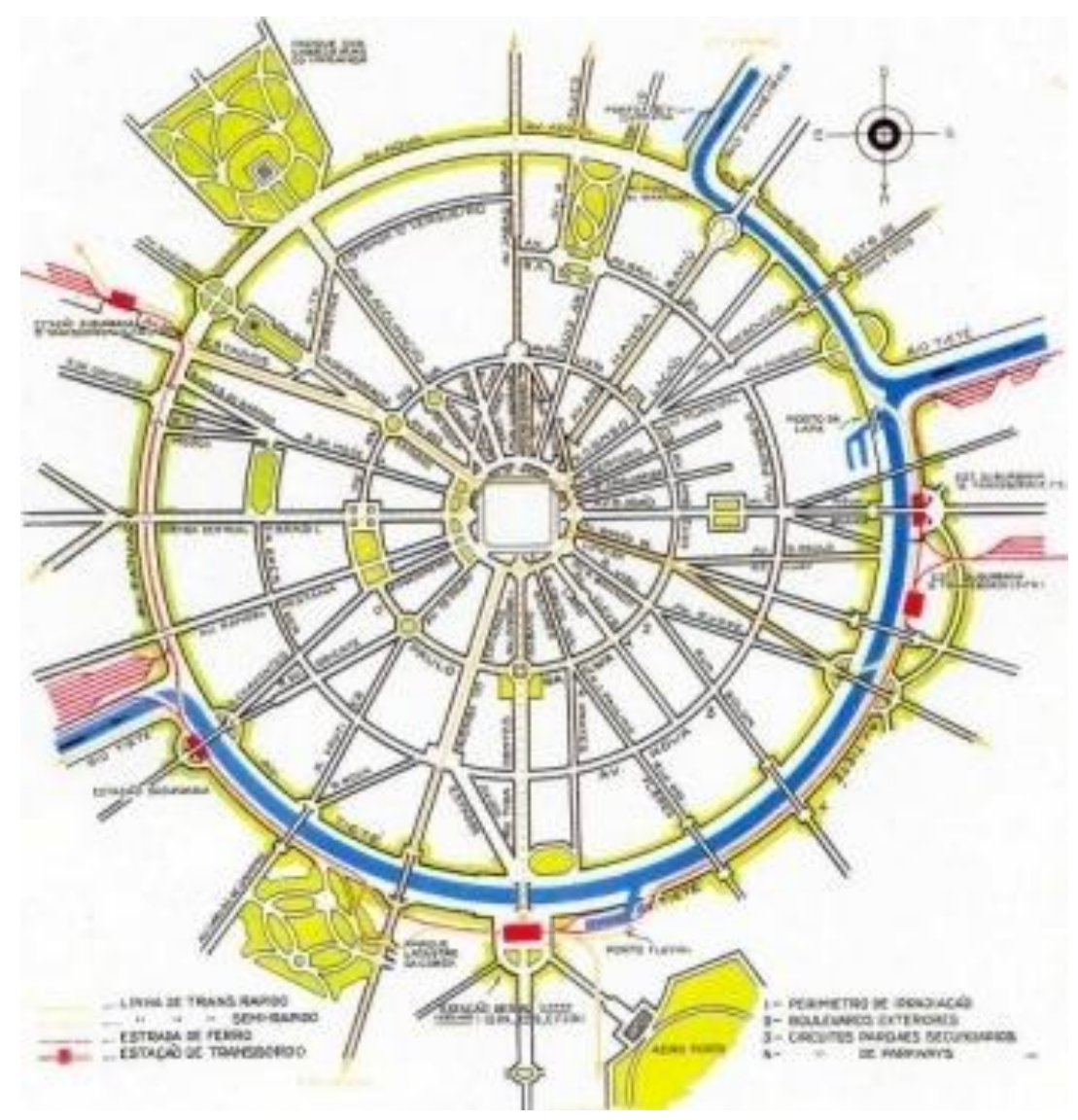

FIGURA 24: Esquema técnico de São Paulo, parte do Plano de Avenidas de autoria de Prestes Maia. Fonte: São Paulo: metrópole em trânsito: percursos urbanos e culturais (CAMPOS et al, 2004). 


\subsection{Quinta reurbanização}

Em 1938, Prestes Maia assume a Prefeitura de São Paulo e realiza mudanças na região central da cidade: alargamento das ruas Liberdade e Duque de Caxias (FIG. 25) e da Avenida São João, construção da Avenida Rio Branco e do novo Viaduto do Chá (FIG. 26), o Parque Bouvard no Anhangabaú é substituído por pistas de tráfego (SÃO PAULO [Cidade] - SEMPLA, 2008).
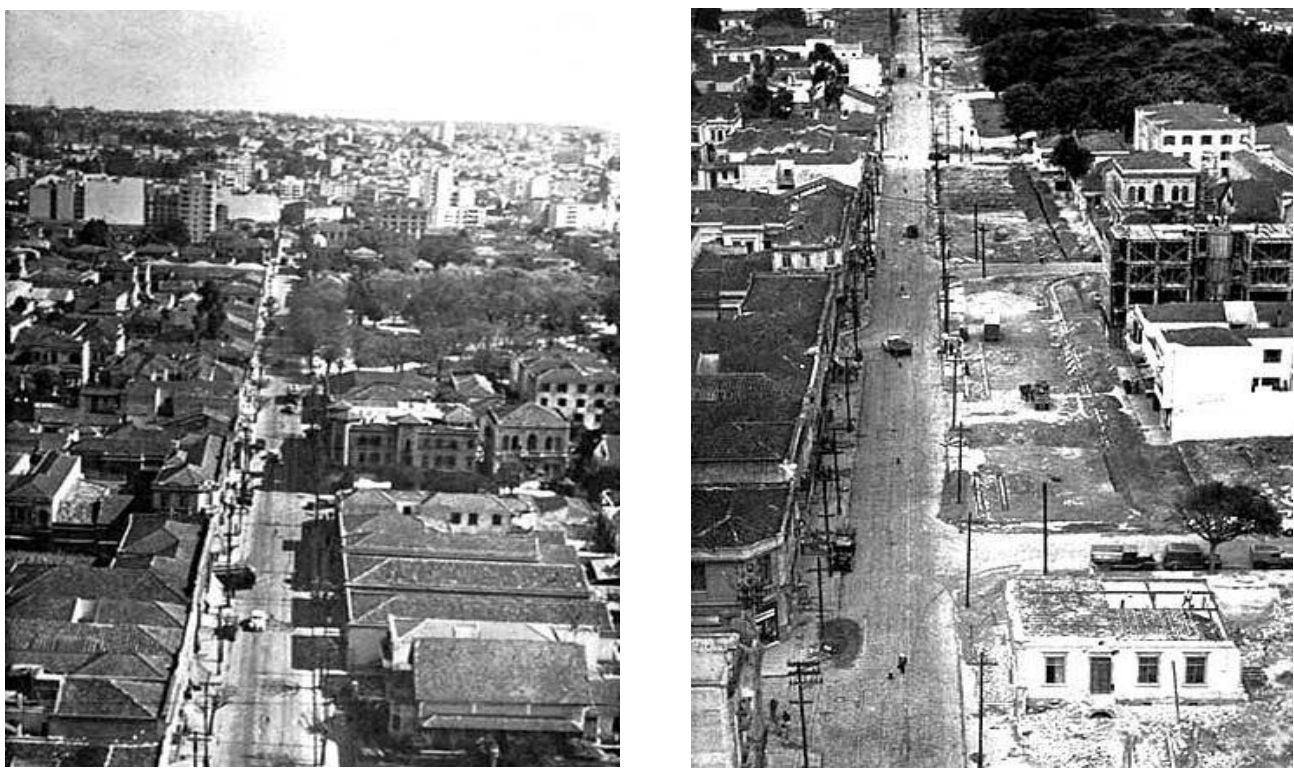

FIGURA 25. Foto das obras da Avenida Duque de Caxias, antes e durante as obras de alargamento. Fonte: Atlas ambiental do município de São Paulo. Disponível em: $<$ http://atlasambiental.prefeitura.sp.gov.br>. Acesso em: 19 jul. 2008.
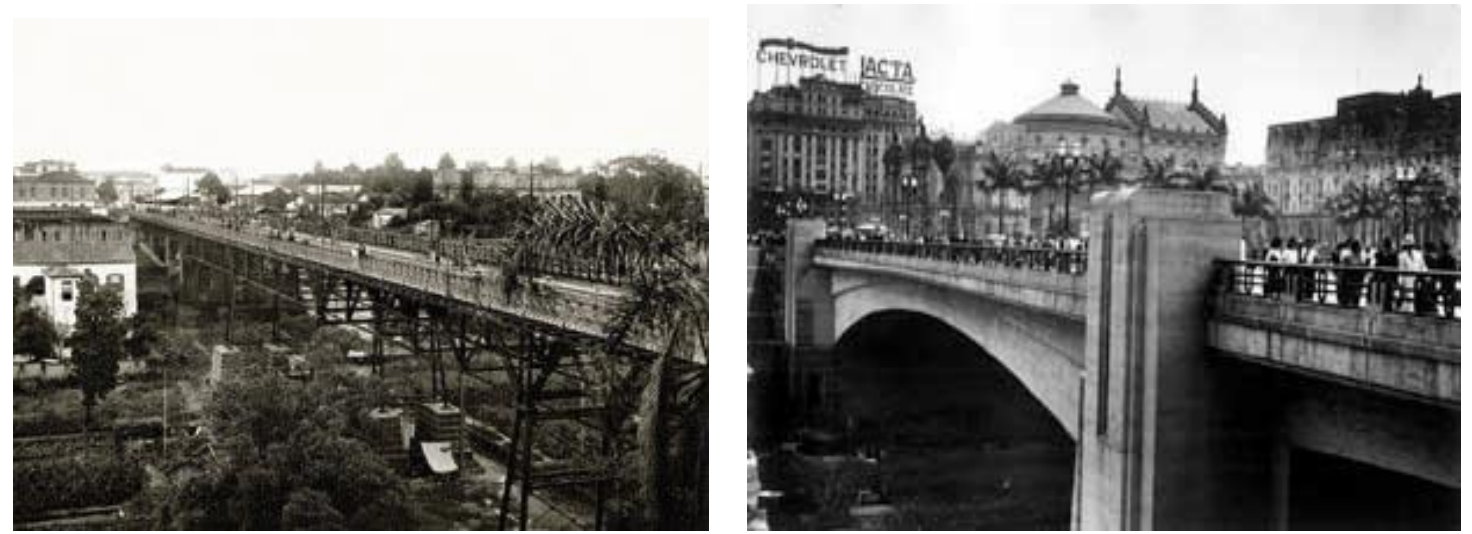

FIGURA 26. Viaduto do Chá, 1920 e 1940. Fonte: São Paulo 450 anos. Disponível em: http://www.aprenda450anos.com.br/450anos/vila metropole/2-3 viaduto cha.asp>. Acesso em: 23 set. 2010. 
A partir de 1940 São Paulo se consolida como metrópole industrial, atraindo imigrantes orientais e migrantes do nordeste, pela oportunidade de trabalho na indústria automobilística, siderúrgica, petroquímica, de eletrodomésticos, papel, borracha, máquinas e equipamentos. Nessa época a cidade conta com 4.876 indústrias, correspondentes a $54 \%$ da produção industrial do Estado (SÃO PAULO [Cidade] - SEMPLA, 2008).

Até o final dos anos 1940, o Centro estava em sua plena exuberância, a sede do governo instalada no Palácio dos Campos Elísios desde 1911 era uma atração para o Centro Novo (CAMPOS et al, 2004).

O Edifício Altino Arantes (também conhecido como edifício do Banco do Estado) é construído de 1939 a 1947, tornando-se um dos ícones da cidade (FIG. 27).

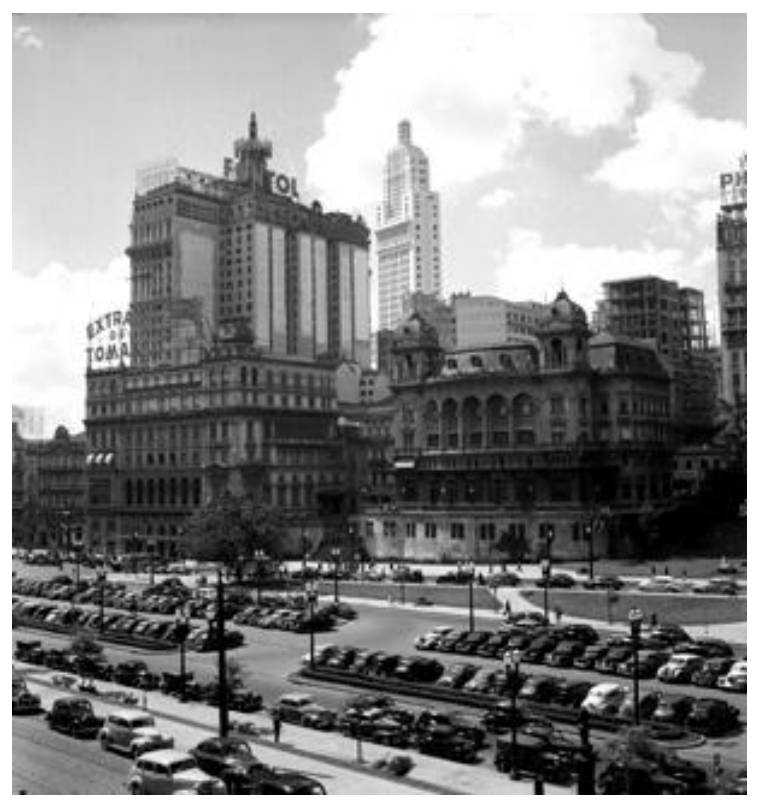

FIGURA 27. Vale do Anhangabaú, Edifícios Martinelli e Altino Arantes, entre 1940 e 1946. Disponível em: http://theurbanearth.wordpress.com/tag/sao-paulo-antigo/. Acesso em: 23 set. 2010.

$\mathrm{Na}$ década de 1950, São Paulo passa a se organizar como cidade policêntrica. Ocorre a mudança da centralidade da cidade, com o comércio de luxo deslocando-se do Centro Novo para a região da Avenida Paulista, para onde as elites também transferem as suas residências. Dá-se início ao abandono do centro. Inicia-se um período de renovação da estrutura do centro, possibilitando aos seus arredores (Bom Retiro, Bela Vista, Cambuci, Santa Ifigênia, Liberdade e Consolação) 
a instalação de centros de comércio popular e atacadista de abrangência nacional. Surgem, no centro, locais de moradia para classes média e baixa, tornando-se um centro metropolitano deselitizado (CAMPOS et al, 2004).

Entre os anos de 1950 e 1960 a população de São Paulo passa para 2 milhões de habitantes e seu parque industrial para 6.156 indústrias e 585 mil operários.

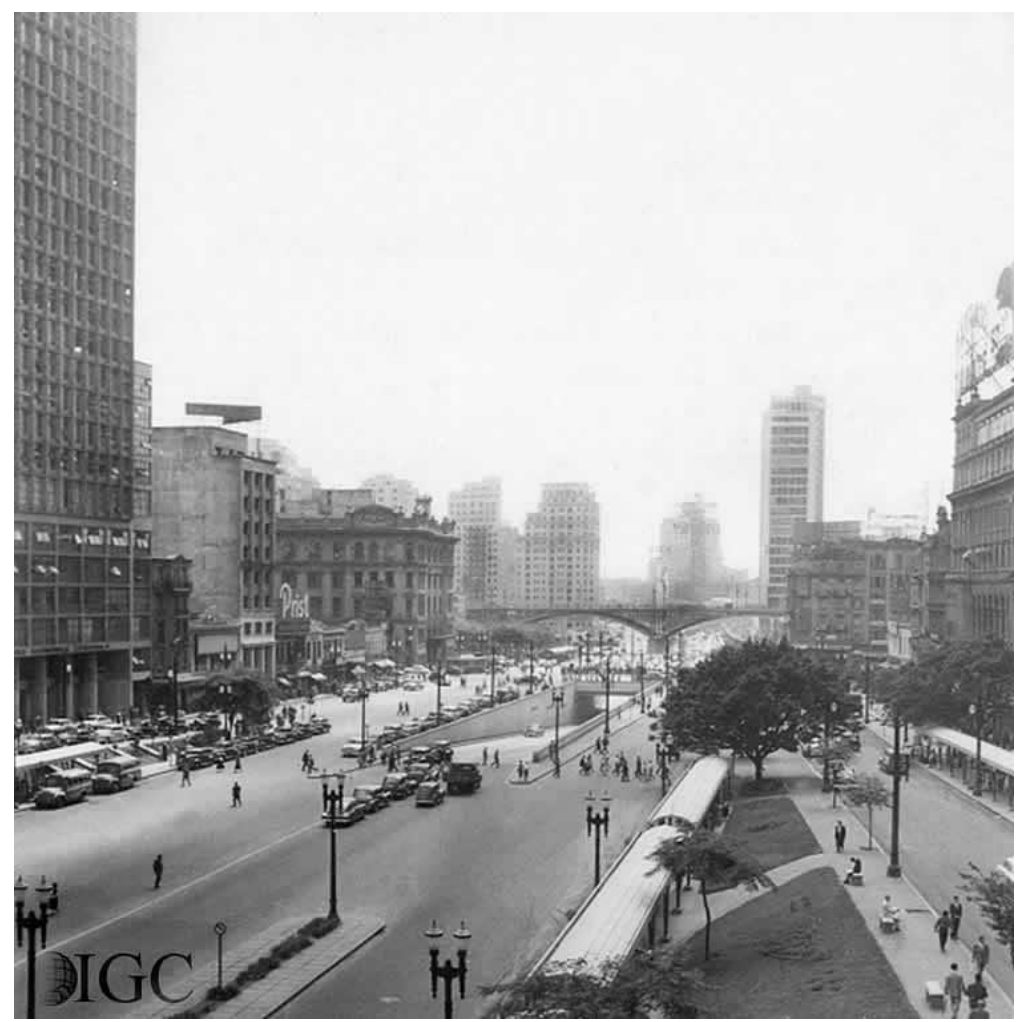

FIGURA 28. Vale do Anhangabaú 1957. Disponível em:

<http://www.igc.sp.gov.br/histarghist/aspecturb/sao-paulo0867.html>. Acesso em: 20 set. 2010.

No início dos anos 1960 tem início o processo de desindustrialização do centro, local onde se instalaram as primeiras indústrias da cidade, com a supressão de inúmeros postos de trabalho e causando pesadas perdas para a região.

Prestes Maia assume novamente a Prefeitura e dá prosseguimento a seu plano de urbanização com grandes obras de engenharia. Ocorre então a transformação de vales em grandes corredores viários, com o objetivo de eliminar os congestionamentos de veículos da área central e diminuir as enchentes. São canalizados córregos e construídas avenidas, impermeabilizando grandes áreas. 
Fica comprometida a capacidade natural do solo de absorção das águas pluviais, diminui o teor de umidade do ar, eleva-se a sensação térmica e, contrariando o que se esperava, agravam-se as enchentes e a poluição do ar no centro com a construção das vias radiais.

A partir de 1970 políticas públicas de transporte incentivam o acesso ao centro através do transporte coletivo que, associado aos grupos sociais de mais baixa renda, contribuem para a perda de atratividade e deslocamento da população do centro para a região da Avenida Berrini, que oferece acesso facilitado por meio de automóveis.

Este processo resulta na desvalorização, estagnação imobiliária, degradação dos imóveis, perda da qualidade de vida e comprometimento do valor histórico da região central da cidade (BIDONE, 2003).

Em 1971 é construído o Elevado Costa e Silva, o "Minhocão", sobre a Avenida São João, provocando profunda descaracterização da região central da cidade. Enquanto em 1960 a cidade contava com capacidade industrial de 52\% da produção estadual e 28\% da nacional, em 1967 esses índices caem para 42\% e $24 \%$, respectivamente. Durante a década de 1970 intensifica-se o processo de desindustrialização da região central da cidade, ficando estabelecidas somente fábricas antigas de bens de consumo e indústrias mais novas do setor elétrico e de telecomunicações (FIG. 29) (SÃO PAULO [Cidade] - SEMPLA, 2008).

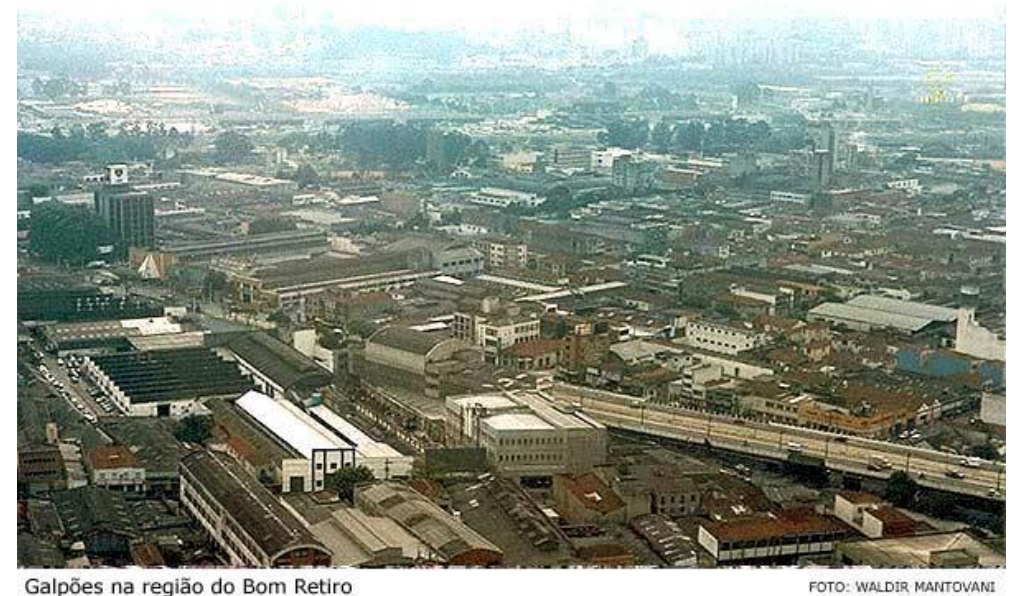

FIGURA 29. Vista dos galpões industriais no bairro do Bom Retiro. Fonte: Atlas ambiental do município de São Paulo. Disponível em: <http://atlasambiental.prefeitura.sp.gov.br>. Acesso em: 19 jul. 2008. 
De 1970 a 1980, as ruas do centro recebem os calçadões, com o objetivo de aumentar o espaço de circulação para pedestres. Hoje o calçadão é considerado exagerado uma vez que, em nenhuma outra cidade do mundo, o espaço reservado para os calçadões é tão grande quanto ao de São Paulo, que chega a $8 \mathrm{~km}$ de extensão (LUZ, 1999).

Nos anos 1980, com a liberalização econômica e a retração das ações do Estado (ARAUJO, 2001), prossegue a expansão da centralidade da cidade de São Paulo para o vetor sudoeste, fato motivado pela infraestrutura viária da região, capaz de absorver a crescente frota de veículos, e ao custo inferior dos terrenos em relação aos da região central (ABASCAL, 2008).

$O$ processo desenvolvido, na segunda metade do século $X X$, resultou na queda da população da Subprefeitura da Sé de 432.708 habitantes em 1960 para 373.914 habitantes no ano 2000 (TAB. 1) e o grupo constituído pelos distritos Sé, Bom Retiro e Cambuci transformou-se no grupo com menor densidade demográfica desta Subprefeitura (FIG. 30) (SEPE; GOMES, 2008).

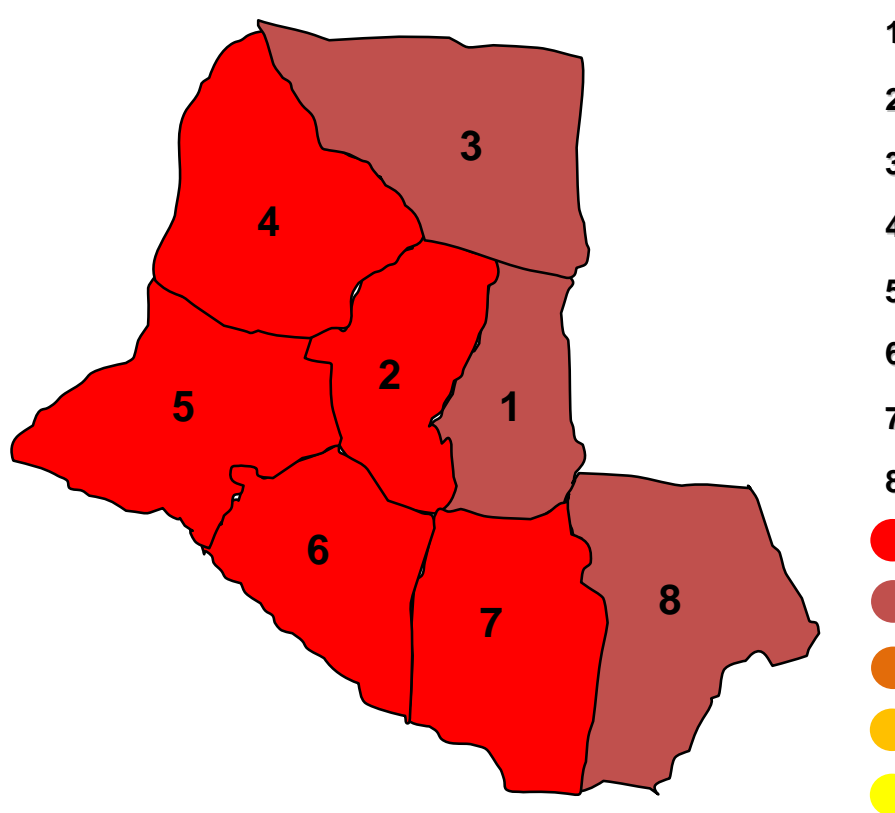

\begin{tabular}{|c|c|}
\hline & Sé \\
\hline 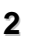 & República \\
\hline 3 & Bom Retiro \\
\hline 4 & Santa Cecília \\
\hline & Consolação \\
\hline & Bela Vista \\
\hline & Liberdade \\
\hline & Cambuci \\
\hline & 100 a 244 habitantes/ha \\
\hline & 50 a 100 habitantes/ha \\
\hline & 25 a 50 habitantes/ha \\
\hline & 10 a 25 habitantes/ha \\
\hline & 0 a10 habitantes/ha \\
\hline
\end{tabular}

FIGURA 30. Densidade demográfica por distrito da região central. Fonte: IBGE, 2000. Adaptado de Indicadores Ambientais e Gestão Urbana (SEPE; GOMES, 2008).

A densidade demográfica de cada distrito revela valores abaixo dos recomendados, de 350 a 420 habitantes/ha. Estes valores, obtidos por estudos 
realizados em 1996 para a cidade de Porto Alegre, são utilizados pela Prefeitura do Município de São Paulo por levarem em consideração o equilíbrio entre questões ambientais e a utilização da infraestrutura implantada (TAB. 1) (MASCARÓ, 1996).

TABELA 1. Densidade demográfica por distrito da Subprefeitura da Sé. Fonte: IBGE, 1960 e 2000 - SEPE; GOMES, 2008.

\begin{tabular}{lccccc}
\hline \multirow{2}{*}{ Distrito } & \multicolumn{2}{c}{ População } & \multicolumn{2}{c}{ Área } & \multicolumn{2}{c}{$\begin{array}{c}\text { Densidade demográfica } \\
\text { (habitantes/ha) }\end{array}$} \\
& (IBGE-1960) & (IBGE-2000) & (ha) & \multicolumn{1}{c}{1960} & 2000 \\
\hline Santa Cecília & 80.581 & 71.179 & 385 & 209,30 & 184,88 \\
Bela Vista & 57.364 & 63.190 & 271 & 211,67 & 233,17 \\
Liberdade & 68.210 & 61.875 & 364 & 187,39 & 169,98 \\
Consolação & 52.182 & 54.522 & 383 & 136,25 & 142,35 \\
República & 48.346 & 47.718 & 242 & 199,78 & 197,18 \\
Cambuci & 39.789 & 28.717 & 391 & 101,76 & $\mathbf{7 7 , 4 4}$ \\
Bom Retiro & 53.893 & 26.598 & 411 & 131,13 & $\mathbf{6 4 , 7 0}$ \\
Sé & 32.343 & 20.115 & 220 & 147,01 & $\mathbf{9 1 , 4 3}$ \\
TOTAL & $\mathbf{4 3 2 . 7 0 8}$ & $\mathbf{3 7 3 . 9 1 4}$ & 2.667 & $\mathbf{1 6 2 , 2 5}$ & $\mathbf{1 4 0 , 2 0}$ \\
\hline
\end{tabular}

Os baixos índices de adensamento demográfico dos distritos Cambuci, Bom Retiro e Sé são decorrentes do uso predominante dos imóveis para fins comerciais e uso reduzido para fins residenciais. Apesar de 2 milhões de pessoas por dia se dirigirem ao centro no horário comercial, fora desse horário, devido ao reduzido número de moradores, as ruas ficam desertas, gerando problemas de segurança que agravam o processo de deterioração do centro (BAENINGER, 2005).

A reversão desse processo se dá pela revitalização da área, metodologia adotada a partir da década de 1990 às áreas centrais de grandes cidades do mundo (MEYER, 2000). Tais projetos têm como objetivo a melhor utilização do patrimônio instalado, sem o uso de projetos renovadores agressivos ou exageradamente conservadores e a reabilitação econômica, social, cultural existente no passado. Estabelecem uma ação conjunta entre o setor público, investidores e usuários para que sejam viabilizados projetos integrados de curto a longo prazos e que promovam uma nova imagem para locais decadentes (DEL RIO, 2008). 


\section{REVISÃO DA LITERATURA}

\subsection{Considerações preliminares}

A palavra ecologia é composta pelos vocábulos gregos oikos e logos, que significam respectivamente casa e ciência. Ecologia é o estudo do comportamento de todos os organismos vivos entre si e entre os organismos não vivos. Este conjunto, denominado biosfera, é composto pelos biótopos (lugares onde há vida) e pelas biocenoses (populações vivas). Quando há biocenoses vivendo em biótopos temos um ecossistema, que, por sua vez, é formado por componentes essenciais, não essenciais, vivos e não-vivos. A ação da luz do Sol sobre a clorofila produz a fotossíntese, base da vida dos vegetais. Os vegetais morrem, são decompostos por bactérias em substâncias nutritivas que retornam ao solo e alimentam novos vegetais. Essa sequência forma um ciclo de vida simples, onde estão identificados todos os componentes essenciais (Sol, vegetal, água, bactérias e substâncias nutritivas). Na falta de um desses componentes a vida é interrompida (CARVALHO, 1984).

O homem faz parte dos grupos dos seres vivos que não depende somente dos componentes essenciais. Depende também da utilização de fontes de energia que poluem o meio ambiente. Da construção de abrigos que empregam materiais absorvedores e refletores de calor (CARVALHO, 1984).

Rachel Carson, através do livro Primavera silenciosa, publicado pela primeira vez em 1962, alerta sobre as consequências provocadas pelo desenvolvimento que não leva em consideração os impactos ambientais que pode causar (CARSON, 2010).

Em 1987 a Comissão Mundial sobre Meio Ambiente e Desenvolvimento (CMMAD), da Assembleia Geral das Nações Unidas, apresenta o relatório "Nosso Futuro Comum", da ministra da Noruega, Gro Brundtland, com o conceito de desenvolvimento sustentável, mostrando que o atendimento às necessidades do presente deve ser realizado sem comprometer as necessidades das gerações futuras (JOLY, 2003). 
Em 1992 a Conferência das Nações Unidas para o Meio Ambiente e Desenvolvimento (CNUMAD), no Rio de Janeiro, apresenta a Declaração do Rio de Janeiro sobre Meio Ambiente e o Desenvolvimento, a Convenção sobre Mudanças Climáticas, a Convenção da Biodiversidade e a Agenda 21. A Declaração do Rio de Janeiro endossa o conceito de desenvolvimento sustentável, lançado em 1987, enquanto a Agenda 21 lança um padrão de desenvolvimento que concilia proteção ambiental e eficiência econômica, com justiça social (GROSTEIN, 2001).

Em 1956, H. E. Landsberg apresenta, no Simpósio Internacional "Man's Role in Change of the World", o trabalho "The climate of de towns", onde as causas da mudança no clima das cidades são atribuídas a diversos fatores: remoção da vegetação, drenagem de áreas úmidas e impermeabilização do solo, por provocarem rápido escoamento superficial e diminuição da umidade; concentração de construções, por utilizarem materiais absorvedores e refletores de calor que aumentam a rugosidade da superfície reduzindo a velocidade dos ventos; poluição urbana, por contribuir para a elevação da concentração de gases do efeito estufa que permitem a passagem dos raios de luz e impedem a passagem de ondas de calor e ainda pelo acúmulo de material particulado no ar que absorve e reemite calor (LANDSBERG, 1956).

O calor é a principal ação do meio ambiente sobre a vida, interferindo nos processos vitais, da mesma forma como interfere nas reações físico-químicas, retardando-as a baixas temperaturas e acelerando-as nas altas. A temperatura é o elemento que define o clima, variando ao longo do dia, conforme a altitude, latitude, estação do ano, ventos e umidade.

\subsection{Densidade vertical}

Aumentando a densidade da ocupação e a intensidade do uso do espaço urbano, maximiza-se a utilização da infraestrutura e do solo em detrimento do clima urbano.

Para enfrentar esse antagonismo, é defendida a urbanização compacta de uso misto, com prioridade para pedestres, bicicletas, reurbanização, conservação dos recursos naturais e participação popular. 
Estudos realizados em 1996, que consideram tanto os custos da infraestrutura quanto as questões do clima, apontam como ideais a densidade demográfica entre 350 e 420 habitantes por hectare e construções de três a quatro pavimentos (MASCARÓ, 1996).

\subsection{Impermeabilização do solo}

A proteção do solo contra a erosão pode ser realizada por depósitos de detritos de origem vegetal ou pela cobertura vegetal. As folhas interceptam as gotas de chuva, diminuindo sua energia, e impedem que atinjam diretamente o solo. A água por elas retida vaporiza para a atmosfera e a maior parte da água que chega à superfície é absorvida pelo solo.

A proteção do solo ainda pode ficar comprometida quando a cobertura vegetal é constituída somente por árvores com mais de nove metros de altura (CARVALHO, 1984).

\subsection{Umidade}

A umidade aumenta pela evaporação da água dos lagos, rios e pela transpiração das plantas. A transição da água do estado líquido para o estado de vapor, e vice-versa, ocorre pela troca de calor, absorvendo ou cedendo energia ao meio ambiente e agindo como um regulador térmico. A quantidade de água dos mananciais depende do coeficiente de escoamento superficial, que varia com a permeabilidade do solo. Em terrenos com grande cobertura vegetal a permeabilidade chega a atingir somente $20 \%$ (CARVALHO, 1984).

\subsection{Vento}

A dispersão da poluição do ar depende de condições ambientais como a queda contínua da temperatura à medida que se distancia do solo, da topografia, da chuva e dos ventos (SEWELL, 1978).

A dispersão dos poluentes depende diretamente do vento existente em locais abertos e de brisas frequentes. A topografia natural ou artificial influencia na circulação dos ventos, num fluxo contra uma montanha os poluentes se concentram, 
em um fluxo contra edifícios cria-se turbulência capaz de diluir a poluição (SEWELL, 1978).

A velocidade dos fluidos em movimento aumenta de acordo com 0 afastamento das superfícies. A velocidade dos ventos, da mesma forma, aumenta diretamente com o aumento da altura em relação à superfície terrestre. A velocidade dos fluidos ainda depende da rugosidade das superfícies que os contêm. A velocidade dos ventos depende da rugosidade dos terrenos. Os terrenos planos apresentam baixa rugosidade favorecendo as altas velocidades, ao passo que os terrenos com irregularidades diminuem a sua velocidade junto à superfície. As áreas urbanas estão classificadas como superfícies que apresentam alta rugosidade e, portanto, apresentam ventos com baixas velocidades a baixas alturas (FIG. 31) (GALDINO; SILVA, 2004).
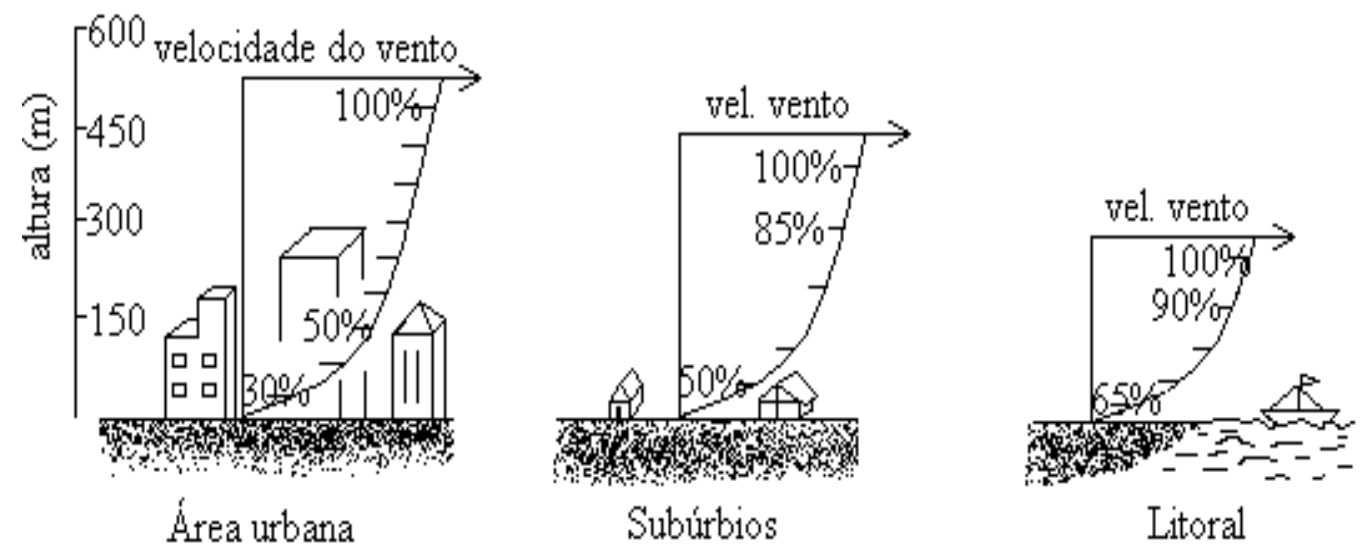

FIGURA 31: As diferentes áreas e a relação entre altura e velocidade do vento. Fonte: FERREIRA; LEITE, 2000. Disponível em: <http://www.fem.unicamp.br/ em313/paginas/eolica.htm>. Acesso em: 19 nov. 2007.

\subsection{Poluição do ar}

O uso particular ou público do solo consiste na maioria das origens dos problemas ambientais, também interferindo na temperatura, uma vez que a classificação e localização das zonas da cidade definem a intensidade de uso do transporte público e individual e a quantidade de lançamento de poluentes no meio ambiente (SEWELL, 1978). 
Gases tóxicos e partículas provenientes da combustão de veículos automotores e de processos industriais poluem o ar, causam problemas de saúde, diminuem a qualidade de vida e provocam alterações na temperatura ambiente (CARVALHO; OLIVEIRA, 2005).

As condições meteorológicas provocam concentração de monóxido e dióxido de carbono e material particulado no inverno, devido à dificuldade de dispersão desses poluentes nesse período. Durante a primavera e o verão elevamse as concentrações de ozônio, que é formado pela concentração de óxidos de nitrogênio e pela intensidade da luz (CETESB, 2009).

As atividades antrópicas têm contribuído para a elevação da temperatura ambiente através do lançamento na troposfera de gases de efeito estufa (metano, ozônio, dióxido de carbono e clorofluorcarbonados) e de material particulado que absorve e libera calor.

A atmosfera é formada pela troposfera (camada estabelecida do nível do solo de 10 a $15 \mathrm{~km}$ de altura), estratosfera (localizada acima da troposfera até $50 \mathrm{~km}$ de altura, onde está a camada de ozônio), mesosfera (camada situada entre 50 e 80 $\mathrm{km}$ de altura) e termosfera ou ionosfera (camada acima da mesosfera até $190 \mathrm{~km}$ ). A composição do ar contida na troposfera é: $78 \%$ de nitrogênio, $20,95 \%$ de oxigênio, 0,93\% de argônio, 0,03\% de dióxido de carbono e outros componentes em quantidades menores (CASEIRO, 2006).

\subsubsection{Padrões de qualidade do ar}

Os Padrões de Qualidade do Ar (PQAr) estão estabelecidos no Brasil desde 27 de março de 1976, através da Portaria GM № 0231, ampliada pelo Instituto Brasileiro do Meio Ambiente e dos Recursos Naturais Renováveis (Ibama) pela Portaria Normativa no 348, de 14 de março de 1990, submetida ao Conselho Nacional do Meio Ambiente (Conama) em 28 de junho de 1990 e transformada na Resolução Conama № 03/90 (CETESB, 2009).

O Relatório de Avaliação Ambiental (RAA) do Procentro aponta que no ar da metrópole são encontrados todos os principais poluentes, que os problemas de qualidade do ar não são decorrentes de um poluente específico. Aponta ainda que 
não se tem registro de recorde de concentração de poluente atmosférico e que o conjunto dos poluentes encontrados é que tornam o ar nocivo à saúde da população, à conservação do patrimônio e à vegetação.

A poluição atmosférica do Município de São Paulo tem sua origem na emissão dos veículos automotores (90\%) e industriais (10\%) (CETESB, 1999).

No centro da cidade de São Paulo circulam diariamente centenas de milhares de veículos, mas as soluções para controle da poluição atmosférica devem considerar toda a região metropolitana (BIDONE, 2003).

Os PQAr são divididos em primários e secundários. Os padrões primários apresentam concentrações de poluentes acima dos quais pode haver dano à saúde, considerados níveis máximos tolerados, devendo ser incluídos como metas a serem atingidas em curto e médio prazo. Padrões secundários apresentam concentrações de poluentes abaixo das quais se prevê o mínimo efeito adverso sobre o bem-estar da população, mínimo dano à fauna e à flora, aos materiais e ao meio ambiente. São os níveis desejáveis de concentração de poluentes, devendo ser incluídos nas metas de longo prazo (TAB. 2). Assim, os padrões primários devem ser aplicados nas áreas de desenvolvimento e os secundários nas áreas de preservação. Nos locais onde a classificação não foi estabelecida devem ser aplicados os padrões primários (CASEIRO, 2006).

Para se controlar a qualidade do ar são instaladas estações de medição que levam em consideração a área mais poluída, a região mais povoada, o local de entrada do ar para a região, as perspectivas de desenvolvimento. Nestas estações os equipamentos são instalados entre três e seis metros de altura, distantes de obstáculos e chaminés (CASEIRO, 2006).

A Resolução CONAMA №03/90 estabelece critérios para episódios agudos de poluição do ar, definindo estados de Atenção, Alerta e Emergência. Os níveis de Atenção e Alerta foram estabelecidos para se evitar atngir o nível de Emergência (CASEIRO, 2006). 
TABELA 2 Padrões de qualidade do ar. Fonte: Programa Nacional de Qualidade do Ar. Disponível em: $<$ http://ambientes.ambientebrasil.com.br/urbano/programas e projetos/pronar programa nacional de qualidade do ar.html>. Acesso em: 16 nov. 2007.

\begin{tabular}{|c|c|c|c|c|}
\hline Poluente & $\begin{array}{c}\text { Tempo de } \\
\text { amostragem }\end{array}$ & $\begin{array}{l}\text { Padrão } \\
\text { Primário } \\
\left(\mu \mathrm{g} / \mathrm{m}^{3}\right) \\
\end{array}$ & $\begin{array}{c}\text { Padrão } \\
\text { Secundário } \\
\left(\mu \mathrm{g} / \mathrm{m}^{3}\right) \\
\end{array}$ & Método de medição \\
\hline $\begin{array}{l}\text { Partículas totais } \\
\text { em suspensão }\end{array}$ & 24 horas $^{*}$ & 340 & 100 & $\begin{array}{l}\text { Amostrador de } \\
\text { grandes volumes }\end{array}$ \\
\hline $\begin{array}{l}\text { Partículas } \\
\text { inaláveis }\end{array}$ & 24 horas* & 150 & 150 & $\begin{array}{c}\text { Separação } \\
\text { inercial/filtração }\end{array}$ \\
\hline Ozônio & 1 hora* & 160 & 160 & Quimioluminescência \\
\hline Fumaça & 24 horas & 150 & 160 & Refletância \\
\hline $\begin{array}{l}\text { Dióxido de } \\
\text { nitrogênio }\end{array}$ & 1 hora & 320 & 190 & Quimioluminescência \\
\hline $\begin{array}{l}{ }^{*} \text { Não exceder mais de } \\
\text { Poluente }\end{array}$ & $\begin{array}{c}\text { uma vez/ano. } \\
\text { Tempo de } \\
\text { amostragem }\end{array}$ & $\begin{array}{l}\text { Atenção } \\
\left(\mu \mathrm{g} / \mathrm{m}^{3}\right)\end{array}$ & $\begin{array}{c}\text { Alerta } \\
\left(\mu \mathrm{g} / \mathrm{m}^{3}\right)\end{array}$ & $\begin{array}{l}\text { Emergência } \\
\left(\mu \mathrm{g} / \mathrm{m}^{3}\right)\end{array}$ \\
\hline $\begin{array}{l}\text { Partículas totais } \\
\text { em suspensão }\end{array}$ & 24 horas & 375 & 625 & 875 \\
\hline Partículas inaláveis & 24 horas & 250 & 420 & 500 \\
\hline Dióxido de enxofre & 24horas & 800 & 1600 & 2100 \\
\hline Ozônio & 1hora & 400 & 800 & 1000 \\
\hline Fumaça & 24horas & 250 & 420 & 500 \\
\hline Dióxido de nitrogênio & 1hora & 1130 & 2260 & 3000 \\
\hline Poluente & $\begin{array}{c}\text { Tempo de } \\
\text { amostragem }\end{array}$ & $\begin{array}{l}\text { Atenção } \\
\text { (ppm) }\end{array}$ & $\begin{array}{l}\text { Alerta } \\
\text { (ppm) }\end{array}$ & $\begin{array}{l}\text { Emergência } \\
\text { (ppm) }\end{array}$ \\
\hline $\begin{array}{l}\text { Monóxido de } \\
\text { carbono }\end{array}$ & 8 horas & 15 & 30 & 40 \\
\hline
\end{tabular}




\subsubsection{Efeito estufa}

Dióxido de carbono $\left(\mathrm{CO}_{2}\right.$, gás carbônico), metano $\left(\mathrm{CH}_{4}\right)$, ozônio $\left(\mathrm{O}_{3}\right)$ e clorofluorcarbonados (CFC) são gases de efeito estufa.

O efeito estufa surge devido à energia luminosa do Sol ser composta por ondas curtas, que ultrapassam com facilidade esses gases existentes na atmosfera, enquanto as ondas mais longas, como a da radiação infravermelha, de energia calorífica, são por eles absorvidas, aumentando a temperatura da Terra (FIG. 32) (SEWELL, 1978).

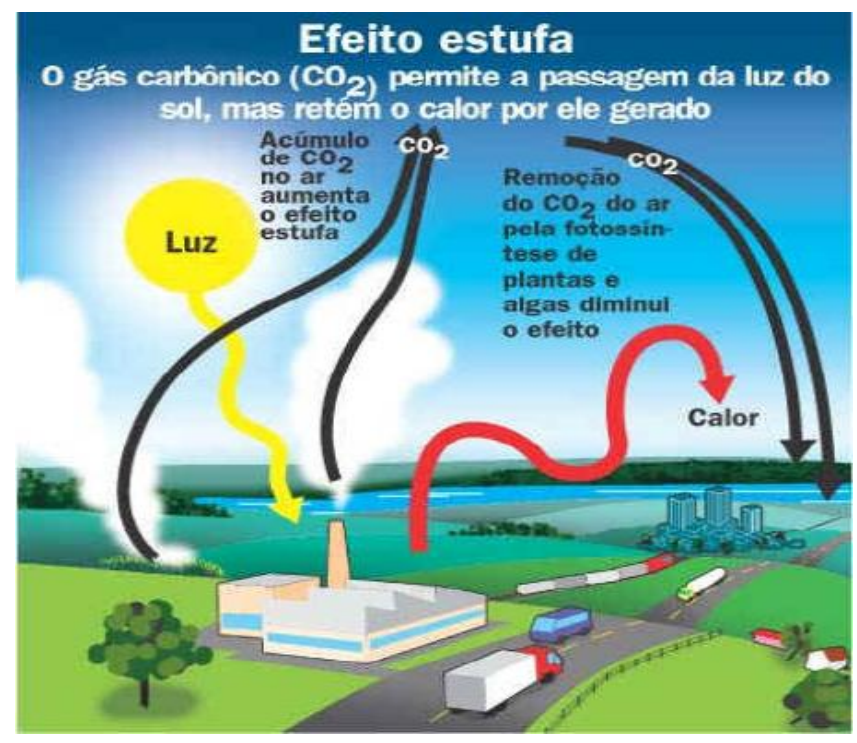

FIGURA 32 Efeito estufa. Fonte: CASEIRO, 2006.

O calor gerado pelo Sol é necessário para a manutenção da vida, entretanto, quando a composição da atmosfera é alterada pelo aumento da concentração destes gases, a dispersão do calor fica comprometida, o que intensifica a ação do efeito estufa e a consequente elevação da temperatura ambiente (CASEIRO, 2006).

A queima de combustíveis fósseis produz óxidos de nitrogênio $\left(\mathrm{N}_{\mathrm{x}} \mathrm{O}_{\mathrm{y}}\right)$ que, quando ativados pela luz, formam $\circ \mathrm{O}_{3}$, gás de efeito estufa (CAMPOS et al, 2006). 


\subsubsection{Dióxido de carbono}

$\mathrm{O} \mathrm{CO}_{2}$ é atualmente o gás de efeito estufa mais importante devido à sua elevada concentração na atmosfera, sendo responsável por $60 \%$ do efeito estufa. Desde 1750, a quantidade de dióxido de carbono na atmosfera aumentou $31 \%$ devido à queima de combustíveis fósseis, óleo, madeira e destruição das áreas verdes. Com o aumento das emissões de $\mathrm{CO}_{2}$, seu ciclo natural entrou em desequilíbrio, a vegetação remanescente não conseguiu transformar a quantidade total lançada na atmosfera, aumentando o efeito estufa e a temperatura (JOLY, 2007). Outras fontes de $\mathrm{CO}_{2}$, além da queima de combustíveis fósseis, são os materiais em decomposição, os seres vivos e as plantas no período noturno.

\subsubsection{Metano}

$\mathrm{O} \mathrm{CH}_{4}$, também conhecido como gás do pântano ou biogás, é responsável por $20 \%$ do efeito estufa. Tem capacidade 21 vezes maior do que o $\mathrm{CO}_{2}$ para reter calor na atmosfera. Nos últimos duzentos anos a concentração de $\mathrm{CH}_{4}$ na atmosfera aumentou $150 \%$. Na região central da cidade de São Paulo as contribuições para o aumento da concentração de $\mathrm{CH}_{4}$ no ar se dão através dos veículos automotores, da queima do gás natural, do carvão, de material vegetal, da fermentação de matéria orgânica como esterco, esgoto e lixo (MOTAVALLI, 2008).

Durante longo período, da história da evolução, os resíduos produzidos pelo ser humano se restringiram a compostos orgânicos, originários dos elementos necessários à sua subsistência. O meio ambiente não sofria pesadas perdas, os resíduos eram facilmente decompostos, não havia regras de higiene, a sujeira estava relacionada às doenças e a purificação, a rituais religiosos. As fezes, urina e resíduos eram lançados pelos caminhos ou pelas ruas estreitas da cidade, gerando epidemias. No final do século XIX, período que caracteriza a implantação da República, reformula-se o serviço sanitário, finalizando-se as epidemias. A situação do lixo volta a agravar-se no final do século XX, com o adensamento da população urbana e o crescimento das populações cada vez mais pobres da periferia, sem acesso aos serviços de saúde e dispondo seus resíduos em depósitos clandestinos (ROCHA, 1992). 
A partir da Resolução Conama № 1 de 1986, o planejamento da coleta e da destinação do lixo, além do caráter técnico, econômico e financeiro, passa a dar prioridade às questões ambientais através da exigência da elaboração dos Estudos de Impacto Ambiental (EIA) e dos Relatórios de Impacto ambiental (Rima) (BOAVENTURA, 1992).

Os resíduos orgânicos, quando mal tratados ou não tratados, podem poluir o ar com $\mathrm{CH}_{4}$, um dos gases que causam o efeito estufa (SEWELL, 1978).

Os resíduos sólidos podem ser reutilizados como produto similar (caso da reciclagem do papel e vidro), reutilizados como produto diferente (reciclagem de matéria orgânica em adubo, denominada compostagem, que consiste em trituração, homogeneização e fermentação aeróbica por cinco dias), ter o peso e volume diminuídos através da incineração, ou, ainda, serem encaminhados para aterros sanitários ou energéticos (SEWELL, 1978).

Faz parte do gerenciamento dos resíduos a análise e a implementação de ações para a diminuição das quantidades a serem enviadas para o aterro, para diminuição de custos e eliminação da periculosidade em relação ao meio ambiente (JARDIM et al, 1996).

O Município de São Paulo possui 16 centrais de triagem (uma delas na Subprefeitura da Sé, no distrito Bom Retiro, na Avenida do Estado no 300). De acordo com lei aprovada em 2003, até o ano de 2007 a cidade deveria ter 31 centrais de triagem.

No aterro sanitário a disposição dos resíduos é realizada sobre o terreno, que é recoberto diariamente com solo do próprio local, evitando a presença de insetos e roedores. A movimentação de máquinas compacta o material, o lixo se degrada produzindo $\mathrm{CH}_{4}$ e chorume, que são recolhidos e tratados. No aterro sanitário energético $\circ \mathrm{CH}_{4}$ é utilizado como combustível para a geração de energia elétrica (CASEIRO, 2006).

Nos incineradores, devem ser instalados equipamentos adicionais de controle da poluição do ar, no caso da formação de gases tóxicos e partículas como furanos e dioxinas (provenientes de materiais que possuem cloro), $\mathrm{N}_{\mathrm{x}} \mathrm{O}_{\mathrm{y}}$, amônia, 
aldeídos, éteres, compostos de silicone, sódio, potássio e magnésio (SEWELL, 1978).

Um incinerador, além de permitir a recepção e armazenagem adequada do lixo, deve apresentar sistemas de aproveitamento do calor gerado na combustão, remoção de poeira e purificação dos gases. A incineração é a alternativa utilizada como a melhor solução para o tratamento dos resíduos tóxicos, inflamáveis, óleos não recicláveis, defensivos agrícolas não recuperáveis e produtos químicos como resíduos orgânicos compostos por carbono, hidrogênio, oxigênio e com teores de cloro inferiores a $30 \%$.

Os resíduos da área de saúde devem ser tratados pelo processo de desativação eletrotérmica e os resíduos industriais devem ser encaminhados, conforme a sua classificação, para aterros industriais, incineração ou para tratamento específico conforme o caso (CASEIRO, 2006).

\subsubsection{Ozônio}

$\mathrm{O}_{3}$ está em terceiro lugar na escala de contribuição para formação do efeito estufa, estando atrás do $\mathrm{CO}_{2}$ e do $\mathrm{CH}_{4} \cdot \mathrm{O}_{3}$ está presente em toda a atmosfera. $\mathrm{Na}$ estratosfera atua como um poderoso filtro de raios ultravioleta $\mathrm{B}$, enquanto na troposfera é um poluente que causa irritações nos olhos e nas vias respiratórias, bem como provoca redução da capacidade pulmonar e danos nas plantações.

No Brasil, os padrões primário e secundário para $\mathrm{O}_{3}$ estão estabelecidos pela Resolução Conama № 03/1990, como valor máximo para uma hora, não podendo ser ultrapassado mais do que uma vez por ano, no limite de $160 \mu \mathrm{g} / \mathrm{m}^{3}$.

As fontes de $\mathrm{O}_{3}$ na troposfera são os motores de combustão interna e as usinas geradoras de energia que liberam $\mathrm{N}_{\mathrm{x}} \mathrm{O}_{\mathrm{y}}$, precursores do $\mathrm{O}_{3}$.

A formação do $\mathrm{O}_{3}$ na troposfera ocorre através da fotólise do $\mathrm{NO}_{2}$, lançado na atmosfera pelos motores dos veículos, o que proporciona a formação $\mathrm{NO}$ e oxigênio atômico no estado fundamental $(O)$ (Reação 1), este reage com o oxigênio molecular $\left(\mathrm{O}_{2}\right)$ existente na atmosfera, formando o $\mathrm{O}_{3}$ (Reação 2) (Cetesb, 2000). 


$$
\begin{gathered}
\mathrm{NO}_{2} \rightarrow \mathrm{NO}+\mathrm{O}(1) \\
\mathrm{O}+\mathrm{O}_{2} \rightarrow \mathrm{O}_{3}(2)
\end{gathered}
$$

\subsubsection{Clorofluorcarbonados}

O CFC colabora com $14 \%$ do efeito estufa.

Pelo fato de destruir a camada de $\mathrm{O}_{3}$, localizada na estratosfera, foram realizados os acordos internacionais de Viena e Montreal com o intuito de eliminar a utilização do CFC em refrigeradores, condicionadores de ar e aerossóis.

Até o final de 1994, a produção mundial de CFC havia caído $75 \%$ em relação a 1986.

A previsão do Protocolo de Montreal de 1987 é a recuperação gradativa da camada de $\mathrm{O}_{3}$ a partir do ano 2000 , com a diminuição da produção de CFC, até a eliminação mundial do seu uso em 2010 e a plena recuperação da camada de $\mathrm{O}_{3}$ até 2050 (UNEP, 1996).

No Brasil, a produção e a importação de CFC estão proibidas desde 2007.

No ano de 2010 foi calculada a falha da camada de Ozônio como sendo de 22 milhões de quilômetros quadrados, nove milhões a menos do registrado no ano 2000, quando atingiu seu maior tamanho (FOLHA.COM, 2010)

\subsection{Ilha de calor}

As alterações climáticas são atribuídas às mudanças no uso da energia que aconteceram a partir de meados do século XIX, durante a Revolução Industrial, com a intensificação do uso do carvão, e a partir do início do século XX, com o uso do petróleo em motores de combustão. Estas ações são responsáveis pelo aumento de $\mathrm{CO}_{2}$ na atmosfera, bem como de outros gases responsáveis pelo efeito estufa como $\mathrm{CH}_{4}$ e $\mathrm{N}_{x} \mathrm{O}_{y}$ (SEPE; GOMES, 2008).

Em 1978, T. R. Oke publicou o livro Boundary Layer Climates, em que, pela primeira vez, a expressão "ilha de calor" é utilizada.

Utilizando um mapa da cidade de Vancouver, fazia analogia da elevação de temperatura na área urbana com a forma de uma ilha, mostrando que a área 
urbana mais aquecida (que apresentava aumento de temperatura suave, constante, em direção à região central) se destacava da área rural circundante com temperaturas amenas.

A uniformidade da progressão da temperatura era interrompida nos locais onde estavam localizados parques e lagos e tornava-se mais elevada nas áreas comerciais, industriais e nas áreas densamente construídas.

Nesta obra ainda foi definido o conceito de intensidade da ilha de calor como sendo a diferença de temperatura entre o ponto mais quente da área urbana e o ponto com temperatura mais amena da região do entorno.

Foi demonstrado que a intensidade seria maior algumas horas após o Sol se pôr e menor ao meio do dia porque as áreas verdes perdem calor e se aquecem mais rapidamente do que as áreas urbanas (OKE, 1978).

O clima subtropical da cidade de São Paulo, no qual predomina o tempo seco no inverno, instável no outono e primavera, com aumento da temperatura no verão, apresenta poucas restrições às atividades urbanas, o que favorece a formação da ilha de calor que apresenta variações de intensidade frequentes devido às constantes mudanças climáticas na região. 


\section{METODOLOGIA}

A metodologia adotada para esta dissertação compreende a análise do processo de transformação da área central da cidade de São Paulo e dos registros das variações climáticas, utilizando-se os seguintes procedimentos:

- levantamento do processo de urbanização do centro e dos fatores que contribuem para a alteração do clima como: índices de verticalização, cobertura vegetal, produção e disposição de resíduos sólidos, através de dados bibliográficos, iconográficos, censitários e cartográficos da base de dados da Prefeitura do Município de São Paulo, livros, documentos eletrônicos, revistas e jornais;

- $\quad$ análise de dados e relatórios de órgãos ambientais e institutos de pesquisa para levantamento da qualidade do ar no centro, estudo comparativo das condições de temperatura e umidade na área central e nos arredores da cidade, onde as condições ambientais permanecem praticamente inalteradas, identificando mudanças ambientais ocorridas nos distritos da Sé e da República;

- análise do Programa Procentro, identificando ações que possam causar elevação ou redução da temperatura na área delimitada pela Subprefeitura da Sé. 


\section{DESENVOLVIMENTO}

Este trabalho foi realizado fazendo uso do levantamento histórico do processo de desenvolvimento e transformação do centro da cidade de São Paulo para o entendimento da situação atual e o estabelecimento da relação entre as atividades urbanas e as alterações climáticas na região. Foram pesquisadas as variações das temperaturas, os índices de verticalização, cobertura vegetal, qualidade do ar, produção e disposição de resíduos sólidos, relacionando-os com o processo de desenvolvimento do centro. A pesquisa foi possível graças ao acesso às bases de dados da Prefeitura do Município de São Paulo, consulta da literatura existente sobre a história da cidade e os efeitos da poluição, consulta ao Plano Diretor Estratégico do Município de São Paulo de 2002 e à documentação do Programa Procentro.

\subsection{Temperatura e umidade relativa do ar}

A Cetesb controla a temperatura e a umidade relativa do ar na região central através da rede de analisadores automáticos, instalada em 1981. Esta instalação foi renovada em 1996 e serviu de base para a realização deste trabalho (Cetesb, 2005).

Na Subprefeitura da Sé estão localizadas duas estações automáticas de monitoramento do ar, das quais foram utilizados os dados relativos às medições de temperatura e umidade relativa: Estação Automática Centro e Estação Automática Parque D. Pedro II (SÃO PAULO [Cidade] - SVMA, 2004).

A Estação de Monitoramento Parque D. Pedro II fica localizada no Palácio das Indústrias, Parque D. Pedro II, s/ №, Centro.

A Estação de Monitoramento Centro ficava localizada no Prédio dos Correios, Vale do Anhangabaú, República (FIG. 33). 


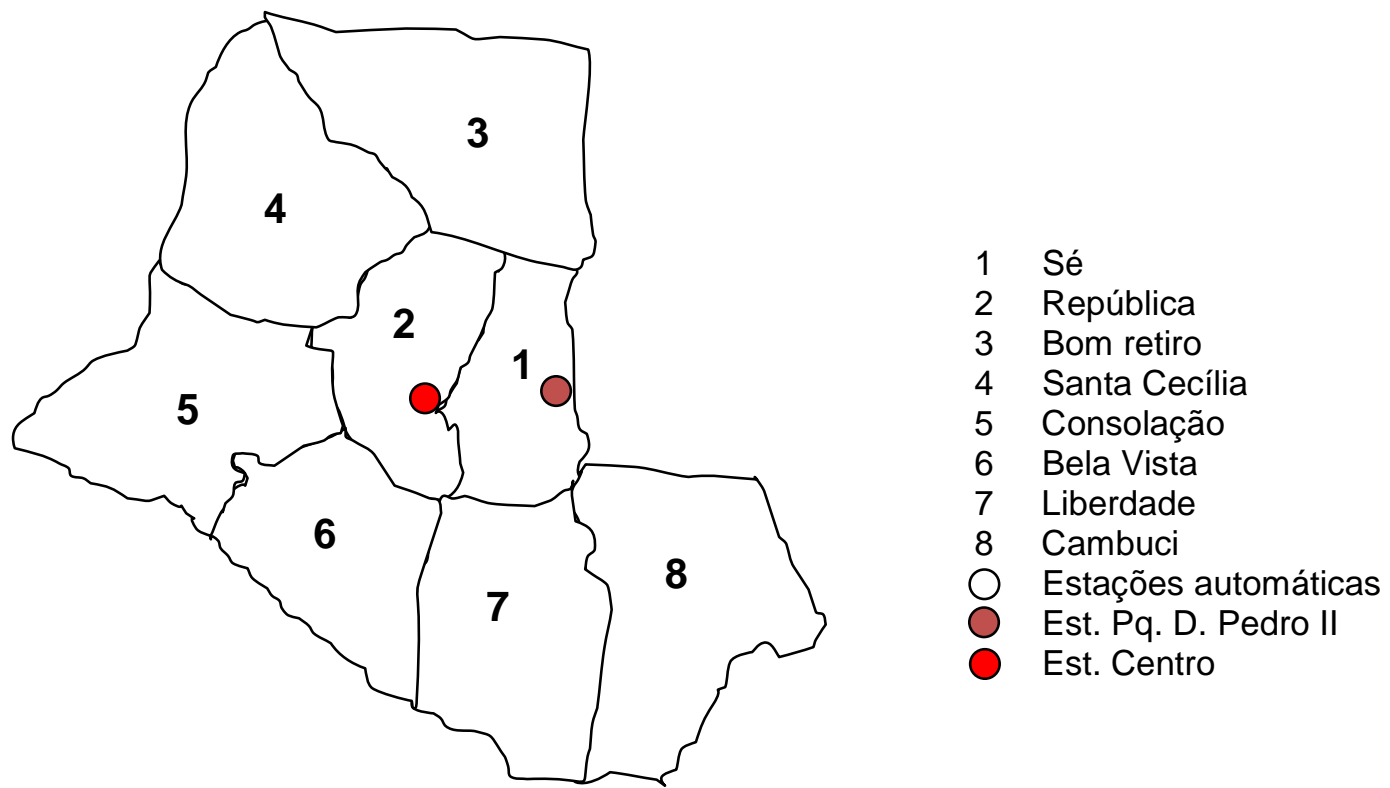

FIGURA 33. Localização das estações de monitoramento Centro e Pq. D. Pedro II. Fonte: Adaptado de Panorama do meio ambiente urbano. Geo cidade de São Paulo. (MUNICÍPIO DE SÃO PAULO SVMA, 2004).

Para o desenvolvimento deste trabalho foram escolhidos aleatoriamente um dia de cada mês nos anos de 1981, 1983, 1988, 1993, 1998 e 2003. Foram então levantados os registros de temperatura e umidade, durante as 24 horas desses dias, na Estação de Monitoramento Automático Centro, nos anos de 1981, 1983 e 1988, e na Estação de Monitoramento Automático Parque D. Pedro II, em 1993, 1998 e 2003.

Os levantamentos de temperatura e umidade relativa do ar foram realizados de 1981 a 1988 na Estação Centro por estar localizada, neste período, no Prédio dos Correios, Vale do Anhangabaú, distrito da República, e por ser a única estação de monitoramento do ar, na região central, que realizava estas medições.

Em 1992 a Estação Centro foi transferida para a Biblioteca Mário de Andrade, na Rua da Consolação, onde passou a monitorar somente os poluentes do ar, sendo o monitoramento de temperatura e umidade relativa da região central, a partir desta data, transferido para a Estação de Monitoramento Automático Parque D. Pedro II. 
As temperaturas e umidades relativas obtidas a partir destes registros foram organizadas em tabelas e construídos gráficos para facilitar a análise dos comportamentos das suas variações.

Outro local que possui temperatura e umidade relativa do ar monitorada, que fica nos arredores da cidade e que se manteve praticamente intocado do ponto de vista ambiental desde 1936, é o Parque Fontes do Ipiranga, ex-Parque do Estado, próximo ao Jardim Botânico, em frente ao Jardim Zoológico, onde fica localizado o Instituto de Astronomia, Geofísica e Ciências Atmosféricas (IAG) da Universidade de São Paulo (USP).

Para se conhecer as alterações climáticas da área urbanizada do centro de São Paulo em relação à área periférica da cidade foram levantadas as temperaturas e umidades relativas no Parque Fontes do Ipiranga, nos mesmos dias e horários anteriormente determinados nas estações Centro e Parque D. Pedro II, de 1981 até 2003, incluídas nas tabelas anteriormente organizadas.

Com estes resultados, foram calculadas as intensidades da ilha de calor na região central da cidade de São Paulo em relação ao Parque Fontes do Ipiranga, bem como a variação da umidade relativa.

Os resultados foram incluídos nos gráficos para auxílio da análise do comportamento, da variação da intensidade da ilha de calor e da variação da umidade relativa ao longo das 24 horas de cada um dos dias analisados,

Os gráficos e tabelas construídos fazem parte dos Apêndices B e C. Para temperaturas são apresentados gráficos e tabelas existentes no Apêndice B. Para umidade relativa do ar, gráficos e tabelas existentes no Apêndice $C$.

\subsection{Poluição atmosférica}

A Cetesb iniciou o controle da poluição na Região Metropolitana de São Paulo em 1973 através da implantação de redes manuais medidoras de dióxido de enxofre $\left(\mathrm{SO}_{2}\right)$ e fumaça. Em 1981 instalou a rede de analisadores automáticos que foi renovada em 1996 (CETESB, 2005).

Para a realização deste trabalho, os levantamentos dos poluentes atmosféricos na Subprefeitura da Sé foram obtidos das Estações Automáticas de 
Monitoramento Parque D. Pedro II, Cambuci, Cerqueira César, Centro e das Estações Manuais Campos Elísios, Cerqueira César, Parque D. Pedro II e Praça da República (FIG. 34) (SÃO PAULO [Cidade] - SVMA, 2004).

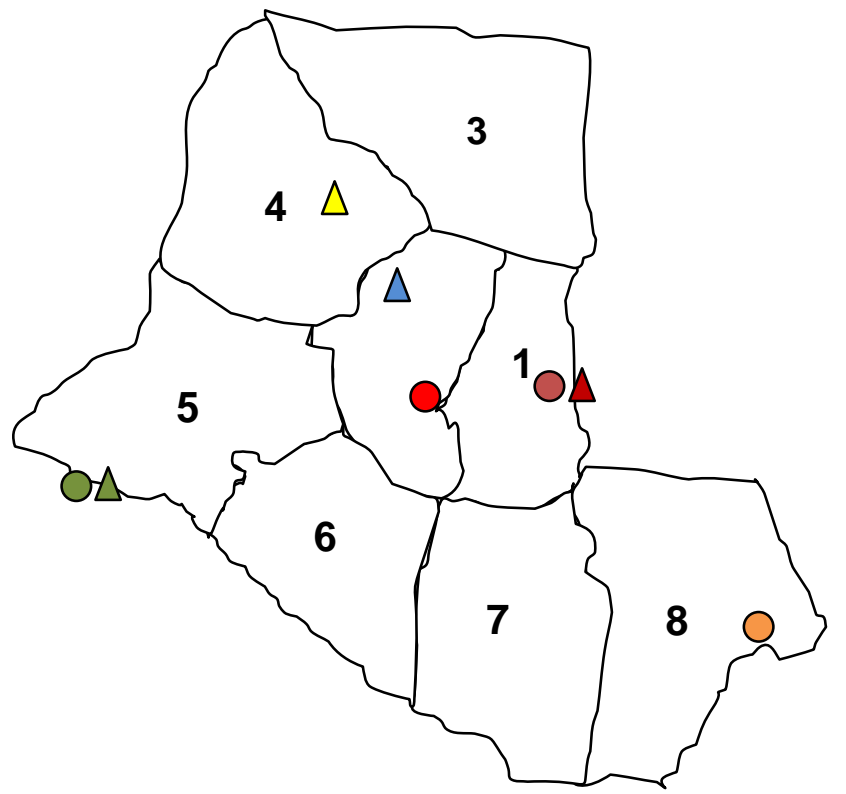

1 Sé

2 República

3 Bom retiro

4 Santa Cecília

5 Consolação

6 Bela Vista

7 Liberdade

8 Cambuci

Estações automáticas

$\triangle$ Estações manuais

$\bigcirc$ Est. Pq. D. Pedro II

Est. Centro

OA Est. Cerqueira César

Est. Cambuci

$\triangle$ Est. Pça. República

$\triangle$ Est. Campos Elísios

FIGURA 34. Localização das estações de monitoramento do ar. Fonte: Adaptado de Panorama do meio ambiente urbano. Geo cidade de São Paulo. (SÃO PAULO [Cidade] - SVMA, 2004).

A Estação de Monitoramento Parque D. Pedro II fica localizada no Palácio das Indústrias, Parque D. Pedro II, s/ №, Centro. Monitora os seguintes poluentes que podem interferir na temperatura ambiente: partículas inaláveis (MP10), $\mathrm{N}_{x} \mathrm{O}_{\mathrm{y}}$ e $\mathrm{O}_{3}$.

A Estação Cambuci fazia parte da rede automática da Cetesb. Ficava localizada no IV Comando Aéreo Regional, Avenida D. Pedro I, № 100, Cambuci, região comercial e residencial, com pouca atividade industrial, monitorava MP10, que podem interferir na temperatura ambiente, e foi desativada em 7 de abril de 2008.

A Estação de Monitoramento Cerqueira César faz parte da rede automática, fica localizada na Faculdade de Saúde Pública, Avenida Dr. Arnaldo, nº 725, Sumaré, distante $7 \mathrm{~m}$ dessa via pública, numa região com tráfego intenso de veículos leves e pesados, e monitora os seguintes poluentes que podem interferir na temperatura ambiente: MP10 e $\mathrm{N}_{\mathrm{x}} \mathrm{O}_{\mathrm{y}}$. 
A Estação de Monitoramento Centro, desde 1993, fica localizada na Biblioteca Mário de Andrade, Rua da Consolação no 94, Consolação. Está aparelhada para monitorar concentrações dos seguintes poluentes que podem interferir na temperatura ambiente: MP10 e NO 2 (CETESB, 2005).

A rede automática utiliza os métodos e equipamentos descritos na Tabela

3.

TABELA 3. Parâmetros e métodos nas estações automáticas. Fonte: Caracterização da rede automática de monitoramento da qualidade do ar na Região Metropolitana de São Paulo (CETESB, 2005). Disponível em: <www.cetesb.sp.gov.br/relatóriosepublicações/ar>. Acesso em: 20 nov. 2009.

\begin{tabular}{cc}
\hline Parâmetros & Método \\
\hline Partículas inaláveis $-\mathrm{MP}_{10}$ & Radiação Beta \\
Dióxido de enxofre $-\mathrm{SO}_{2}$ & Flourescência de Pulso (ultravioleta) \\
Monóxido de carbono $-\mathrm{CO}$ & Infravermelho não dispersivo \\
Óxidos de nitrogênio $-\mathrm{N}_{\mathrm{x}} \mathrm{O}_{\mathrm{y}}$ & Quimiluminescência \\
Ozônio $-\mathrm{O}_{3}$ & Ultravioleta \\
\hline
\end{tabular}

Além da rede automática acima descrita, a Cetesb dispõe de uma rede manual de atendimento à região central, assim constituída:

- Estação Manual Campos Elíseos, situada na Avenida Rio Branco, 1.210, nas dependências da Faculdade Estadual Paulista "Júlio de Mesquita Filho", que monitora teores de fumaça que podem interferir na temperatura ambiente;

- Estação Cerqueira César, Avenida Dr. Arnaldo, 725, Sumaré, nas dependências da Faculdade de Saúde Pública da USP, que monitora os seguintes poluentes que podem interferir na temperatura ambiente: MP10, fumaça e partículas totais em suspensão (PTS);

- Estação Parque D. Pedro II, situada no Parque D. Pedro II, Centro, nas dependências do Palácio das Indústrias, monitora PTS;

- Estação Praça da República, situada na Praça da República s/non, República, monitora teores de fumaça (CETESB, 2005). 
A rede manual usa os métodos abaixo especificados (TAB. 4) (CETESB, 2005).

TABELA 4. Parâmetros e métodos nas estações manuais. Fonte: Caracterização da rede automática de monitoramento da qualidade do ar na Região Metropolitana de São Paulo (CETESB, 2005). Disponível em: <www.cetesb.sp.gov.br/relatóriosepublicações/ar>. Acesso em: 20 nov. 2009.

\begin{tabular}{cc}
\hline Parâmetro & Método \\
\hline Partículas inaláveis $-\mathrm{MP}_{10}$ & Gravimétrico \\
Partículas totais em suspensão - PTS & Gravimétrico \\
Fumaça & Refletância \\
\hline
\end{tabular}

O objetivo deste levantamento é verificar a evolução das concentrações dos poluentes do ar na região central que contribuem para a elevação da temperatura ambiente.

Foram analisadas as evoluções das concentrações dos teores de fumaça e de PTS no período de 1989 até 2008. Também foram analisadas as concentrações dos teores de $\mathrm{NO}_{2}, \mathrm{NO}, \mathrm{O}_{3}$ e partículas inaláveis de 1998 até 2008. As análises foram realizadas após dispor os dados obtidos nas tabelas e gráficos que compõem o Apêndice A.

\subsection{Densidade demográfica}

Foi realizado inicialmente o levantamento da densidade demográfica dos distritos da Subprefeitura da Sé, obtendo-se valores em faixas amplas que não permitiram as conclusões esperadas.

Para a obtenção de valores exatos foi construída tabela com a densidade demográfica calculada de cada distrito através das informações do Censo do Instituto Brasileiro de Geografia e Estatística (IBGE) de 2000 e da base de dados da prefeitura.

O aspecto densidade demográfica foi usado para avaliação da redução das atividades profissionais, na subprefeitura da Sé, na segunda metade do século $\mathrm{XX}$. 


\subsection{Cobertura vegetal}

No primeiro levantamento realizado, a distribuição das áreas verdes revelou situações diferentes para os distritos da Subprefeitura da Sé e faixas excessivamente extensas que impediram a análise da situação.

A obtenção de valores mais exatos foi calculada com dados obtidos pela pesquisa de áreas verdes por distrito, existente em documentação da Prefeitura e através das informações do Censo do IBGE de 2000. Com os resultados destes cálculos foi organizada tabela para auxílio da análise.

\subsection{Resíduos sólidos}

Foi realizada pesquisa através dos dados disponíveis do Departamento de Limpeza Urbana do Município de São Paulo (Limpurb) e de dados censitários referentes à produção diária de lixo e à sua distribuição na cidade de São Paulo.

Estes resultados foram colocados em gráficos para auxiliar a análise e interpretação.

\subsection{Adensamento vertical}

Realizada pesquisa, através de documentação existente na Prefeitura, do adensamento vertical nos distritos do município de São Paulo, com o objetivo de verificar a real situação referente ao uso e utilização do solo dos distritos da Subprefeitura da Sé.

Utilizou-se para esta análise o indicador ambiental com edifícios com mais de cinco pavimentos, utilizado na documentação da Prefeitura do Município de São Paulo, por entender-se que tais edificações alteram as condições microclimáticas (SEPE; GOMES, 2008).

\subsection{Drenagem}

Realizada pesquisa em documentação existente na Prefeitura para verificação das áreas verdes na Subprefeitura da Sé.

Pesquisa em documentação da Limpurb com o objetivo de conhecer as ações de manutenção do sistema de drenagem da região central. 


\subsection{Programa Procentro}

Pesquisa realizada através de documentação disponibilizada pela Prefeitura do Município de São Paulo para conhecimento das ações e da abrangência do Procentro.

O conhecimento das ações em andamento foi realizado através de pesquisa na mídia eletrônica, livros, revistas, jornais e visitas aos locais.

O resultado desta pesquisa é apresentado nos Apêndices D, E e F. 


\section{RESULTADOS E DISCUSSÃO}

\subsection{A ilha de calor na Subprefeitura da Sé}

Após 1930, quando a cidade passa a se desenvolver para todas as direções, acontece a destruição da vegetação nativa e a impermeabilização do solo através da ampliação do sistema viário e da construção de casas e elevados edifícios (FIG. 35).

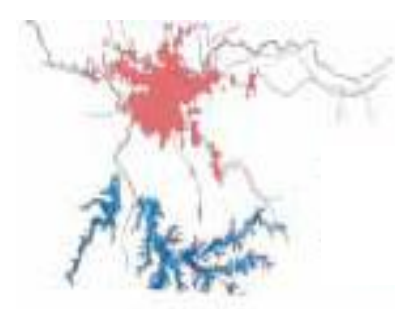

Mancha urbana 1930

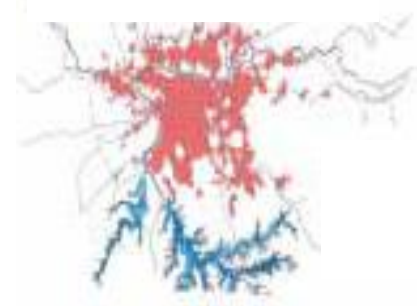

Mancha urbana 1952

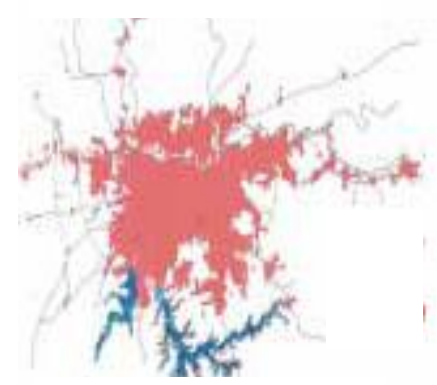

Mancha urbana 1962
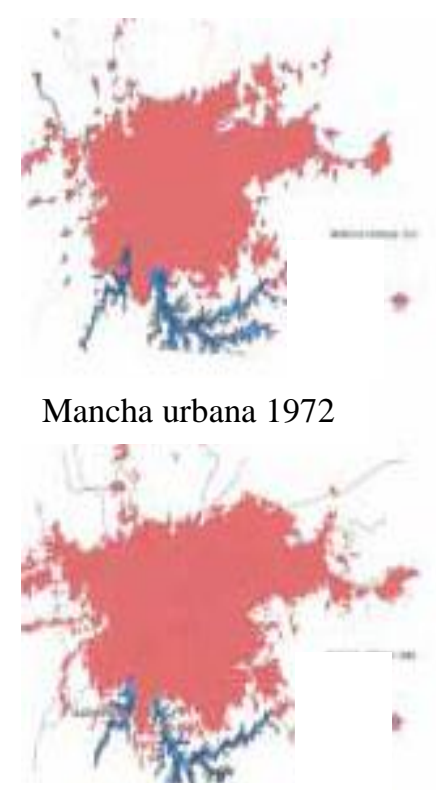

Mancha urbana 1983

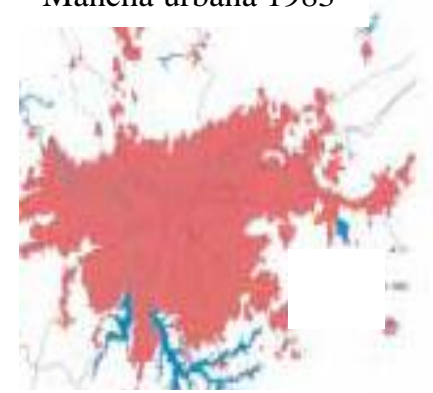

Mancha urbana 1995

FIGURA 35. Evolução da área com ocupação urbana na região metropolitana de São Paulo de 1930 a 1995. Fonte: Panorama do meio ambiente urbano. Geo, cidade de São Paulo. (SÃO PAULO [Cidade] - SVMA, 2004).

Analisando-se os registros das temperaturas no Parque Estadual Fontes do Ipiranga de 1936 até 2005, observa-se elevação gradativa das temperaturas médias mensais de $22^{\circ} \mathrm{C}$ para $24^{\circ} \mathrm{C}$, bem como maior duração dos períodos anuais com temperaturas médias acima de $20^{\circ} \mathrm{C}$ (FIG. 36) (PEREIRA FILHO et al, 2007). 


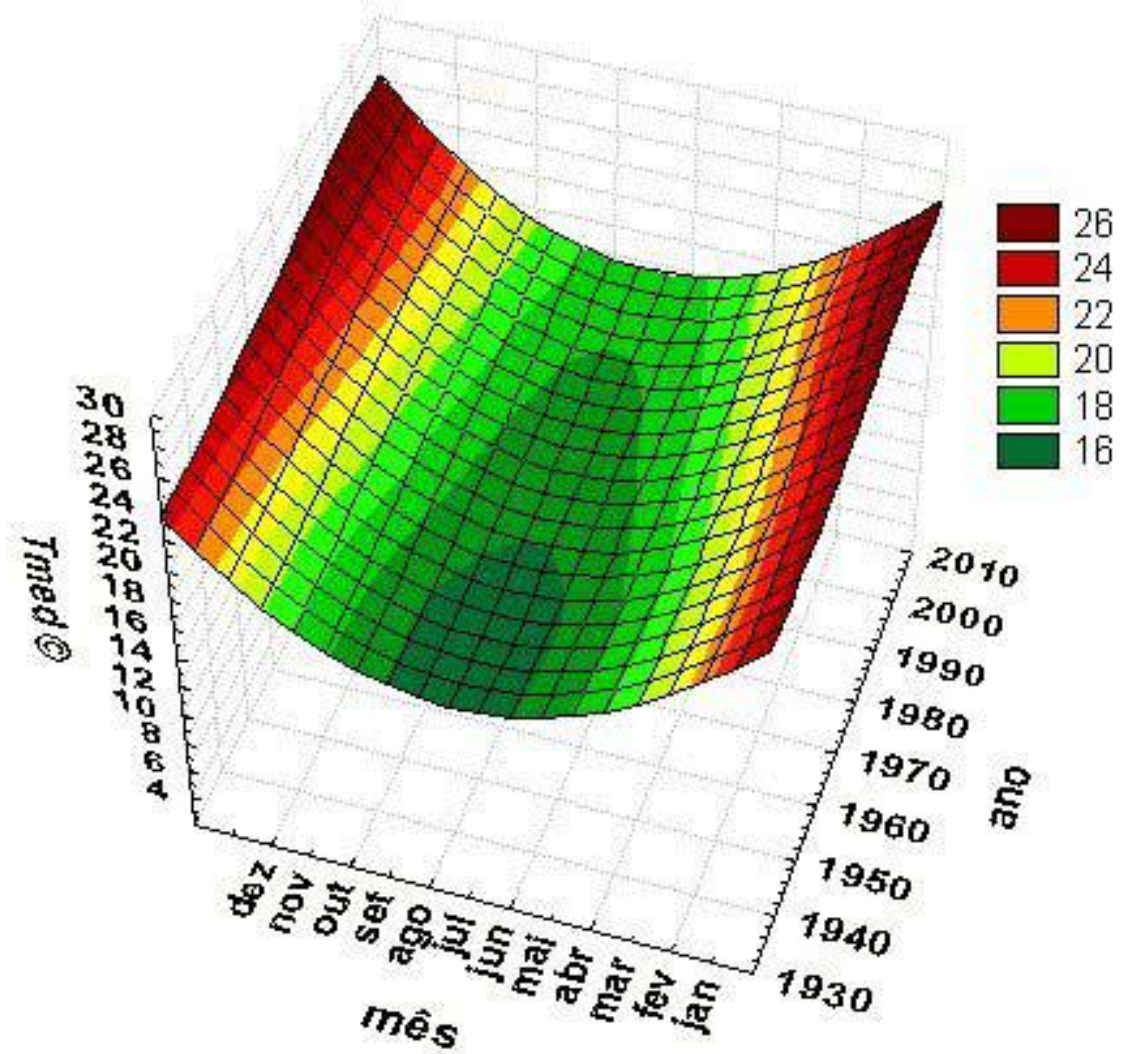

FIGURA 36. Evolução mensal e anual das médias diárias de temperatura de 1936 a 2005 . Fonte: PEREIRA FILHO et al, 2007, apud SANTOS et al, 2006. Disponível em: <http://www.nossasaopaulo.org.br/portal/files/impactos antropicos clima.pdf>. Acesso em: 14 jan. 2010.

Também se observa a queda gradativa da umidade média mensal, que de 1936 até 1950 apresenta valores acima de $85 \%$, valores estes não mais atingidos a partir de 1990 (FIG. 37) (PEREIRA FILHO et al, 2007). 


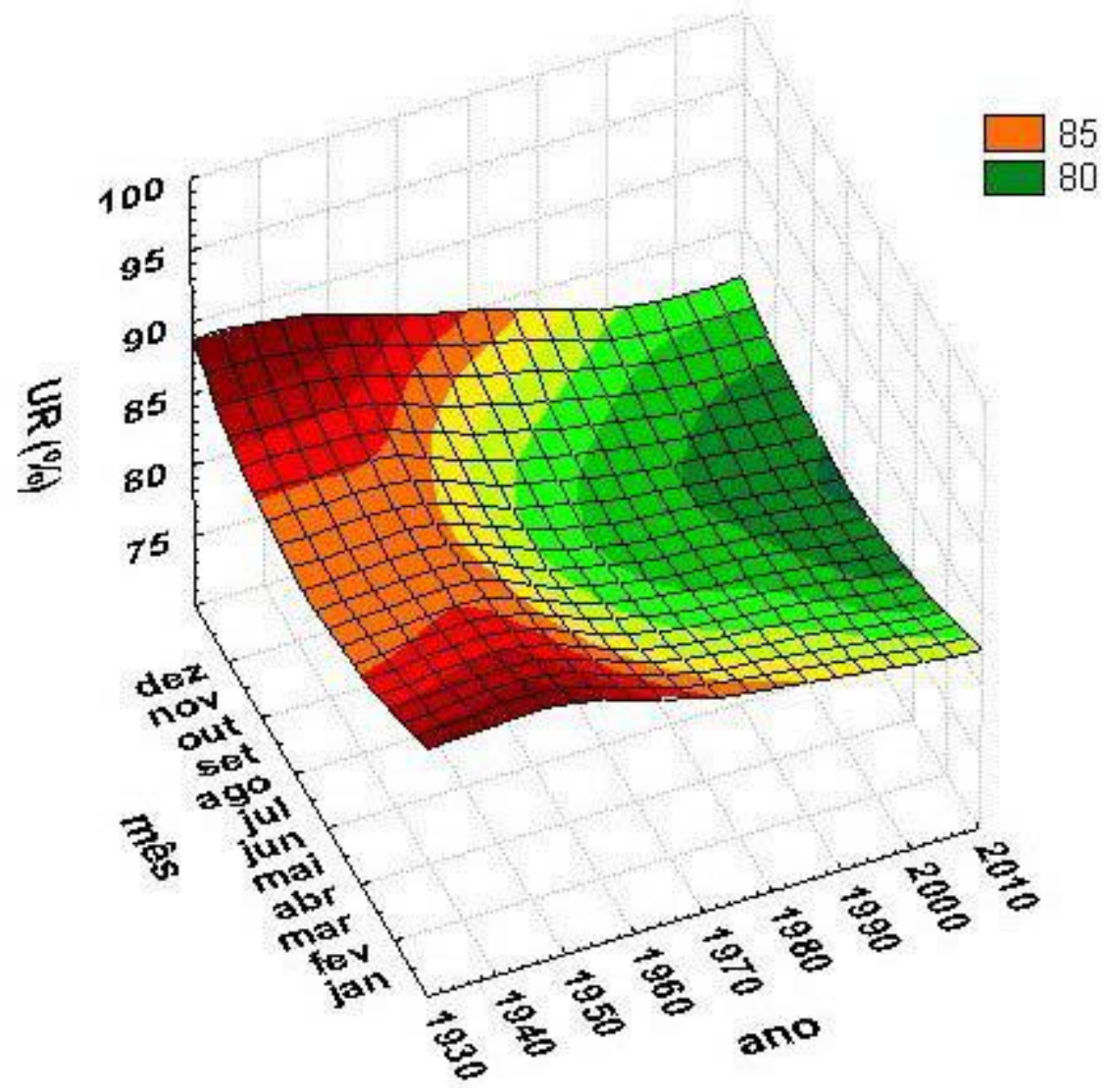

FIGURA 37. Evolução anual e mensal das médias diárias da umidade relativa do ar de 1936 a 2005. Fonte: PEREIRA FILHO et al, 2007 apud SANTOS et al, 2006. Disponível em: $<$ http://www.nossasaopaulo.org.br/portal/files/impactos antropicos clima.pdf>. Acesso em: 14 jan. 2010.

Estes gráficos revelam que alterações na temperatura e umidade relativa do ar ocorreram na cidade de São Paulo no século XX, uma vez que as alterações climáticas no Parque Fontes do Ipiranga, que se mantém intocado desde a década de 1930, decorreram de ações antrópicas na Região Metropolitana.

Da mesma forma, como no exemplo do mapa de Vancouver, apresentado por Oke, o mapa das temperaturas de superfície da cidade de São Paulo mostra claramente a mancha urbana com temperaturas que sobem, gradativamente, em direção à região central, envolvida pela região periférica a temperaturas mais baixas (FIG. 38) (OKE, 1978).

No detalhe do mapa, que mostra a região central, revela-se a área onde são registradas as temperaturas mais elevadas no município, distribuídas pelos distritos Pari, Brás, Belém, Mooca, Cambuci e Bom Retiro (FIG. 39). 

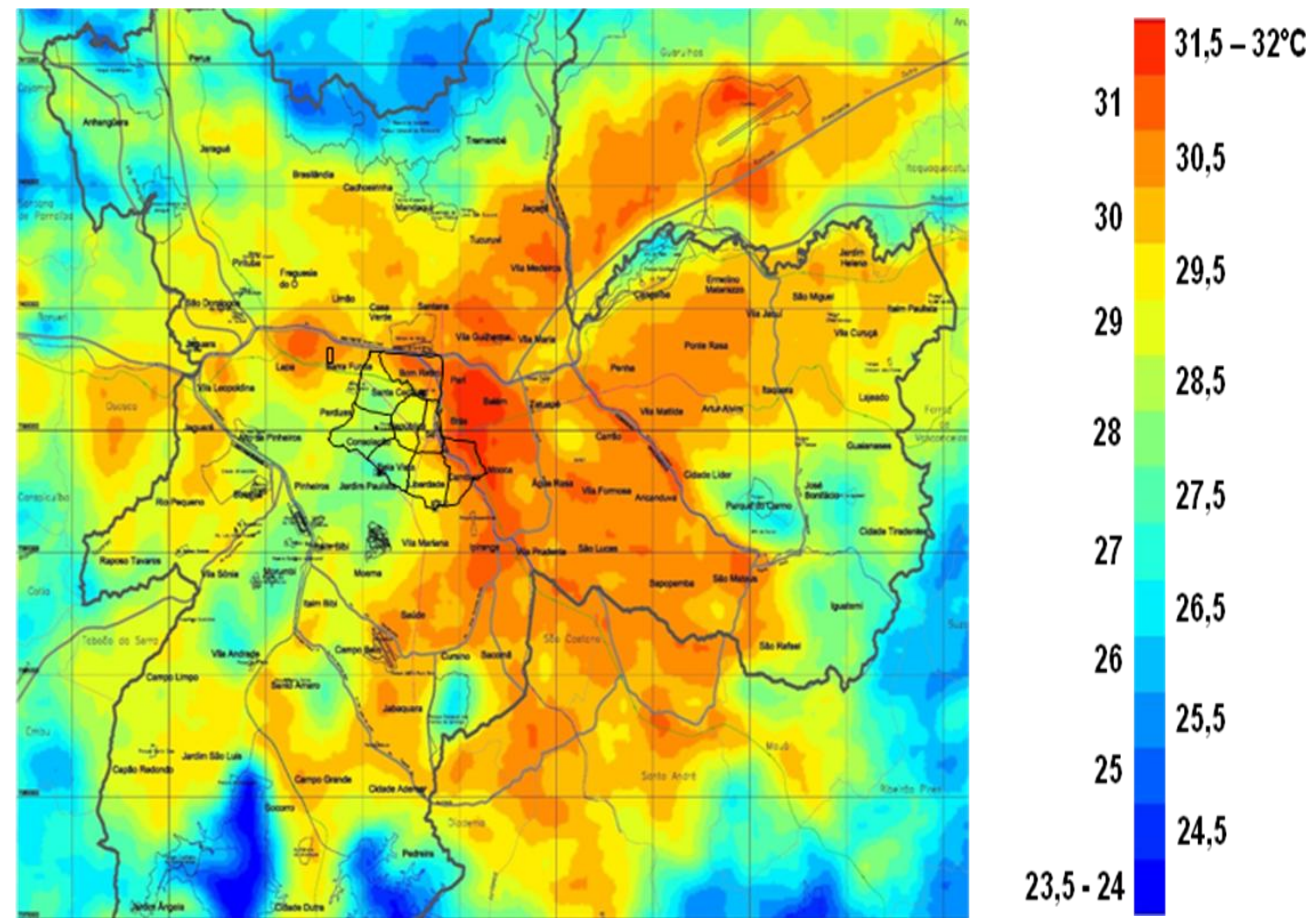

FIGURA 38. Mapa das temperaturas de superfície da cidade de São Paulo em 03 de setembro de 1999 às 9,57hs. Fonte: Atlas ambiental da cidade de São Paulo. Disponível em: $<$ http://atlasambiental.prefeitura.sp.gov.br>. Acesso em: 19 jul. 2008.
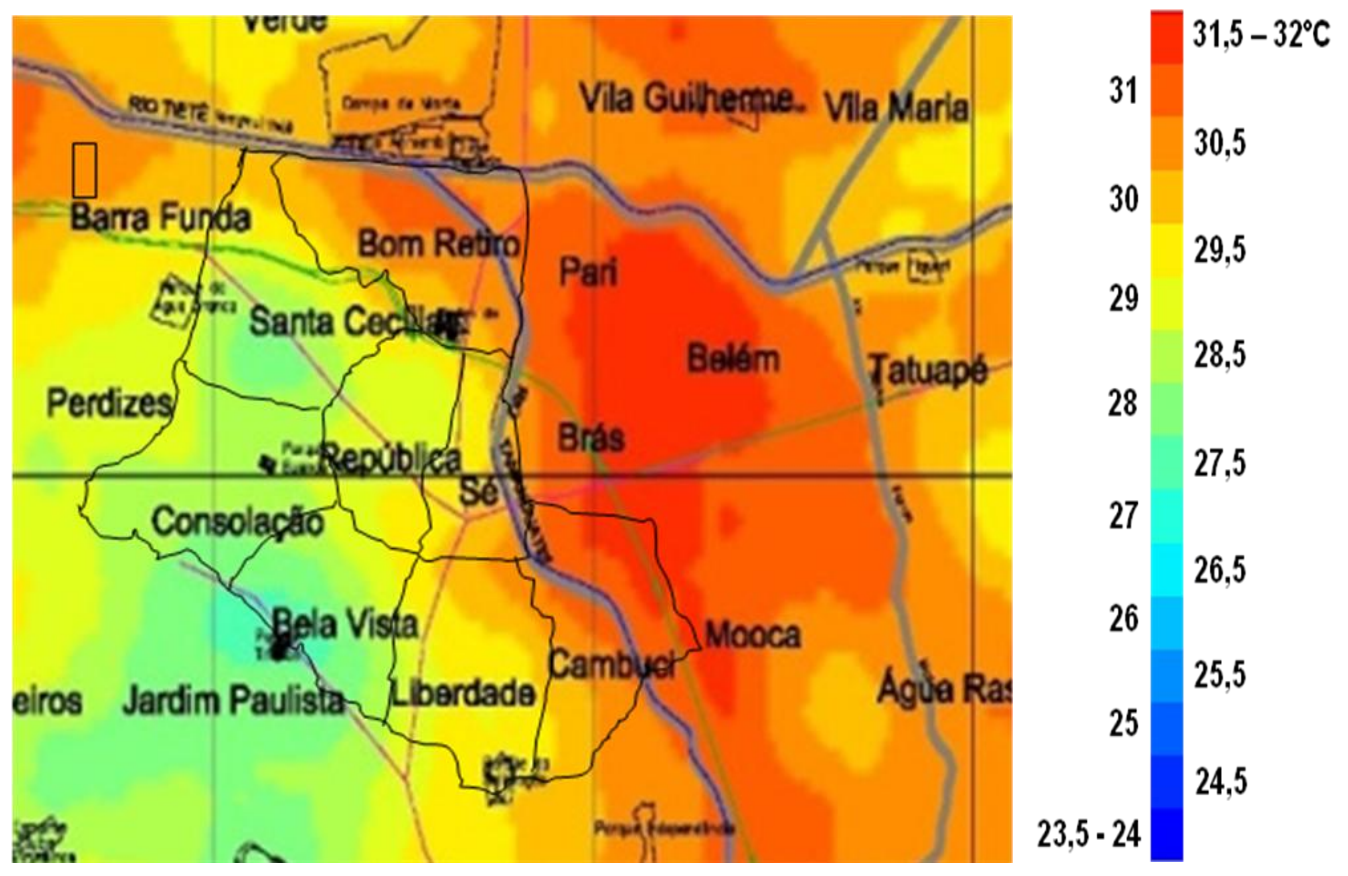

FIGURA 39. Detalhe da situação da Subprefeitura da Sé no mapa das temperaturas de superfície da cidade de São Paulo. Fonte: Atlas ambiental da cidade de São Paulo. Disponível em: $<$ http://atlasambiental.prefeitura.sp.gov.br>. Acesso em: 19 jul. 2008. 
Através do mapa das isotermas observa-se que as temperaturas mais amenas, na região central, são registradas na Avenida Paulista, nas proximidades do Parque Trianon, e se elevam à medida que se distancia do distrito da Consolação em direção às regiões norte (Bom Retiro) e leste (Cambuci) (FIG. 40).

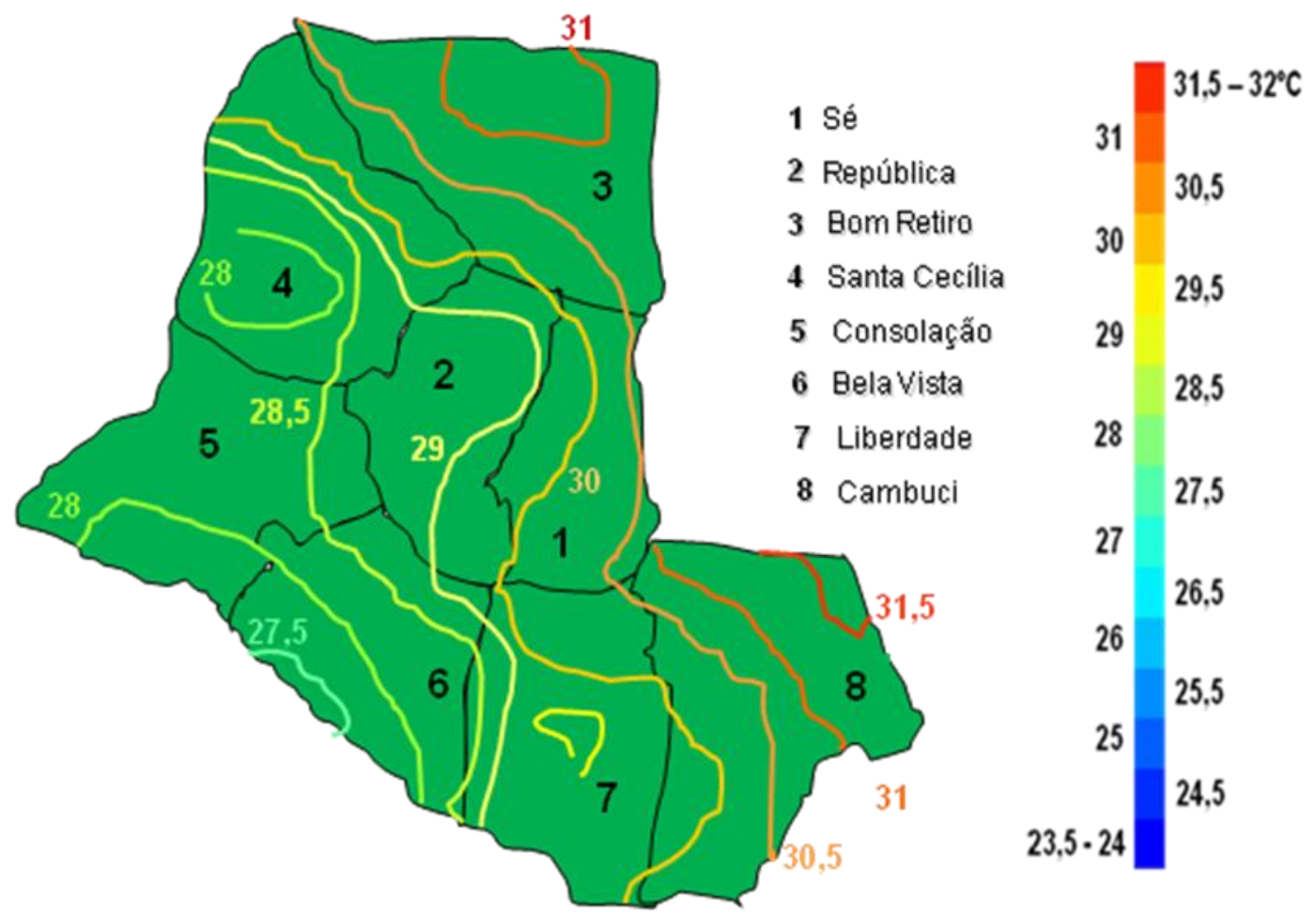

FIGURA 40: Mapa das isotermas no centro de São Paulo. Fonte: Adaptado de Instituto Polis/Subprefeitura Sé, apud NAKANO, 2004.

\subsubsection{Cobertura vegetal}

As temperaturas mais amenas, verificadas na região oeste da Subprefeitura da Sé e a sua elevação gradativa à medida que se afasta do distrito da Consolação resultam da maior concentração de áreas verdes existentes neste local. $\mathrm{Na}$ Bela Vista (7.200 $\mathrm{m}^{2}$ de área verde) há os jardins dos canteiros da Av. 23 de Maio e, nas suas proximidades o Parque Trianon (Parque Tenente Siqueira Campos, $49.000 \mathrm{~m}^{2}$ ). Próximo à Santa Cecília (que não possui áreas verdes) o Parque da Água Branca (Parque Fernando Costa, $136.765 \mathrm{~m}^{2}$ ), no Bom Retiro o Parque da Luz $\left(113.000 \mathrm{~m}^{2}\right)$. A Consolação, possui a maior área verde da Subprefeitura da Sé 
(639.000 m², com $25.000 \mathrm{~m}^{2}$ correspondentes ao Parque Buenos Aires). No distrito da Sé a Praça da Sé e o Parque D. Pedro II. Na região sul do distrito da Liberdade, o Parque da Aclimação (112.000 m²) (FIG 41). Cada uma destas áreas verdes interferem no traçado geométrico das isotermas ampliando as áreas da Subprefeitura da Sé que apresentam temperaturas mais amenas (FIG. 40) (SEPE; GOMES, 2008).

A vegetação da região ocupada pela cidade de São Paulo foi sendo eliminada à medida que progrediu a ocupação urbana. $O$ total de área verde existente nos dias de hoje é de $150 \mathrm{~km}^{2}, 15 \%$ da área total do município.

Um primeiro levantamento através do mapa de distribuição das áreas verdes por habitante, por faixas de áreas verdes, revela situações diferentes para os distritos da Subprefeitura da Sé e faixas largas que dificultam a análise da situação (FIG. 41).

Os índices de áreas verdes por habitante, específico de cada distrito, dão maior precisão à análise e revelam situação típica de ocupação urbana sem preservação de área verde. Neste caso, todos os índices ficam abaixo dos 12 $\mathrm{m}^{2} /$ habitante recomendados pela Organização Mundial da Saúde (OMS) (TAB. 5).
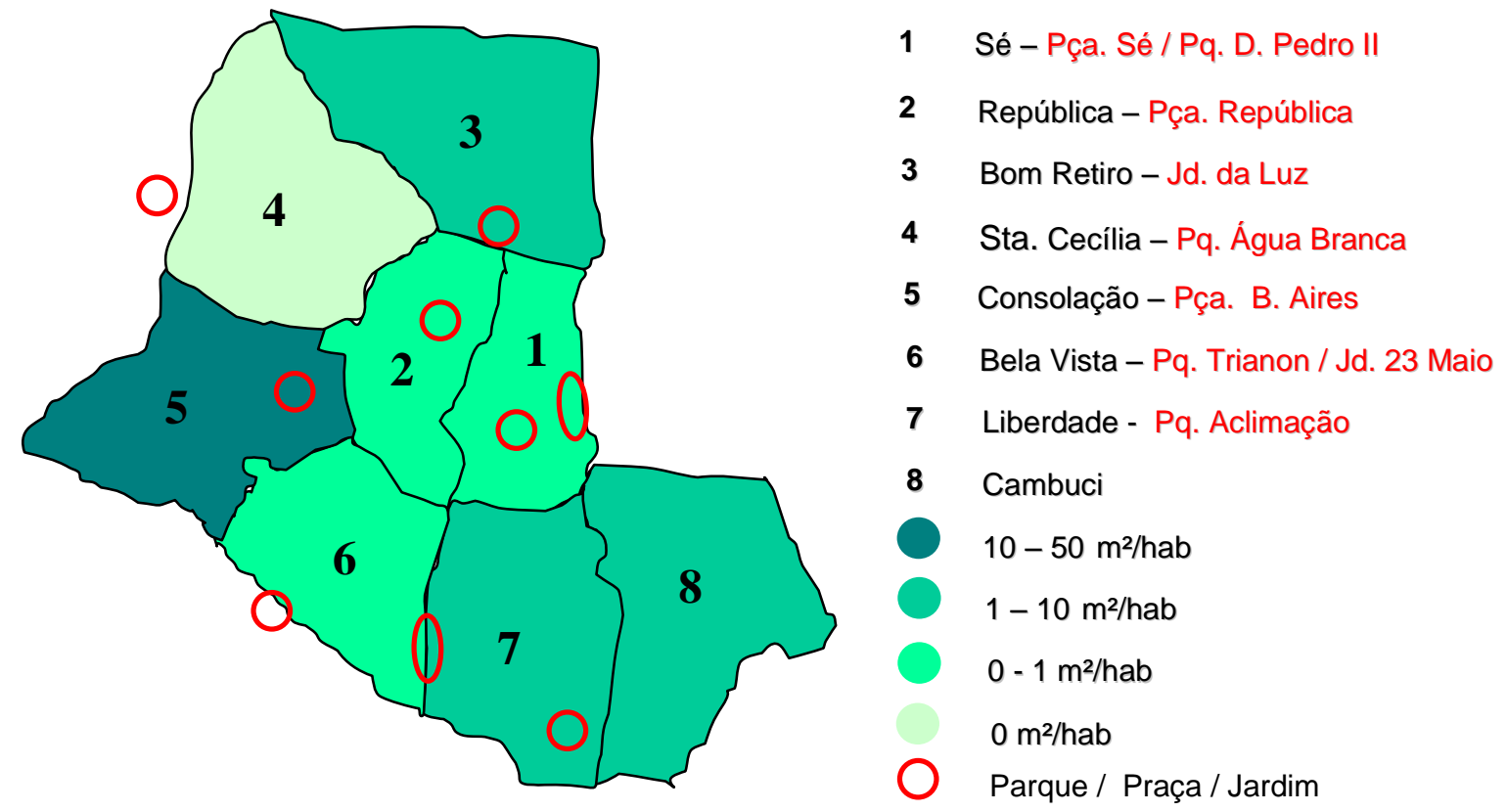

FIGURA 41. Áreas verdes por distrito no centro de São Paulo. Fonte: Adaptado de SÃO PAULO [Cidade] - SUBSÉ. Autor: Kazuo Nakano, 2004. 
TABELA 5. Cobertura vegetal por distrito da Subprefeitura da Sé. Fonte: IBGE, 2000 - SEPE; GOMES, 2008.

\begin{tabular}{lccc}
\hline Distrito & $\begin{array}{c}\text { Cobertura vegetal } \\
\text { em } 1999\left(\mathrm{~m}^{2}\right)\end{array}$ & $\begin{array}{c}\text { População } \\
(\text { IBGE-2000) }\end{array}$ & $\begin{array}{c}\text { Cobertura vegetal por } \\
\text { habitante por distrito } \\
\left(\mathrm{m}^{2} / \mathrm{hab}\right)\end{array}$ \\
\hline Consolação & 639.000 & 54.522 & 11,72 \\
Bom Retiro & 200.700 & 26.598 & 7,54 \\
Liberdade & 114.300 & 61.875 & 1,75 \\
Cambuci & 66.600 & 28.717 & 2,32 \\
República & 11.700 & 47.718 & $\mathbf{0 , 2 4}$ \\
Bela Vista & 7.200 & 63.190 & 0,11 \\
Sé & 4.500 & 20.115 & $\mathbf{0 , 2 2}$ \\
Santa Cecília & 0 & 71.179 & 0 \\
\hline
\end{tabular}

A análise do mapa das isotermas e dos índices de cobertura vegetal por área dos distritos revela que, na Consolação, o índice de 166,84.10³ mantém variação de temperatura de $0,5^{\circ} \mathrm{C}$ em $3.830 .000 \mathrm{~m}^{2}$. No distrito de Santa Cecília, o índice zero provoca variação de temperatura de $2^{\circ} \mathrm{C}$ em $3.850 .000 \mathrm{~m}^{2}$ (FIG. 40 e TAB. 6).

TABELA 6. Índice de cobertura vegetal por área dos distritos da Subprefeitura da Sé. Fonte: SEPE; GOMES, 2008.

\begin{tabular}{lccc}
\hline Distrito & $\begin{array}{c}\text { Cobertura vegetal } \\
\text { em } 1999\left(\mathrm{~m}^{2}\right)\end{array}$ & $\begin{array}{c}\text { Área do Distrito } \\
\left(\mathrm{m}^{2}\right)\end{array}$ & $\begin{array}{c}\text { Índice de cobertura vegetal por } \\
\text { área do Distrito }\end{array}$ \\
\hline Consolação & 639.000 & 3.830 .000 & $166,84 \cdot 10^{-3}$ \\
Bom Retiro & 200.700 & 4.110 .000 & $48,8 \cdot 10^{-3}$ \\
Liberdade & 114.300 & 3.640 .000 & $31,4 \cdot 10^{-3}$ \\
Cambuci & 66.600 & 3.910 .000 & $17 \cdot 10^{-3}$ \\
República & 11.700 & 2.420 .000 & $4,83 \cdot 10^{-3}$ \\
Bela Vista & 7.200 & 2.710 .000 & $2,66 \cdot 10^{-3}$ \\
Sé & 4.500 & 2.200 .000 & $2.10^{-3}$ \\
Santa Cecília & 0 & 3.850 .000 & 0 \\
\hline
\end{tabular}




\subsubsection{Adensamento vertical}

As temperaturas observadas no mapa das isotermas nos distritos Bom

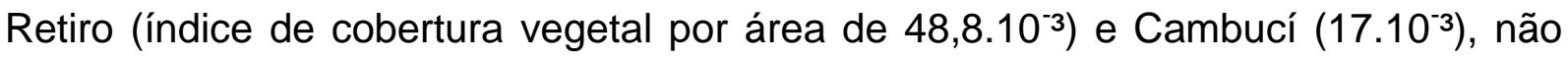
são alcançadas nos distritos Sé $\left(2.10^{-3}\right)$ e República $\left(4,83.10^{-3}\right)$ devido às áreas de sombreamento geradas pela concentração de elevados edifícios (FIG. 40).

Observa-se nos distritos da Sé e República o mais elevado adensamento vertical dos 96 distritos da cidade, conforme levantamento realizado utilizando-se o índice que considera edifícios com mais de cinco pavimentos, aos quais se atribui maior contribuição à elevação da temperatura urbana (FIG. 42) (SEPE; GOMES, 2008).

Até 1929 a cidade dispunha de pouco mais de 50 edifícios com mais de quatro andares, concentrados principalmente no centro (CAMPOS et al, 2004).

Após a década de 1930 passam a ser construídos elevados edifícios na região central e a cidade passa a se desenvolver em todas as direções.
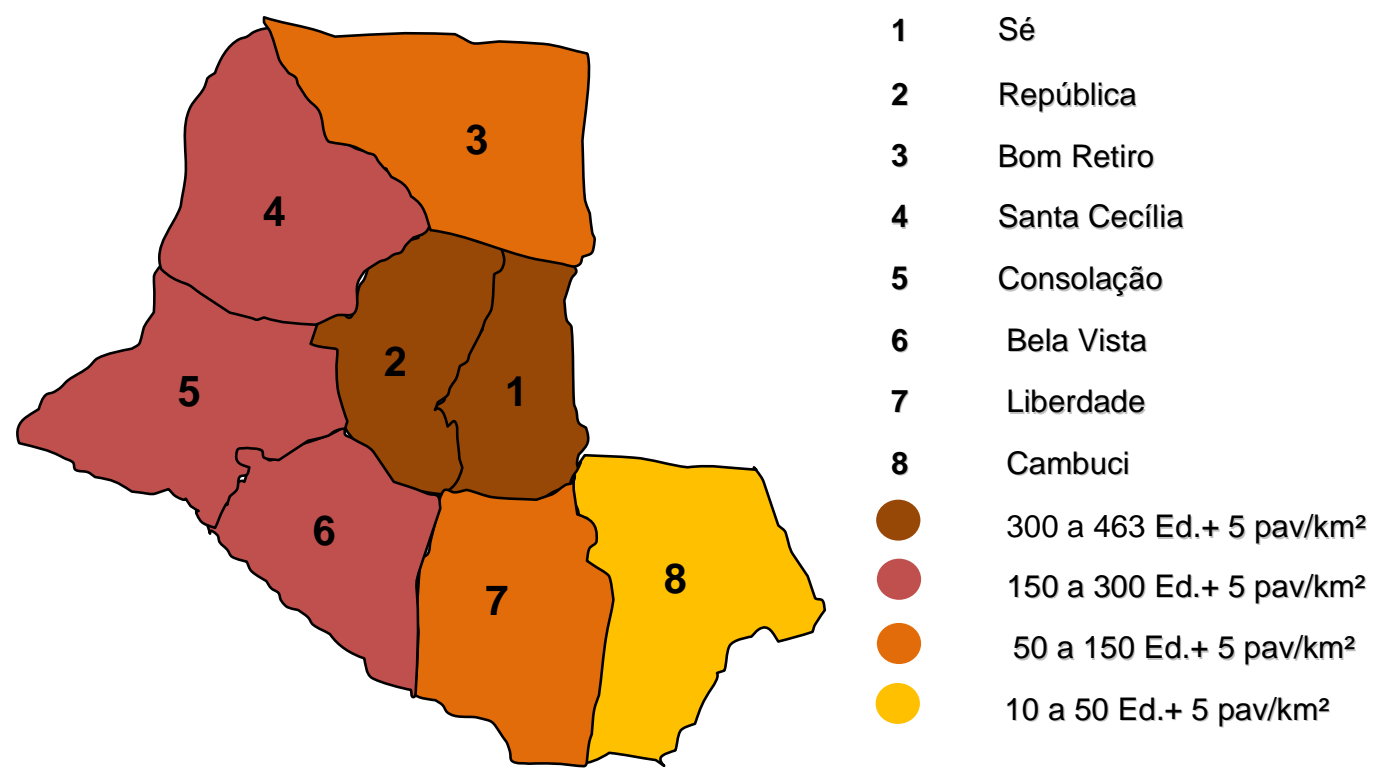

FIGURA 42 Número de edifícios com mais de cinco pavimentos por $\mathrm{km}^{2}$, por distrito da região central, 2007. Fonte: Adaptado de Indicadores Ambientais e Gestão Urbana (SEPE; GOMES, 2008). 


\subsubsection{Poluentes do ar}

Os poluentes que podem interferir na temperatura ambiente são lançados na atmosfera pelas indústrias (emitentes de material particulado e $\mathrm{CH}_{4}$ ), ônibus e caminhões a diesel (material particulado e $\left.\mathrm{N}_{\mathrm{x}} \mathrm{O}_{\mathrm{y}}\right)$ e automóveis $\left(\mathrm{N}_{\mathrm{x}} \mathrm{O}_{\mathrm{y}}, \mathrm{CO}_{2}\right.$ e $\left.\mathrm{CH}_{4}\right)$, sendo que os veículos automotores são responsáveis por $90 \%$ da poluição atmosférica (BIDONE, 2003).

Para a realização da análise das concentrações dos poluentes atmosféricos na região central de São Paulo foram utilizados os registros de todas as estações de monitoramento da Cetesb localizadas na Subprefeitura da Sé: Estações de Monitoramento Automático Parque D. Pedro II, Cambuci, Cerqueira César, Centro e Estações Manuais Cerqueira César, Parque D. Pedro II, Praça da República e Campos Elísios.

\subsubsection{Teores de fumaça}

$\mathrm{Na}$ área central de São Paulo, o Padrão Primário dos teores de fumaça deixou de ser atingido a partir de 2002, quando se tendeu a alcançar o Padrão Secundário. Mas, com o reaquecimento da atividade econômica, nos anos 2006, 2007 e 2008 notou-se elevação, reaproximando-se do Padrão Primário (APÊNDICE A, FIG. 51 e TAB. 9).

\subsubsection{Partículas inaláveis}

Apresentaram tendência de se manter abaixo do Padrão Primário/Secundário a partir de 2005 (APÊNDICE A, FIG. 52 e TAB. 10).

\subsubsection{Partículas totais em suspensão}

As máximas concentrações anuais de PTS apresentaram queda progressiva de 1989 a 2008; com a retomada da atividade econômica nos anos 2006, 2007 e 2008, observa-se tendência de reaproximação do Padrão Primário (APÊNDICE A, FIG. 53 e TAB. 11).

O controle das emissões dos poluentes até agora analisados é importante para a diminuição da absorção de calor pela nuvem de poluição que se instala sobre 
a cidade e, consequentemente, pela queda da reflexão de calor, que contribui para a formação da ilha de calor nos centros urbanos.

\subsubsection{Dióxido de carbono}

A Cetesb não faz as análises de $\mathrm{CO}_{2}$ em suas estações de monitoramento.

Os únicos registros referentes aos teores de $\mathrm{CO}_{2}$ emitidos foram encontrados nas tabelas dos fatores médios de emissão de veículos leves novos e de fatores típicos de emissão para veículos usados convertidos para o uso de gás natural, a partir do ano de 2002.

Com os dados destas tabelas foram construídos gráficos, onde se observa redução de $10 \%$ de $\mathrm{CO}_{2}$ para veículos novos tipo flex quando utilizam álcool (FIG. 43).

Para veículos movidos a gasolina transformados para gás natural veicular, do ano de 2002 até 2007, a redução da emissão de $\mathrm{CO}_{2}$ manteve-se na faixa de 15\% (FIG. 44) (CETESB, 2008).

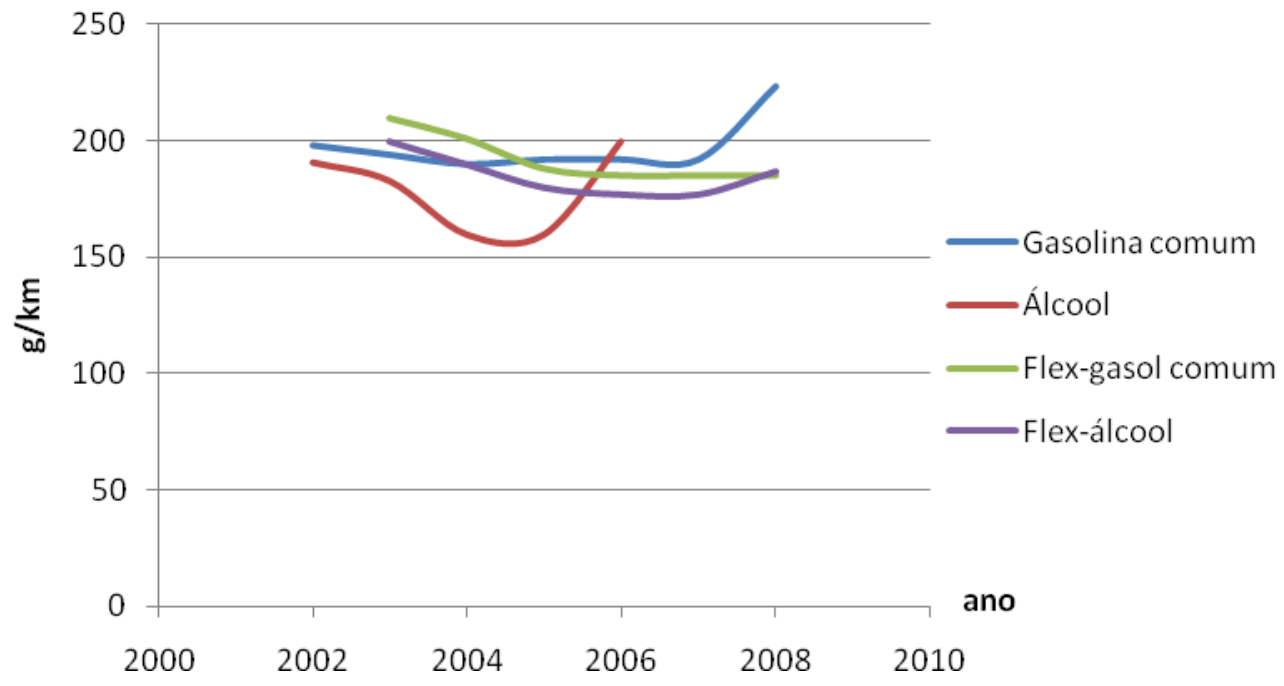

FIGURA 43. Fatores médios de emissão de $\mathrm{CO}_{2}$ para veículos leves novos no período de 2002 a 2008. Fonte: Adaptado do Relatório de Qualidade do Ar no Estado de São Paulo, 2008. CETESB, 2009. Disponível em: <http://www.cetesb.sp.gov.br/Ar/publicacoes.asp>. Acesso em: 22 nov. 2009. 


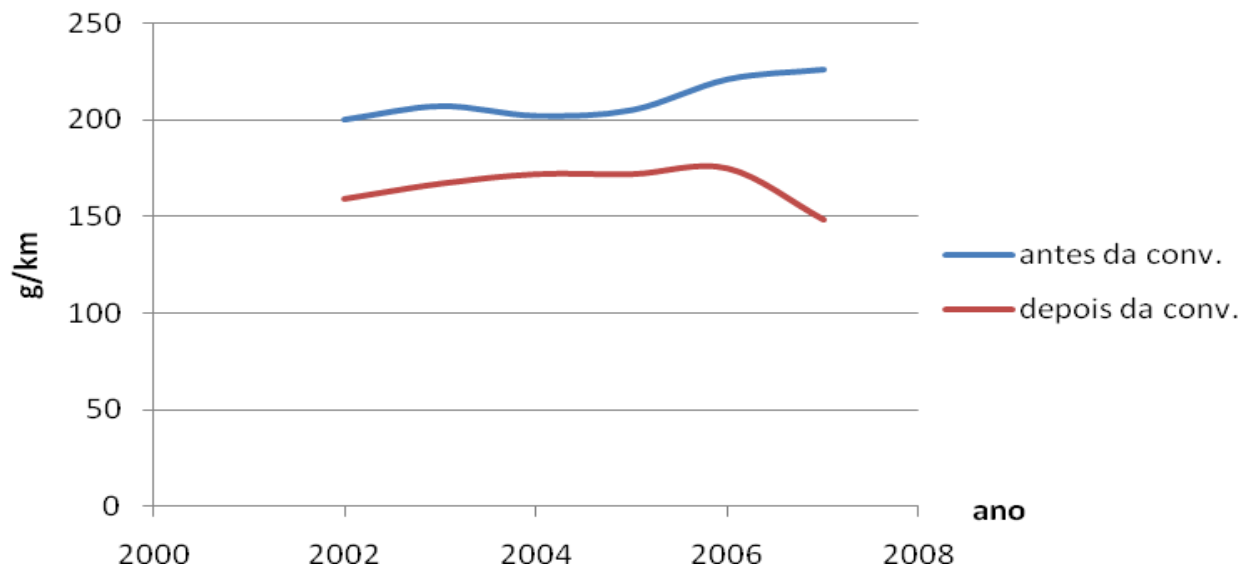

FIGURA 44. Valores típicos de emissão de $\mathrm{CO}_{2}$ para veículos em uso, movidos a gasolina convertidos para gás natural veicular, no período de 2002 a 2008. Fonte: Adaptado do Relatório de Qualidade do Ar no Estado de São Paulo, 2008. CETESB, 2009. Disponível em: <http://www.cetesb.sp.gov.br/Ar/publicacoes.asp >. Acesso em: 22 nov. 2009.

Apesar das reduções nas emissões de poluentes, a frota de veículos na cidade de São Paulo aumentou, de 2002 para 2008, de 6.100.000 para 6.900.000 veículos, aumento da ordem de 15\%, representado na sua quase totalidade pela introdução de veículos flex álcool/gasolina (FIG. 45) (CETESB, 2008).

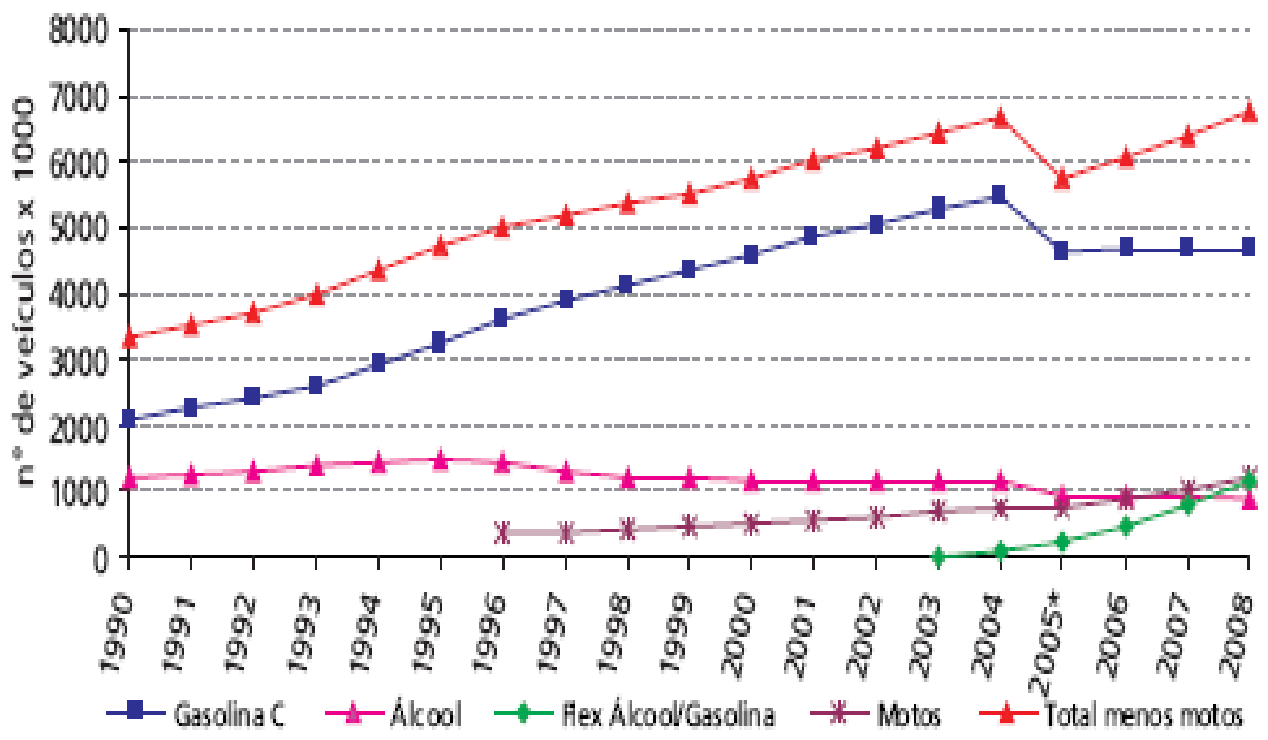

FIGURA 45. Evolução da frota de veículos automotores leves da região metropolitana de São Paulo. Fonte: Relatório de Qualidade do Ar no Estado de São Paulo, 2008. CETESB, 2008.

Disponível em: <http://www.cetesb.sp.gov.br/Ar/publicacoes.asp>. Acesso em: 22 nov. 2009. 


\subsubsection{Dióxido de nitrogênio}

Pelos resultados das análises, de 1998 até 2008, pequena tendência de queda dos teores $\mathrm{NO}_{2}$, superando dez vezes os limites do Padrão Primário (APÊNDICE A, FIG. 54 e TAB. 12).

\subsubsection{Monóxido de nitrogênio}

O NO, apesar de não possuir limites estabelecidos, apresenta resultados semelhantes aos do $\mathrm{NO}_{2}$, grande instabilidade, numa faixa com pequena tendência de queda (APÊNDICE A, FIG. 55 e TAB. 13).

\subsubsection{Ozônio}

Como constatado para $\mathrm{NO}$ e $\mathrm{NO}_{2}$, os teores de $\mathrm{O}_{3}$, permaneceram com pequena tendência de queda, mantendo-se acima do Padrão Primário/Secundário e tendo o Nível de Atenção (TAB. 2) superado sete vezes, de 2004 a 2008 (APÊNDICE A, FIG. 56 e TAB. 14).

As maiores ocorrências das altas concentrações do ozônio na cidade de São Paulo ocorrem entre $13 \mathrm{~h} 00$ e $15 \mathrm{~h} 00$, no período compreendido entre o final do inverno e o começo do verão, não havendo diferenças significativas entre os dias úteis e os finais de semana.

Não ocorrem durante o período do verão devido ao aumento da nebulosidade na região.

Quando os resultados da Estação de Monitoramento D. Pedro II são comparados com os resultados da Estação Ibirapuera, nota-se uma quantidade menor de ultrapassagens na Estação D. Pedro II. Este fato é atribuído aos elevados teores de NO proveniente dos veículos, devido à proximidade da estação da via de tráfego, possibilitando a reação do $\mathrm{NO}$ excedente com o $\mathrm{O}_{3}$.

Os resultados obtidos na estação D. Pedro II são primeiramente decorrentes da fotólise do $\mathrm{NO}_{2}$ lançado pelos motores dos veículos que circulam nas proximidades da estação, o que proporciona a formação NO e oxigênio atômico no estado fundamental $(O)$ (Reação 1 ); este reage com o oxigênio molecular $\left(\mathrm{O}_{2}\right)$, 
formando $\mathrm{O}_{3} \mathrm{O}_{3}$ (Reação 2), e que, em seguida, reage com o NO excedente (proveniente dos veículos), formando $\mathrm{NO}_{2}$ e $\mathrm{O}_{2}$ (Reação 3) (CETESB, 2000).

$$
\begin{array}{r}
\mathrm{NO}_{2} \rightarrow \mathrm{NO}+\mathrm{O}(1) \\
\mathrm{O}+\mathrm{O}_{2} \rightarrow \mathrm{O}_{3}(2) \\
\mathrm{O}_{3}+\mathrm{NO} \rightarrow \mathrm{NO}_{2}+\mathrm{O}_{2}
\end{array}
$$

\subsubsection{Temperatura do ar}

Através do levantamento das temperaturas realizado nas estações de monitoramento da Cetesb localizadas na área central e na estação meteorológica do IAG, localizada no Parque Fontes do Ipiranga, constatou-se que:

- $\quad$ as temperaturas no distrito da Sé permaneceramm mais elevadas durante todo o transcorrer do dia em 18 dos 70 dias analisados, quando comparadas com as temperaturas da Estação Meteorológica Parque Fontes do Ipiranga, conforme o exemplo do dia três de março de 1988 (FIG. 46);

- nos demais 52 dias analisados $(74,3 \%)$, as temperaturas da Estação Meteorológica Parque Fontes do Ipiranga se elevaram mais rapidamente durante o período da manhã e no período da tarde caíram mais rapidamente do que no distrito da Sé, confirmando que as áreas urbanizadas aquecem e resfriam mais lentamente do que a periferia, conforme o exemplo do dia 12 de setembro de 1998 (FIG. 47); 


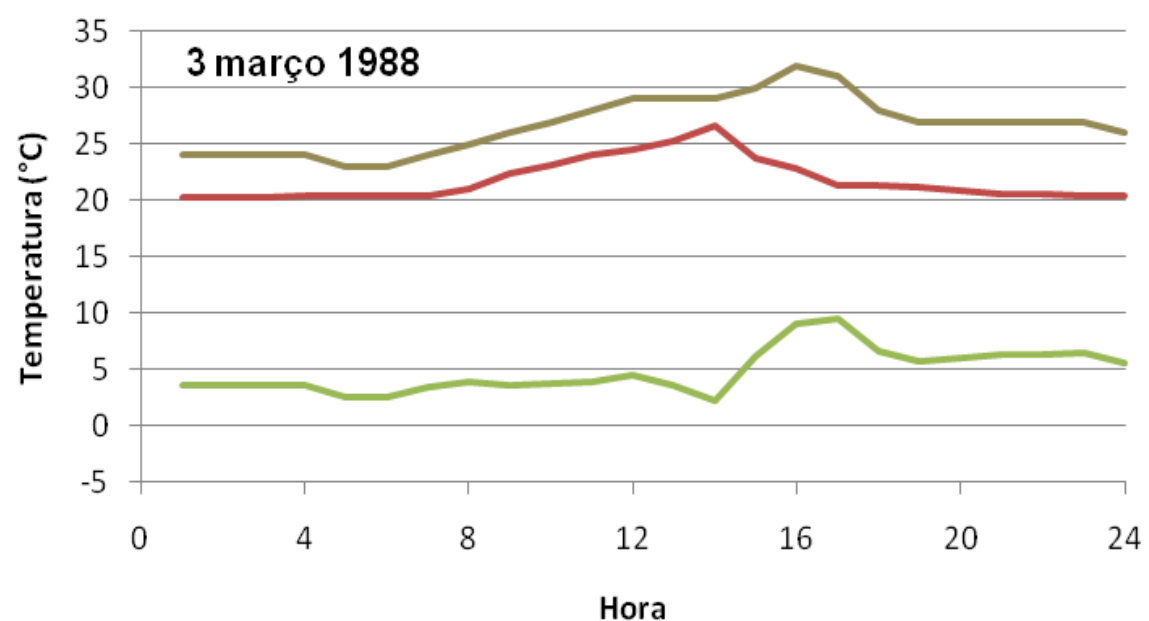

Est. Centro $\longrightarrow$ F. Ipiranga Intensidade

FIGURA 46. Gráfico horário das temperaturas, no dia três de março de 1988, na Estação de Monitoramento Centro, Estação Meteorológica do Parque Estadual Fontes do Ipiranga e da Intensidade da Ilha de Calor. Fonte: CETESB, 1999 e IAG.

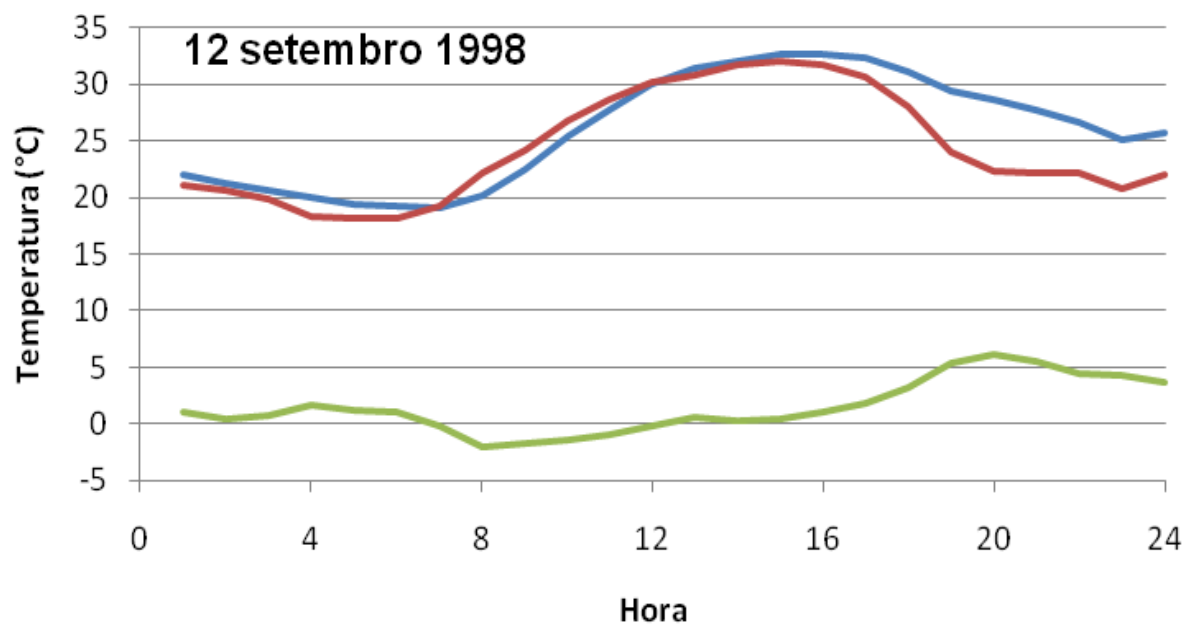

—Pq. D. Pedro II —F. Ipiranga —Intensidade

FIGURA 47. Gráfico horário das temperaturas, no dia 12 de setembro de 1998, na Estação de Monitoramento do Pq. D. Pedro II, Estação Meteorológica do Parque Estadual Fontes do Ipiranga e da Intensidade da llha de Calor. Fonte: CETESB, 1999 e IAG.

- nos 70 dias analisados, o distrito da Sé atingiu temperaturas mais elevadas do que a área representada pela Estação Meteorológica Parque Fontes do Ipiranga, confirmando que a urbanização causa elevação da temperatura; 
- $\quad$ as intensidades máximas da ilha de calor compreendidas entre $3,1^{\circ} \mathrm{C}$ e $5^{\circ} \mathrm{C}$ ocorrem 31 vezes (44,3\%) (TAB. 7 );

- as maiores intensidades da ilha de calor ocorrem 34 vezes entre $15 \mathrm{~h} 00$ e 17h00 (48.6\%) (TAB. 8);

- a maior intensidade da ilha de calor $\left(11^{\circ} \mathrm{C}\right)$ foi observada no inverno, em agosto de 1993, às 15 h00 (TAB. 7).

Variações observadas das intensidades máximas mensais da ilha de calor, por estação climática:

- no verão (janeiro, fevereiro e março de 1981 a 2003) a intensidade da ilha de calor variou de $1,5^{\circ} \mathrm{C}$ até $7,1^{\circ} \mathrm{C}$;

- no outono (abril, maio e junho de 1981 a 2003) a intensidade da ilha de calor variou de $2,9^{\circ} \mathrm{C}$ até $7,5^{\circ} \mathrm{C}$;

- no inverno (julho, agosto e setembro de 1981 a 2003) a intensidade da ilha de calor variou de $2,5^{\circ} \mathrm{C}$ até $11^{\circ} \mathrm{C}$;

- na primavera (outubro, novembro e dezembro de 1981 a 2003) a intensidade da ilha de calor variou de $1,2^{\circ} \mathrm{C}$ até $9,4^{\circ} \mathrm{C}$ (APÊNDICE B).

TABELA 7. Frequência das máximas intensidades da ilha de calor registradas nos anos de 1981, 1983, 1988, 1993, 1998 e 2003. Dados da Estação de Monitoramento do Pq. D. Pedro II, Estação Centro e Estação Meteorológica do Parque Estadual Fontes do Ipiranga. Fonte: CETESB, 1999 e 2004 e IAG.

\begin{tabular}{|c|c|}
\hline $\begin{array}{l}\text { Intensidade diária } \\
\text { máxima }\left({ }^{\circ} \mathrm{C}\right) \\
\end{array}$ & Frequência \\
\hline 1,1 e 2 & 6 vezes \\
\hline 2,1 e 3 & 9 vezes \\
\hline 3,1 e 4 & 14 vezes \\
\hline 4,1 e 5 & 17 vezes \\
\hline 5,1 e 6 & 7 vezes \\
\hline 6,1 e 7 & 7 vezes \\
\hline 7,1 e 8 & 4 vezes \\
\hline 8,1 e 9 & 2 vezes \\
\hline 9,1 e 10 & 2 vezes \\
\hline 10,1 e 11 & 2 vezes \\
\hline
\end{tabular}


TABELA 8. Frequências dos horários em que ocorreram as máximas intensidades da ilha de calor registradas nos anos de 1981, 1983, 1988, 1993, 1998 e 2003. Dados obtidos a partir dos registros da Estação de Monitoramento do Parque D. Pedro II, Estação Centro e Estação Meteorológica do Parque Estadual Fontes do Ipiranga. Fonte: CETESB, 1999 e 2004 e IAG.

\begin{tabular}{cc}
\hline Hora & Frequência \\
\hline 3,00 & 1 vez \\
12,00 & 3 vezes \\
14,00 & 5 vezes \\
$\mathbf{1 5 , 0 0}$ & $\mathbf{1 0}$ vezes \\
$\mathbf{1 6 , 0 0}$ & $\mathbf{1 1}$ vezes \\
$\mathbf{1 7 , 0 0}$ & $\mathbf{1 3}$ vezes \\
18,00 & 4 vezes \\
19,00 & $\mathbf{7}$ vezes \\
20,00 & $\mathbf{7}$ vezes \\
21,00 & 3 vezes \\
22,00 & 6 vezes \\
\hline
\end{tabular}

As análises das concentrações de poluentes atmosféricos, temperaturas e umidades relativas do ar, na região central, de 1920 a 1970, auxiliariam no entendimento das transformações ambientais e nos fatores que mais interferiram nestas mudanças; entretanto, não há registros destas variáveis neste período na área central.

\subsubsection{Umidade relativa}

Através do levantamento da umidade relativa realizado nas estações de monitoramento da Cetesb, localizadas na área central, e na estação meteorológica do IAG, localizada no Parque Fontes do Ipiranga, constatou-se que, em 42 dias dos 70 analisados, os menores teores de umidade relativa do ar são registrados nas Estações de Monitoramento Centro e Parque D. Pedro II (APÊNDICE C).

Os índices mais baixos de Umidade Relativa identificados no período foram:

- no verão (janeiro, fevereiro e março de 1981 a 2003) UR=38,4\%, em março de 2003;

- No outono (abril, maio e junho de 1981 a 2003) UR=30,5\%, em abril de 2003; 
- no inverno (julho, agosto e setembro de 1981 a 2003) UR=10\%, em agosto de 1981 ;

- na primavera (outubro, novembro e dezembro de 1981 a 2003) UR=28,3\%, em novembro de 2003 (APÊNDICE C).

\subsection{Drenagem}

O sistema de varrição de ruas, importante por prevenir enchentes e o assoreamento dos rios, depende diretamente do uso e ocupação do solo (JARDIM et al, 1996).

Na região central da cidade de São Paulo, região comercial e de grande fluxo de pedestres, a varrição das ruas e calçadões é realizada dez vezes por dia, sendo quatro vezes pela manhã, quatro vezes à tarde e duas vezes à noite (SÃO PAULO [Cidade] - SUBSÉ, 2009).

No sistema de coleta de lixo os resíduos são despejados em recipientes, acondicionados em sacos plásticos, levados para fora dos edifícios, transportados manualmente para a traseira de caminhões (definidos pela norma da Associação Brasileira de Normas Técnicas, NBR-12980, como coletores compactadores, com capacidade máxima para $15 \mathrm{~m}^{3}$ ou $3.700 \mathrm{~kg}$ ) que comprimem cada 250 ou $300 \mathrm{~kg}$ de resíduos do volume de cinco metros cúbicos para um metro cúbico. Quando o caminhão está com a carga completa segue para estação de transferência, onde é realizado o transbordo para caminhões maiores, com capacidade entre 40 e $60 \mathrm{~m}^{3}$, que viabilizam economicamente 0 transporte para o destino final e triagem, localizados a grandes distâncias do centro (SEWELL, 1978).

Na região central da cidade de São Paulo, geradora de grande quantidade de resíduos por se tratar de uma região comercial, com calçadões, que recebem 2 milhões de pessoas diariamente, a coleta é realizada uma vez por dia para se evitar acúmulo de lixo (JARDIM et al, 1996).

As operações de transbordo para veículos maiores, triagem e reciclagem são realizadas em locais isolados devido ao mau cheiro e à proliferação de insetos (CASEIRO, 2006). 
A coleta de lixo utiliza um processo primitivo, se comparado com os sofisticados métodos automatizados em uso em diversos países. Utiliza-se para a coleta o processo o manual de transporte do lixo das residências para os caminhões. As ruas ficam congestionadas e parte do lixo fica espalhado pelo solo (SEWELL, 1978).

No centro da cidade de São Paulo este problema se agrava com a dificuldade de acesso dos caminhões de coleta nas ruas estreitas e nos locais onde está implantado o calçadão.

\subsection{Resíduos sólidos no Município de São Paulo}

Os resíduos, quando mal tratados ou não tratados, podem poluir o ar com $\mathrm{CH}_{4}$, gás de efeito estufa proveniente da fermentação da matéria orgânica.

A partir da resolução número um do Conama, de 1986, o planejamento da coleta e da destinação do lixo, além do caráter técnico, econômico e financeiro, passou a dar prioridade às questões ambientais (BOAVENTURA, 1992).

O lixo no município de São Paulo é composto por $57,5 \%$ de matéria orgânica, $1,8 \%$ de vidro, $2,2 \%$ de metais, $16 \%$ de plástico, $11,1 \%$ de papel e $11,4 \%$ de outros materiais (FIG. 48) (CASEIRO, 2006).

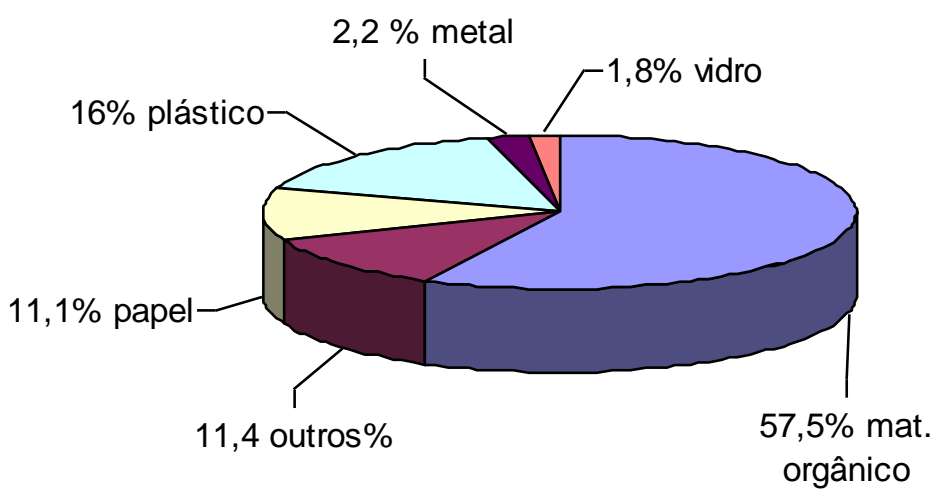

FIGURA 48. Composição do lixo no Município de São Paulo. Fonte: CASEIRO, 2006.

Segundo Pesquisa Nacional de Saneamento Básico (PNSB) 2000, realizada pelo IBGE, na cidade de São Paulo são coletadas 20.150,2 t/dia de lixo, das quais 15.426,5 t (76\%) são destinadas a aterros sanitários, 4.290 t (21\%) a 
estação de compostagem, 331 t (2\%) para estação de triagem e 102,7 t (1\%) para incineração FIG. 49 (IBGE, 2000).

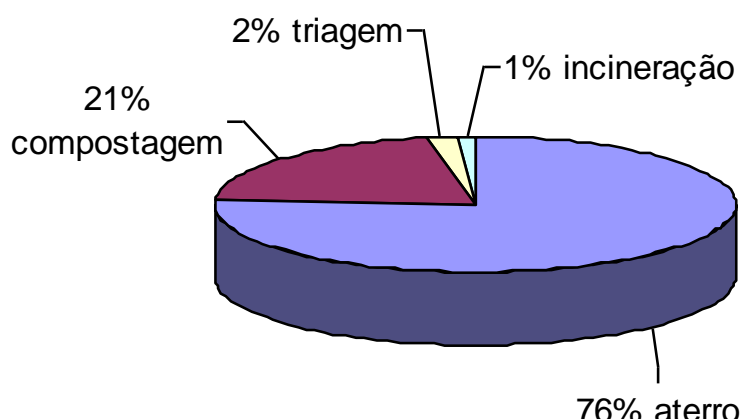

FIGURA 49. Distribuição do lixo no Município de São Paulo. Fonte: IBGE-PNSB 2000.

Para minimizar os efeitos da poluição sobre o meio ambiente, a quantidade diária de lixo enviada para aterros sanitários não deveria ser superior a $30 \%$ do total de lixo produzido (SÃO PAULO [Cidade] - SVMA, 2004).

Para tanto, a quantidade de lixo enviada para triagem deveria ser correspondente ao total de materiais que poderiam ser recicláveis para mesma utilização (papel, plástico, metais e vidro), isto é, deveria ser elevada de $2 \%$ para $31,1 \%(6.266,7 \mathrm{t} / \mathrm{dia})$.

Complementando os $70 \%$ dos resíduos que devem ser desviados da destinação para o aterro, a quantidade de material orgânico enviado para compostagem deveria ser elevada de $21 \%$ para $38,9 \%(7.838,4 \mathrm{t} / \mathrm{dia})$.

Esta composição, além de reduzir os efeitos da poluição sobre o meio ambiente, minimizaria os problemas de gestão da destinação do lixo relativos a custo e disponibilidade de locais para aterros (SÃO PAULO [Cidade] - SVMA, 2004).

Os $29,1 \%$ dos materiais que poderiam ser reciclados e que estão sendo enviados para aterro implicam num acréscimo de produção de 5.863,7 t/dia de novas embalagens e, consequentemente, no aumento de $\mathrm{CO}_{2}$ lançado pelas indústrias na atmosfera.

A cidade de São Paulo possui 16 centrais de triagem, uma delas na Subprefeitura da Sé, Avenida do Estado no 300, distrito Bom Retiro (JARDIM et al, 
1996). De acordo com lei aprovada em 2003, até o ano de 2007 a cidade deveria ter 31 centrais de triagem.

Os $17,9 \%$ dos materiais orgânicos que poderiam ser reciclados e que estão sendo enviados para aterro não estão contribuindo para a elevação dos teores de metano (gás de efeito estufa) no ar, uma vez que o gás, gerado pela fermentação destes resíduos, tem sido queimado ou recolhido na origem.

\subsection{Ações do Procentro}

O Procentro é um programa a ser desenvolvido a longo prazo. Abrange como área de intervenção os distritos da Sé e da República (Centro Histórico), e como área de impacto os distritos do Cambuci, Liberdade, Bela Vista, Consolação, Santa Cecília e Bom Retiro (FIG. 50).

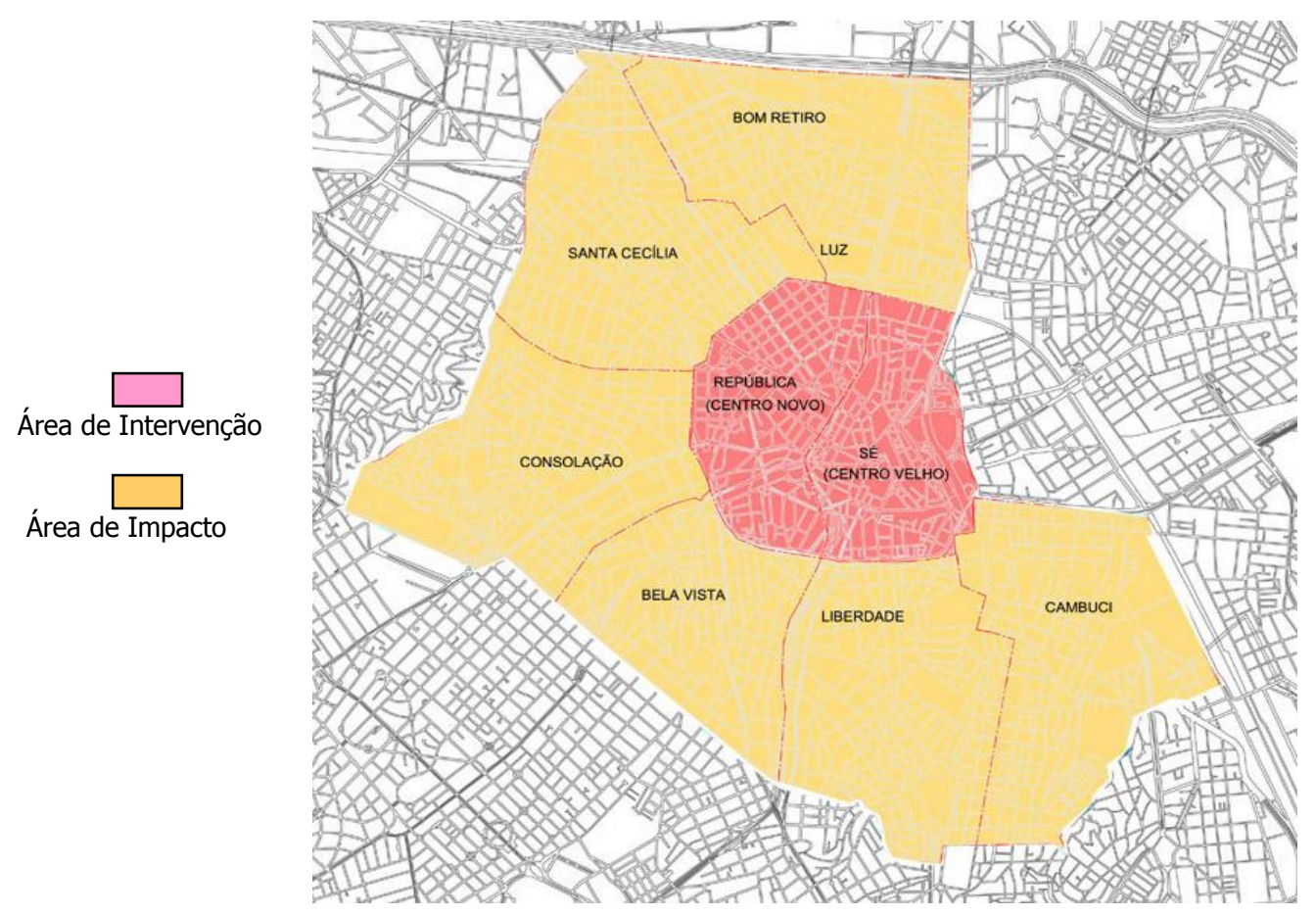

FIGURA 50: Área de intervenção e área de impacto do Procentro. Fonte: EMURB, 2007

Seu objetivo é promover o desenvolvimento social e econômico, com diversidade, da área central da cidade de São Paulo, dinamizar e criar condições de atração e suporte de atividades compatíveis com o centro metropolitano e promover 
a reabilitação urbanística e ambiental da área, com inclusão social (SÃO PAULO [Cidade] - EMURB, 2007).

O programa apresenta o problema da drenagem da cidade como decorrente da ocupação das várzeas, da impermeabilização do solo, do lançamento de esgoto e lixo nos rios e galerias de águas pluviais, limpeza de bueiros, manutenção e capacidade de galerias. Para a solução destes problemas propõe a revisão e compatibilização do sistema de drenagem do centro com o Plano de Macrodrenagem Municipal e Metropolitano e a criação de um programa de desimpermeabilização (BIDONE, 2003).

Para promover a reabilitação ambiental da região, o Procentro propõe melhoramentos para a qualidade do ar através do deslocamento de veículos para fora dos distritos da Sé e República; quanto às áreas verdes, prevê um plano de arborização de vias públicas (BIDONE, 2003).

Com relação aos resíduos provenientes das residências e comércio (lixo doméstico), ruas e praças (lixo de varrição ou público), das indústrias e serviços de saúde (resíduos especiais), as principais dificuldades referem-se à restrição para a circulação de veículos para a coleta, ao número de ambulantes, à falta da capacidade de gestão, ao pessoal e equipamento especializado, ao destino dos resíduos especiais e à implantação da coleta seletiva. Para a implantação da coleta seletiva propõe a mudança de hábito da população, por meio de campanhas de educação e ação do governo municipal, instalação de centros de triagem, ações sociais de várias secretarias, o fortalecimento institucional e a capacitação pessoal (BIDONE, 2003).

A zeladoria é considerada importante como instrumento de manutenção e conservação do espaço público após sua implantação (BIDONE, 2003).

\subsubsection{Ações de revitalização}

As ações de revitalização do Procentro têm por principal objetivo levar moradores para o centro, atrair público em busca de cultura/lazer/comércio, incentivar empresas não poluidoras a se instalar na região e aumentar a segurança. 
Para isto serão realizadas as seguintes ações de revitalização nos distritos da Sé e da República:

- reurbanização de praças e ruas comerciais (APÊNDICE D, FIG. 109 a 115);

- restauração dos edifícios históricos (APÊNDICE D, de FIG. 116 a 121);

- implantação de bases comunitárias da Guarda Civil Metropolitana (GCM) em pontos estratégicos;

- construção das sedes da Subprefeitura da Sé, da Empresa de Tecnologia da Informação (Prodam), GCM e da Escola Técnica Estadual Centro Paula Souza (APÊNDICE D, FIG. 106);

- construção de conjuntos residenciais e recuperação de edifícios degradados para uso residencial (APÊNDICE D, FIG. 107 e 108);

- transferência das Secretarias da Prefeitura de São Paulo para o centro;

- implantação do Projeto Nova Luz (APÊNDICE D, FIG. 105 e 106).

\subsubsection{Ações de drenagem}

As ações de drenagem do Procentro, que estão sendo realizadas no momento do desenvolvimento desta pesquisa, não apresentam como objetivos a preservação do meio ambiente ou a elevação da permeabilidade do solo. Têm como meta eliminar as enchentes do Vale do Anhangabaú, que trazem inúmeros transtornos para a população.

Serão realizadas as seguintes ações:

- implantação do projeto de microdrenagem da Vila Economizadora (PROCENTRO, 2010);

- ampliação da galeria do Córrego Moringuinho (APÊNDICE E, FIG. 128);

- construção dos piscinões da Praça 14 Bis e da Praça da Bandeira (APÊNDICE E, FIG. 127);

- recuperação das galerias dos Córregos Saracura e Bixiga sob a Avenida Nove de Julho (APÊNDICE E, FIG. 128) (HIDROSTUDIO ENGENHARIA, 2004). 


\subsubsection{Ações de controle da poluição do ar}

As ações de controle da poluição do ar do Procentro têm por objetivo desviar o tráfego de veículos automotores da região central, aumentar a área verde e o percentual de resíduos recicláveis.

Dentro do programa de aumento de áreas verdes está a implantação do Plano Diretor de Arborização de Vias Públicas dos Distritos Sé e República, que inclui, entre outras atividades, a arborização das ruas do centro (APÊNDICE F, FIG.129 e130) (SÃO PAULO [Cidade] - EMURB, 2009).

Para desviar o tráfego de veículos automotores da região central, o projeto prevê a implantação do Terminal de Compras e do Sistema Integrado de Monitoramento (SIM) da Rótula e da Contrarrótula (APÊNDICE F, FIG. 131).

Para elevação do percentual de resíduos recicláveis está prevista a implantação de três centrais de triagem e de três pontos de entrega voluntária de entulho de até $1 \mathrm{~m}^{3}$ na Subprefeitura da Sé. 


\section{CONCLUSÃO}

- $\quad$ crescimento intenso e rápido vivido no século XX na cidade de São Paulo ocorreu com falhas de planejamento e políticas públicas inadequadas, sem preocupação com a preservação de áreas verdes, gerando problemas ambientais, sociais e de qualidade de vida. De 1930 até 2010 foram construídos elevados edifícios, a cidade se transformou através da implantação do Plano de Avenidas e se expandiu para todas as direções. Como consequência, a temperatura mensal média na região elevou-se $2^{\circ} \mathrm{C}$, a umidade relativa média mensal, no período de inverno, caiu de 85 para $80 \%$ e os períodos de calor ficaram maiores.

- Na Subprefeitura da Sé, o período noturno apresenta temperaturas superiores à da periferia. As temperaturas apresentam-se mais amenas no sudoeste do distrito da Bela Vista, na Consolação e sudoeste de Santa Cecília devido à área verde do distrito da Consolação (único distrito da Subprefeitura da Sé com índice de área verde próximo ao recomendado pela OMS) e à proximidade dos Parques Trianon e Água Branca. Estas temperaturas se elevam em direção às regiões norte $\mathrm{e}$ leste devido à reduzida área verde nestes locais. A colina ocupada pelo Centro Histórico (distritos República e Sé) apresenta temperatura média inferior às dos distritos Pari, Belém, Brás, Mooca, Bom Retiro e Cambuci devido ao elevado adensamento vertical (o maior dos 96 distritos do Município), que ocasiona grandes períodos de sombreamento. As temperaturas na Subprefeitura da Sé elevam-se mais lentamente no período da manhã e caem mais lentamente no período da tarde, do que no Parque Fontes do Ipiranga.

- A tendência de queda das concentrações de poluentes atmosféricos na área central é consequência dos programas implantados pela Cetesb de redução de emissões de particulados (1979), controle da poluição por veículos automotores (1986) e do êxodo das indústrias da região (a partir de 1960). A tendência de elevação dos poluentes atmosféricos, observada de 2006 a 2008, pode ser atribuída à retomada do desenvolvimento econômico. Tal situação alerta para que os futuros projetos levem em consideração soluções que não contribuam para a 
elevação dos índices de poluição para valores superiores aos limites estabelecidos para o Padrão Primário.

- O programa Procentro atrai para a área central novos moradores e frequentadores para atividades de cultura e lazer, promovendo a reversão do processo de degradação e empobrecimento. As ações que reutilizam estruturas das edificações, por evitarem a construção de novos edifícios, atendem ao conceito de sustentabilidade e não contribuem para a elevação da temperatura ambiente. Entretanto, atraindo nova população frequentadora do centro, provocará impactos negativos e a elevação da temperatura ambiente:

a) pelo aumento da frota de veículos automotores que se dirigirá para o centro, elevando os teores de poluição para acima do limite do Padrão Primário;

b) pela elevação de área construída do Projeto Nova Luz, que aumenta a rugosidade, diminui a velocidade dos ventos dificultando a dispersão dos poluentes e pela utilização de materiais da construção civil que absorvem e refletem calor.

Todas as ações previstas para desviar o aumento do fluxo de veículos, decorrente da revitalização do centro, devem ser implantadas tendo como objetivo atingir concentrações de poluentes atmosféricos, na região central, abaixo dos limites estabelecidos para o Padrão Primário.

Para que o Projeto Nova Luz não contribua para a elevação da temperatura ambiente:

a) a elevação da densidade demográfica para 350 habitantes por hectare deverá ser acompanhada da construção de edifícios limitada a cinco pavimentos;

b) o Projeto Nova Luz, em conjunto com o Plano Diretor de Arborização de Vias Públicas dos distritos da Sé e da República e o Plano de Reurbanização de Praças, deverá promover a elevação da área verde dos distritos da Sé e da República para $12 \mathrm{~m} / \mathrm{hab}$., considerando-se a densidade demográfica de 420 hab./ha (máxima densidade demográfica para utilização da infraestrutura instalada sem prejuízo ambiental).

As ações utilizadas pelo Procentro, para eliminação dos problemas de drenagem da área central, não têm como objetivo a preservação do meio ambiente, 
preocupando-se exclusivamente com a eliminação das enchentes do Vale do Anhangabaú, que trazem inúmeros transtornos para a população.

- A destinação dos resíduos sólidos, no Município de São Paulo, apresenta problemas de gestão que agravam os fatores relativos a custo e disponibilidade de locais para aterros. Do total dos resíduos sólidos produzidos diariamente, $28 \%$ devem ser reciclados e estão sendo enviados para aterro. Isto implica perda do material, necessidade de produção de $5.714 \mathrm{t} /$ dia de novas embalagens e a elevação de $\mathrm{CO}_{2}$ (gás de efeito estufa) na atmosfera lançado pelas indústrias.

- Para que outros distritos do Município de São Paulo não sofram o esvaziamento, ocorrido na Subprefeitura da Sé na segunda metade do século XX, é necessário manter políticas de ocupação do solo com áreas verdes, que atendam a recomendação da OMS de $12 \mathrm{~m}^{2}$ de área verde por habitante, que incentivem o uso misto dos imóveis para fins residenciais e comerciais, finalmente estabelecer incentivos à instalação de empresas não poluidoras geradoras de postos de trabalho. 


\section{APÊNDICE A - Concentração de poluentes no ar}

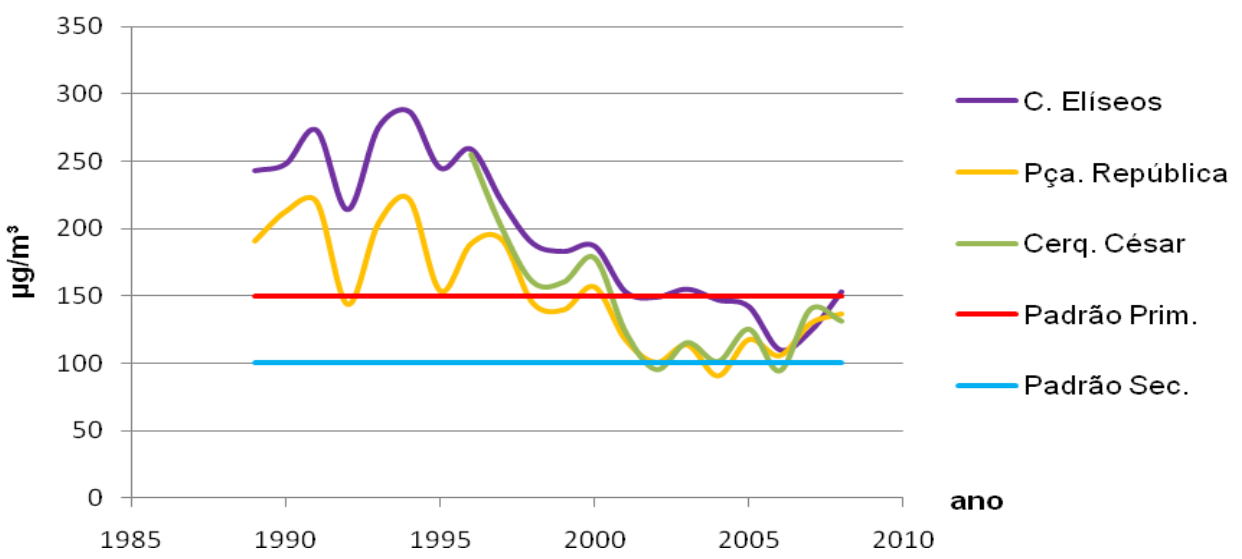

FIGURA 51. Concentrações máximas anuais dos teores de fumaça na Subprefeitura da Sé, de 1989 a 2008. Fonte: CETESB, 2009. Disponível em http://www.cetesb.sp.gov.br/Ar/publicacoes.asp.

TABELA 9. Concentrações máximas anuais dos teores de fumaça na Subprefeitura da Sé de 1989 a 2008. Fonte: CETESB, 2009. Disponível em http://www.cetesb.sp.gov.br/Ar/publicacoes.asp

\begin{tabular}{|c|c|c|c|}
\hline \multirow{3}{*}{$\frac{\text { Ano }}{1989}$} & \multicolumn{3}{|c|}{ Máx. teores anuais de fumaça por estação $\left(\mu \mathrm{g} / \mathrm{m}^{3}\right)-$ Padrão Prim. $150 \mu \mathrm{g} / \mathrm{m}^{3}$} \\
\hline & Campos Elíseos & Pça. da República & Cerqueira César \\
\hline & $243 \quad(10)$ & 191 (1) & ND \\
\hline 1990 & $248 \quad(9)$ & $213(2)$ & ND \\
\hline 1991 & $273(6)$ & $220(1)$ & ND \\
\hline 1992 & $214 \quad(6)$ & 144 & ND \\
\hline 1993 & $275 \quad(8)$ & $204 \quad(4)$ & ND \\
\hline 1994 & $287 \quad(10)$ & $222(2)$ & ND \\
\hline 1995 & $245 \quad(7)$ & 154 & ND \\
\hline 1996 & $259 \quad(6)$ & 189 & 255 \\
\hline 1997 & $220 \quad(4)$ & $192 \quad$ (3) & $200 \quad$ (2) \\
\hline 1998 & $189 \quad$ (2) & 145 & 160 \\
\hline 1999 & 183 & 140 & 160 \\
\hline 2000 & $187 \quad(1)$ & $157 \quad(1)$ & $178 \quad$ (2) \\
\hline 2001 & 153 & 118 & 123 \\
\hline 2002 & 149 & 101 & 95 \\
\hline 2003 & 155 & 114 & 115 \\
\hline 2004 & 147 & 91 & 101 \\
\hline 2005 & 142 & 118 & 125 \\
\hline 2006 & 110 & 106 & 94 \\
\hline 2007 & 124 & 130 & 140 \\
\hline 2008 & $153 \quad(1)$ & 137 & ND \\
\hline
\end{tabular}

(N) número de vezes no ano em que o Padrão Primário foi ultrapassado. (ND) não disponível. 


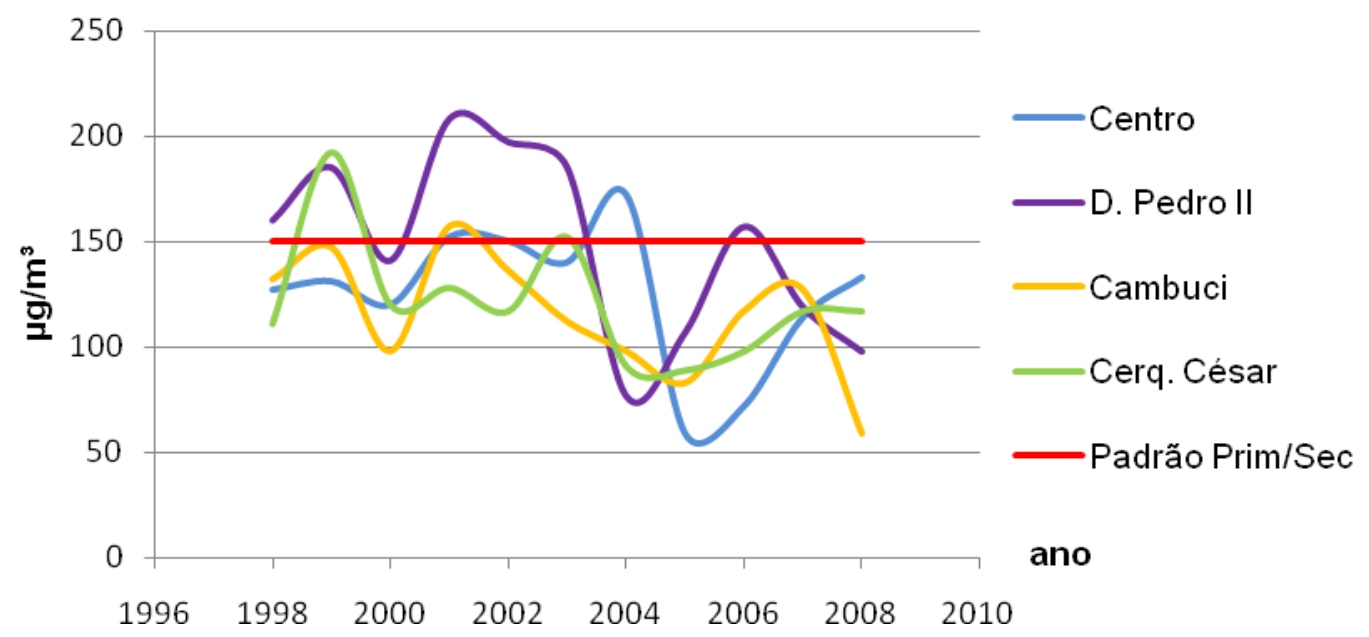

FIGURA 52. Concentrações máximas anuais de partículas inaláveis na Subprefeitura da Sé, de 1998 a 2008. Fonte: CETESB, 2009. Disponível em http://www.cetesb.sp.gov.br/Ar/publicacoes.asp

TABELA 10. Concentrações máximas anuais de partículas inaláveis na Subprefeitura da Sé de 1998 a 2008. Fonte: CETESB, 2009. Disponível em http://www.cetesb.sp.gov.br/Ar/publicacoes.asp

\begin{tabular}{|c|c|c|c|c|}
\hline \multirow{2}{*}{ Ano } & \multicolumn{4}{|c|}{ Máximas anuais de $\mathrm{MP}_{10}$ por estação $\left(\mu \mathrm{g} / \mathrm{m}^{3}\right)$ - Padrão Prim. $150 \mu \mathrm{g} / \mathrm{m}^{3}$} \\
\hline & Centro & Pq. D. Pedro II & Cambuci & Cerqueira César \\
\hline 1998 & 127 & 160 & $132^{*}$ & 111 \\
\hline 1999 & 131 & $185^{\star}$ & 147 & 192 \\
\hline 2000 & $120^{*}$ & 141 & $98^{*}$ & 120 \\
\hline 2001 & 152 & 208 & $157^{*}(1)$ & 128 \\
\hline 2002 & 150 & 197 & 136 & 117 \\
\hline 2003 & 140 & 185 & 112 & 152 \\
\hline 2004 & $172^{*}$ & $77^{*}$ & 98 & $91^{*}$ \\
\hline 2005 & $59^{*}$ & $107^{*}$ & 83 & 89 \\
\hline 2006 & $72^{*}$ & 157 & 117 & 98 \\
\hline 2007 & 114 & 119 & 127 & 117 \\
\hline 2008 & 133 & $98^{*}$ & $59^{*}$ & 117 \\
\hline
\end{tabular}

* Resultados que não atenderam aos critérios de representatividade. (N) número de vezes em que o Padrão Primário foi ultrapassado. 


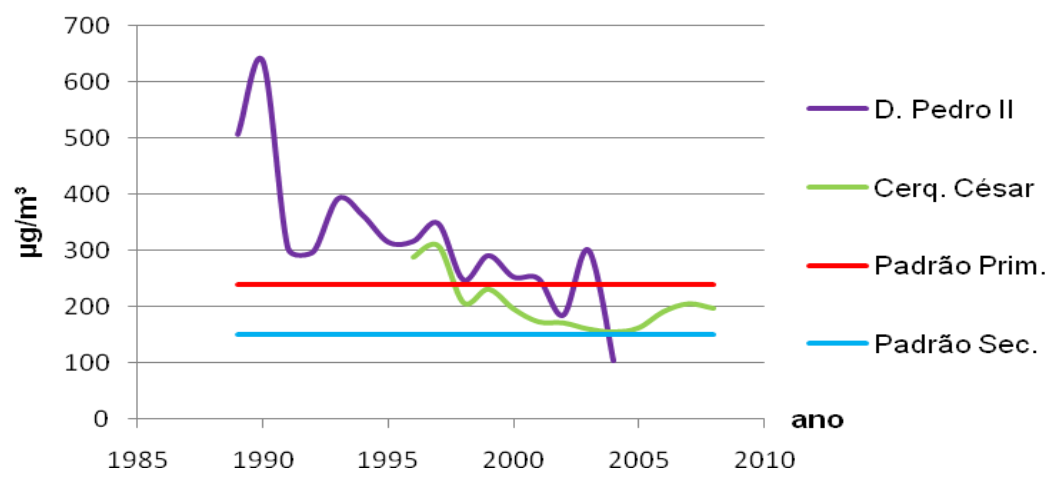

FIGURA 53. Concentrações máximas anuais de partículas totais em suspensão na Subprefeitura da Sé de 1989 a 2008. Fonte: CETESB, 2009. Disponível em:

http://www.cetesb.sp.gov.br/Ar/publicacoes.asp

TABELA 11. Concentrações máximas anuais de partículas totais em suspensão na Subprefeitura da Sé de 1989 a 2008. Fonte: CETESB, 2009. Disponível em:

http://www.cetesb.sp.gov.br/Ar/publicacoes.asp

Ano $\quad$ PTS máximas anuais por estação $\left(\mu \mathrm{g} / \mathrm{m}^{3}\right)$ - Padrão Prim. $240 \mu \mathrm{g} / \mathrm{m}^{3}$

Pq. D. Pedro II

Cerqueira César

\begin{tabular}{lccccc}
\hline 1989 & 507 & $(15)$ & $(5)^{* *}$ & ND \\
1990 & 637 & $(19)$ & $(6)^{* *}$ & $(1)^{* * *}$ & ND \\
1991 & 305 & $(3)$ & & ND \\
1992 & 298 & $(5)$ & & ND \\
1993 & 393 & $(4)$ & $(1)^{* *}$ & ND \\
1994 & 363 & $(5)$ & & ND \\
1995 & 316 & $(5)$ & ND & \\
1996 & 317 & $(4)$ & $289^{*}$ & $(2)$ \\
1997 & 349 & $(4)$ & 309 & $(2)$ \\
1998 & 249 & $(1)$ & 208 \\
1999 & 292 & $(2)$ & 232 \\
2000 & 254 & $(2)$ & 197 \\
2001 & 251 & & 174 \\
2002 & 186 & & 172 \\
2003 & 302 & $(1)$ & 161 \\
2004 & $105^{*}$ & & 156 \\
2005 & $N D$ & 163 \\
2006 & $N D$ & 192 \\
2007 & $N D$ & 206 \\
2008 & $N D$ & 198 \\
\hline
\end{tabular}

* Resultados que não atendem critérios de representatividade. (N) número de vezes em que o Padrão Primário, (N) ${ }^{\star \star}$ Nível de Atenção e $(\mathrm{N})^{\star \star \star}$ Nível de Alerta foram ultrapassados. (ND) não disponível. 


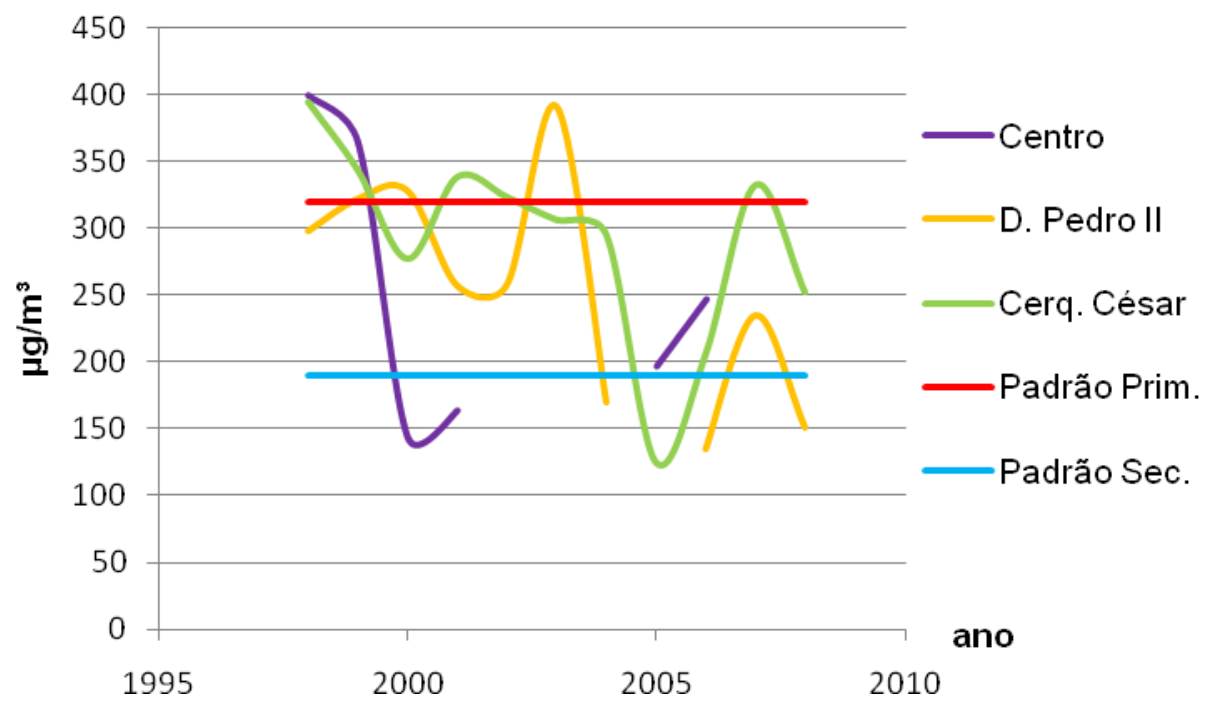

FIGURA 54. Concentrações máximas anuais de dióxido de nitrogênio na Subprefeitura da Sé de 1998 a 2008. Fonte: CETESB, 2009. Disponível em http://www.cetesb.sp.gov.br/Ar/publicacoes.asp

TABELA 12. Concentrações máximas anuais de dióxido de nitrogênio na Subprefeitura da Sé de 1998 a 2008. Fonte: CETESB, 2009. Disponível em http://www.cetesb.sp.gov.br/Ar/publicacoes.asp

\begin{tabular}{|c|c|c|c|c|}
\hline \multirow{3}{*}{$\begin{array}{l}\text { Ano } \\
1998\end{array}$} & \multicolumn{4}{|c|}{ Máximas anuais de $\mathrm{NO}_{2}$ por estação $\left(\mu \mathrm{g} / \mathrm{m}^{3}\right)$ - Padrão Prim. $320 \mu \mathrm{g} / \mathrm{m}$} \\
\hline & Centro & Pq. D. Pedro II & \multicolumn{2}{|c|}{ Cerqueira César } \\
\hline & $399 \quad(1)$ & 298 & 394 & (1) \\
\hline 1999 & 364 & 322 & $343^{*}$ & (1) \\
\hline 2000 & $144^{*}$ & $328 \quad(1)$ & $277^{*}$ & \\
\hline 2001 & $164^{*}$ & 257 & 338 & (1) \\
\hline 2002 & ND & 258 & 323 & $(1)$ \\
\hline 2003 & ND & 391 & $306^{*}$ & \\
\hline 2004 & ND & $170^{*}$ & $295^{\star}$ & \\
\hline 2005 & $197^{*}$ & ND & $125^{*}$ & \\
\hline 2006 & $247^{*}$ & $135^{*}$ & 206 & \\
\hline 2007 & ND & 235 & 332 & (1) \\
\hline 2008 & ND & 151 & 252 & \\
\hline
\end{tabular}

* Resultados que não atenderam aos critérios de representatividade. (N) número de vezes no ano em que o Padrão Primário/ Secundário foi ultrapassado. (ND) não disponível. 


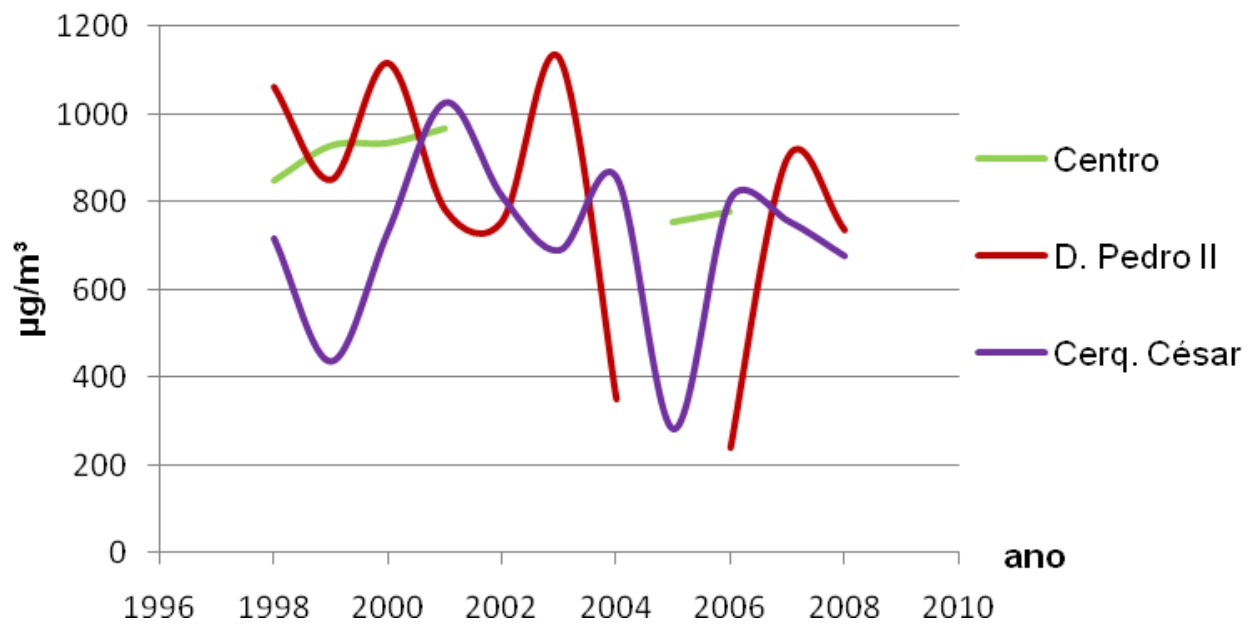

FIGURA 55. Concentrações máximas anuais de monóxido de nitrogênio na Subprefeitura da Sé de 1998 a 2008. Fonte: CETESB, 2009. Disponível em http://www.cetesb.sp.gov.br/Ar/publicacoes.asp

TABELA 13. Concentrações máximas anuais de monóxido de nitrogênio na Subprefeitura da Sé de 1998 a 2008. Fonte: CETESB, 2009. Disponível em http://www.cetesb.sp.gov.br/Ar/publicacoes.asp

\begin{tabular}{cccc}
\hline \multirow{2}{*}{ Ano } & \multicolumn{2}{c}{ Máximas anuais de NO por estação $\left(\mu \mathrm{g} / \mathrm{m}^{3}\right)-$ Padrão Prim. não determinado } \\
\cline { 2 - 4 } & Centro & Pq. D. Pedro II & Cerqueira César \\
\hline 1998 & 848 & 1063 & 717 \\
1999 & 928 & 851 & $436^{*}$ \\
2000 & $934^{*}$ & 1117 & $734^{*}$ \\
2001 & $967^{*}$ & 782 & 1028 \\
2002 & ND & 757 & 813 \\
2003 & ND & 1129 & $690^{*}$ \\
2004 & ND & $350^{*}$ & $857^{\star}$ \\
2005 & $753^{*}$ & ND & $281^{*}$ \\
2006 & 777 & $239^{*}$ & 808 \\
2007 & ND & 901 & 758 \\
2008 & ND & 736 & 677 \\
\hline
\end{tabular}

* Resultados que não atenderam aos critérios de representatividade. (ND) não disponível. 


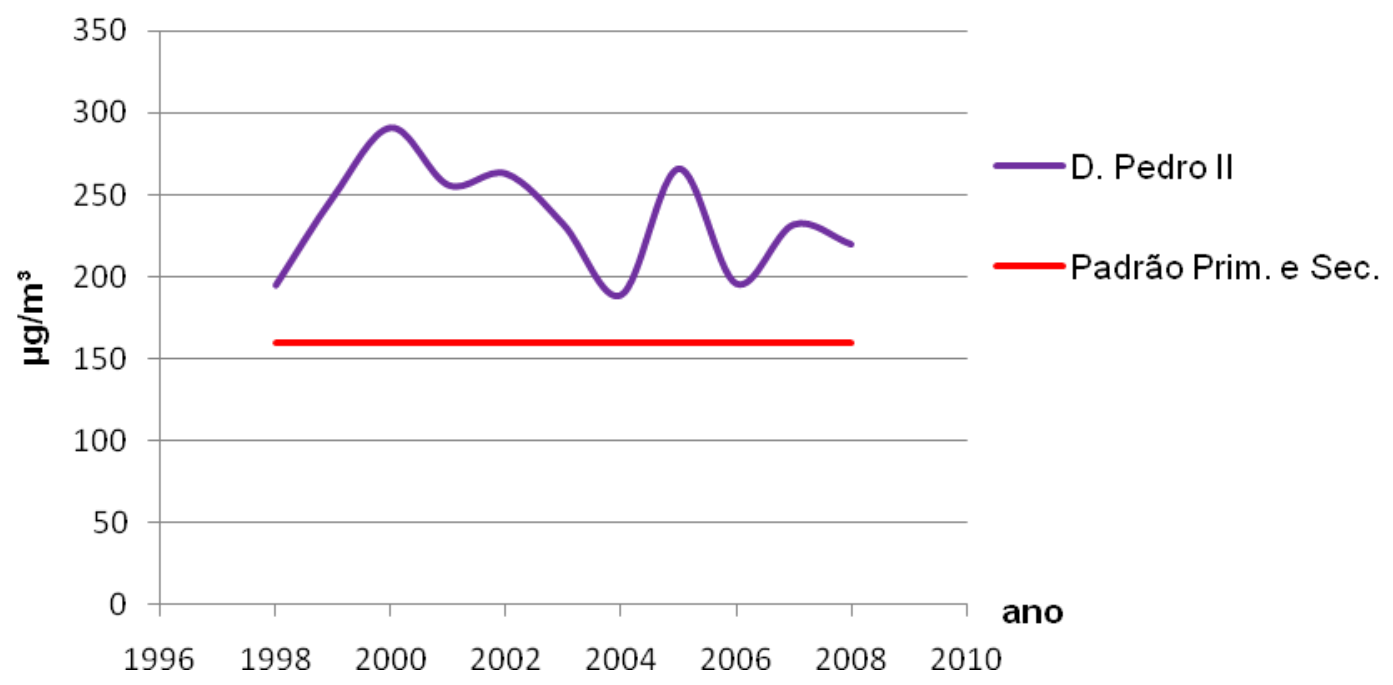

FIGURA 56. Concentrações máximas anuais de ozônio na Subprefeitura da Sé de 1998 a 2008. Fonte: CETESB, 2009. Disponível em http://www.cetesb.sp.gov.br/Ar/publicacoes.asp

TABELA 14. Concentrações máximas anuais de ozônio na Subprefeitura da Sé de 1998 a 2008. Fonte: CETESB, 2009. Disponível em http://www.cetesb.sp.gov.br/Ar/publicacoes.asp

\begin{tabular}{|c|c|c|c|}
\hline \multirow{2}{*}{$\frac{\text { Ano }}{1998}$} & \multicolumn{3}{|c|}{$\begin{array}{c}\text { Máx. anuais de } \mathrm{O}_{3} \text { por estação }\left(\mu \mathrm{g} / \mathrm{m}^{3}\right) \text {. Padrão Prim. } 160 \mu \mathrm{g} / \mathrm{m}^{3}(1 \mathrm{hora}) \\
\text { Pq. D. Pedro II }\end{array}$} \\
\hline & 195 & (9) & \\
\hline 1999 & 249 & (19) & $(6)^{\star *}$ \\
\hline 2000 & 291 & (19) & $(7)^{\star \star}$ \\
\hline 2001 & 256 & (16) & $(3)^{\star *}$ \\
\hline 2002 & 263 & (17) & $(5)^{\star \star}$ \\
\hline 2003 & 232 & (8) & $(2)^{\star *}$ \\
\hline 2004 & $189^{*}$ & (3) & \\
\hline 2005 & $266^{*}$ & (8) & $(2)^{* *}$ \\
\hline 2006 & 196 & (12) & \\
\hline 2007 & 232 & (6) & $(3)^{\star *}$ \\
\hline 2008 & $220^{*}$ & (5) & $(2)^{\star *}$ \\
\hline
\end{tabular}

* Resultados que não atenderam aos critérios de representatividade. (N) número de vezes em que o Padrão Primário/Secundário e $(\mathrm{N})^{* *}$ Nível de Atenção foram ultrapassados. 


\section{APÊNDICE B - Gráficos e tabelas de temperatura}
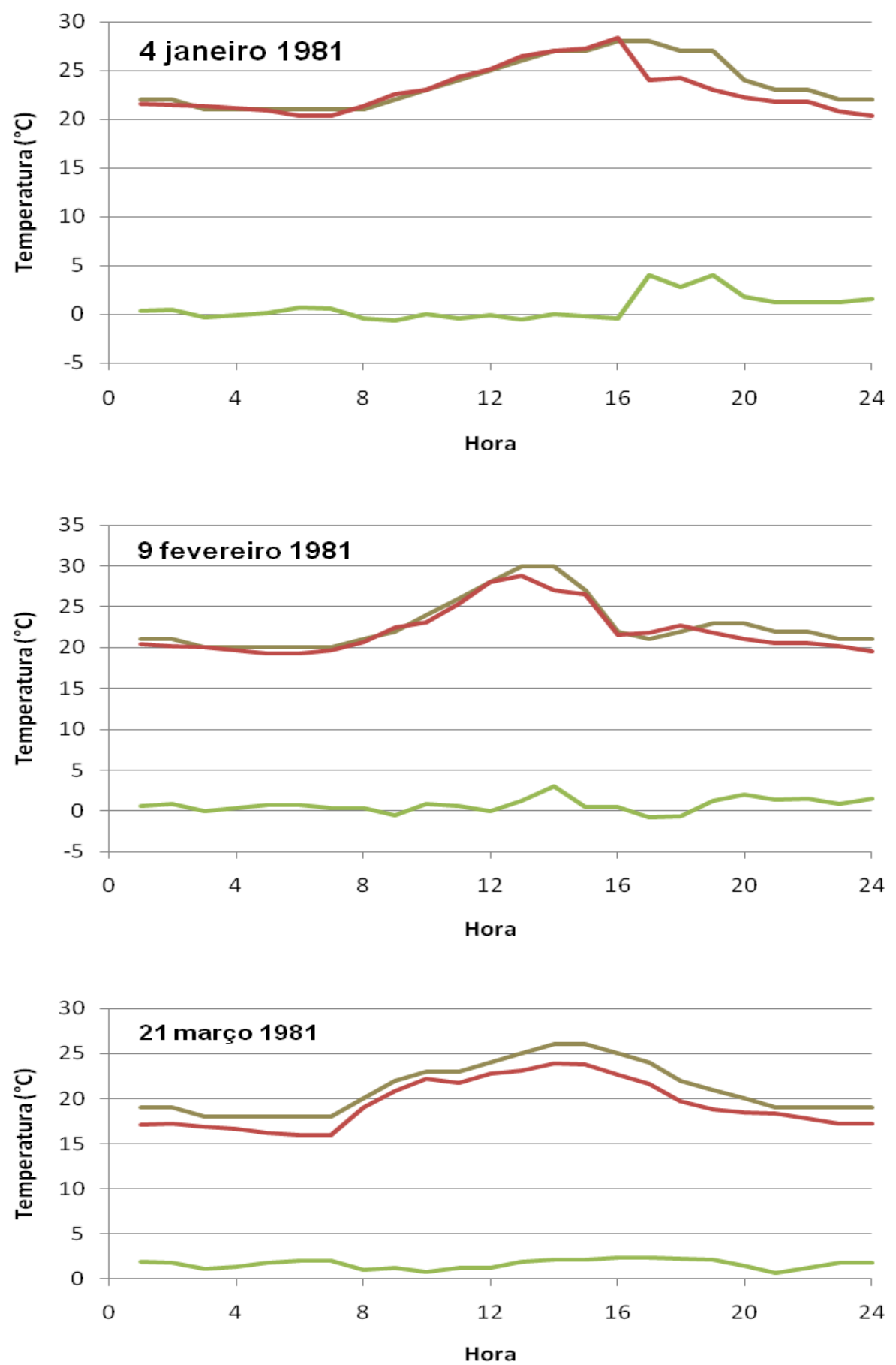

Est. Centro $\longrightarrow$ Pq. Estado Intensidade

FIGURA 57. Gráficos horários das temperaturas e da intensidade da ilha de Calor, nos dias 4 de janeiro, 9 de fevereiro e 21 de março de 1981, na Estação de Monitoramento Centro, Estação Meteorológica do Parque Estadual Fontes do Ipiranga. Fonte: CETESB, 1999 e IAG, 1981. 
TABELA 15. Registros horários das temperaturas e da intensidade da ilha de Calor $\left({ }^{\circ} \mathrm{C}\right)$ nos dias 4 de janeiro, 9 de fevereiro e 21 de março de 1981, na Estação de Monitoramento Centro, Estação Meteorológica do Parque Estadual Fontes do Ipiranga. Fonte: CETESB, 1999 e IAG,1981.

\begin{tabular}{|c|c|c|c|c|c|c|c|c|c|}
\hline Mês & \multicolumn{3}{|c|}{4 Janeiro 1981} & \multicolumn{3}{|c|}{9 Fevereiro 1981} & \multicolumn{3}{|c|}{21 Março 1981} \\
\hline Hora & EC & PE & Int. & EC & $\mathrm{PE}$ & Int. & EC & $\mathrm{PE}$ & Int. \\
\hline 1 & 22 & 21,6 & 0,4 & 21 & 20,4 & 0,6 & 19 & 17,1 & 1,9 \\
\hline 2 & 22 & 21,5 & 0,5 & 21 & 20,2 & 0,8 & 19 & 17,2 & 1,8 \\
\hline 3 & 21 & 21,3 & $-0,3$ & 20 & 20,0 & 0,0 & 18 & 16,9 & 1,1 \\
\hline 4 & 21 & 21,1 & $-0,1$ & 20 & 19,6 & 0,4 & 18 & 16,6 & 1,4 \\
\hline 5 & 21 & 20,9 & 0,1 & 20 & 19,3 & 0,7 & 18 & 16,2 & 1,8 \\
\hline 6 & 21 & 20,3 & 0,7 & 20 & 19,3 & 0,7 & 18 & 16,0 & 2,0 \\
\hline 7 & 21 & 20,4 & 0,6 & 20 & 19,6 & 0,4 & 18 & 16,0 & 2,0 \\
\hline 8 & 21 & 21,4 & $-0,4$ & 21 & 20,7 & 0,3 & 20 & 19,0 & 1,0 \\
\hline 9 & 22 & 22,6 & $-0,6$ & 22 & 22,5 & $-0,5$ & 22 & 20,8 & 1,2 \\
\hline 10 & 23 & 23,0 & 0,0 & 24 & 23,1 & 0,9 & 23 & 22,2 & 0,8 \\
\hline 11 & 24 & 24,4 & $-0,4$ & 26 & 25,4 & 0,6 & 23 & 21,8 & 1,2 \\
\hline 12 & 25 & 25,1 & $-0,1$ & 28 & 28,0 & 0,0 & 24 & 22,8 & 1,2 \\
\hline 13 & 26 & 26,5 & $-0,5$ & 30 & 28,8 & 1,2 & 25 & 23,1 & 1,9 \\
\hline 14 & 27 & 27,0 & 0,0 & 30 & 27,0 & 3,0 & 26 & 23,9 & 2,1 \\
\hline 15 & 27 & 27,2 & $-0,2$ & 27 & 26,5 & 0,5 & 26 & 23,8 & 2,2 \\
\hline 16 & 28 & 28,4 & $-0,4$ & 22 & 21,5 & 0,5 & 25 & 22,6 & 2,4 \\
\hline 17 & 28 & 24,0 & 4,0 & 21 & 21,8 & $-0,8$ & 24 & 21,6 & 2,4 \\
\hline 18 & 27 & 24,2 & 2,8 & 22 & 22,7 & $-0,7$ & 22 & 19,7 & 2,3 \\
\hline 19 & 27 & 23,0 & 4,0 & 23 & 21,8 & 1,2 & 21 & 18,8 & 2,2 \\
\hline 20 & 24 & 22,2 & 1,8 & 23 & 21,0 & 2,0 & 20 & 18,5 & 1,5 \\
\hline 21 & 23 & 21,8 & 1,2 & 22 & 20,6 & 1,4 & 19 & 18,3 & 0,7 \\
\hline 22 & 23 & 21,8 & 1,2 & 22 & 20,5 & 1,5 & 19 & 17,8 & 1,2 \\
\hline 23 & 22 & 20,8 & 1,2 & 21 & 20,1 & 0,9 & 19 & 17,2 & 1,8 \\
\hline 24 & 22 & 20,4 & 1,6 & 21 & 19,5 & 1,5 & 19 & 17,2 & 1,8 \\
\hline
\end{tabular}



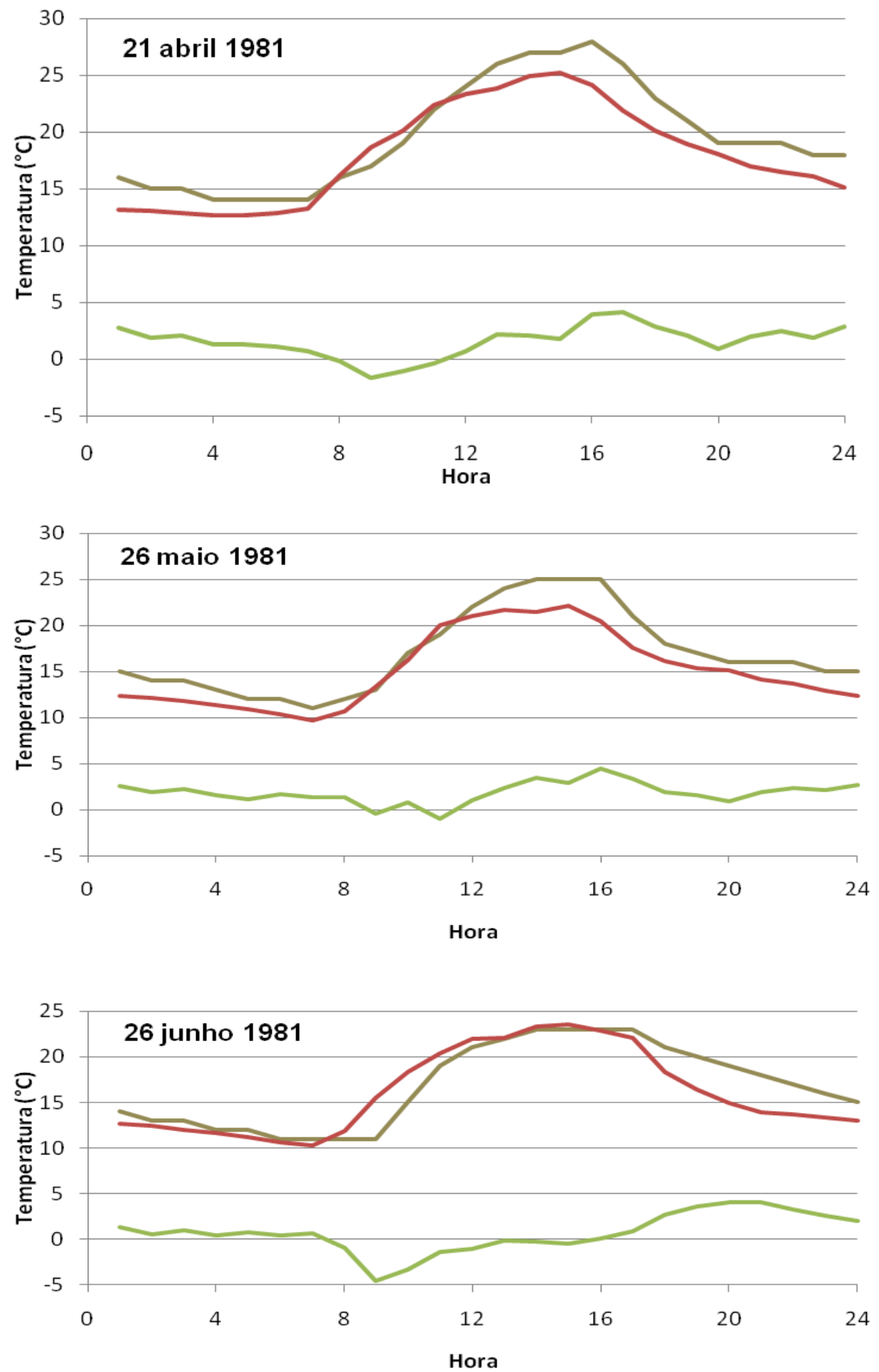

Est. Centro —Pq. Estado Intensidade

FIGURA 58. Gráficos horários das temperaturas e da intensidade da ilha de Calor, nos dias 21 de abril, 26 de maio e 26 de junho de 1981, na Estação de Monitoramento Centro, Estação Meteorológica do Parque Estadual Fontes do Ipiranga . Fonte: CETESB, 1999 e IAG, 1981. 
TABELA 16. Registros horários das temperaturas e da intensidade da ilha de Calor $\left({ }^{\circ} \mathrm{C}\right)$ nos dias 21 de abril, 26 de maio e 26 de junho de 1981, na Estação de Monitoramento Centro, Estação Meteorológica do Parque Estadual Fontes do Ipiranga. Fonte: CETESB, 1999 e IAG, 1981.

\begin{tabular}{|c|c|c|c|c|c|c|c|c|c|}
\hline Mês & \multicolumn{3}{|c|}{21 abril 1981} & \multicolumn{3}{|c|}{26 maio 1981} & \multicolumn{3}{|c|}{26 junho 1981} \\
\hline Hora & $E C$ & $\mathrm{PE}$ & Int. & EC & $\mathrm{PE}$ & Int. & $\mathrm{EC}$ & $\mathrm{PE}$ & Int. \\
\hline 1 & 16 & 13,2 & 2,8 & 15 & 12,4 & 2,6 & 14 & 12,7 & 1,3 \\
\hline 2 & 15 & 13,1 & 1,9 & 14 & 12,1 & 1,9 & 13 & 12,4 & 0,6 \\
\hline 3 & 15 & 12,9 & 2,1 & 14 & 11,8 & 2,2 & 13 & 12,0 & 1,0 \\
\hline 4 & 14 & 12,7 & 1,3 & 13 & 11,4 & 1,6 & 12 & 11,6 & 0,4 \\
\hline 5 & 14 & 12,7 & 1,3 & 12 & 10,9 & 1,1 & 12 & 11,2 & 0,8 \\
\hline 6 & 14 & 12,9 & 1,1 & 12 & 10,3 & 1,7 & 11 & 10,6 & 0,4 \\
\hline 7 & 14 & 13,3 & 0,7 & 11 & 9,7 & 1,3 & 11 & 10,3 & 0,7 \\
\hline 8 & 16 & 16,2 & $-0,2$ & 12 & 10,7 & 1,3 & 11 & 11,9 & $-0,9$ \\
\hline 9 & 17 & 18,6 & $-1,6$ & 13 & 13,4 & $-0,4$ & 11 & 15,5 & $-4,5$ \\
\hline 10 & 19 & 20,1 & $-1,1$ & 17,0 & 16,2 & 0,8 & 15 & 18,3 & $-3,3$ \\
\hline 11 & 22 & 22,4 & $-0,4$ & 19,0 & 20,0 & $-1,0$ & 19 & 20,4 & $-1,4$ \\
\hline 12 & 24 & 23,3 & 0,7 & 22,0 & 21,0 & 1,0 & 21 & 22,0 & $-1,0$ \\
\hline 13 & 26 & 23,8 & 2,2 & 24,0 & 21,7 & 2,3 & 22 & 22,1 & $-0,1$ \\
\hline 14 & 27 & 24,9 & 2,1 & 25,0 & 21,5 & 3,5 & 23 & 23,3 & $-0,3$ \\
\hline 15 & 27 & 25,2 & 1,8 & 25,0 & 22,1 & 2,9 & 23 & 23,5 & $-0,5$ \\
\hline 16 & 28 & 24,1 & 3,9 & 25,0 & 20,5 & 4,5 & 23 & 22,9 & 0,1 \\
\hline 17 & 26 & 21,9 & 4,1 & 21,0 & 17,6 & 3,4 & 23 & 22,1 & 0,9 \\
\hline 18 & 23 & 20,1 & 2,9 & 18,0 & 16,1 & 1,9 & 21 & 18,3 & 2,7 \\
\hline 19 & 21 & 18,9 & 2,1 & 17,0 & 15,4 & 1,6 & 20 & 16,4 & 3,6 \\
\hline 20 & 19 & 18,1 & 0,9 & 16,0 & 15,1 & 0,9 & 19 & 14,9 & 4,1 \\
\hline 21 & 19 & 17,0 & 2,0 & 16,0 & 14,1 & 1,9 & 18 & 13,9 & 4,1 \\
\hline 22 & 19 & 16,5 & 2,5 & 16,0 & 13,7 & 2,3 & 17 & 13,7 & 3,3 \\
\hline 23 & 18 & 16,1 & 1,9 & 15,0 & 12,9 & 2,1 & 16 & 13,4 & 2,6 \\
\hline 24 & 18 & 15,1 & 2,9 & 15,0 & 12,3 & 2,7 & 15 & 13,0 & 2,0 \\
\hline
\end{tabular}



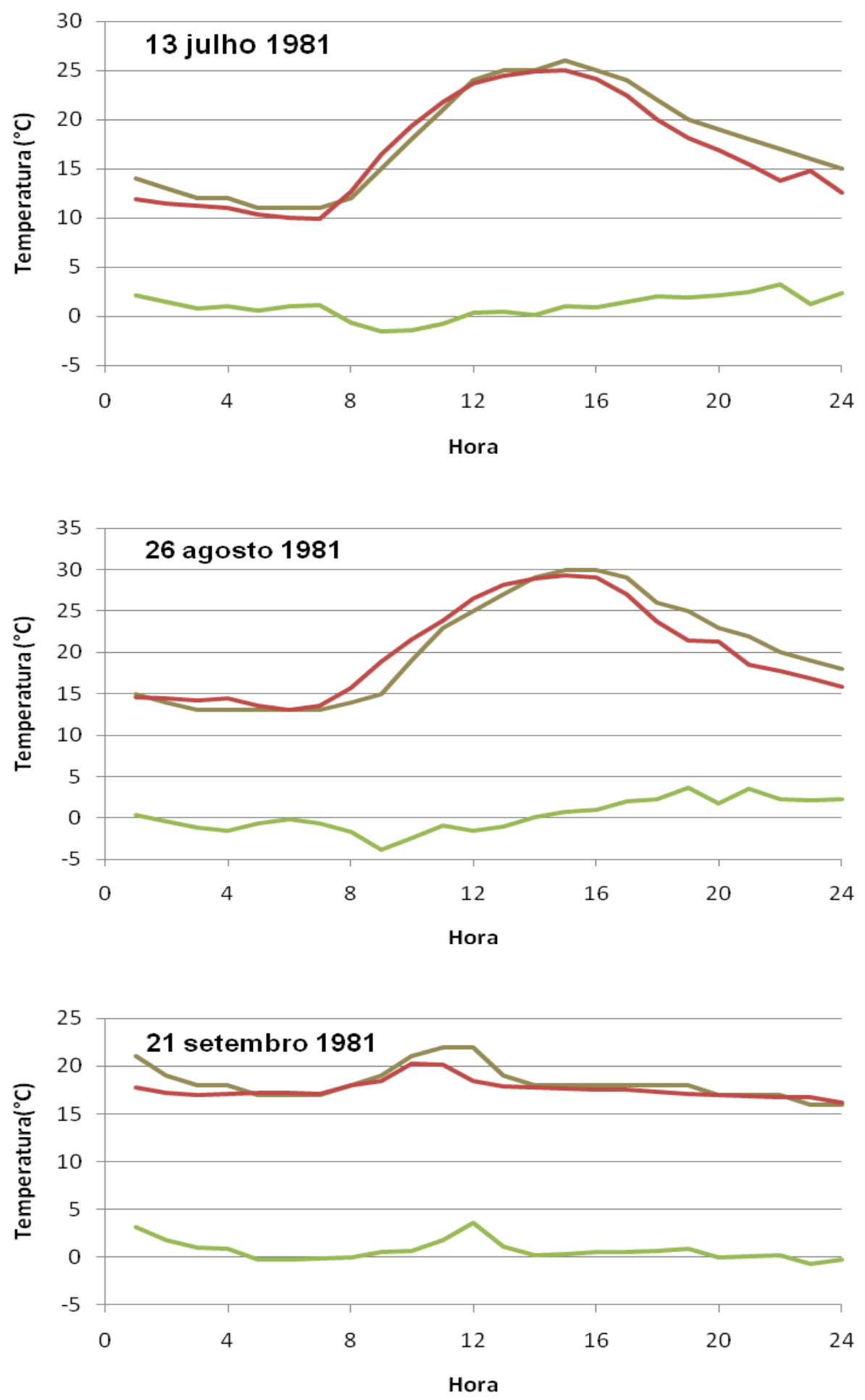

Est. Centro —Pq. Estado Intensidade

FIGURA 59. Gráficos horários das temperaturas e da intensidade da ilha de Calor, nos dias 13 de julho, 26 de agosto e 21 de setembro de 1981, na Estação de Monitoramento Centro, Estação Meteorológica do Parque Estadual Fontes do Ipiranga. Fonte: CETESB, 1999 e IAG, 1981. 
TABELA 17. Registros horários das temperaturas e da intensidade da ilha de Calor $\left({ }^{\circ} \mathrm{C}\right)$ nos dias 13 de julho, 26 de agosto e 21 de setembro de 1981, na Estação de Monitoramento Centro, Estação Meteorológica do Parque Estadual Fontes do Ipiranga. Fonte: CETESB, 1999 e IAG, 1981.

\begin{tabular}{|c|c|c|c|c|c|c|c|c|c|}
\hline Mês & \multicolumn{3}{|c|}{13 julho 1981} & \multicolumn{3}{|c|}{26 agosto 1981} & \multicolumn{3}{|c|}{21 setembro 1981} \\
\hline Hora & EC & $\mathrm{PE}$ & Int. & EC & $\mathrm{PE}$ & Int. & EC & $\mathrm{PE}$ & Int. \\
\hline 1 & 14 & 11,9 & 2,1 & 15 & 14,6 & 0,4 & 21 & 17,8 & 3,2 \\
\hline 2 & 13 & 11,5 & 1,5 & 14 & 14,4 & $-0,4$ & 19 & 17,2 & 1,8 \\
\hline 3 & 12 & 11,2 & 0,8 & 13 & 14,2 & $-1,2$ & 18 & 17,0 & 1,0 \\
\hline 4 & 12 & 11,0 & 1,0 & 13 & 14,5 & $-1,5$ & 18 & 17,1 & 0,9 \\
\hline 5 & 11 & 10,4 & 0,6 & 13 & 13,6 & $-0,6$ & 17 & 17,2 & $-0,2$ \\
\hline 6 & 11 & 10,0 & 1,0 & 13 & 13,1 & $-0,1$ & 17 & 17,2 & $-0,2$ \\
\hline 7 & 11 & 9,9 & 1,1 & 13 & 13,6 & $-0,6$ & 17 & 17,1 & $-0,1$ \\
\hline 8 & 12 & 12,7 & $-0,7$ & 14 & 15,7 & $-1,7$ & 18 & 18,0 & 0,0 \\
\hline 9 & 15 & 16,5 & $-1,5$ & 15 & 18,9 & $-3,9$ & 19 & 18,5 & 0,5 \\
\hline 10 & 18 & 19,4 & $-1,4$ & 19 & 21,5 & $-2,5$ & 21 & 20,3 & 0,7 \\
\hline 11 & 21 & 21,8 & $-0,8$ & 23 & 23,9 & $-0,9$ & 22 & 20,2 & 1,8 \\
\hline 12 & 24 & 23,7 & 0,3 & 25 & 26,5 & $-1,5$ & 22 & 18,4 & 3,6 \\
\hline 13 & 25 & 24,5 & 0,5 & 27 & 28,1 & $-1,1$ & 19 & 17,9 & 1,1 \\
\hline 14 & 25 & 24,9 & 0,1 & 29 & 28,9 & 0,1 & 18 & 17,8 & 0,2 \\
\hline 15 & 26 & 25,0 & 1,0 & 30 & 29,3 & 0,7 & 18 & 17,7 & 0,3 \\
\hline 16 & 25 & 24,1 & 0,9 & 30 & 29,0 & 1,0 & 18 & 17,5 & 0,5 \\
\hline 17 & 24 & 22,5 & 1,5 & 29 & 27,0 & 2,0 & 18 & 17,5 & 0,5 \\
\hline 18 & 22 & 20,0 & 2,0 & 26 & 23,7 & 2,3 & 18 & 17,3 & 0,7 \\
\hline 19 & 20 & 18,1 & 1,9 & 25 & 21,4 & 3,6 & 18 & 17,1 & 0,9 \\
\hline 20 & 19 & 16,9 & 2,1 & 23 & 21,3 & 1,7 & 17 & 17,0 & 0,0 \\
\hline 21 & 18 & 15,5 & 2,5 & 22 & 18,5 & 3,5 & 17 & 16,9 & 0,1 \\
\hline 22 & 17 & 13,8 & 3,2 & 20 & 17,7 & 2,3 & 17 & 16,8 & 0,2 \\
\hline 23 & 16 & 14,8 & 1,2 & 19 & 16,9 & 2,1 & 16 & 16,7 & $-0,7$ \\
\hline 24 & 15 & 12,6 & 2,4 & 18 & 15,8 & 2,2 & 16 & 16,2 & $-0,2$ \\
\hline
\end{tabular}



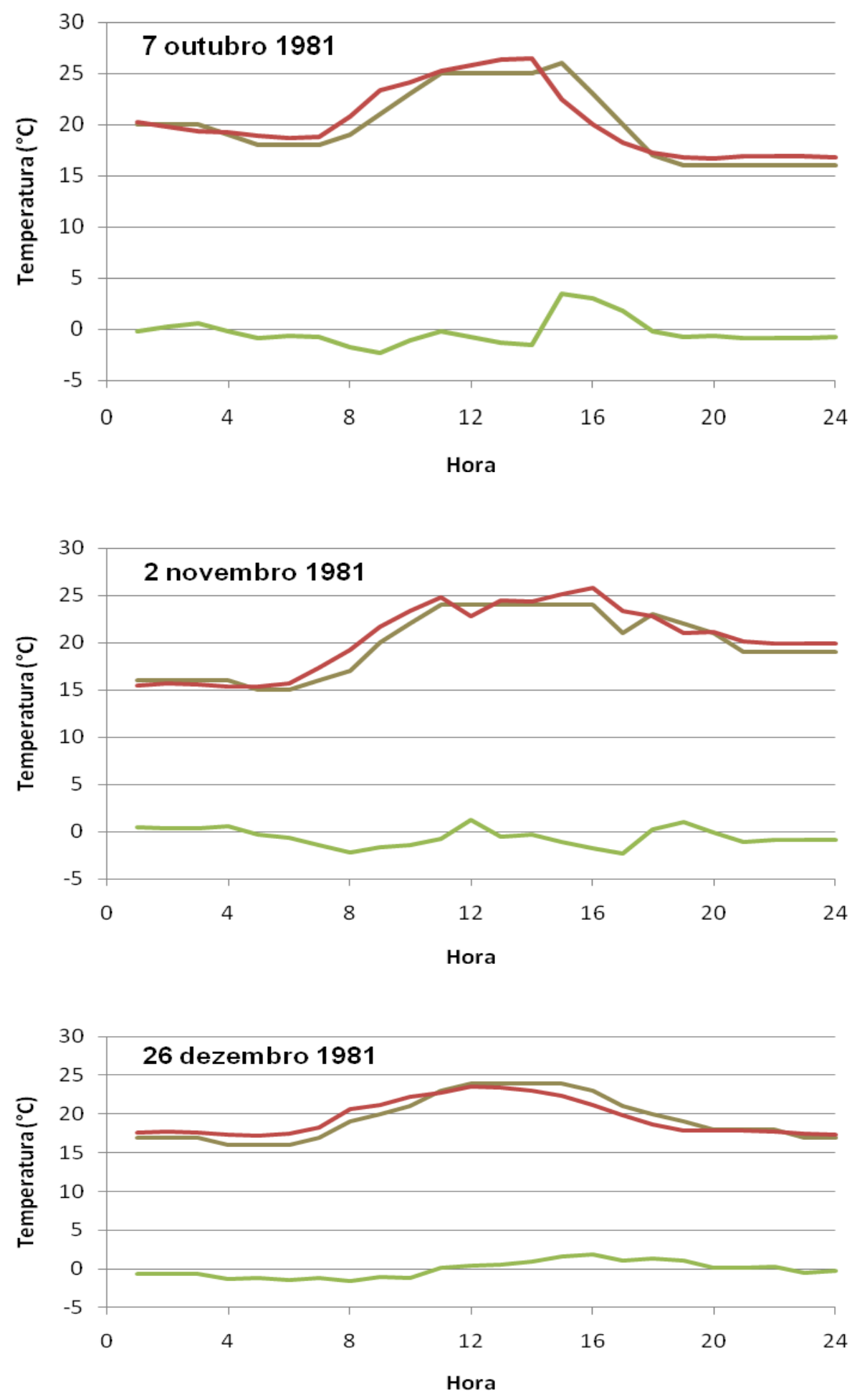

- Est. Centro $\longrightarrow$ Pq. Estado Intensidade

FIGURA 60. Gráficos horários das temperaturas e da intensidade da ilha de Calor, nos dias 7 outubro, 2 de novembro e 26 de dezembro de 1981, na Estação de Monitoramento Centro, Estação Meteorológica do Parque Estadual Fontes do Ipiranga. Fonte: CETESB, 1999 e IAG, 1981. 
TABELA 18. Registros horários das temperaturas e da intensidade da ilha de Calor $\left({ }^{\circ} \mathrm{C}\right)$ nos dias 7 de outubro, 2 de novembro e 26 de dezembro de 1981, na Estação de Monitoramento Centro, Estação Meteorológica do Parque Estadual Fontes do Ipiranga. Fonte: CETESB, 1999 e IAG, 1981.

\begin{tabular}{|c|c|c|c|c|c|c|c|c|c|}
\hline Mês & \multicolumn{3}{|c|}{7 outubro 1981} & \multicolumn{3}{|c|}{2 novembro 1981} & \multicolumn{3}{|c|}{26 dezembro 1981} \\
\hline Hora & EC & $\mathrm{PE}$ & Int. & EC & $\mathrm{PE}$ & Int. & EC & $\mathrm{PE}$ & Int. \\
\hline 1 & 20 & 20,2 & $-0,2$ & 16 & 15,5 & 0,5 & 17 & 17,6 & $-0,6$ \\
\hline 2 & 20 & 19,8 & 0,2 & 16 & 15,7 & 0,3 & 17 & 17,7 & $-0,7$ \\
\hline 3 & 20 & 19,4 & 0,6 & 16 & 15,6 & 0,4 & 17 & 17,6 & $-0,6$ \\
\hline 4 & 19 & 19,2 & $-0,2$ & 16 & 15,4 & 0,6 & 16 & 17,3 & $-1,3$ \\
\hline 5 & 18 & 18,9 & $-0,9$ & 15 & 15,3 & $-0,3$ & 16 & 17,2 & $-1,2$ \\
\hline 6 & 18 & 18,7 & $-0,7$ & 15 & 15,7 & $-0,7$ & 16 & 17,5 & $-1,5$ \\
\hline 7 & 18 & 18,8 & $-0,8$ & 16 & 17,4 & $-1,4$ & 17 & 18,2 & $-1,2$ \\
\hline 8 & 19 & 20,8 & $-1,8$ & 17 & 19,2 & $-2,2$ & 19 & 20,6 & $-1,6$ \\
\hline 9 & 21 & 23,3 & $-2,3$ & 20 & 21,7 & $-1,7$ & 20 & 21,1 & $-1,1$ \\
\hline 10 & 23 & 24,1 & $-1,1$ & 22 & 23,4 & $-1,4$ & 21 & 22,2 & $-1,2$ \\
\hline 11 & 25 & 25,2 & $-0,2$ & 24 & 24,8 & $-0,8$ & 23 & 22,8 & 0,2 \\
\hline 12 & 25 & 25,8 & $-0,8$ & 24 & 22,8 & 1,2 & 24 & 23,6 & 0,4 \\
\hline 13 & 25 & 26,3 & $-1,3$ & 24 & 24,5 & $-0,5$ & 24 & 23,4 & 0,6 \\
\hline 14 & 25 & 26,5 & $-1,5$ & 24 & 24,3 & $-0,3$ & 24 & 23,0 & 1,0 \\
\hline 15 & 26 & 22,5 & 3,5 & 24 & 25,1 & $-1,1$ & 24 & 22,4 & 1,6 \\
\hline 16 & 23 & 20,0 & 3,0 & 24 & 25,8 & $-1,8$ & 23 & 21,1 & 1,9 \\
\hline 17 & 20 & 18,2 & 1,8 & 21 & 23,3 & $-2,3$ & 21 & 19,9 & 1,1 \\
\hline 18 & 17 & 17,2 & $-0,2$ & 23 & 22,8 & 0,2 & 20 & 18,7 & 1,3 \\
\hline 19 & 16 & 16,8 & $-0,8$ & 22 & 21,0 & 1,0 & 19 & 17,9 & 1,1 \\
\hline 20 & 16 & 16,7 & $-0,7$ & 21 & 21,1 & $-0,1$ & 18 & 17,8 & 0,2 \\
\hline 21 & 16 & 16,9 & $-0,9$ & 19 & 20,1 & $-1,1$ & 18 & 17,8 & 0,2 \\
\hline 22 & 16 & 16,9 & $-0,9$ & 19 & 19,9 & $-0,9$ & 18 & 17,7 & 0,3 \\
\hline 23 & 16 & 16,9 & $-0,9$ & 19 & 19,9 & $-0,9$ & 17 & 17,5 & $-0,5$ \\
\hline 24 & 16 & 16,8 & $-0,8$ & 19 & 19,9 & $-0,9$ & 17 & 17,3 & $-0,3$ \\
\hline
\end{tabular}



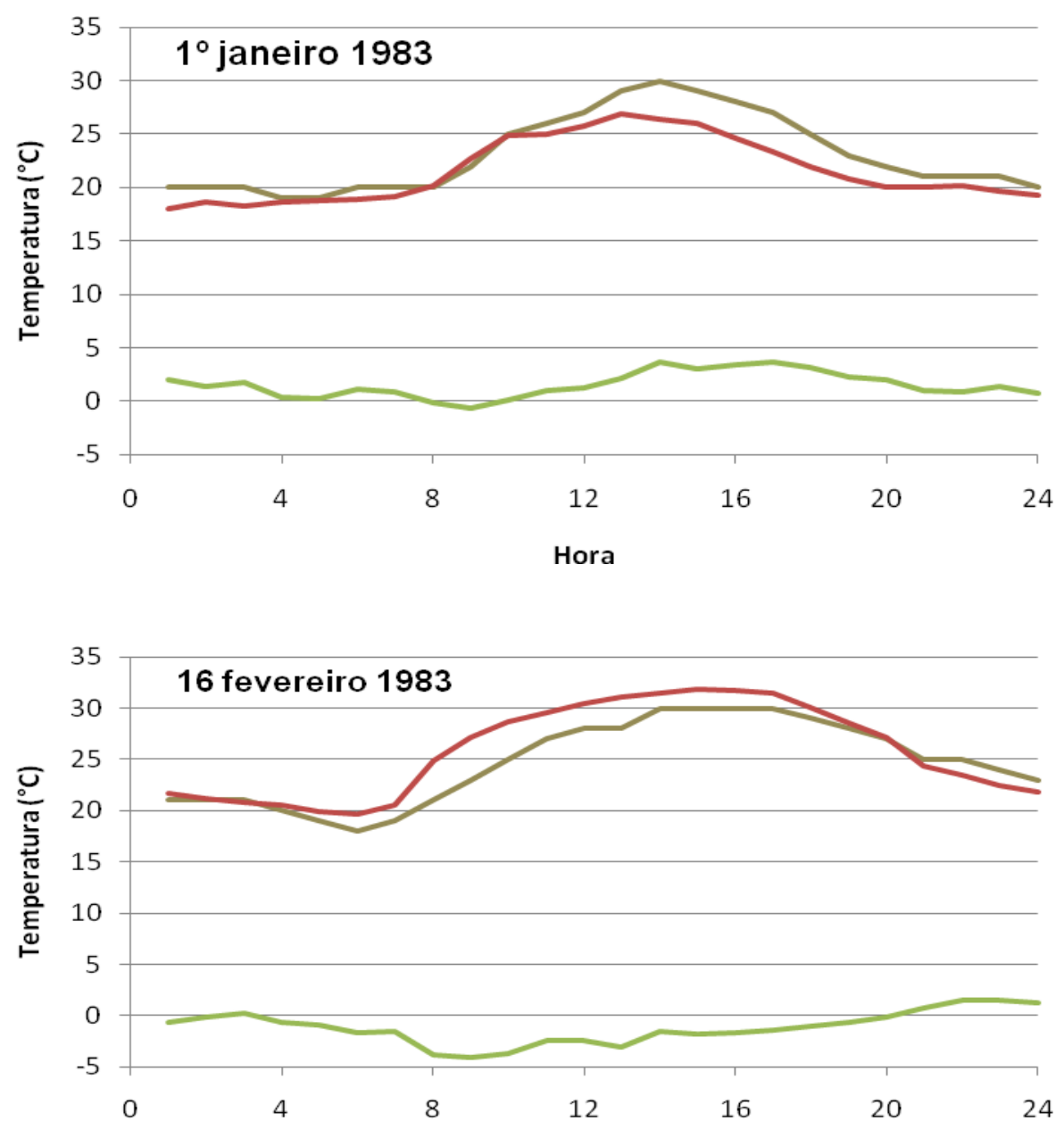

Hora

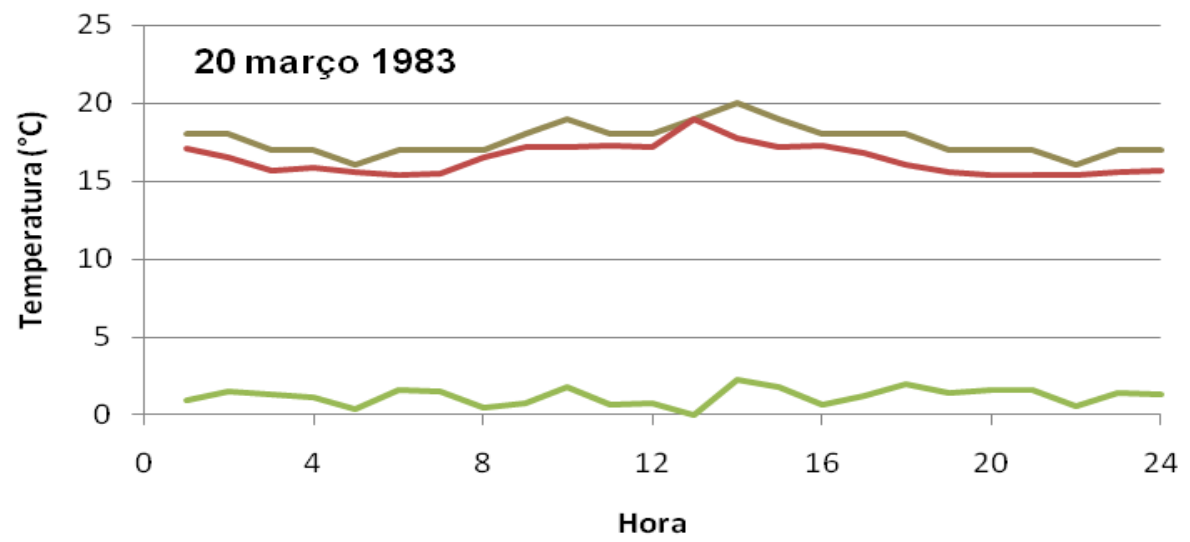

Est. Centro —Pq. D. Pedro II —Intensidade

FIGURA 61. Gráficos horários das temperaturas e da intensidade da ilha de Calor, nos dias 1ำ de janeiro, 16 de fevereiro e 20 de março de 1983, na Estação de Monitoramento Centro, Estação Meteorológica do Parque Estadual Fontes do Ipiranga. Fonte: CETESB, 1999 e IAG, 1983. 
TABELA 19. Registros horários das temperaturas e da intensidade da ilha de Calor $\left({ }^{\circ} \mathrm{C}\right)$ nos dias $1^{\circ}$ de janeiro, 16 de fevereiro e 20 de março de 1983, na Estação de Monitoramento Centro, Estação Meteorológica do Parque Estadual Fontes do Ipiranga. Fonte: CETESB, 1999 e IAG, 1983.

\begin{tabular}{|c|c|c|c|c|c|c|c|c|c|}
\hline Mês & \multicolumn{3}{|c|}{$1^{\circ}$ janeiro 1983} & \multicolumn{3}{|c|}{16 fevereiro 1983} & \multicolumn{3}{|c|}{20 março 1983} \\
\hline Hora & $\mathrm{EC}$ & $\mathrm{PE}$ & Int. & $\mathrm{EC}$ & $\mathrm{PE}$ & Int. & EC & $\mathrm{PE}$ & Int. \\
\hline 1 & 20 & 18,0 & 2,0 & 21 & 21,7 & $-0,7$ & 18 & 17,1 & 0,9 \\
\hline 2 & 20 & 18,6 & 1,4 & 21 & 21,2 & $-0,2$ & 18 & 16,5 & 1,5 \\
\hline 3 & 20 & 18,2 & 1,8 & 21 & 20,8 & 0,2 & 17 & 15,7 & 1,3 \\
\hline 4 & 19 & 18,6 & 0,4 & 20 & 20,6 & $-0,6$ & 17 & 15,9 & 1,1 \\
\hline 5 & 19 & 18,8 & 0,2 & 19 & 19,9 & $-0,9$ & 16 & 15,6 & 0,4 \\
\hline 6 & 20 & 18,9 & 1,1 & 18 & 19,7 & $-1,7$ & 17 & 15,4 & 1,6 \\
\hline 7 & 20 & 19,2 & 0,8 & 19 & 20,5 & $-1,5$ & 17 & 15,5 & 1,5 \\
\hline 8 & 20 & 20,2 & $-0,2$ & 21 & 24,8 & $-3,8$ & 17 & 16,5 & 0,5 \\
\hline 9 & 22 & 22,7 & $-0,7$ & 23 & 27,1 & $-4,1$ & 18 & 17,2 & 0,8 \\
\hline 10 & 25 & 24,9 & 0,1 & 25 & 28,7 & $-3,7$ & 19 & 17,2 & 1,8 \\
\hline 11 & 26 & 25,0 & 1,0 & 27 & 29,5 & $-2,5$ & 18 & 17,3 & 0,7 \\
\hline 12 & 27 & 25,8 & 1,2 & 28 & 30,5 & $-2,5$ & 18 & 17,2 & 0,8 \\
\hline 13 & 29 & 26,9 & 2,1 & 28 & 31,1 & $-3,1$ & 19 & 19,0 & 0,0 \\
\hline 14 & 30 & 26,4 & 3,6 & 30 & 31,5 & $-1,5$ & 20 & 17,7 & 2,3 \\
\hline 15 & 29 & 26,0 & 3,0 & 30 & 31,8 & $-1,8$ & 19 & 17,2 & 1,8 \\
\hline 16 & 28 & 24,6 & 3,4 & 30 & 31,7 & $-1,7$ & 18 & 17,3 & 0,7 \\
\hline 17 & 27 & 23,3 & 3,7 & 30 & 31,4 & $-1,4$ & 18 & 16,8 & 1,2 \\
\hline 18 & 25 & 21,9 & 3,1 & 29 & 30,1 & $-1,1$ & 18 & 16,0 & 2,0 \\
\hline 19 & 23 & 20,8 & 2,2 & 28 & 28,6 & $-0,6$ & 17 & 15,6 & 1,4 \\
\hline 20 & 22 & 20,0 & 2,0 & 27 & 27,1 & $-0,1$ & 17 & 15,4 & 1,6 \\
\hline 21 & 21 & 20,0 & 1,0 & 25 & 24,3 & 0,7 & 17 & 15,4 & 1,6 \\
\hline 22 & 21 & 20,2 & 0,8 & 25 & 23,5 & 1,5 & 16 & 15,4 & 0,6 \\
\hline 23 & 21 & 19,6 & 1,4 & 24 & 22,5 & 1,5 & 17 & 15,6 & 1,4 \\
\hline 24 & 20 & 19,3 & 0,7 & 23 & 21,8 & 1,2 & 17 & 15,7 & 1,3 \\
\hline
\end{tabular}



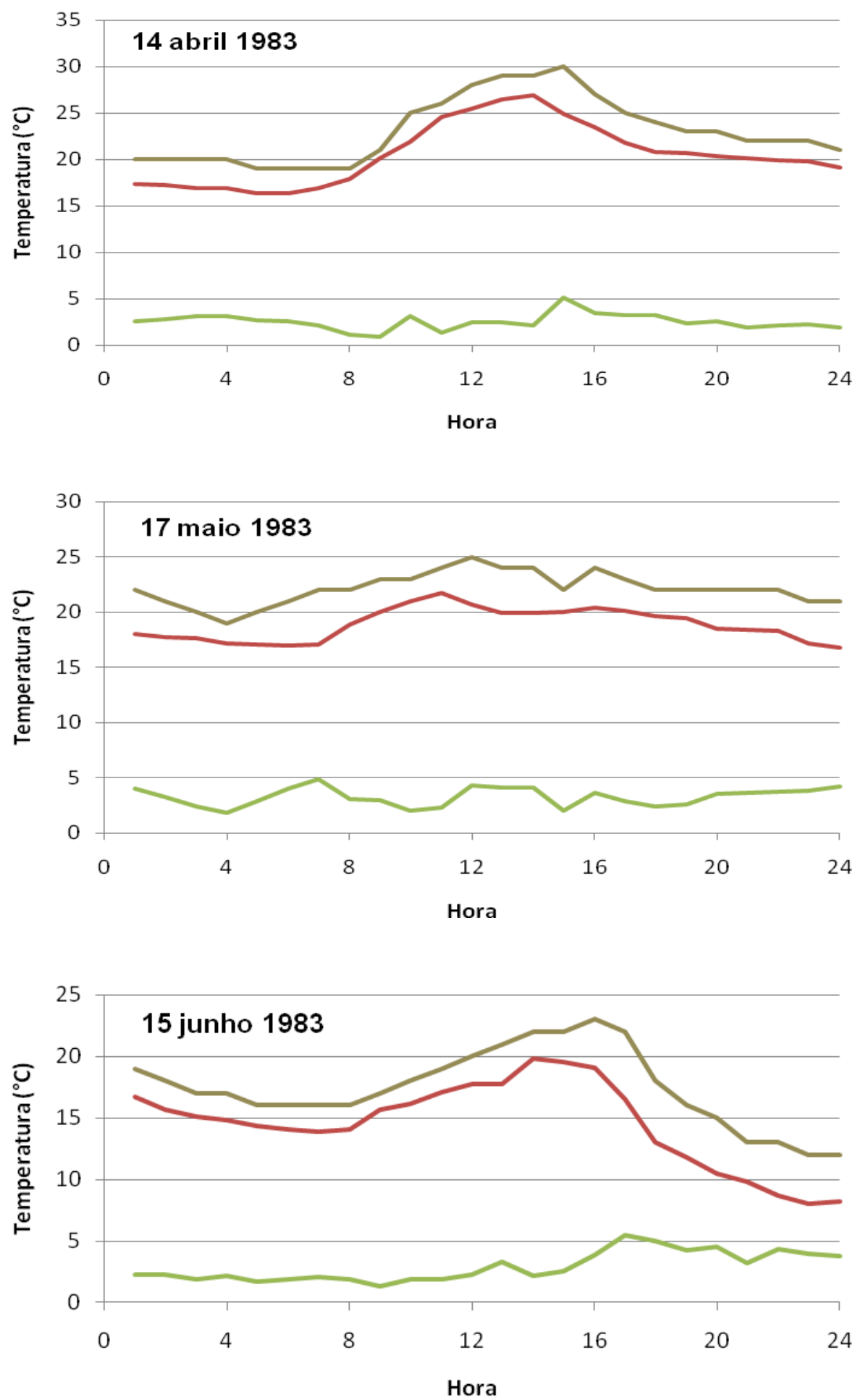

—Est. Centro —Pq. Estado —Intensidade

FIGURA 62. Gráficos horários das temperaturas e da intensidade da ilha de Calor, nos dias 14 de abril, 17 de maio e 15 de junho de 1983, na Estação de Monitoramento Centro, Estação Meteorológica do Parque Estadual Fontes do Ipiranga. Fonte: CETESB, 1999 e IAG, 1983. 
TABELA 20. Registros horários das temperaturas e da intensidade da ilha de Calor $\left({ }^{\circ} \mathrm{C}\right)$ nos dias 14 de abril, 17 de maio e 15 de junho de 1983, na Estação de Monitoramento Centro, Estação Meteorológica do Parque Estadual Fontes do Ipiranga. Fonte: CETESB, 1999 e IAG, 1983.

\begin{tabular}{|c|c|c|c|c|c|c|c|c|c|}
\hline Mês & \multicolumn{3}{|c|}{14 abril 1983} & \multicolumn{3}{|c|}{17 maio 1983} & \multicolumn{3}{|c|}{15 junho 1983} \\
\hline Hora & $E C$ & $\mathrm{PE}$ & Int. & $\mathrm{EC}$ & $P E$ & Int. & $E C$ & $\mathrm{PE}$ & Int. \\
\hline 1 & 20 & 17,4 & 2,6 & 22 & 18,0 & 4,0 & 19 & 16,7 & 2,3 \\
\hline 2 & 20 & 17,2 & 2,8 & 21 & 17,7 & 3,3 & 18 & 15,7 & 2,3 \\
\hline 3 & 20 & 16,9 & 3,1 & 20 & 17,6 & 2,4 & 17 & 15,1 & 1,9 \\
\hline 4 & 20 & 16,9 & 3,1 & 19 & 17,2 & 1,8 & 17 & 14,8 & 2,2 \\
\hline 5 & 19 & 16,3 & 2,7 & 20 & 17,1 & 2,9 & 16 & 14,3 & 1,7 \\
\hline 6 & 19 & 16,4 & 2,6 & 21 & 17,0 & 4,0 & 16 & 14,1 & 1,9 \\
\hline 7 & 19 & 16,9 & 2,1 & 22 & 17,1 & 4,9 & 16 & 13,9 & 2,1 \\
\hline 8 & 19 & 17,9 & 1,1 & 22 & 18,9 & 3,1 & 16 & 14,1 & 1,9 \\
\hline 9 & 21 & 20,1 & 0,9 & 23 & 20,0 & 3,0 & 17 & 15,7 & 1,3 \\
\hline 10 & 25 & 21,9 & 3,1 & 23 & 21,0 & 2,0 & 18 & 16,1 & 1,9 \\
\hline 11 & 26 & 24,6 & 1,4 & 24 & 21,7 & 2,3 & 19 & 17,1 & 1,9 \\
\hline 12 & 28 & 25,5 & 2,5 & 25 & 20,7 & 4,3 & 20 & 17,7 & 2,3 \\
\hline 13 & 29 & 26,5 & 2,5 & 24 & 19,9 & 4,1 & 21 & 17,7 & 3,3 \\
\hline 14 & 29 & 26,9 & 2,1 & 24 & 19,9 & 4,1 & 22 & 19,8 & 2,2 \\
\hline 15 & 30 & 24,9 & 5,1 & 22 & 20,0 & 2,0 & 22 & 19,5 & 2,5 \\
\hline 16 & 27 & 23,5 & 3,5 & 24 & 20,4 & 3,6 & 23 & 19,1 & 3,9 \\
\hline 17 & 25 & 21,8 & 3,2 & 23 & 20,1 & 2,9 & 22 & 16,5 & 5,5 \\
\hline 18 & 24 & 20,8 & 3,2 & 22 & 19,6 & 2,4 & 18 & 13,0 & 5,0 \\
\hline 19 & 23 & 20,7 & 2,3 & 22 & 19,4 & 2,6 & 16 & 11,8 & 4,2 \\
\hline 20 & 23 & 20,4 & 2,6 & 22 & 18,5 & 3,5 & 15 & 10,5 & 4,5 \\
\hline 21 & 22 & 20,1 & 1,9 & 22 & 18,4 & 3,6 & 13 & 9,8 & 3,2 \\
\hline 22 & 22 & 19,9 & 2,1 & 22 & 18,3 & 3,7 & 13 & 8,7 & 4,3 \\
\hline 23 & 22 & 19,8 & 2,2 & 21 & 17,2 & 3,8 & 12 & 8,0 & 4,0 \\
\hline 24 & 21 & 19,1 & 1,9 & 21 & 16,8 & 4,2 & 12 & 8,2 & 3,8 \\
\hline
\end{tabular}



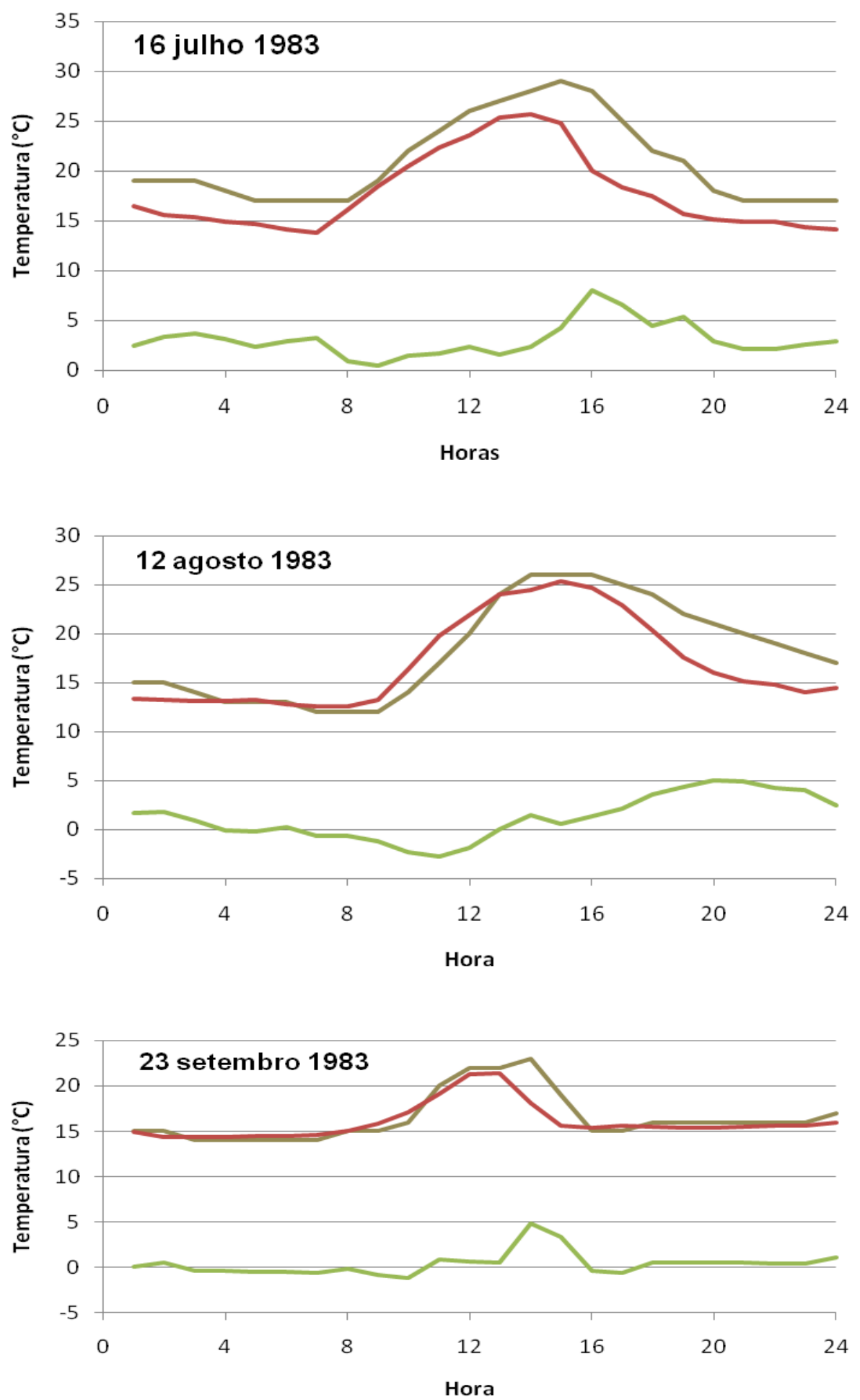

Est. Centro —Pq. D. Pedro II

FIGURA 63. Gráficos horários das temperaturas e da intensidade da ilha de Calor, nos dias 16 de julho, 12 de agosto e 13 de setembro de 1983, na Estação de Monitoramento Centro, Estação Meteorológica do Parque Estadual Fontes do Ipiranga. Fonte: CETESB, 1999 e IAG, 1983. 
TABELA 21. Registros horários das temperaturas e da intensidade da ilha de Calor $\left({ }^{\circ} \mathrm{C}\right)$ nos dias 16 de julho, 12 de agosto e 22 de setembro de 1983, na Estação de Monitoramento Centro, Estação Meteorológica do Parque Estadual Fontes do Ipiranga. Fonte: CETESB, 1999 e IAG, 1983.

\begin{tabular}{|c|c|c|c|c|c|c|c|c|c|}
\hline Mês & \multicolumn{3}{|c|}{16 julho 1983} & \multicolumn{3}{|c|}{12 agosto 1983} & \multicolumn{3}{|c|}{23 setembro 1983} \\
\hline Hora & $\mathrm{EC}$ & $\mathrm{PE}$ & Int. & $\mathrm{EC}$ & $\mathrm{PE}$ & Int. & $\mathrm{EC}$ & $\mathrm{PE}$ & Int. \\
\hline 1 & 19 & 16,5 & 2,5 & 15 & 13,3 & 1,7 & 15 & 14,9 & 0,1 \\
\hline 2 & 19 & 15,6 & 3,4 & 15 & 13,2 & 1,8 & 15 & 14,4 & 0,6 \\
\hline 3 & 19 & 15,3 & 3,7 & 14 & 13,1 & 0,9 & 14 & 14,4 & $-0,4$ \\
\hline 4 & 18 & 14,9 & 3,1 & 13 & 13,1 & $-0,1$ & 14 & 14,4 & $-0,4$ \\
\hline 5 & 17 & 14,7 & 2,3 & 13 & 13,2 & $-0,2$ & 14 & 14,5 & $-0,5$ \\
\hline 6 & 17 & 14,1 & 2,9 & 13 & 12,8 & 0,2 & 14 & 14,5 & $-0,5$ \\
\hline 7 & 17 & 13,8 & 3,2 & 12 & 12,6 & $-0,6$ & 14 & 14,6 & $-0,6$ \\
\hline 8 & 17 & 16,1 & 0,9 & 12 & 12,6 & $-0,6$ & 15 & 15,1 & $-0,1$ \\
\hline 9 & 19 & 18,5 & 0,5 & 12 & 13,2 & $-1,2$ & 15 & 15,8 & $-0,8$ \\
\hline 10 & 22 & 20,5 & 1,5 & 14 & 16,3 & $-2,3$ & 16 & 17,1 & $-1,1$ \\
\hline 11 & 24 & 22,3 & 1,7 & 17 & 19,8 & $-2,8$ & 20 & 19,1 & 0,9 \\
\hline 12 & 26 & 23,6 & 2,4 & 20 & 21,9 & $-1,9$ & 22 & 21,3 & 0,7 \\
\hline 13 & 27 & 25,4 & 1,6 & 24 & 24,0 & 0,0 & 22 & 21,4 & 0,6 \\
\hline 14 & 28 & 25,7 & 2,3 & 26 & 24,5 & 1,5 & 23 & 18,1 & 4,9 \\
\hline 15 & 29 & 24,8 & 4,2 & 26 & 25,4 & 0,6 & 19 & 15,6 & 3,4 \\
\hline 16 & 28 & 20,0 & 8,0 & 26 & 24,7 & 1,3 & 15 & 15,4 & $-0,4$ \\
\hline 17 & 25 & 18,4 & 6,6 & 25 & 22,9 & 2,1 & 15 & 15,6 & $-0,6$ \\
\hline 18 & 22 & 17,5 & 4,5 & 24 & 20,4 & 3,6 & 16 & 15,5 & 0,5 \\
\hline 19 & 21 & 15,7 & 5,3 & 22 & 17,6 & 4,4 & 16 & 15,4 & 0,6 \\
\hline 20 & 18 & 15,1 & 2,9 & 21 & 16,0 & 5,0 & 16 & 15,4 & 0,6 \\
\hline 21 & 17 & 14,9 & 2,1 & 20 & 15,1 & 4,9 & 16 & 15,5 & 0,5 \\
\hline 22 & 17 & 14,9 & 2,1 & 19 & 14,8 & 4,2 & 16 & 15,6 & 0,4 \\
\hline 23 & 17 & 14,4 & 2,6 & 18 & 14,0 & 4,0 & 16 & 15,6 & 0,4 \\
\hline 24 & 17 & 14,1 & 2,9 & 17 & 14,5 & 2,5 & 17 & 15,9 & 1,1 \\
\hline
\end{tabular}



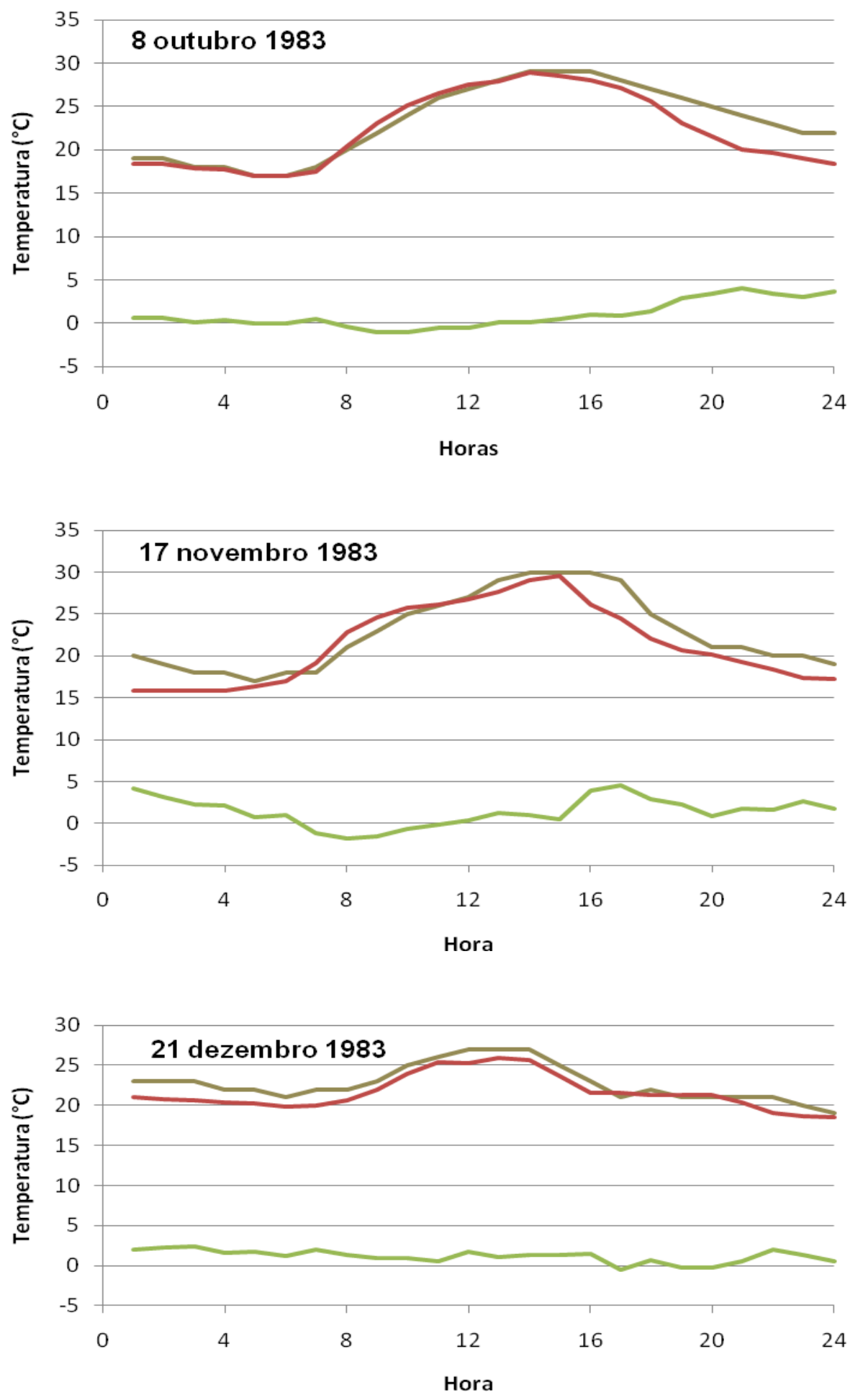

Est. Central —Pq. Estado Intensidade

FIGURA 64. Gráficos horários das temperaturas e da intensidade da ilha de Calor, nos dias 8 outubro, 17 de novembro e 21 de dezembro de 1983, na Estação de Monitoramento Centro, Estação Meteorológica do Parque Estadual Fontes do Ipiranga. Fonte: CETESB, 1999 e IAG, 1983. 
TABELA 22. Registros horários das temperaturas e da intensidade da ilha de Calor $\left({ }^{\circ} \mathrm{C}\right)$ nos dias 8 de outubro, 17 de novembro e 21 de dezembro de 1983, na Estação de Monitoramento Centro, Estação Meteorológica do Parque Estadual Fontes do Ipiranga. Fonte: CETESB, 1999 e IAG, 1983.

\begin{tabular}{|c|c|c|c|c|c|c|c|c|c|}
\hline Mês & \multicolumn{3}{|c|}{8 outubro 1983} & \multicolumn{3}{|c|}{17 novembro 1983} & \multicolumn{3}{|c|}{21 dezembro 1983} \\
\hline Hora & $\mathrm{EC}$ & $\mathrm{PE}$ & Int. & $\mathrm{EC}$ & $\mathrm{PE}$ & Int. & $\mathrm{EC}$ & $\mathrm{PE}$ & Int. \\
\hline 1 & 19 & 18,4 & 0,6 & 20 & 15,8 & 4,2 & 23 & 21,0 & 2,0 \\
\hline 2 & 19 & 18,4 & 0,6 & 19 & 15,9 & 3,1 & 23 & 20,8 & 2,2 \\
\hline 3 & 18 & 17,9 & 0,1 & 18 & 15,8 & 2,2 & 23 & 20,6 & 2,4 \\
\hline 4 & 18 & 17,7 & 0,3 & 18 & 15,9 & 2,1 & 22 & 20,4 & 1,6 \\
\hline 5 & 17 & 17,0 & 0,0 & 17 & 16,3 & 0,7 & 22 & 20,2 & 1,8 \\
\hline 6 & 17 & 17,0 & 0,0 & 18 & 17,0 & 1,0 & 21 & 19,8 & 1,2 \\
\hline 7 & 18 & 17,5 & 0,5 & 18 & 19,2 & $-1,2$ & 22 & 20,0 & 2,0 \\
\hline 8 & 20 & 20,4 & $-0,4$ & 21 & 22,8 & $-1,8$ & 22 & 20,6 & 1,4 \\
\hline 9 & 22 & 23,1 & $-1,1$ & 23 & 24,6 & $-1,6$ & 23 & 22,0 & 1,0 \\
\hline 10 & 24 & 25,1 & $-1,1$ & 25 & 25,7 & $-0,7$ & 25 & 24,0 & 1,0 \\
\hline 11 & 26 & 26,5 & $-0,5$ & 26 & 26,1 & $-0,1$ & 26 & 25,4 & 0,6 \\
\hline 12 & 27 & 27,5 & $-0,5$ & 27 & 26,7 & 0,3 & 27 & 25,2 & 1,8 \\
\hline 13 & 28 & 27,9 & 0,1 & 29 & 27,7 & 1,3 & 27 & 25,9 & 1,1 \\
\hline 14 & 29 & 28,9 & 0,1 & 30 & 29,0 & 1,0 & 27 & 25,6 & 1,4 \\
\hline 15 & 29 & 28,5 & 0,5 & 30 & 29,5 & 0,5 & 25 & 23,7 & 1,3 \\
\hline 16 & 29 & 28,0 & 1,0 & 30 & 26,1 & 3,9 & 23 & 21,5 & 1,5 \\
\hline 17 & 28 & 27,2 & 0,8 & 29 & 24,5 & 4,5 & 21 & 21,5 & $-0,5$ \\
\hline 18 & 27 & 25,6 & 1,4 & 25 & 22,1 & 2,9 & 22 & 21,3 & 0,7 \\
\hline 19 & 26 & 23,1 & 2,9 & 23 & 20,7 & 2,3 & 21 & 21,3 & $-0,3$ \\
\hline 20 & 25 & 21,6 & 3,4 & 21 & 20,1 & 0,9 & 21 & 21,3 & $-0,3$ \\
\hline 21 & 24 & 20,0 & 4,0 & 21 & 19,3 & 1,7 & 21 & 20,4 & 0,6 \\
\hline 22 & 23 & 19,6 & 3,4 & 20 & 18,4 & 1,6 & 21 & 19,0 & 2,0 \\
\hline 23 & 22 & 19,0 & 3,0 & 20 & 17,4 & 2,6 & 20 & 18,7 & 1,3 \\
\hline 24 & 22 & 18,4 & 3,6 & 19 & 17,3 & 1,7 & 19 & 18,5 & 0,5 \\
\hline
\end{tabular}



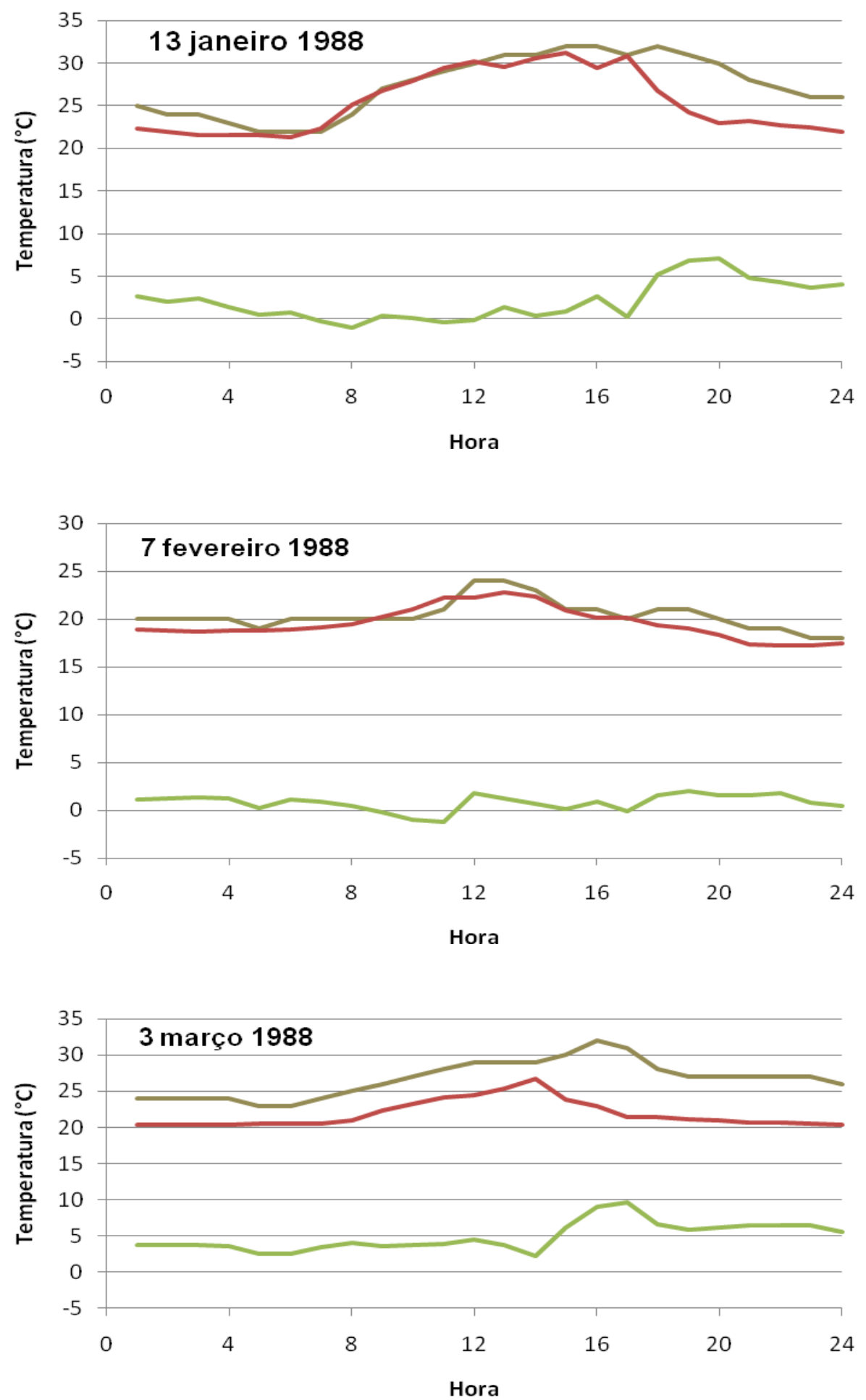

Est. Centro —Pq. Estado Intensidade

FIGURA 65. Gráficos horários das temperaturas e da intensidade da ilha de Calor, nos dias 13 de janeiro, 7 de fevereiro e 3 de março de 1988, na Estação de Monitoramento Centro, Estação Meteorológica do Parque Estadual Fontes do Ipiranga. Fonte: CETESB, 1999 e IAG, 1983. 
TABELA 23. Registros horários das temperaturas e da intensidade da ilha de Calor $\left({ }^{\circ} \mathrm{C}\right)$ nos dias 13 de janeiro, 7 de fevereiro e 3 de março de 1988, na Estação de Monitoramento Centro, Estação Meteorológica do Parque Estadual Fontes do Ipiranga. Fonte: CETESB, 1999 e IAG, 1983.

\begin{tabular}{|c|c|c|c|c|c|c|c|c|c|}
\hline Mês & \multicolumn{3}{|c|}{13 janeiro 1988} & \multicolumn{3}{|c|}{7 fevereiro 1988} & \multicolumn{3}{|c|}{3 março 1988} \\
\hline Hora & $\mathrm{EC}$ & $\mathrm{PE}$ & Int. & $\mathrm{EC}$ & $\mathrm{PE}$ & Int. & $\mathrm{EC}$ & $\mathrm{PE}$ & Int. \\
\hline 1 & 25 & 22,3 & 2,7 & 20 & 18,9 & 1,1 & 24 & 20,3 & 3,7 \\
\hline 2 & 24 & 22,0 & 2,0 & 20 & 18,8 & 1,2 & 24 & 20,3 & 3,7 \\
\hline 3 & 24 & 21,6 & 2,4 & 20 & 18,7 & 1,3 & 24 & 20,3 & 3,7 \\
\hline 4 & 23 & 21,6 & 1,4 & 20 & 18,8 & 1,2 & 24 & 20,4 & 3,6 \\
\hline 5 & 22 & 21,5 & 0,5 & 19 & 18,8 & 0,2 & 23 & 20,5 & 2,5 \\
\hline 6 & 22 & 21,3 & 0,7 & 20 & 18,9 & 1,1 & 23 & 20,5 & 2,5 \\
\hline 7 & 22 & 22,3 & $-0,3$ & 20 & 19,1 & 0,9 & 24 & 20,5 & 3,5 \\
\hline 8 & 24 & 25,1 & $-1,1$ & 20 & 19,5 & 0,5 & 25 & 21,0 & 4,0 \\
\hline 9 & 27 & 26,7 & 0,3 & 20 & 20,2 & $-0,2$ & 26 & 22,4 & 3,6 \\
\hline 10 & 28 & 27,9 & 0,1 & 20 & 21,0 & $-1,0$ & 27 & 23,2 & 3,8 \\
\hline 11 & 29 & 29,4 & $-0,4$ & 21 & 22,2 & $-1,2$ & 28 & 24,1 & 3,9 \\
\hline 12 & 30 & 30,2 & $-0,2$ & 24 & 22,2 & 1,8 & 29 & 24,5 & 4,5 \\
\hline 13 & 31 & 29,6 & 1,4 & 24 & 22,8 & 1,2 & 29 & 25,3 & 3,7 \\
\hline 14 & 31 & 30,6 & 0,4 & 23 & 22,3 & 0,7 & 29 & 26,7 & 2,3 \\
\hline 15 & 32 & 31,2 & 0,8 & 21 & 20,9 & 0,1 & 30 & 23,8 & 6,2 \\
\hline 16 & 32 & 29,4 & 2,6 & 21 & 20,1 & 0,9 & 32 & 22,9 & 9,1 \\
\hline 17 & 31 & 30,8 & 0,2 & 20 & 20,1 & $-0,1$ & 31 & 21,4 & 9,6 \\
\hline 18 & 32 & 26,8 & 5,2 & 21 & 19,4 & 1,6 & 28 & 21,4 & 6,6 \\
\hline 19 & 31 & 24,2 & 6,8 & 21 & 19,0 & 2,0 & 27 & 21,2 & 5,8 \\
\hline 20 & 30 & 22,9 & 7,1 & 20 & 18,4 & 1,6 & 27 & 20,9 & 6,1 \\
\hline 21 & 28 & 23,2 & 4,8 & 19 & 17,4 & 1,6 & 27 & 20,6 & 6,4 \\
\hline 22 & 27 & 22,7 & 4,3 & 19 & 17,2 & 1,8 & 27 & 20,6 & 6,4 \\
\hline 23 & 26 & 22,4 & 3,6 & 18 & 17,2 & 0,8 & 27 & 20,5 & 6,5 \\
\hline 24 & 26 & 22,0 & 4,0 & 18 & 17,5 & 0,5 & 26 & 20,4 & 5,6 \\
\hline
\end{tabular}



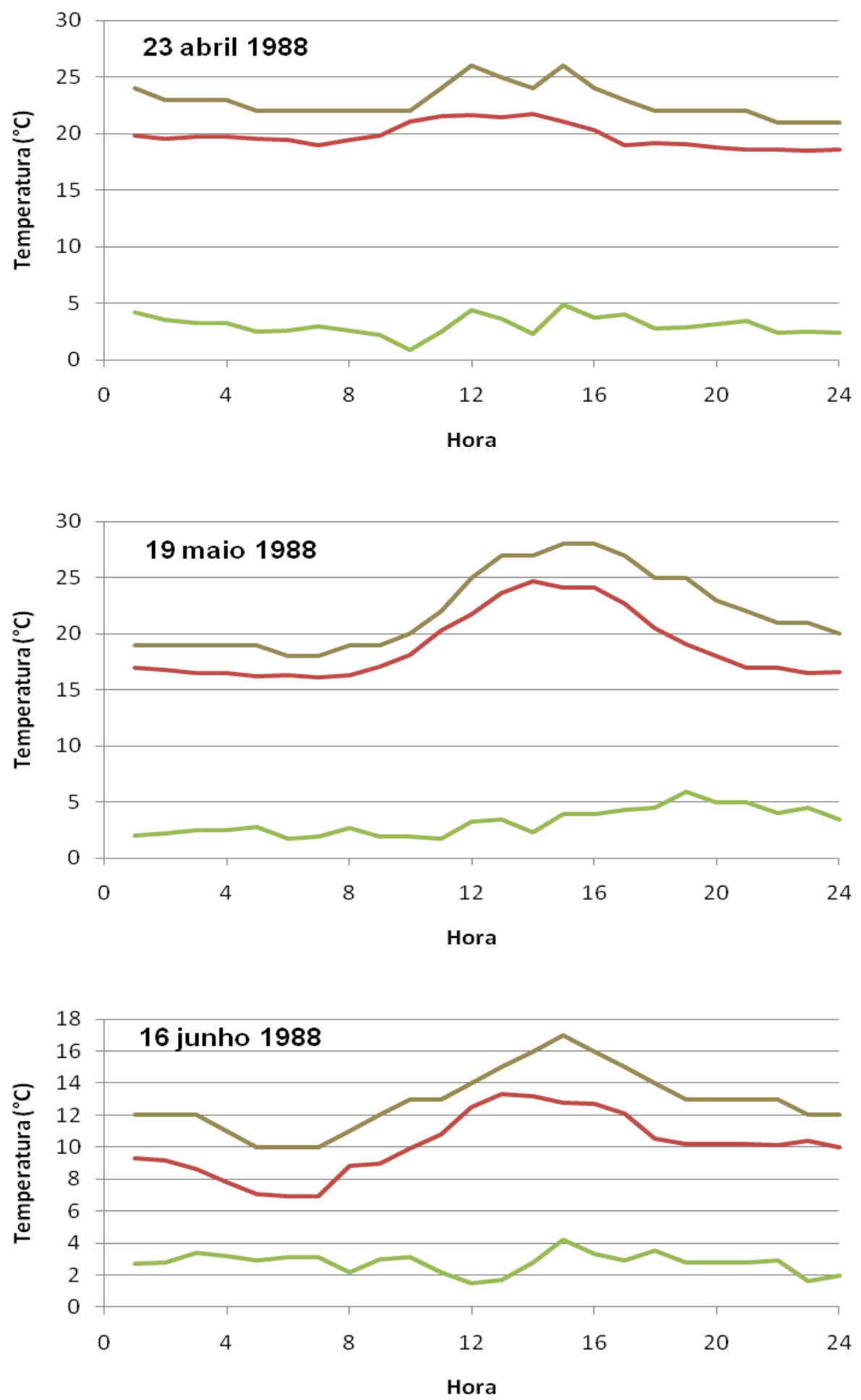

Est. Centro $\longrightarrow$ Pq. Estado Intensidade

FIGURA 66. Gráficos horários das temperaturas e da intensidade da ilha de Calor, nos dias 23 abril, 19 de maio e 16 de junho de 1988, na Estação de Monitoramento Centro, Estação Meteorológica do Parque Estadual Fontes do Ipiranga. Fonte: CETESB, 1999 e IAG, 1988. 
TABELA 24. Registros horários das temperaturas e da intensidade da ilha de Calor $\left({ }^{\circ} \mathrm{C}\right)$ nos dias 23 de abril, 19 de maio e 16 de junho de 1988, na Estação de Monitoramento Centro, Estação Meteorológica do Parque Estadual Fontes do Ipiranga. Fonte: CETESB, 1999 e IAG, 1988.

\begin{tabular}{|c|c|c|c|c|c|c|c|c|c|}
\hline Mês & \multicolumn{3}{|c|}{23 abril 1988} & \multicolumn{3}{|c|}{19 maio 1988} & \multicolumn{3}{|c|}{16 junho 1988} \\
\hline Hora & EC & $\mathrm{PE}$ & Int. & $\mathrm{EC}$ & $\mathrm{PE}$ & Int. & $\mathrm{EC}$ & $\mathrm{PE}$ & Int. \\
\hline 1 & 24 & 19,8 & 4,2 & 19 & 17,0 & 2,0 & 12 & 9,3 & 2,7 \\
\hline 2 & 23 & 19,5 & 3,5 & 19 & 16,8 & 2,2 & 12 & 9,2 & 2,8 \\
\hline 3 & 23 & 19,7 & 3,3 & 19 & 16,5 & 2,5 & 12 & 8,6 & 3,4 \\
\hline 4 & 23 & 19,7 & 3,3 & 19 & 16,5 & 2,5 & 11 & 7,8 & 3,2 \\
\hline 5 & 22 & 19,5 & 2,5 & 19 & 16,2 & 2,8 & 10 & 7,1 & 2,9 \\
\hline 6 & 22 & 19,4 & 2,6 & 18 & 16,3 & 1,7 & 10 & 6,9 & 3,1 \\
\hline 7 & 22 & 19,0 & 3,0 & 18 & 16,1 & 1,9 & 10 & 6,9 & 3,1 \\
\hline 8 & 22 & 19,4 & 2,6 & 19 & 16,3 & 2,7 & 11 & 8,8 & 2,2 \\
\hline 9 & 22 & 19,8 & 2,2 & 19 & 17,1 & 1,9 & 12 & 9,0 & 3,0 \\
\hline 10 & 22 & 21,1 & 0,9 & 20 & 18,1 & 1,9 & 13 & 9,9 & 3,1 \\
\hline 11 & 24 & 21,5 & 2,5 & 22 & 20,3 & 1,7 & 13 & 10,8 & 2,2 \\
\hline 12 & 26 & 21,6 & 4,4 & 25 & 21,7 & 3,3 & 14 & 12,5 & 1,5 \\
\hline 13 & 25 & 21,4 & 3,6 & 27 & 23,6 & 3,4 & 15 & 13,3 & 1,7 \\
\hline 14 & 24 & 21,7 & 2,3 & 27 & 24,7 & 2,3 & 16 & 13,2 & 2,8 \\
\hline 15 & 26 & 21,1 & 4,9 & 28 & 24,1 & 3,9 & 17 & 12,8 & 4,2 \\
\hline 16 & 24 & 20,3 & 3,7 & 28 & 24,1 & 3,9 & 16 & 12,7 & 3,3 \\
\hline 17 & 23 & 19,0 & 4,0 & 27 & 22,7 & 4,3 & 15 & 12,1 & 2,9 \\
\hline 18 & 22 & 19,2 & 2,8 & 25 & 20,5 & 4,5 & 14 & 10,5 & 3,5 \\
\hline 19 & 22 & 19,1 & 2,9 & 25 & 19,1 & 5,9 & 13 & 10,2 & 2,8 \\
\hline 20 & 22 & 18,8 & 3,2 & 23 & 18,0 & 5,0 & 13 & 10,2 & 2,8 \\
\hline 21 & 22 & 18,6 & 3,4 & 22 & 17,0 & 5,0 & 13 & 10,2 & 2,8 \\
\hline 22 & 21 & 18,6 & 2,4 & 21 & 17,0 & 4,0 & 13 & 10,1 & 2,9 \\
\hline 23 & 21 & 18,5 & 2,5 & 21 & 16,5 & 4,5 & 12 & 10,4 & 1,6 \\
\hline 24 & 21 & 18,6 & 2,4 & 20 & 16,6 & 3,4 & 12 & 10,0 & 2,0 \\
\hline
\end{tabular}



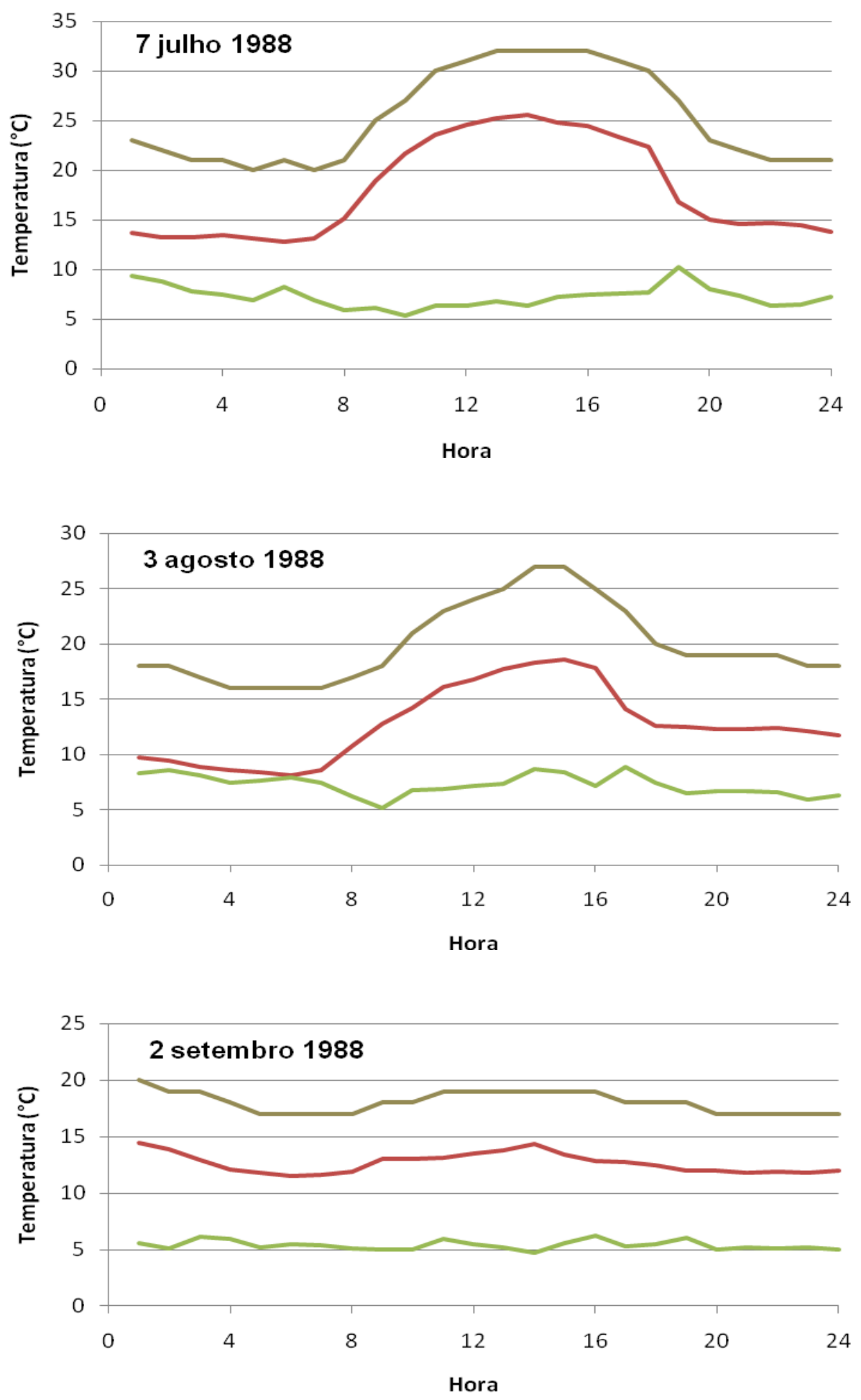

Est. Centro —Pq. Estado Intensidade

FIGURA 67. Gráficos horários das temperaturas e da intensidade da ilha de Calor, nos dias 7 de julho, 3 de agosto e 2 de setembro de 1988, na Estação de Monitoramento Centro, Estação Meteorológica do Parque Estadual Fontes do Ipiranga. Fonte: CETESB, 1999 e IAG, 1988. 
TABELA 25. Registros horários das temperaturas e da intensidade da ilha de Calor $\left({ }^{\circ} \mathrm{C}\right)$ nos dias 7 de julho, 3 de agosto e 2 de setembro de 1988, na Estação de Monitoramento Centro, Estação Meteorológica do Parque Estadual Fontes do Ipiranga. Fonte: CETESB, 1999 e IAG, 1988.

\begin{tabular}{|c|c|c|c|c|c|c|c|c|c|}
\hline Mês & \multicolumn{3}{|c|}{7 julho 1988} & \multicolumn{3}{|c|}{3 agosto 1988} & \multicolumn{3}{|c|}{2 setembro 1988} \\
\hline Hora & EC & $\mathrm{PE}$ & Int. & $\mathrm{EC}$ & $\mathrm{PE}$ & Int. & $\mathrm{EC}$ & $\mathrm{PE}$ & Int. \\
\hline 1 & 23 & 13,7 & 9,3 & 18 & 9,7 & 8,3 & 20 & 14,4 & 5,6 \\
\hline 2 & 22 & 13,2 & 8,8 & 18 & 9,4 & 8,6 & 19 & 13,9 & 5,1 \\
\hline 3 & 21 & 13,2 & 7,8 & 17 & 8,9 & 8,1 & 19 & 12,9 & 6,1 \\
\hline 4 & 21 & 13,5 & 7,5 & 16 & 8,6 & 7,4 & 18 & 12,1 & 5,9 \\
\hline 5 & 20 & 13,1 & 6,9 & 16 & 8,4 & 7,6 & 17 & 11,8 & 5,2 \\
\hline 6 & 21 & 12,8 & 8,2 & 16 & 8,1 & 7,9 & 17 & 11,5 & 5,5 \\
\hline 7 & 20 & 13,1 & 6,9 & 16 & 8,6 & 7,4 & 17 & 11,6 & 5,4 \\
\hline 8 & 21 & 15,1 & 5,9 & 17 & 10,8 & 6,2 & 17 & 11,9 & 5,1 \\
\hline 9 & 25 & 18,9 & 6,1 & 18 & 12,8 & 5,2 & 18 & 13,0 & 5,0 \\
\hline 10 & 27 & 21,7 & 5,3 & 21 & 14,2 & 6,8 & 18 & 13,0 & 5,0 \\
\hline 11 & 30 & 23,6 & 6,4 & 23 & 16,1 & 6,9 & 19 & 13,1 & 5,9 \\
\hline 12 & 31 & 24,6 & 6,4 & 24 & 16,8 & 7,2 & 19 & 13,5 & 5,5 \\
\hline 13 & 32 & 25,2 & 6,8 & 25 & 17,7 & 7,3 & 19 & 13,8 & 5,2 \\
\hline 14 & 32 & 25,6 & 6,4 & 27 & 18,3 & 8,7 & 19 & 14,3 & 4,7 \\
\hline 15 & 32 & 24,8 & 7,2 & 27 & 18,6 & 8,4 & 19 & 13,4 & 5,6 \\
\hline 16 & 32 & 24,5 & 7,5 & 25 & 17,8 & 7,2 & 19 & 12,8 & 6,2 \\
\hline 17 & 31 & 23,4 & 7,6 & 23 & 14,1 & 8,9 & 18 & 12,7 & 5,3 \\
\hline 18 & 30 & 22,3 & 7,7 & 20 & 12,6 & 7,4 & 18 & 12,5 & 5,5 \\
\hline 19 & 27 & 16,8 & 10,2 & 19 & 12,5 & 6,5 & 18 & 12,0 & 6,0 \\
\hline 20 & 23 & 15,0 & 8,0 & 19 & 12,3 & 6,7 & 17 & 12,0 & 5,0 \\
\hline 21 & 22 & 14,6 & 7,4 & 19 & 12,3 & 6,7 & 17 & 11,8 & 5,2 \\
\hline 22 & 21 & 14,7 & 6,3 & 19 & 12,4 & 6,6 & 17 & 11,9 & 5,1 \\
\hline 23 & 21 & 14,5 & 6,5 & 18 & 12,1 & 5,9 & 17 & 11,8 & 5,2 \\
\hline 24 & 21 & 13,8 & 7,2 & 18 & 11,7 & 6,3 & 17 & 12,0 & 5,0 \\
\hline
\end{tabular}



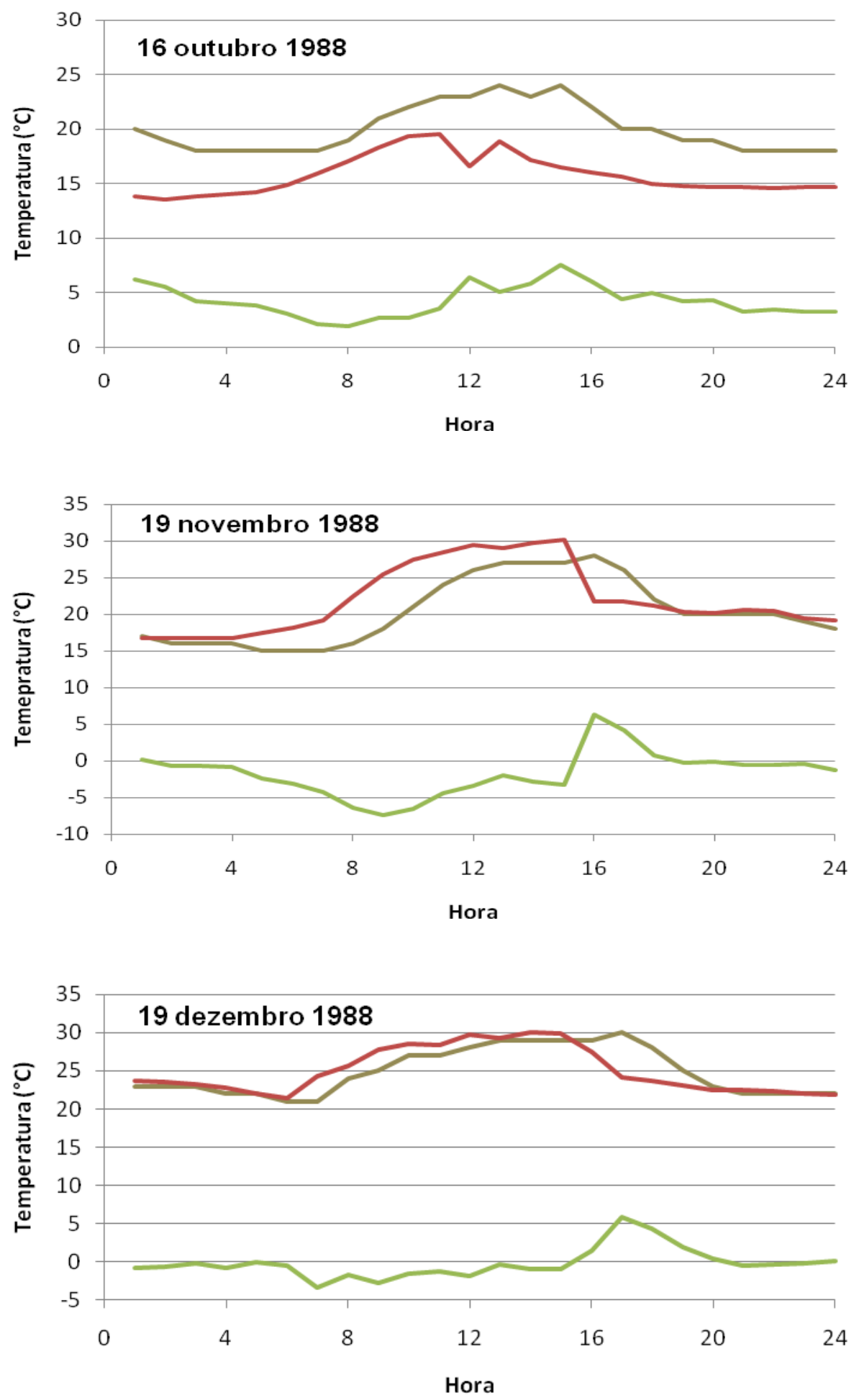

Est. Centro —Pq. Estado Intensidade

FIGURA 68. Gráficos horários das temperaturas e da intensidade da ilha de Calor, nos dias 16 de outubro, 19 de novembro e 19 de dezembro de 1988, na Estação de Monitoramento Centro, Estação Meteorológica do Parque Estadual Fontes do Ipiranga. Fonte: CETESB, 1999 e IAG, 1988. 
TABELA 26. Registros horários das temperaturas e da intensidade da ilha de Calor $\left({ }^{\circ} \mathrm{C}\right)$ nos dias 16 de outubro, 19 de novembro e 19 de dezembro de 1988, na Estação de Monitoramento Centro, Estação Meteorológica do Parque Estadual Fontes do Ipiranga. Fonte: CETESB, 1999 e IAG, 1988.

\begin{tabular}{|c|c|c|c|c|c|c|c|c|c|}
\hline Mês & \multicolumn{3}{|c|}{16 outubro 1988} & \multicolumn{3}{|c|}{19 novembro 1988} & \multicolumn{3}{|c|}{19 dezembro 1988} \\
\hline Hora & $\mathrm{EC}$ & $\mathrm{PE}$ & Int. & $\mathrm{EC}$ & $\mathrm{PE}$ & Int. & $\mathrm{EC}$ & $\mathrm{PE}$ & Int. \\
\hline 1 & 20 & 13,8 & 6,2 & 17 & 16,8 & 0,2 & 23 & 23,7 & $-0,7$ \\
\hline 2 & 19 & 13,5 & 5,5 & 16 & 16,7 & $-0,7$ & 23 & 23,6 & $-0,6$ \\
\hline 3 & 18 & 13,8 & 4,2 & 16 & 16,7 & $-0,7$ & 23 & 23,2 & $-0,2$ \\
\hline 4 & 18 & 14,0 & 4,0 & 16 & 16,8 & $-0,8$ & 22 & 22,8 & $-0,8$ \\
\hline 5 & 18 & 14,2 & 3,8 & 15 & 17,4 & $-2,4$ & 22 & 22,0 & 0,0 \\
\hline 6 & 18 & 14,9 & 3,1 & 15 & 18,1 & $-3,1$ & 21 & 21,4 & $-0,4$ \\
\hline 7 & 18 & 15,9 & 2,1 & 15 & 19,2 & $-4,2$ & 21 & 24,3 & $-3,3$ \\
\hline 8 & 19 & 17,1 & 1,9 & 16 & 22,4 & $-6,4$ & 24 & 25,7 & $-1,7$ \\
\hline 9 & 21 & 18,3 & 2,7 & 18 & 25,4 & $-7,4$ & 25 & 27,8 & $-2,8$ \\
\hline 10 & 22 & 19,3 & 2,7 & 21 & 27,5 & $-6,5$ & 27 & 28,6 & $-1,6$ \\
\hline 11 & 23 & 19,5 & 3,5 & 24 & 28,4 & $-4,4$ & 27 & 28,3 & $-1,3$ \\
\hline 12 & 23 & 16,6 & 6,4 & 26 & 29,4 & $-3,4$ & 28 & 29,8 & $-1,8$ \\
\hline 13 & 24 & 18,9 & 5,1 & 27 & 29,0 & $-2,0$ & 29 & 29,3 & $-0,3$ \\
\hline 14 & 23 & 17,2 & 5,8 & 27 & 29,8 & $-2,8$ & 29 & 30,0 & $-1,0$ \\
\hline 15 & 24 & 16,5 & 7,5 & 27 & 30,2 & $-3,2$ & 29 & 29,9 & $-0,9$ \\
\hline 16 & 22 & 16,0 & 6,0 & 28 & 21,7 & 6,3 & 29 & 27,5 & 1,5 \\
\hline 17 & 20 & 15,6 & 4,4 & 26 & 21,8 & 4,2 & 30 & 24,2 & 5,8 \\
\hline 18 & 20 & 15,0 & 5,0 & 22 & 21,2 & 0,8 & 28 & 23,7 & 4,3 \\
\hline 19 & 19 & 14,8 & 4,2 & 20 & 20,3 & $-0,3$ & 25 & 23,1 & 1,9 \\
\hline 20 & 19 & 14,7 & 4,3 & 20 & 20,1 & $-0,1$ & 23 & 22,5 & 0,5 \\
\hline 21 & 18 & 14,7 & 3,3 & 20 & 20,6 & $-0,6$ & 22 & 22,5 & $-0,5$ \\
\hline 22 & 18 & 14,6 & 3,4 & 20 & 20,5 & $-0,5$ & 22 & 22,3 & $-0,3$ \\
\hline 23 & 18 & 14,7 & 3,3 & 19 & 19,4 & $-0,4$ & 22 & 22,1 & $-0,1$ \\
\hline 24 & 18 & 14,7 & 3,3 & 18 & 19,2 & $-1,2$ & 22 & 21,9 & 0,1 \\
\hline
\end{tabular}



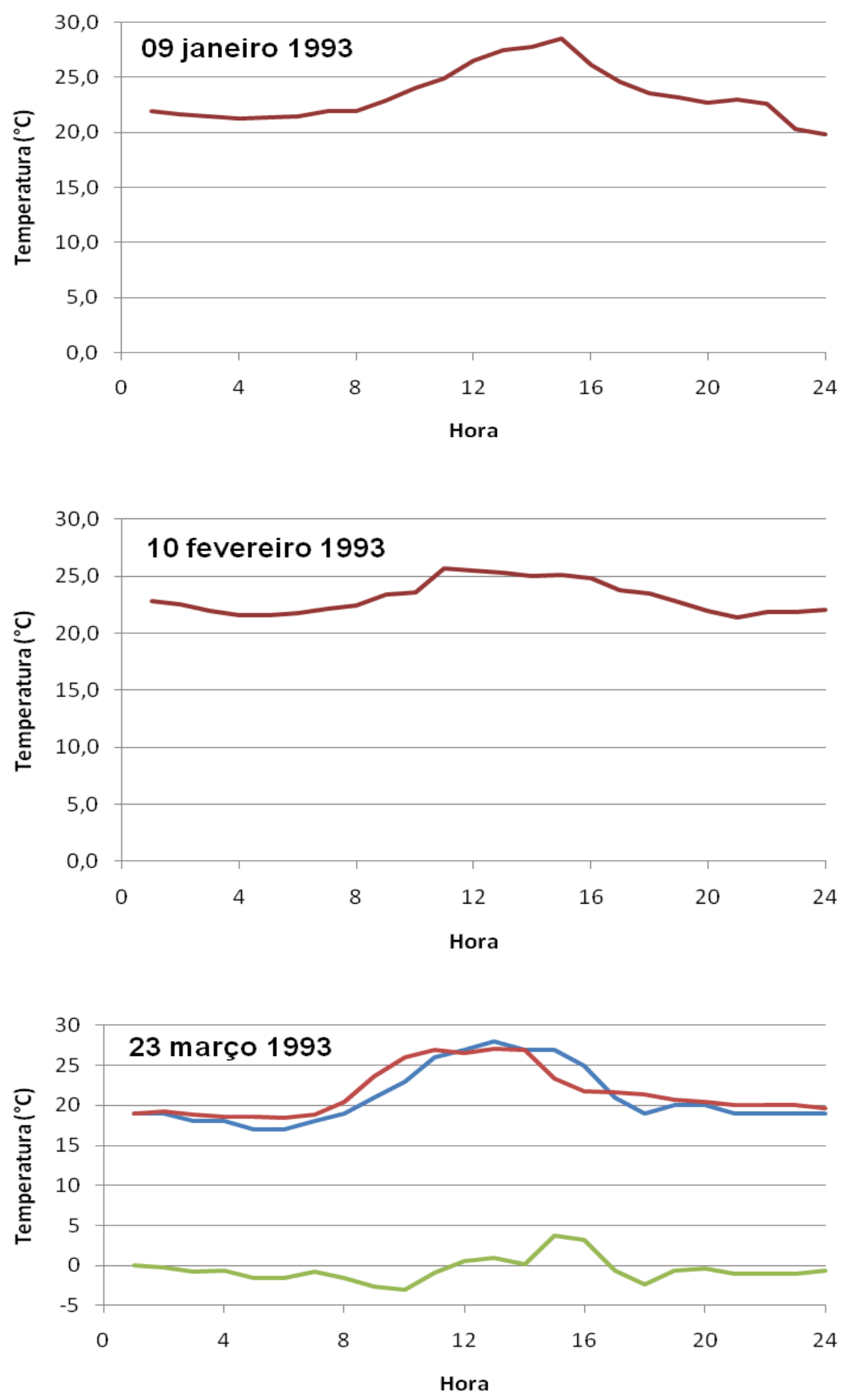

Pq. D. Pedro II —Pq. Estado Intensidade

FIGURA 69. Gráficos horários das temperaturas e da intensidade da ilha de Calor, nos dias 9 de janeiro, 10 de fevereiro e 23 de março de 1993, na Estação de Monitoramento do Pq. D. Pedro II, Estação Meteorológica do Parque Estadual Fontes do Ipiranga. Fonte: CETESB, 1999 e IAG, 1993. 
TABELA 27. Registros horários das temperaturas e da intensidade da ilha de Calor $\left({ }^{\circ} \mathrm{C}\right)$ nos dias 9 de janeiro, 10 de fevereiro e 23 de março de 1993, na Estação de Monitoramento do Pq. D. Pedro II, Estação Meteorológica do Parque Estadual Fontes do Ipiranga. Fonte: CETESB, 1999 e IAG, 1993.

\begin{tabular}{|c|c|c|c|c|c|c|c|c|c|}
\hline Mês & \multicolumn{3}{|c|}{9 Janeiro 1993} & \multicolumn{3}{|c|}{10 Fevereiro 1993} & \multicolumn{3}{|c|}{23 Março 1993} \\
\hline Hora & PDP & $\mathrm{PE}$ & Int. & PDP & $\mathrm{PE}$ & Int. & PDP & PE & Int. \\
\hline 1 & ND & 21,9 & ND & ND & 22,8 & ND & 19 & 19,0 & 0,0 \\
\hline 2 & ND & 21,7 & ND & ND & 22,5 & ND & 19 & 19,2 & $-0,2$ \\
\hline 3 & ND & 21,5 & ND & ND & 22,0 & ND & 18 & 18,8 & $-0,8$ \\
\hline 4 & ND & 21,3 & ND & ND & 21,6 & ND & 18 & 18,6 & $-0,6$ \\
\hline 5 & ND & 21,4 & ND & ND & 21,6 & ND & 17 & 18,6 & $-1,6$ \\
\hline 6 & ND & 21,5 & ND & ND & 21,8 & ND & 17 & 18,5 & $-1,5$ \\
\hline 7 & ND & 21,9 & ND & ND & 22,2 & ND & 18 & 18,8 & $-0,8$ \\
\hline 8 & ND & 21,9 & ND & ND & 22,4 & ND & 19 & 20,5 & $-1,5$ \\
\hline 9 & ND & 22,9 & ND & ND & 23,4 & ND & 21 & 23,6 & $-2,6$ \\
\hline 10 & ND & 24,0 & ND & ND & 23,6 & ND & 23 & 26,0 & $-3,0$ \\
\hline 11 & ND & 24,9 & ND & ND & 25,7 & ND & 26 & 26,9 & $-0,9$ \\
\hline 12 & ND & 26,5 & ND & ND & 25,5 & ND & 27 & 26,5 & 0,5 \\
\hline 13 & ND & 27,5 & ND & ND & 25,3 & ND & 28 & 27,1 & 0,9 \\
\hline 14 & ND & 27,8 & ND & ND & 25,0 & ND & 27 & 26,9 & 0,1 \\
\hline 15 & ND & 28,5 & ND & ND & 25,1 & ND & 27 & 23,3 & 3,7 \\
\hline 16 & ND & 26,1 & ND & ND & 24,8 & ND & 25 & 21,8 & 3,2 \\
\hline 17 & ND & 24,6 & ND & ND & 23,8 & ND & 21 & 21,6 & $-0,6$ \\
\hline 18 & ND & 23,6 & ND & ND & 23,5 & ND & 19 & 21,4 & $-2,4$ \\
\hline 19 & ND & 23,2 & ND & ND & 22,7 & ND & 20 & 20,7 & $-0,7$ \\
\hline 20 & ND & 22,7 & ND & ND & 22,0 & ND & 20 & 20,4 & $-0,4$ \\
\hline 21 & ND & 23,0 & ND & ND & 21,4 & ND & 19 & 20,0 & $-1,0$ \\
\hline 22 & ND & 22,6 & ND & ND & 21,9 & ND & 19 & 20,0 & $-1,0$ \\
\hline 23 & ND & 20,3 & ND & ND & 21,9 & ND & 19 & 20,0 & $-1,0$ \\
\hline 24 & ND & 19,8 & ND & ND & 22,1 & ND & 19 & 19,6 & $-0,6$ \\
\hline
\end{tabular}

ND - Dados não disponíveis. 

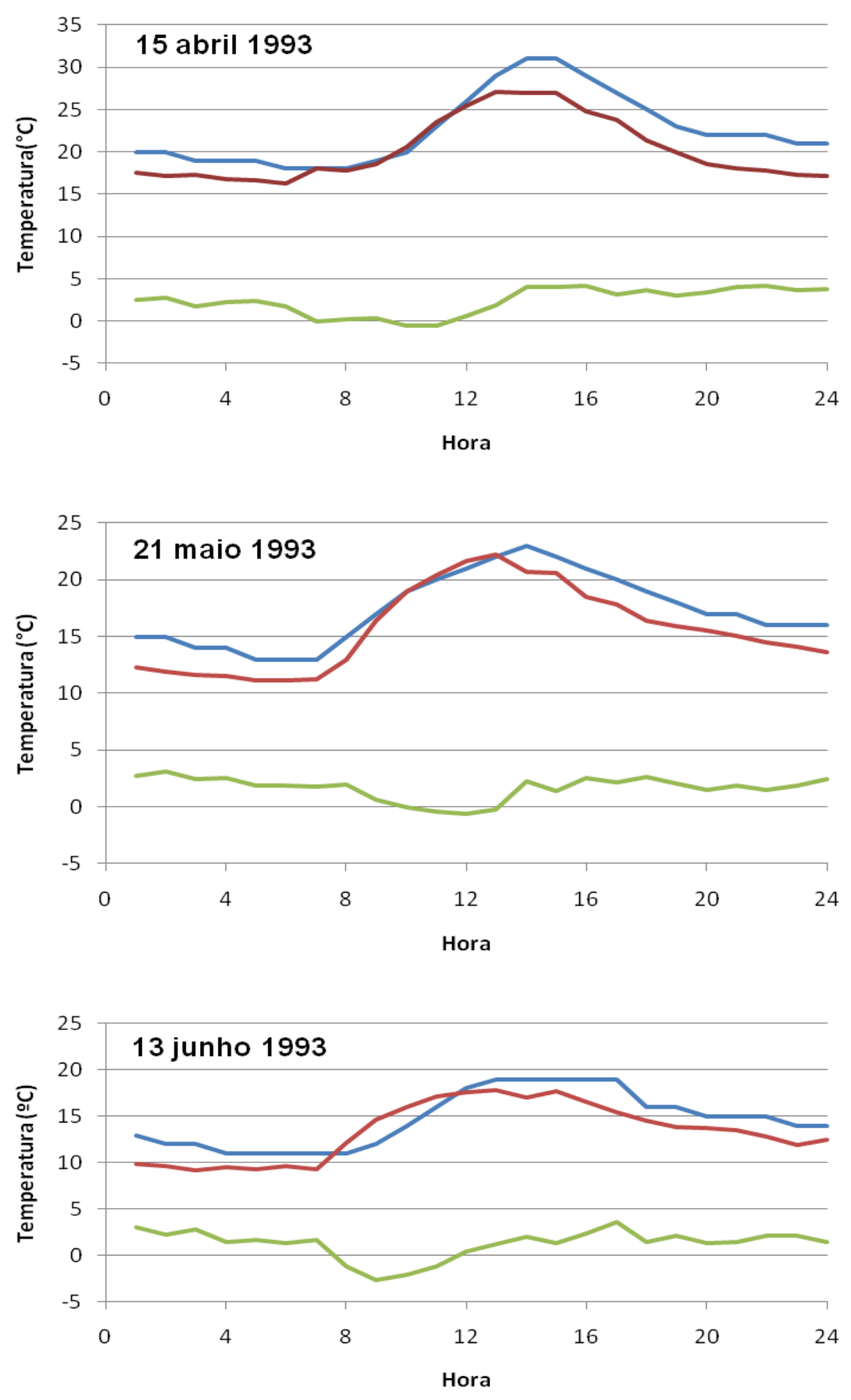

Pq. D. PedroII —Pq. Estado Intensidade

FIGURA 70. Gráficos horários das temperaturas e da intensidade da ilha de Calor, nos dias 15 de abril, 21 de maio e 13 de junho de 1993, na Estação de Monitoramento do Pq. D. Pedro II, Estação Meteorológica do Parque Estadual Fontes do Ipiranga. Fonte: CETESB, 1999 e IAG, 1993. 
TABELA 28. Registros horários das temperaturas e da intensidade da ilha de Calor $\left({ }^{\circ} \mathrm{C}\right)$ nos dias 15 de abril, 21 de maio e 13 de junho de 1993, na Estação de Monitoramento do Pq. D. Pedro II, Estação Meteorológica do Parque Estadual Fontes do Ipiranga. Fonte: CETESB, 1999 e IAG, 1993.

\begin{tabular}{|c|c|c|c|c|c|c|c|c|c|}
\hline Mês & \multicolumn{3}{|c|}{15 de abril de 1993} & \multicolumn{3}{|c|}{21 de maio de 1993} & \multicolumn{3}{|c|}{13 de junho de 1993} \\
\hline Hora & PDP & $\mathrm{PE}$ & Int. & PDP & $\mathrm{PE}$ & Int. & PDP & $\mathrm{PE}$ & Int. \\
\hline 1 & 20 & 17,5 & 2,5 & 15 & 12,3 & 2,7 & 13 & 9,9 & 3,1 \\
\hline 2 & 20 & 17,2 & 2,8 & 15 & 11,9 & 3,1 & 12 & 9,7 & 2,3 \\
\hline 3 & 19 & 17,3 & 1,7 & 14 & 11,6 & 2,4 & 12 & 9,2 & 2,8 \\
\hline 4 & 19 & 16,8 & 2,2 & 14 & 11,5 & 2,5 & 11 & 9,5 & 1,5 \\
\hline 5 & 19 & 16,6 & 2,4 & 13 & 11,1 & 1,9 & 11 & 9,3 & 1,7 \\
\hline 6 & 18 & 16,2 & 1,8 & 13 & 11,1 & 1,9 & 11 & 9,6 & 1,4 \\
\hline 7 & 18 & 18,0 & 0,0 & 13 & 11,2 & 1,8 & 11 & 9,3 & 1,7 \\
\hline 8 & 18 & 17,8 & 0,2 & 15 & 13,0 & 2,0 & 11 & 12,1 & $-1,1$ \\
\hline 9 & 19 & 18,6 & 0,4 & 17 & 16,4 & 0,6 & 12 & 14,6 & $-2,6$ \\
\hline 10 & 20 & 20,6 & $-0,6$ & 19 & 19,0 & 0,0 & 14 & 16,0 & $-2,0$ \\
\hline 11 & 23 & 23,5 & $-0,5$ & 20 & 20,4 & $-0,4$ & 16 & 17,1 & $-1,1$ \\
\hline 12 & 26 & 25,4 & 0,6 & 21 & 21,6 & $-0,6$ & 18 & 17,6 & 0,4 \\
\hline 13 & 29 & 27,1 & 1,9 & 22 & 22,2 & $-0,2$ & 19 & 17,8 & 1,2 \\
\hline 14 & 31 & 27,0 & 4,0 & 23 & 20,7 & 2,3 & 19 & 17,0 & 2,0 \\
\hline 15 & 31 & 27,0 & 4,0 & 22 & 20,6 & 1,4 & 19 & 17,7 & 1,3 \\
\hline 16 & 29 & 24,8 & 4,2 & 21 & 18,5 & 2,5 & 19 & 16,6 & 2,4 \\
\hline 17 & 27 & 23,8 & 3,2 & 20 & 17,8 & 2,2 & 19 & 15,4 & 3,6 \\
\hline 18 & 25 & 21,4 & 3,6 & 19 & 16,4 & 2,6 & 16 & 14,5 & 1,5 \\
\hline 19 & 23 & 20,0 & 3,0 & 18 & 15,9 & 2,1 & 16 & 13,8 & 2,2 \\
\hline 20 & 22 & 18,6 & 3,4 & 17 & 15,5 & 1,5 & 15 & 13,7 & 1,3 \\
\hline 21 & 22 & 18,0 & 4,0 & 17 & 15,1 & 1,9 & 15 & 13,5 & 1,5 \\
\hline 22 & 22 & 17,8 & 4,2 & 16 & 14,5 & 1,5 & 15 & 12,8 & 2,2 \\
\hline 23 & 21 & 17,3 & 3,7 & 16 & 14,1 & 1,9 & 14 & 11,9 & 2,1 \\
\hline 24 & 21 & 17,2 & 3,8 & 16 & 13,6 & 2,4 & 14 & 12,5 & 1,5 \\
\hline
\end{tabular}



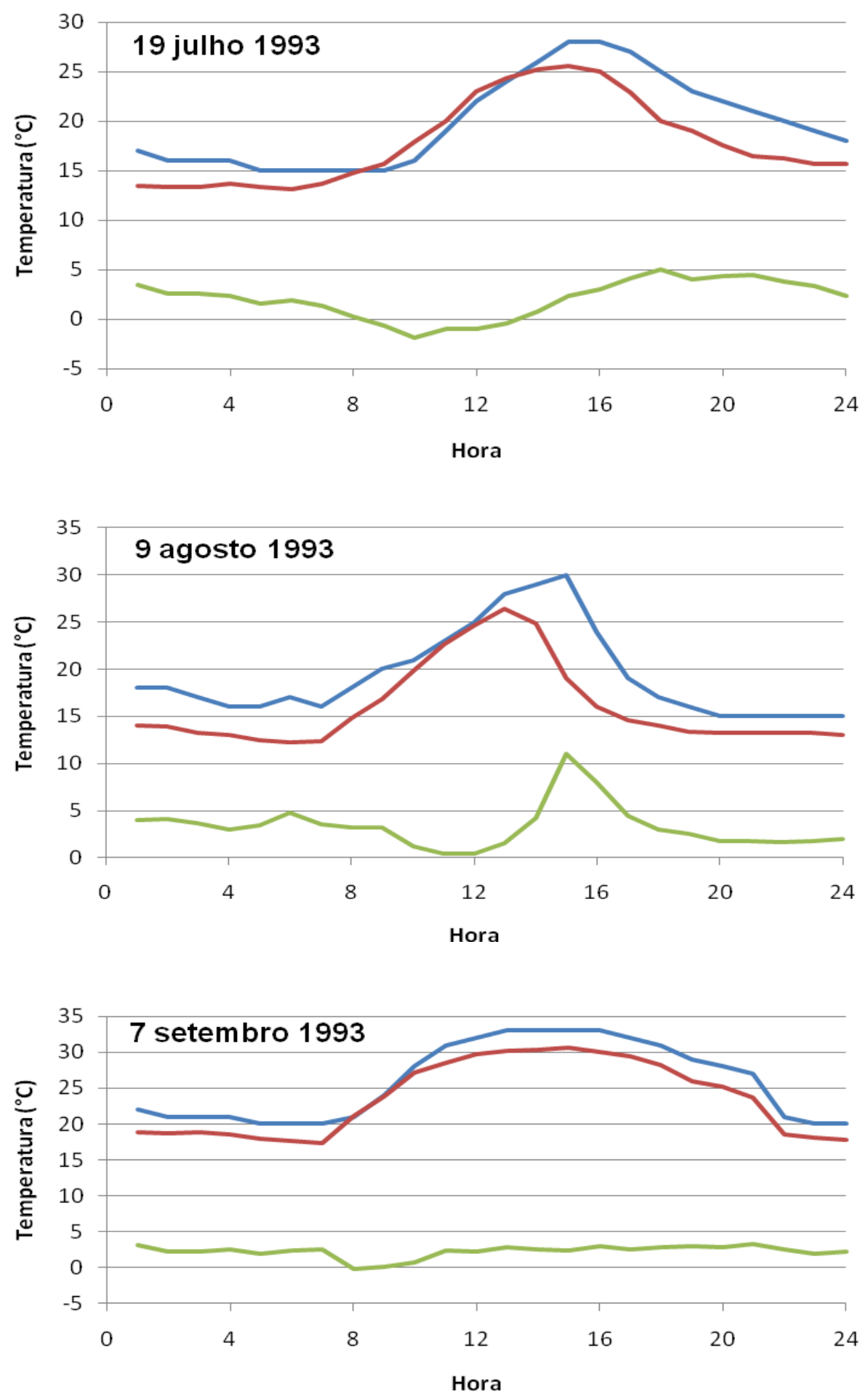

Pq. D. Pedro II —Pq. Estado Intensidade

FIGURA 71. Gráficos horários das temperaturas e da intensidade da ilha de Calor, nos dias 19 de julho, 9 de agosto e 7 de setembro de 1993, na Estação de Monitoramento do Pq. D. Pedro II, Estação Meteorológica do Parque Estadual Fontes do Ipiranga. Fonte: CETESB, 1999 e IAG, 1993. 
TABELA 29. Registros horários das temperaturas e da intensidade da ilha de Calor $\left({ }^{\circ} \mathrm{C}\right)$ nos dias 19 de julho, 9 de agosto e 7 de setembro de 1993, na Estação de Monitoramento do Pq. D. Pedro II, Estação Meteorológica do Parque Estadual Fontes do Ipiranga. Fonte: CETESB, 1999 e IAG, 1993.

\begin{tabular}{|c|c|c|c|c|c|c|c|c|c|}
\hline Mês & \multicolumn{3}{|c|}{19 de julho de 1993} & \multicolumn{3}{|c|}{9 de agosto de 1993} & \multicolumn{3}{|c|}{7 de setembro de 1993} \\
\hline Hora & PDP & $\mathrm{PE}$ & Int. & PDP & $\mathrm{PE}$ & Int. & PDP & $\mathrm{PE}$ & Int. \\
\hline 1 & 17 & 13,5 & 3,5 & 18 & 14,0 & 4,0 & 22 & 18,8 & 3,2 \\
\hline 2 & 16 & 13,4 & 2,6 & 18 & 13,9 & 4,1 & 21 & 18,7 & 2,3 \\
\hline 3 & 16 & 13,4 & 2,6 & 17 & 13,3 & 3,7 & 21 & 18,8 & 2,2 \\
\hline 4 & 16 & 13,7 & 2,3 & 16 & 13,0 & 3,0 & 21 & 18,5 & 2,5 \\
\hline 5 & 15 & 13,4 & 1,6 & 16 & 12,5 & 3,5 & 20 & 18,0 & 2,0 \\
\hline 6 & 15 & 13,1 & 1,9 & 17 & 12,2 & 4,8 & 20 & 17,6 & 2,4 \\
\hline 7 & 15 & 13,7 & 1,3 & 16 & 12,4 & 3,6 & 20 & 17,4 & 2,6 \\
\hline 8 & 15 & 14,8 & 0,2 & 18 & 14,8 & 3,2 & 21 & 21,1 & $-0,1$ \\
\hline 9 & 15 & 15,7 & $-0,7$ & 20 & 16,8 & 3,2 & 24 & 23,8 & 0,2 \\
\hline 10 & 16 & 17,9 & $-1,9$ & 21 & 19,8 & 1,2 & 28 & 27,2 & 0,8 \\
\hline 11 & 19 & 20,0 & $-1,0$ & 23 & 22,6 & 0,4 & 31 & 28,6 & 2,4 \\
\hline 12 & 22 & 23,0 & $-1,0$ & 25 & 24,6 & 0,4 & 32 & 29,8 & 2,2 \\
\hline 13 & 24 & 24,4 & $-0,4$ & 28 & 26,4 & 1,6 & 33 & 30,2 & 2,8 \\
\hline 14 & 26 & 25,2 & 0,8 & 29 & 24,8 & 4,2 & 33 & 30,4 & 2,6 \\
\hline 15 & 28 & 25,6 & 2,4 & 30 & 19,0 & 11,0 & 33 & 30,6 & 2,4 \\
\hline 16 & 28 & 25,0 & 3,0 & 24 & 16,0 & 8,0 & 33 & 30,0 & 3,0 \\
\hline 17 & 27 & 22,9 & 4,1 & 19 & 14,6 & 4,4 & 32 & 29,4 & 2,6 \\
\hline 18 & 25 & 20,0 & 5,0 & 17 & 14,0 & 3,0 & 31 & 28,2 & 2,8 \\
\hline 19 & 23 & 19,0 & 4,0 & 16 & 13,4 & 2,6 & 29 & 26,0 & 3,0 \\
\hline 20 & 22 & 17,6 & 4,4 & 15 & 13,2 & 1,8 & 28 & 25,2 & 2,8 \\
\hline 21 & 21 & 16,5 & 4,5 & 15 & 13,2 & 1,8 & 27 & 23,7 & 3,3 \\
\hline 22 & 20 & 16,2 & 3,8 & 15 & 13,3 & 1,7 & 21 & 18,5 & 2,5 \\
\hline 23 & 19 & 15,7 & 3,3 & 15 & 13,2 & 1,8 & 20 & 18,1 & 1,9 \\
\hline 24 & 18 & 15,7 & 2,3 & 15 & 13,0 & 2,0 & 20 & 17,8 & 2,2 \\
\hline
\end{tabular}



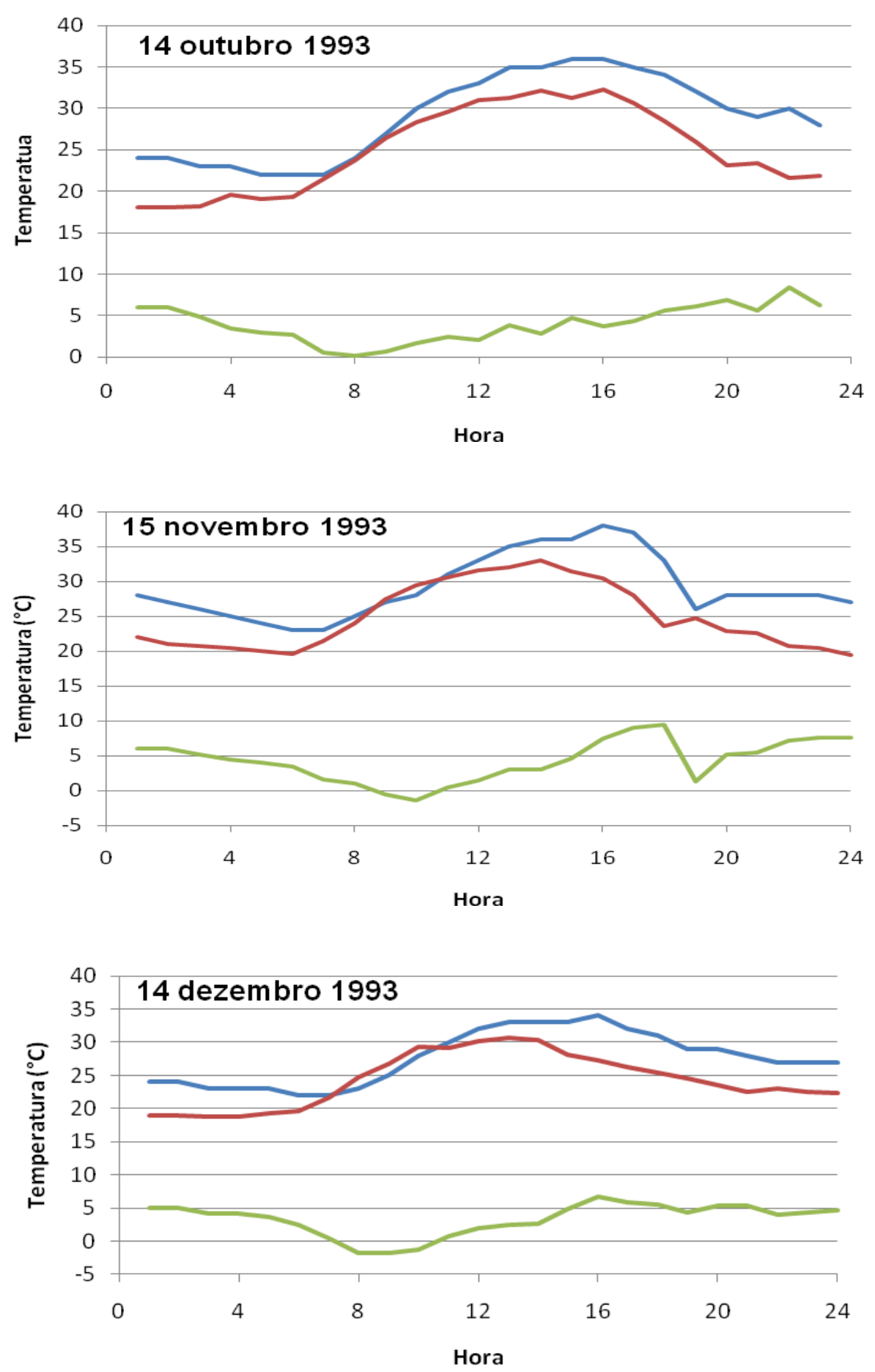

—Pq. D. Pedro II — Pq. Estado Intensidade

FIGURA 72. Gráficos horários das temperaturas e da intensidade da ilha de Calor, nos dias 14 de outubro, 15 de novembro e 14 de dezembro de 1993, na Estação de Monitoramento do Pq. D. Pedro II, Estação Meteorológica do Parque Estadual Fontes do Ipiranga. Fonte: CETESB, 1999 e IAG, 1993. 
TABELA 30. Registros horários das temperaturas e da intensidade da ilha de Calor $\left({ }^{\circ} \mathrm{C}\right)$ nos dias 14 de outubro, 15 de novembro e 14 de dezembro / 1993, na Estação de Monitoramento do Pq. D. Pedro II, Estação Meteorológica do Parque Estadual Fontes do Ipiranga. Fonte: CETESB, 1999 e IAG, 1993.

\begin{tabular}{|c|c|c|c|c|c|c|c|c|c|}
\hline Mês & \multicolumn{3}{|c|}{14 de outubro de 1993} & \multicolumn{3}{|c|}{15 de novembro de 1993} & \multicolumn{3}{|c|}{14 de dezembro de 1993} \\
\hline Hora & PDP & $\mathrm{PE}$ & Int. & PDP & $\mathrm{PE}$ & Int. & PDP & $\mathrm{PE}$ & Int. \\
\hline 1 & 24 & 18,0 & 6,0 & 28 & 22,0 & 6,0 & 24 & 19,0 & 5,0 \\
\hline 2 & 24 & 18,0 & 6,0 & 27 & 21,0 & 6,0 & 24 & 19,0 & 5,0 \\
\hline 3 & 23 & 18,2 & 4,8 & 26 & 20,8 & 5,2 & 23 & 18,8 & 4,2 \\
\hline 4 & 23 & 19,6 & 3,4 & 25 & 20,5 & 4,5 & 23 & 18,8 & 4,2 \\
\hline 5 & 22 & 19,1 & 2,9 & 24 & 20,0 & 4,0 & 23 & 19,3 & 3,7 \\
\hline 6 & 22 & 19,3 & 2,7 & 23 & 19,6 & 3,4 & 22 & 19,6 & 2,4 \\
\hline 7 & 22 & 21,5 & 0,5 & 23 & 21,4 & 1,6 & 22 & 21,6 & 0,4 \\
\hline 8 & 24 & 23,8 & 0,2 & 25 & 24,0 & 1,0 & 23 & 24,7 & $-1,7$ \\
\hline 9 & 27 & 26,4 & 0,6 & 27 & 27,5 & $-0,5$ & 25 & 26,7 & $-1,7$ \\
\hline 10 & 30 & 28,3 & 1,7 & 28 & 29,4 & $-1,4$ & 28 & 29,3 & $-1,3$ \\
\hline 11 & 32 & 29,6 & 2,4 & 31 & 30,6 & 0,4 & 30 & 29,2 & 0,8 \\
\hline 12 & 33 & 31,0 & 2,0 & 33 & 31,6 & 1,4 & 32 & 30,1 & 1,9 \\
\hline 13 & 35 & 31,2 & 3,8 & 35 & 32,0 & 3,0 & 33 & 30,6 & 2,4 \\
\hline 14 & 35 & 32,2 & 2,8 & 36 & 33,0 & 3,0 & 33 & 30,4 & 2,6 \\
\hline 15 & 36 & 31,3 & 4,7 & 36 & 31,4 & 4,6 & 33 & 28,1 & 4,9 \\
\hline 16 & 36 & 32,3 & 3,7 & 38 & 30,5 & 7,5 & 34 & 27,2 & 6,8 \\
\hline 17 & 35 & 30,6 & 4,4 & 37 & 28,0 & 9,0 & 32 & 26,2 & 5,8 \\
\hline 18 & 34 & 28,4 & 5,6 & 33 & 23,6 & 9,4 & 31 & 25,4 & 5,6 \\
\hline 19 & 32 & 25,9 & 6,1 & 26 & 24,7 & 1,3 & 29 & 24,6 & 4,4 \\
\hline 20 & 30 & 23,1 & 6,9 & 28 & 22,9 & 5,1 & 29 & 23,6 & 5,4 \\
\hline 21 & 29 & 23,4 & 5,6 & 28 & 22,6 & 5,4 & 28 & 22,6 & 5,4 \\
\hline 22 & 30 & 21,6 & 8,4 & 28 & 20,8 & 7,2 & 27 & 23,0 & 4,0 \\
\hline 23 & 28 & 21,8 & 6,2 & 28 & 20,4 & 7,6 & 27 & 22,6 & 4,4 \\
\hline 24 & 27 & 20,4 & 6,6 & 27 & 19,4 & 7,6 & 27 & 22,4 & 4,6 \\
\hline
\end{tabular}



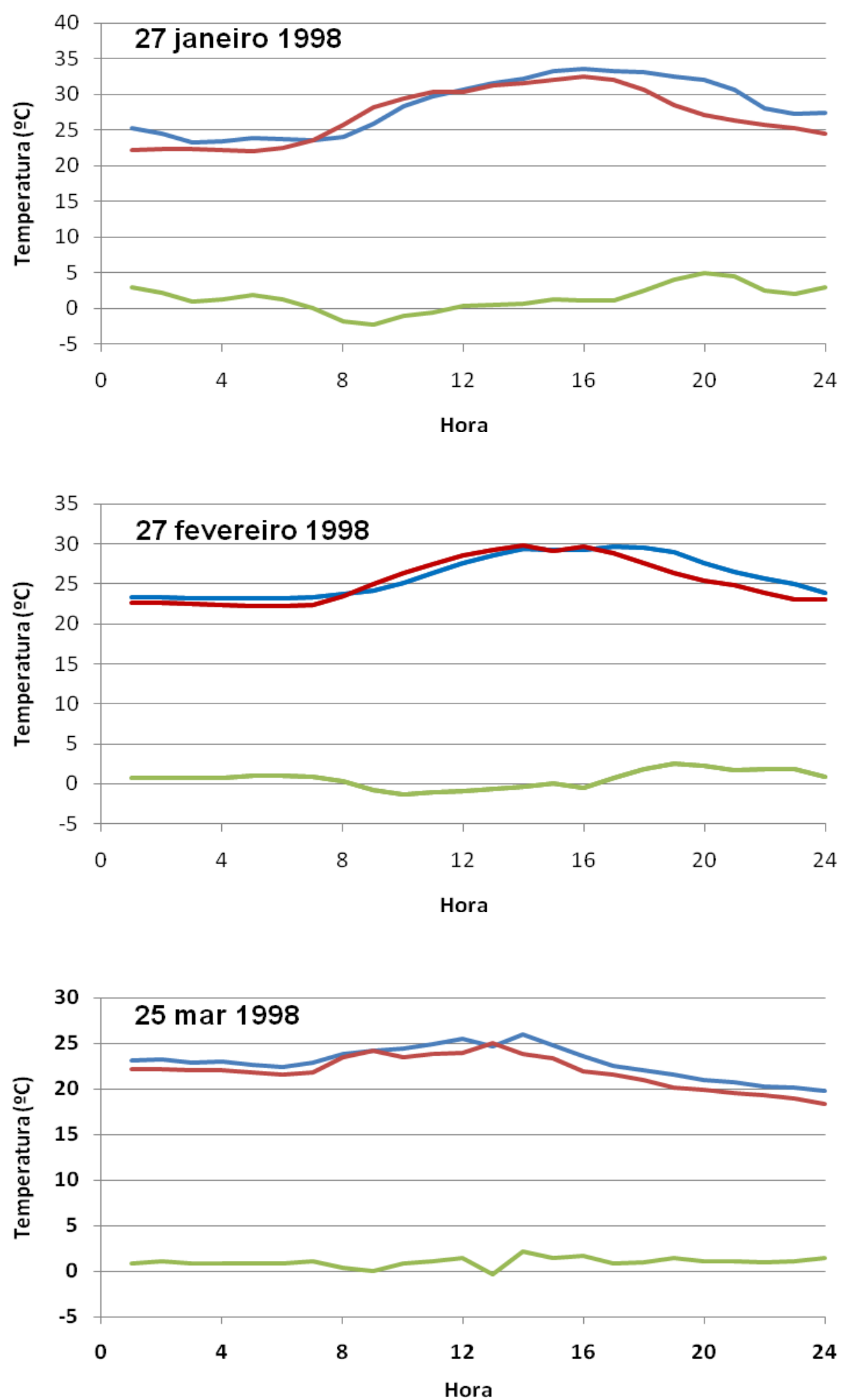

Pq. D. Pedro II — Pq. Estado Intensidade

FIGURA 73. Gráficos horários das temperaturas e da intensidade da ilha de Calor, nos dias 27 de janeiro, 27 de fevereiro e 25 de março de 1998, na Estação de Monitoramento do Pq. D. Pedro II, Estação Meteorológica do Parque Estadual Fontes do Ipiranga. Fonte: CETESB, 1999 e IAG, 1998. 
TABELA 31. Registros horários das temperaturas e da intensidade da ilha de Calor $\left({ }^{\circ} \mathrm{C}\right)$ nos dias 27 de janeiro, 27 de fevereiro e 25 de março de 1998, na Estação de Monitoramento do Pq. D. Pedro II, Estação Meteorológica do Parque Estadual Fontes do Ipiranga. Fonte: CETESB, 1999 e IAG, 1998.

\begin{tabular}{|c|c|c|c|c|c|c|c|c|c|}
\hline Mês & \multicolumn{3}{|c|}{27 Janeiro 1998} & \multicolumn{3}{|c|}{27 Fevereiro 1998} & \multicolumn{3}{|c|}{25 Março 1998} \\
\hline Hora & PDP & $\mathrm{PE}$ & Int. & PDP & $\mathrm{PE}$ & Int. & PDP & $\mathrm{PE}$ & Int. \\
\hline 1 & 25,2 & 22,2 & 3,0 & 23,3 & 22,6 & 0,7 & 23,1 & 22,2 & 0,9 \\
\hline 2 & 24,5 & 22,3 & 2,2 & 23,3 & 22,6 & 0,7 & 23,3 & 22,2 & 1,1 \\
\hline 3 & 23,3 & 22,3 & 1,0 & 23,2 & 22,5 & 0,7 & 22,9 & 22,1 & 0,8 \\
\hline 4 & 23,4 & 22,2 & 1,2 & 23,2 & 22,4 & 0,8 & 23 & 22,1 & 0,9 \\
\hline 5 & 23,9 & 22,1 & 1,8 & 23,2 & 22,2 & 1,0 & 22,7 & 21,8 & 0,9 \\
\hline 6 & 23,8 & 22,5 & 1,3 & 23,2 & 22,2 & 1,0 & 22,4 & 21,6 & 0,8 \\
\hline 7 & 23,6 & 23,6 & 0,0 & 23,3 & 22,4 & 0,9 & 22,9 & 21,8 & 1,1 \\
\hline 8 & 24 & 25,8 & $-1,8$ & 23,7 & 23,4 & 0,3 & 23,9 & 23,5 & 0,4 \\
\hline 9 & 25,9 & 28,2 & $-2,3$ & 24,2 & 25,0 & $-0,8$ & 24,2 & 24,2 & 0,0 \\
\hline 10 & 28,3 & 29,4 & $-1,1$ & 25,1 & 26,4 & $-1,3$ & 24,4 & 23,5 & 0,9 \\
\hline 11 & 29,7 & 30,3 & $-0,6$ & 26,4 & 27,4 & $-1,0$ & 24,9 & 23,8 & 1,1 \\
\hline 12 & 30,7 & 30,4 & 0,3 & 27,6 & 28,5 & $-0,9$ & 25,5 & 24,0 & 1,5 \\
\hline 13 & 31,6 & 31,2 & 0,4 & 28,5 & 29,2 & $-0,7$ & 24,7 & 25,0 & $-0,3$ \\
\hline 14 & 32,2 & 31,6 & 0,6 & 29,4 & 29,8 & $-0,4$ & 26 & 23,8 & 2,2 \\
\hline 15 & 33,3 & 32,1 & 1,2 & 29,2 & 29,1 & 0,1 & 24,8 & 23,4 & 1,4 \\
\hline 16 & 33,6 & 32,5 & 1,1 & 29,2 & 29,7 & $-0,5$ & 23,6 & 21,9 & 1,7 \\
\hline 17 & 33,2 & 32,1 & 1,1 & 29,6 & 28,8 & 0,8 & 22,5 & 21,6 & 0,9 \\
\hline 18 & 33,1 & 30,7 & 2,4 & 29,5 & 27,6 & 1,9 & 22 & 21,0 & 1,0 \\
\hline 19 & 32,5 & 28,5 & 4,0 & 28,9 & 26,4 & 2,5 & 21,6 & 20,1 & 1,5 \\
\hline 20 & 32 & 27,1 & 4,9 & 27,6 & 25,4 & 2,2 & 21 & 19,9 & 1,1 \\
\hline 21 & 30,7 & 26,3 & 4,4 & 26,5 & 24,8 & 1,7 & 20,7 & 19,6 & 1,1 \\
\hline 22 & 28,1 & 25,7 & 2,4 & 25,6 & 23,8 & 1,8 & 20,3 & 19,3 & 1,0 \\
\hline 23 & 27,3 & 25,3 & 2,0 & 24,9 & 23,0 & 1,9 & 20,1 & 19,0 & 1,1 \\
\hline 24 & 27,4 & 24,5 & 2,9 & 23,9 & 23,0 & 0,9 & 19,8 & 18,4 & 1,4 \\
\hline
\end{tabular}



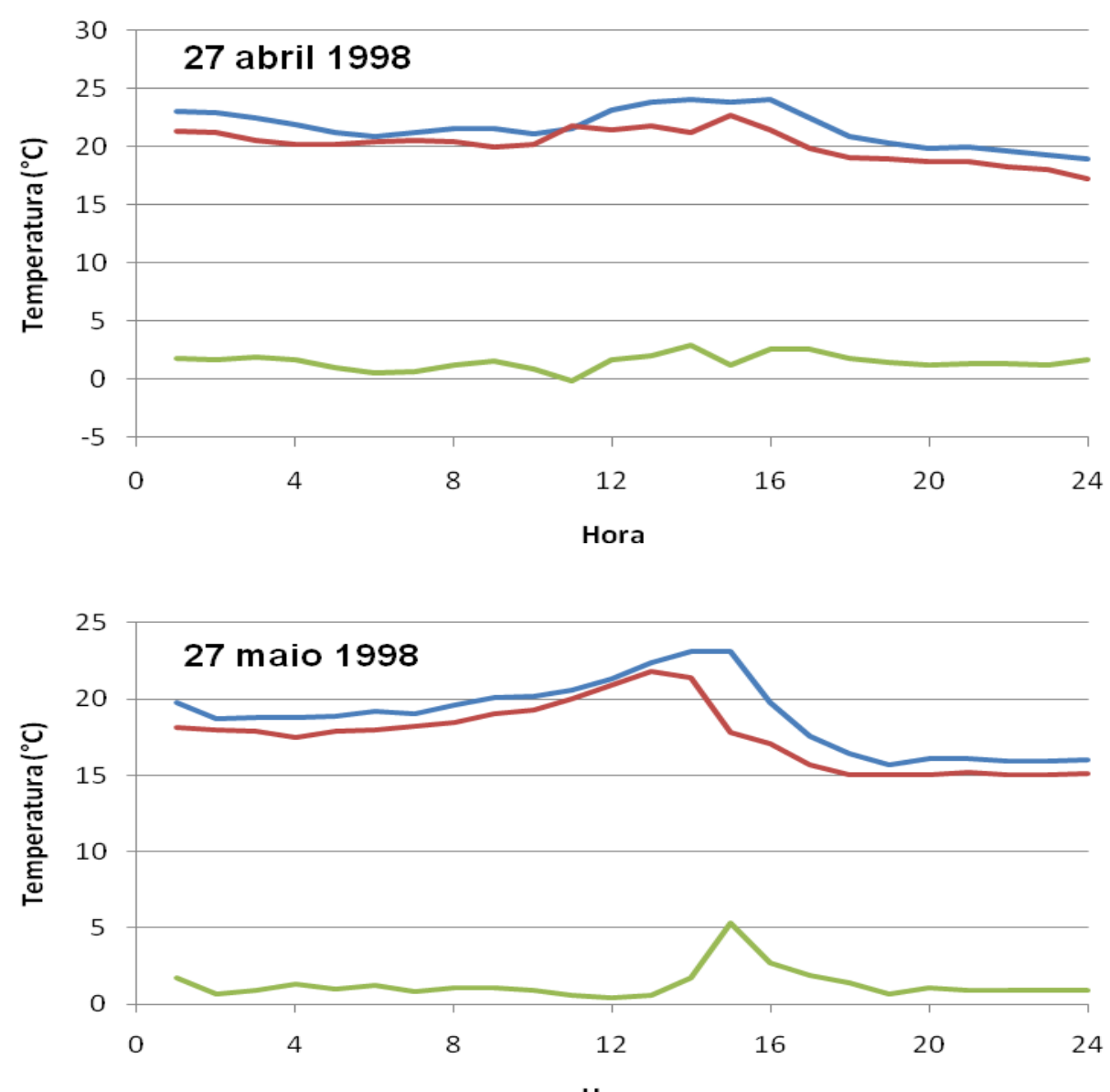

Hora

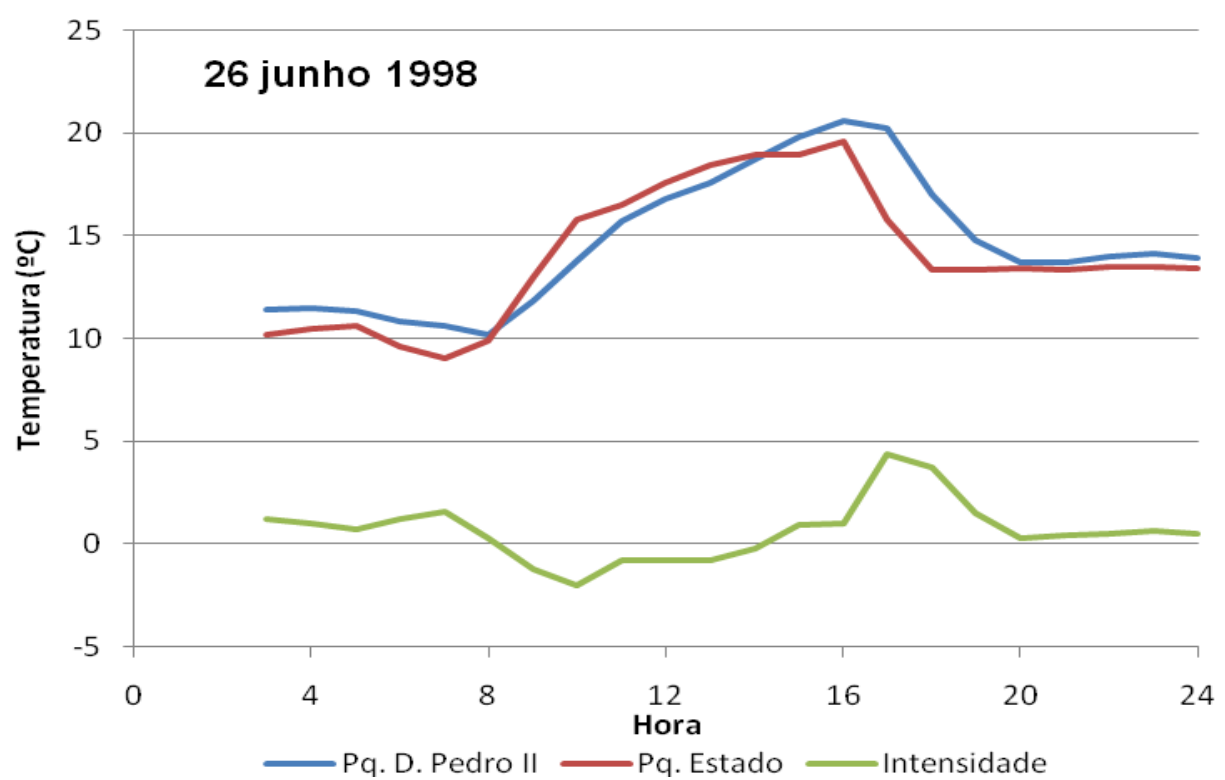

FIGURA 74. Gráficos horários das temperaturas e da intensidade da ilha de Calor, nos dias 25 de abril, 27 de maio e 26 de junho de 1998, na Estação de Monitoramento do Pq. D. Pedro II, Estação Meteorológica do Parque Estadual Fontes do Ipiranga. Fonte: CETESB, 1999 e IAG, 1998. 
TABELA 32. Registros horários das temperaturas e da intensidade da ilha de Calor $\left({ }^{\circ} \mathrm{C}\right)$ nos dias 25 de abril, 27 de maio e 26 junho de 1998, na Estação de Monitoramento do Pq. D. Pedro II, Estação Meteorológica do Parque Estadual Fontes do Ipiranga. Fonte: CETESB, 1999 e IAG, 1998.

\begin{tabular}{|c|c|c|c|c|c|c|c|c|c|}
\hline Mês & \multicolumn{3}{|c|}{25 abril 1998} & \multicolumn{3}{|c|}{27 maio 1998} & \multicolumn{3}{|c|}{26 junho 1998} \\
\hline Hora & PDP & $\mathrm{PE}$ & Int. & PDP & PE & Int. & PDP & $\mathrm{PE}$ & Int. \\
\hline 1 & 23,1 & 21,3 & 1,8 & 19,8 & 18,1 & 1,7 & 11,5 & 10,5 & 1,0 \\
\hline 2 & 22,9 & 21,2 & 1,7 & 18,7 & 18,0 & 0,7 & 11,5 & 9,9 & 1,6 \\
\hline 3 & 22,5 & 20,6 & 1,9 & 18,8 & 17,9 & 0,9 & 11,4 & 10,2 & 1,2 \\
\hline 4 & 21,9 & 20,2 & 1,7 & 18,8 & 17,5 & 1,3 & 11,5 & 10,5 & 1,0 \\
\hline 5 & 21,2 & 20,2 & 1,0 & 18,9 & 17,9 & 1,0 & 11,3 & 10,6 & 0,7 \\
\hline 6 & 20,9 & 20,4 & 0,5 & 19,2 & 18,0 & 1,2 & 10,8 & 9,6 & 1,2 \\
\hline 7 & 21,2 & 20,5 & 0,7 & 19 & 18,2 & 0,8 & 10,6 & 9,0 & 1,6 \\
\hline 8 & 21,6 & 20,4 & 1,2 & 19,6 & 18,5 & 1,1 & 10,2 & 9,9 & 0,3 \\
\hline 9 & 21,6 & 20,0 & 1,6 & 20,1 & 19,0 & 1,1 & 11,8 & 13,0 & $-1,2$ \\
\hline 10 & 21,1 & 20,2 & 0,9 & 20,2 & 19,3 & 0,9 & 13,8 & 15,8 & $-2,0$ \\
\hline 11 & 21,6 & 21,8 & $-0,2$ & 20,6 & 20,0 & 0,6 & 15,7 & 16,5 & $-0,8$ \\
\hline 12 & 23,2 & 21,5 & 1,7 & 21,3 & 20,9 & 0,4 & 16,8 & 17,6 & $-0,8$ \\
\hline 13 & 23,8 & 21,8 & 2,0 & 22,4 & 21,8 & 0,6 & 17,6 & 18,4 & $-0,8$ \\
\hline 14 & 24,1 & 21,2 & 2,9 & 23,1 & 21,4 & 1,7 & 18,7 & 18,9 & $-0,2$ \\
\hline 15 & 23,9 & 22,7 & 1,2 & 23,1 & 17,8 & 5,3 & 19,8 & 18,9 & 0,9 \\
\hline 16 & 24,1 & 21,5 & 2,6 & 19,8 & 17,1 & 2,7 & 20,6 & 19,6 & 1,0 \\
\hline 17 & 22,5 & 19,9 & 2,6 & 17,6 & 15,7 & 1,9 & 20,2 & 15,8 & 4,4 \\
\hline 18 & 20,9 & 19,1 & 1,8 & 16,4 & 15,0 & 1,4 & 17 & 13,3 & 3,7 \\
\hline 19 & 20,3 & 18,9 & 1,4 & 15,7 & 15,0 & 0,7 & 14,8 & 13,3 & 1,5 \\
\hline 20 & 19,9 & 18,7 & 1,2 & 16,1 & 15,0 & 1,1 & 13,7 & 13,4 & 0,3 \\
\hline 21 & 20 & 18,7 & 1,3 & 16,1 & 15,2 & 0,9 & 13,7 & 13,3 & 0,4 \\
\hline 22 & 19,6 & 18,3 & 1,3 & 15,9 & 15,0 & 0,9 & 14 & 13,5 & 0,5 \\
\hline 23 & 19,3 & 18,1 & 1,2 & 15,9 & 15,0 & 0,9 & 14,1 & 13,5 & 0,6 \\
\hline 24 & 19 & 17,3 & 1,7 & 16 & 15,1 & 0,9 & 13,9 & 13,4 & 0,5 \\
\hline
\end{tabular}



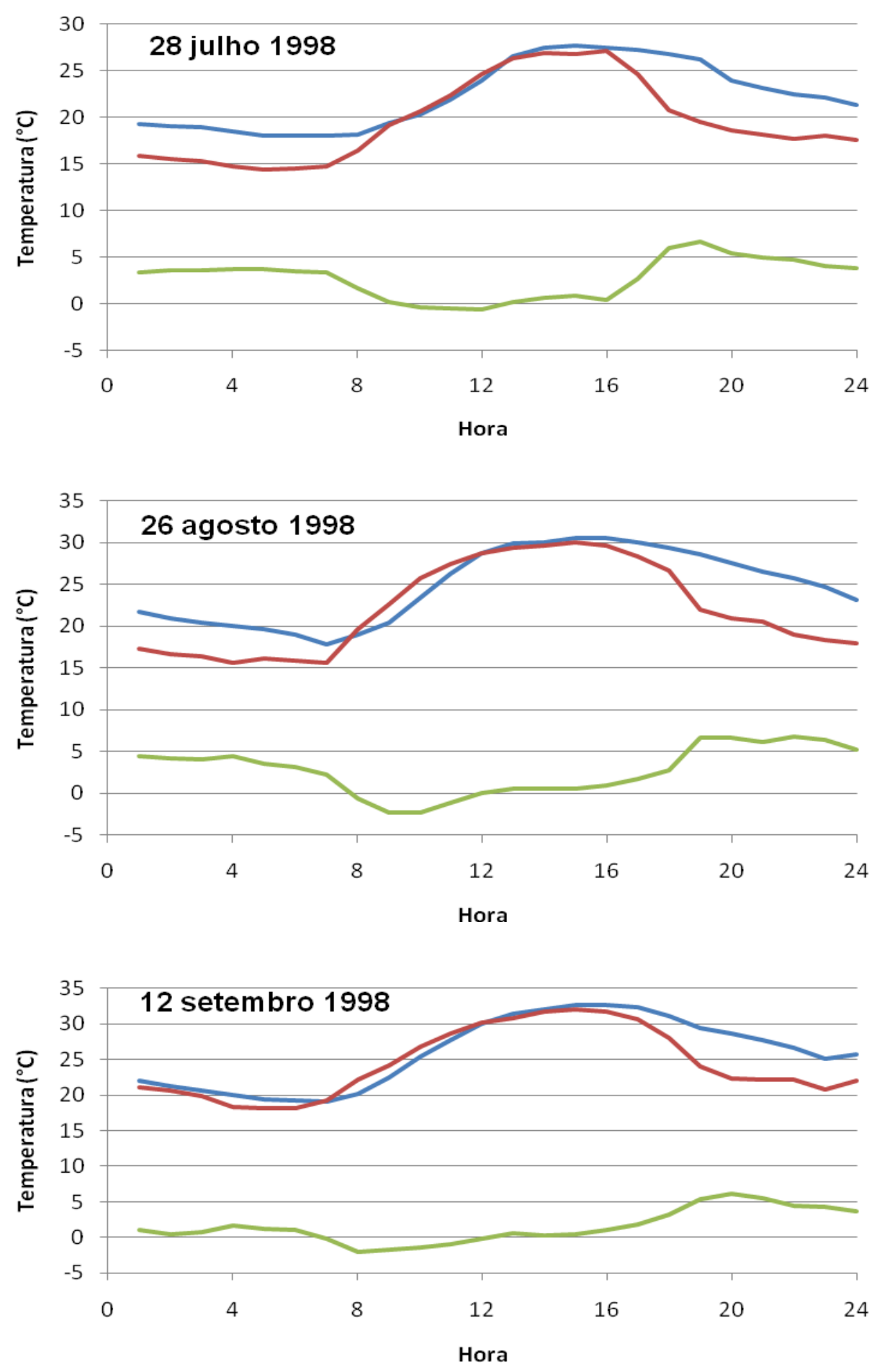

Pq. D. Pedro II — Pq. Estado Intensidade

FIGURA 75. Gráficos horários das temperaturas e da intensidade da ilha de Calor, nos dias 28 de julho, 26 de agosto e 12 de setembro de 1998, na Estação de Monitoramento do Pq. D. Pedro II, Estação Meteorológica do Parque Estadual Fontes do Ipiranga. Fonte: CETESB, 1999 e IAG, 1998. 
TABELA 33. Registros horários das temperaturas e da intensidade da ilha de Calor $\left({ }^{\circ} \mathrm{C}\right)$ nos dias 28 de julho, 26 de agosto e 12 de setembro de 1998, na Estação de Monitoramento do Pq. D. Pedro II, Estação Meteorológica do Parque Estadual Fontes do Ipiranga. Fonte: CETESB, 1999 e IAG, 1998.

\begin{tabular}{|c|c|c|c|c|c|c|c|c|c|}
\hline Mês & \multicolumn{3}{|c|}{28 de julho 1998} & \multicolumn{3}{|c|}{26 de agosto de 1998} & \multicolumn{3}{|c|}{12 de setembro de 1998} \\
\hline Hora & PDP & $\mathrm{PE}$ & Int. & PDP & $\mathrm{PE}$ & Int. & PDP & $\mathrm{PE}$ & Int. \\
\hline 1 & 19,3 & 15,9 & 3,4 & 21,7 & 17,3 & 4,4 & 22,1 & 21,1 & 1,0 \\
\hline 2 & 19,1 & 15,5 & 3,6 & 20,9 & 16,7 & 4,2 & 21,2 & 20,7 & 0,5 \\
\hline 3 & 18,9 & 15,3 & 3,6 & 20,4 & 16,4 & 4,0 & 20,6 & 19,8 & 0,8 \\
\hline 4 & 18,5 & 14,8 & 3,7 & 20,1 & 15,6 & 4,5 & 20 & 18,3 & 1,7 \\
\hline 5 & 18,1 & 14,4 & 3,7 & 19,6 & 16,1 & 3,5 & 19,4 & 18,2 & 1,2 \\
\hline 6 & 18 & 14,5 & 3,5 & 19 & 15,9 & 3,1 & 19,2 & 18,1 & 1,1 \\
\hline 7 & 18,1 & 14,7 & 3,4 & 17,8 & 15,6 & 2,2 & 19,1 & 19,3 & $-0,2$ \\
\hline 8 & 18,2 & 16,5 & 1,7 & 19 & 19,6 & $-0,6$ & 20,1 & 22,2 & $-2,1$ \\
\hline 9 & 19,4 & 19,2 & 0,2 & 20,4 & 22,7 & $-2,3$ & 22,5 & 24,2 & $-1,7$ \\
\hline 10 & 20,3 & 20,7 & $-0,4$ & 23,4 & 25,7 & $-2,3$ & 25,4 & 26,8 & $-1,4$ \\
\hline 11 & 21,9 & 22,4 & $-0,5$ & 26,3 & 27,4 & $-1,1$ & 27,8 & 28,7 & $-0,9$ \\
\hline 12 & 24 & 24,6 & $-0,6$ & 28,7 & 28,7 & 0,0 & 30 & 30,2 & $-0,2$ \\
\hline 13 & 26,6 & 26,4 & 0,2 & 29,9 & 29,4 & 0,5 & 31,4 & 30,8 & 0,6 \\
\hline 14 & 27,5 & 26,9 & 0,6 & 30,1 & 29,6 & 0,5 & 32 & 31,7 & 0,3 \\
\hline 15 & 27,7 & 26,8 & 0,9 & 30,6 & 30,0 & 0,6 & 32,6 & 32,1 & 0,5 \\
\hline 16 & 27,5 & 27,1 & 0,4 & 30,6 & 29,6 & 1,0 & 32,7 & 31,7 & 1,0 \\
\hline 17 & 27,3 & 24,6 & 2,7 & 30 & 28,3 & 1,7 & 32,4 & 30,6 & 1,8 \\
\hline 18 & 26,8 & 20,8 & 6,0 & 29,4 & 26,7 & 2,7 & 31,2 & 28,0 & 3,2 \\
\hline 19 & 26,2 & 19,5 & 6,7 & 28,6 & 22,0 & 6,6 & 29,4 & 24,1 & 5,3 \\
\hline 20 & 24 & 18,6 & 5,4 & 27,6 & 20,9 & 6,7 & 28,6 & 22,4 & 6,2 \\
\hline 21 & 23,2 & 18,2 & 5,0 & 26,6 & 20,5 & 6,1 & 27,7 & 22,2 & 5,5 \\
\hline 22 & 22,5 & 17,7 & 4,8 & 25,8 & 19,0 & 6,8 & 26,6 & 22,2 & 4,4 \\
\hline 23 & 22,1 & 18,0 & 4,1 & 24,7 & 18,3 & 6,4 & 25,1 & 20,8 & 4,3 \\
\hline 24 & 21,4 & 17,6 & 3,8 & 23,1 & 17,9 & 5,2 & 25,7 & 22,1 & 3,6 \\
\hline
\end{tabular}



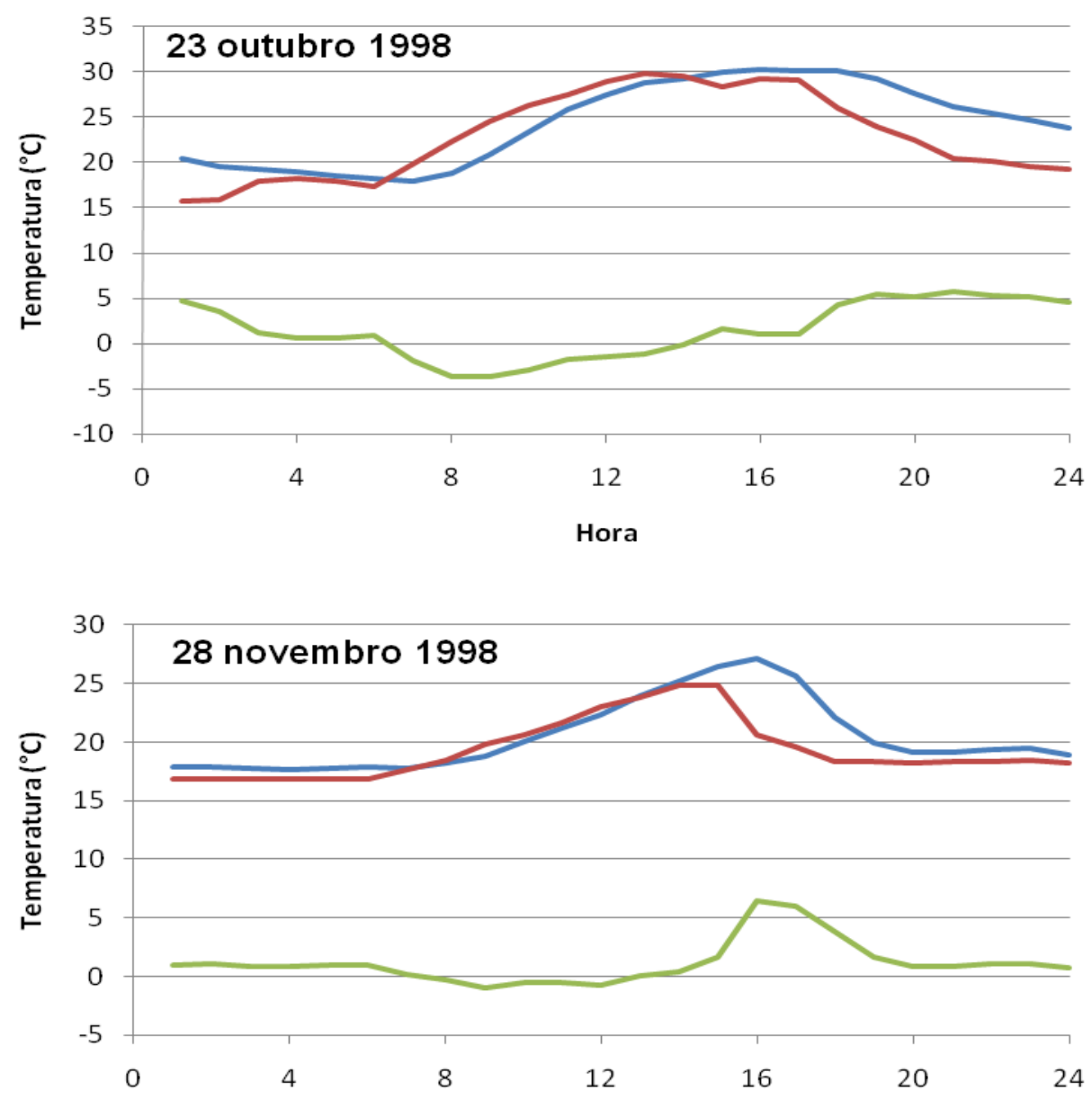

Hora

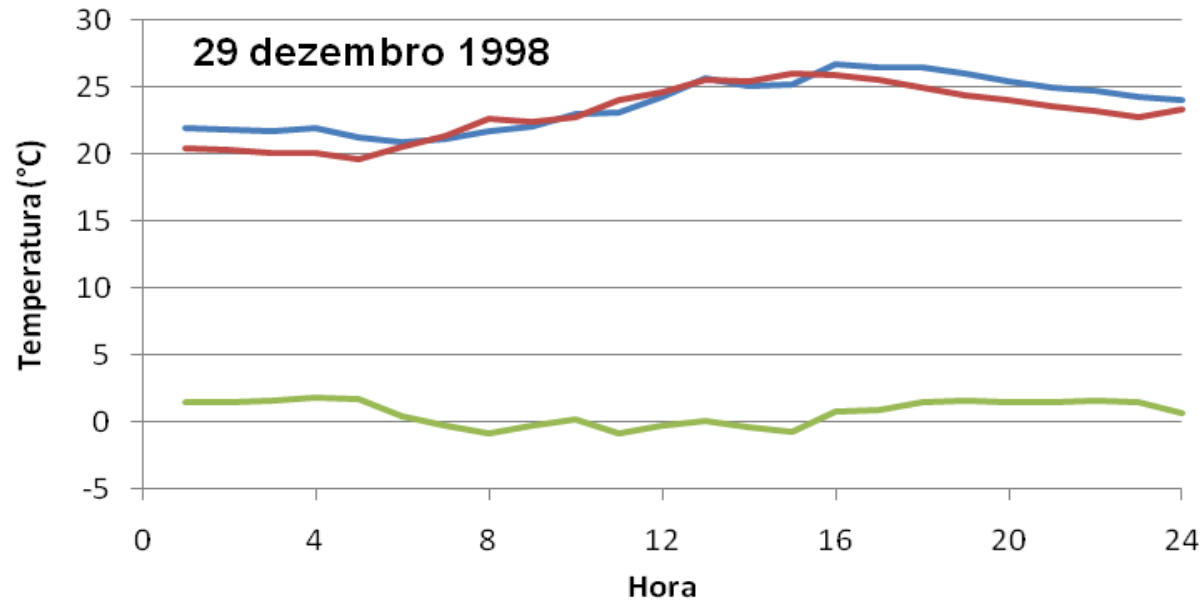

FIGURA 76. Gráficos horários das temperaturas e da intensidade da ilha de Calor, nos dias 23 de outubro, 28 de novembro e 29 de dezembro de 1998, na Estação de Monitoramento do Pq. D. Pedro II, Estação Meteorológica do Parque Estadual Fontes do Ipiranga. Fonte: CETESB, 1999 e IAG, 1998. 
TABELA 34. Registros horários das temperaturas e da intensidade da ilha de Calor $\left({ }^{\circ} \mathrm{C}\right)$ nos dias 23 de outubro, 28 de novembro e 29 de dezembro de 1998, na Estação de Monitoramento do Pq. D. Pedro II, Estação Meteorológica do Parque Estadual Fontes do Ipiranga. Fonte: CETESB, 1999 e IAG, 1998.

\begin{tabular}{|c|c|c|c|c|c|c|c|c|c|}
\hline Mês & \multicolumn{3}{|c|}{23 de outubro de 1998} & \multicolumn{3}{|c|}{28 de novembro de 1998} & \multicolumn{3}{|c|}{29 de dezembro de 1998} \\
\hline Hora & PDP & $\mathrm{PE}$ & Int. & PDP & $\mathrm{PE}$ & Int. & PDP & $\mathrm{PE}$ & Int. \\
\hline 1 & 20,5 & 15,8 & 4,7 & 17,9 & 16,9 & 1,0 & 21,9 & 20,4 & 1,5 \\
\hline 2 & 19,5 & 15,9 & 3,6 & 17,9 & 16,8 & 1,1 & 21,8 & 20,3 & 1,5 \\
\hline 3 & 19,2 & 18,0 & 1,2 & 17,8 & 16,9 & 0,9 & 21,7 & 20,1 & 1,6 \\
\hline 4 & 18,9 & 18,3 & 0,6 & 17,6 & 16,8 & 0,8 & 21,9 & 20,1 & 1,8 \\
\hline 5 & 18,5 & 17,9 & 0,6 & 17,8 & 16,8 & 1,0 & 21,3 & 19,6 & 1,7 \\
\hline 6 & 18,3 & 17,4 & 0,9 & 17,9 & 16,9 & 1,0 & 20,9 & 20,5 & 0,4 \\
\hline 7 & 17,9 & 19,8 & $-1,9$ & 17,8 & 17,6 & 0,2 & 21,1 & 21,4 & $-0,3$ \\
\hline 8 & 18,8 & 22,4 & $-3,6$ & 18,2 & 18,5 & $-0,3$ & 21,7 & 22,6 & $-0,9$ \\
\hline 9 & 20,9 & 24,5 & $-3,6$ & 18,8 & 19,8 & $-1,0$ & 22,1 & 22,4 & $-0,3$ \\
\hline 10 & 23,4 & 26,3 & $-2,9$ & 20,1 & 20,6 & $-0,5$ & 23 & 22,8 & 0,2 \\
\hline 11 & 25,8 & 27,5 & $-1,7$ & 21,2 & 21,7 & $-0,5$ & 23,1 & 24,0 & $-0,9$ \\
\hline 12 & 27,5 & 28,9 & $-1,4$ & 22,3 & 23,0 & $-0,7$ & 24,3 & 24,6 & $-0,3$ \\
\hline 13 & 28,8 & 29,9 & $-1,1$ & 23,9 & 23,8 & 0,1 & 25,7 & 25,6 & 0,1 \\
\hline 14 & 29,3 & 29,5 & $-0,2$ & 25,2 & 24,8 & 0,4 & 25,1 & 25,5 & $-0,4$ \\
\hline 15 & 30 & 28,3 & 1,7 & 26,4 & 24,8 & 1,6 & 25,2 & 26,0 & $-0,8$ \\
\hline 16 & 30,3 & 29,2 & 1,1 & 27,1 & 20,6 & 6,5 & 26,7 & 25,9 & 0,8 \\
\hline 17 & 30,2 & 29,1 & 1,1 & 25,6 & 19,6 & 6,0 & 26,5 & 25,6 & 0,9 \\
\hline 18 & 30,2 & 26,0 & 4,2 & 22,1 & 18,3 & 3,8 & 26,5 & 25,0 & 1,5 \\
\hline 19 & 29,3 & 23,9 & 5,4 & 19,9 & 18,3 & 1,6 & 26 & 24,4 & 1,6 \\
\hline 20 & 27,6 & 22,5 & 5,1 & 19,1 & 18,2 & 0,9 & 25,4 & 24,0 & 1,4 \\
\hline 21 & 26,1 & 20,4 & 5,7 & 19,1 & 18,3 & 0,8 & 25 & 23,6 & 1,4 \\
\hline 22 & 25,4 & 20,1 & 5,3 & 19,4 & 18,3 & 1,1 & 24,8 & 23,2 & 1,6 \\
\hline 23 & 24,7 & 19,6 & 5,1 & 19,5 & 18,4 & 1,1 & 24,3 & 22,8 & 1,5 \\
\hline 24 & 23,8 & 19,2 & 4,6 & 18,9 & 18,2 & 0,7 & 24 & 23,4 & 0,6 \\
\hline
\end{tabular}



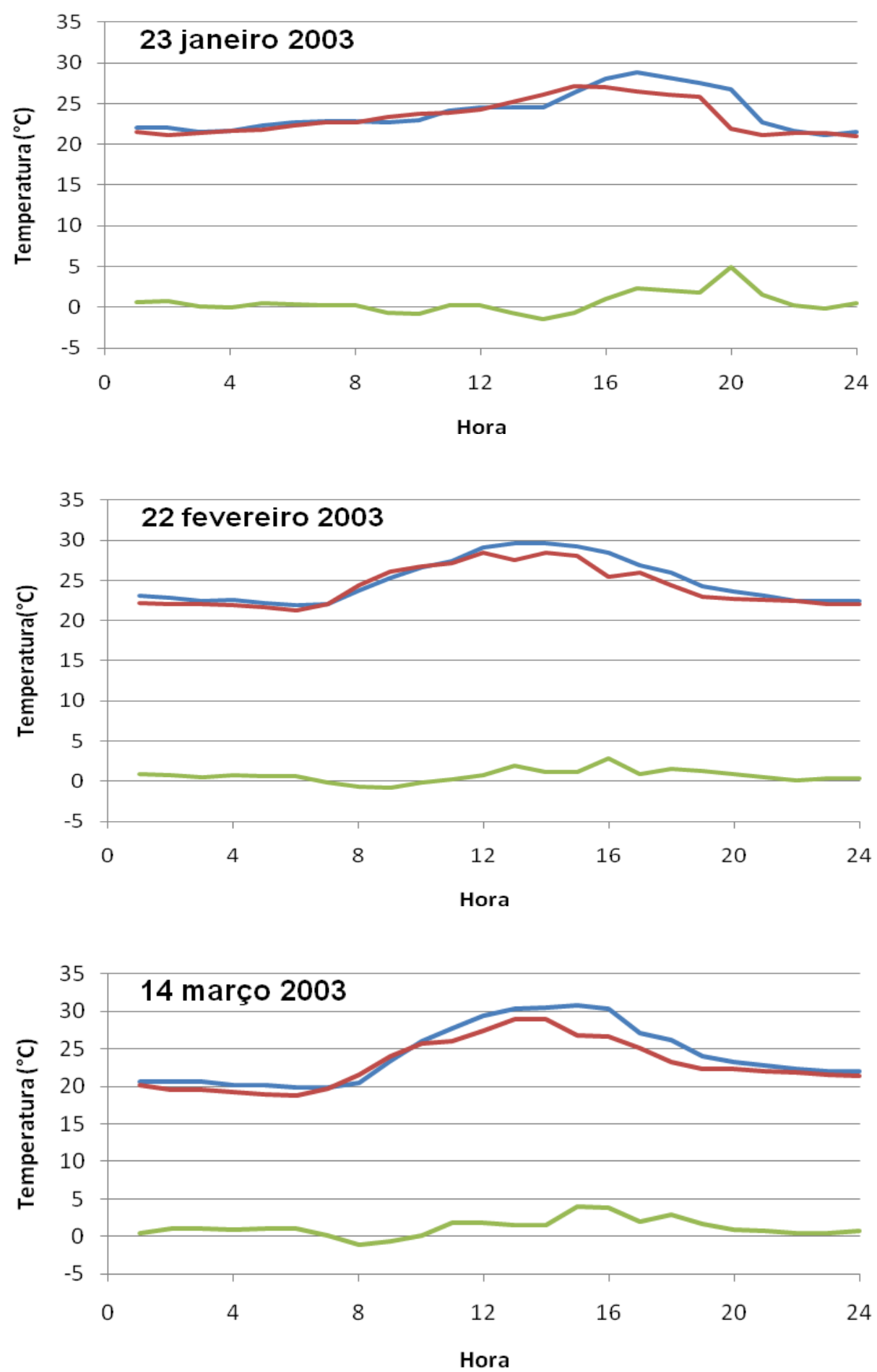

— pq. D. Pedro II — Pq. Estado — Intensidade

FIGURA 77. Gráficos horários das temperaturas e da intensidade da ilha de Calor, nos dias 23 de janeiro, 23 de fevereiro e 14 de março de 2003, na Estação de Monitoramento do Pq. D. Pedro II, Estação Meteorológica do Parque Estadual Fontes do Ipiranga. Fonte: CETESB, 2004 e IAG, 2003. 
TABELA 35. Registros horários das temperaturas e da intensidade da ilha de Calor $\left({ }^{\circ} \mathrm{C}\right)$ nos dias 23 de janeiro, 23 de fevereiro e 14 de março de 2003, na Estação de Monitoramento do Pq. D. Pedro II, Estação Meteorológica do Parque Estadual Fontes do Ipiranga. Fonte: CETESB, 2004 e IAG, 2003.

\begin{tabular}{|c|c|c|c|c|c|c|c|c|c|}
\hline Mês & \multicolumn{3}{|c|}{23 Janeiro 2003} & \multicolumn{3}{|c|}{23 Fevereiro 2003} & \multicolumn{3}{|c|}{14 Março 2003} \\
\hline Hora & PDP & $\mathrm{PE}$ & Int. & PDP & $\mathrm{PE}$ & Int. & PDP & $\mathrm{PE}$ & Int. \\
\hline 1 & 22,1 & 21,5 & 0,6 & 23,1 & 22,2 & 0,9 & 20,6 & 20,2 & 0,4 \\
\hline 2 & 22 & 21,2 & 0,8 & 22,8 & 22,1 & 0,7 & 20,7 & 19,6 & 1,1 \\
\hline 3 & 21,5 & 21,4 & 0,1 & 22,5 & 22 & 0,5 & 20,7 & 19,6 & 1,1 \\
\hline 4 & 21,6 & 21,6 & 0 & 22,6 & 21,9 & 0,7 & 20,2 & 19,3 & 0,9 \\
\hline 5 & 22,3 & 21,8 & 0,5 & 22,2 & 21,6 & 0,6 & 20,1 & 19,0 & 1,1 \\
\hline 6 & 22,7 & 22,3 & 0,4 & 21,9 & 21,3 & 0,6 & 19,8 & 18,8 & 1 \\
\hline 7 & 22,9 & 22,7 & 0,2 & 22 & 22,1 & $-0,1$ & 19,9 & 19,7 & 0,2 \\
\hline 8 & 22,9 & 22,7 & 0,2 & 23,7 & 24,4 & $-0,7$ & 20,5 & 21,6 & $-1,1$ \\
\hline 9 & 22,7 & 23,4 & $-0,7$ & 25,3 & 26,1 & $-0,8$ & 23,4 & 24,0 & $-0,6$ \\
\hline 10 & 23 & 23,8 & $-0,8$ & 26,6 & 26,7 & $-0,1$ & 26 & 25,8 & 0,2 \\
\hline 11 & 24,1 & 23,9 & 0,2 & 27,4 & 27,1 & 0,3 & 27,8 & 26,0 & 1,8 \\
\hline 12 & 24,6 & 24,3 & 0,3 & 29,1 & 28,4 & 0,7 & 29,4 & 27,5 & 1,9 \\
\hline 13 & 24,5 & 25,2 & $-0,7$ & 29,6 & 27,6 & 2 & 30,4 & 28,9 & 1,5 \\
\hline 14 & 24,6 & 26,1 & $-1,5$ & 29,6 & 28,4 & 1,2 & 30,5 & 29,0 & 1,5 \\
\hline 15 & 26,4 & 27,1 & $-0,7$ & 29,2 & 28 & 1,2 & 30,8 & 26,8 & 4 \\
\hline 16 & 28 & 27 & 1 & 28,4 & 25,5 & 2,9 & 30,4 & 26,6 & 3,8 \\
\hline 17 & 28,8 & 26,5 & 2,3 & 26,9 & 26 & 0,9 & 27,1 & 25,1 & 2 \\
\hline 18 & 28,2 & 26,1 & 2,1 & 26 & 24,4 & 1,6 & 26,2 & 23,3 & 2,9 \\
\hline 19 & 27,6 & 25,8 & 1,8 & 24,3 & 23 & 1,3 & 24 & 22,3 & 1,7 \\
\hline 20 & 26,8 & 21,9 & 4,9 & 23,6 & 22,7 & 0,9 & 23,3 & 22,4 & 0,9 \\
\hline 21 & 22,7 & 21,2 & 1,5 & 23,1 & 22,6 & 0,5 & 22,8 & 22,0 & 0,8 \\
\hline 22 & 21,6 & 21,4 & 0,2 & 22,5 & 22,4 & 0,1 & 22,3 & 21,8 & 0,5 \\
\hline 23 & 21,2 & 21,4 & $-0,2$ & 22,4 & 22 & 0,4 & 22 & 21,6 & 0,4 \\
\hline 24 & 21,5 & 21 & 0,5 & 22,4 & 22 & 0,4 & 22,1 & 21,4 & 0,7 \\
\hline
\end{tabular}



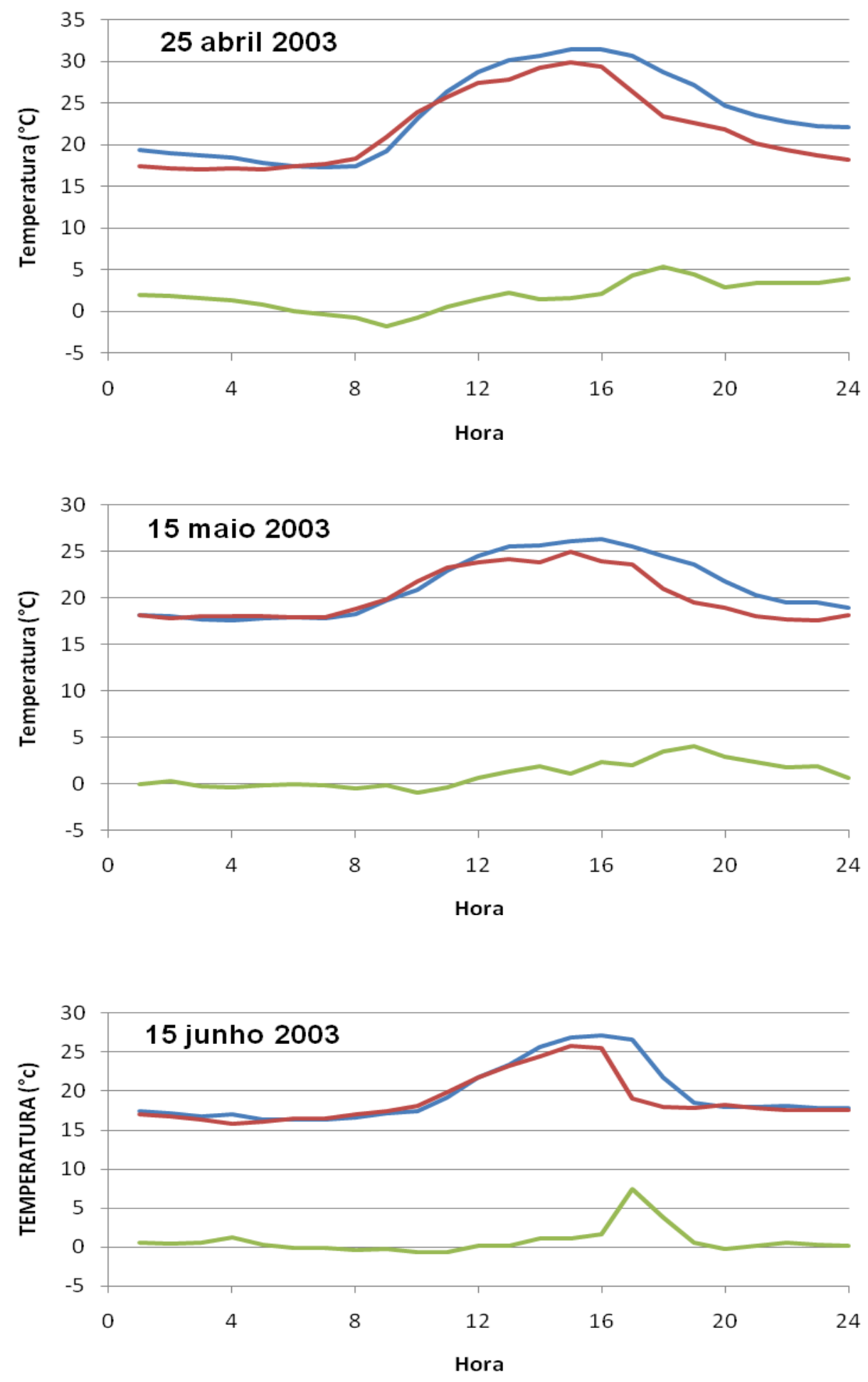

Pq. D. Pedro II — Pq. Estado Intensidade

FIGURA 78. Gráficos horários das temperaturas e da intensidade da ilha de Calor, nos dias 25 de abril, 15 de maio e 15 de junho de 2003, na Estação de Monitoramento do Pq. D. Pedro II, Estação Meteorológica do Parque Estadual Fontes do Ipiranga. Fonte: CETESB, 2004 e IAG, 2003. 
TABELA 36. Registros horários das temperaturas e da intensidade da ilha de Calor $\left({ }^{\circ} \mathrm{C}\right)$ nos dias 25 de abril, 15 de maio e 15 de junho de 2003, na Estação de Monitoramento do Pq. D. Pedro II, Estação Meteorológica do Parque Estadual Fontes do Ipiranga. Fonte: CETESB, 2004 e IAG, 2003.

\begin{tabular}{|c|c|c|c|c|c|c|c|c|c|}
\hline Mês & \multicolumn{3}{|c|}{25 Abril 2003} & \multicolumn{3}{|c|}{15 Maio 2003} & \multicolumn{3}{|c|}{15 Junho 2003} \\
\hline Hora & PDP & $\mathrm{PE}$ & Int. & PDP & $\mathrm{PE}$ & Int. & PDP & $\mathrm{PE}$ & Int. \\
\hline 1 & 19,4 & 17,4 & 2 & 18,2 & 18,2 & 0 & 17,5 & 17 & 0,5 \\
\hline 2 & 19 & 17,2 & 1,8 & 18,1 & 17,8 & 0,3 & 17,1 & 16,7 & 0,4 \\
\hline 3 & 18,7 & 17,1 & 1,6 & 17,7 & 18 & $-0,3$ & 16,8 & 16,3 & 0,5 \\
\hline 4 & 18,5 & 17,2 & 1,3 & 17,6 & 18 & $-0,4$ & 17 & 15,8 & 1,2 \\
\hline 5 & 17,8 & 17 & 0,8 & 17,8 & 18 & $-0,2$ & 16,4 & 16,1 & 0,3 \\
\hline 6 & 17,4 & 17,4 & 0 & 17,9 & 17,9 & 0 & 16,4 & 16,5 & $-0,1$ \\
\hline 7 & 17,3 & 17,7 & $-0,4$ & 17,8 & 17,9 & $-0,1$ & 16,4 & 16,5 & $-0,1$ \\
\hline 8 & 17,5 & 18,3 & $-0,8$ & 18,3 & 18,8 & $-0,5$ & 16,6 & 17 & $-0,4$ \\
\hline 9 & 19,2 & 21 & $-1,8$ & 19,7 & 19,9 & $-0,2$ & 17,2 & 17,4 & $-0,2$ \\
\hline 10 & 23,2 & 24 & $-0,8$ & 20,9 & 21,8 & $-0,9$ & 17,5 & 18,1 & $-0,6$ \\
\hline 11 & 26,4 & 25,8 & 0,6 & 22,9 & 23,3 & $-0,4$ & 19,2 & 19,8 & $-0,6$ \\
\hline 12 & 28,8 & 27,4 & 1,4 & 24,5 & 23,8 & 0,7 & 21,8 & 21,7 & 0,1 \\
\hline 13 & 30,2 & 27,9 & 2,3 & 25,5 & 24,2 & 1,3 & 23,4 & 23,3 & 0,1 \\
\hline 14 & 30,7 & 29,3 & 1,4 & 25,7 & 23,8 & 1,9 & 25,6 & 24,5 & 1,1 \\
\hline 15 & 31,5 & 29,9 & 1,6 & 26,1 & 25 & 1,1 & 26,9 & 25,8 & 1,1 \\
\hline 16 & 31,5 & 29,4 & 2,1 & 26,3 & 24 & 2,3 & 27,1 & 25,5 & 1,6 \\
\hline 17 & 30,7 & 26,4 & 4,3 & 25,6 & 23,6 & 2 & 26,6 & 19,1 & 7,5 \\
\hline 18 & 28,7 & 23,4 & 5,3 & 24,5 & 21 & 3,5 & 21,8 & 18 & 3,8 \\
\hline 19 & 27,2 & 22,7 & 4,5 & 23,6 & 19,5 & 4,1 & 18,5 & 17,9 & 0,6 \\
\hline 20 & 24,7 & 21,8 & 2,9 & 21,8 & 18,9 & 2,9 & 18 & 18,2 & $-0,2$ \\
\hline 21 & 23,6 & 20,2 & 3,4 & 20,3 & 18 & 2,3 & 18 & 17,8 & 0,2 \\
\hline 22 & 22,8 & 19,4 & 3,4 & 19,5 & 17,7 & 1,8 & 18,1 & 17,6 & 0,5 \\
\hline 23 & 22,2 & 18,8 & 3,4 & 19,5 & 17,6 & 1,9 & 17,9 & 17,6 & 0,3 \\
\hline 24 & 22,1 & 18,2 & 3,9 & 18,9 & 18,2 & 0,7 & 17,8 & 17,6 & 0,2 \\
\hline
\end{tabular}



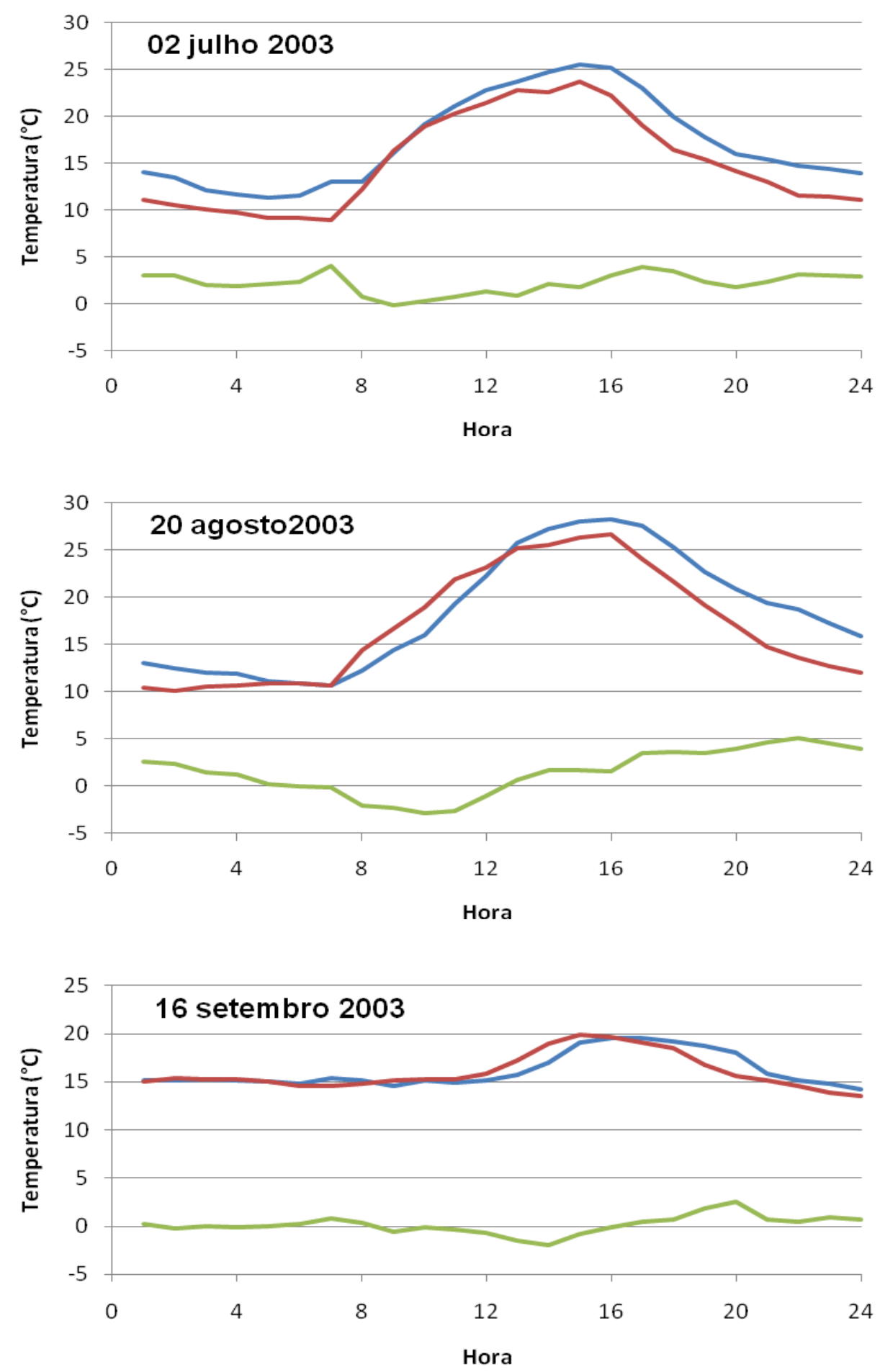

—Pq. D. Pedro II — Pq. Estado Intensidade

FIGURA 79. Gráficos horários das temperaturas e da intensidade da ilha de Calor, nos dias 2 de julho, 20 de agosto e 16 de setembro de 2003, na Estação de Monitoramento do Pq. D. Pedro II, Estação Meteorológica do Parque Estadual Fontes do Ipiranga. Fonte: CETESB, 2004 e IAG, 2003. 
TABELA 37. Registros horários das temperaturas e da intensidade da ilha de Calor $\left({ }^{\circ} \mathrm{C}\right)$ nos dias 2 de julho, 20 de agosto e 16 de setembro de 2003, na Estação de Monitoramento do Pq. D. Pedro II, Estação Meteorológica do Parque Estadual Fontes do Ipiranga. Fonte: CETESB, 2004 e IAG, 2003.

\begin{tabular}{|c|c|c|c|c|c|c|c|c|c|}
\hline Mês & \multicolumn{3}{|c|}{2 Julho 2003} & \multicolumn{3}{|c|}{20 Agosto 2003} & \multicolumn{3}{|c|}{16 Setembro 2003} \\
\hline Hora & PDP & $\mathrm{PE}$ & Int. & PDP & $\mathrm{PE}$ & Int. & PDP & $\mathrm{PE}$ & Int. \\
\hline 1 & 14,1 & 11,1 & 3 & 13 & 10,4 & 2,6 & 15,2 & 15 & 0,2 \\
\hline 2 & 13,5 & 10,5 & 3 & 12,5 & 10,1 & 2,4 & 15,2 & 15,4 & $-0,2$ \\
\hline 3 & 12,1 & 10,1 & 2 & 12 & 10,5 & 1,5 & 15,3 & 15,3 & 0 \\
\hline 4 & 11,7 & 9,8 & 1,9 & 11,9 & 10,7 & 1,2 & 15,2 & 15,3 & $-0,1$ \\
\hline 5 & 11,3 & 9,2 & 2,1 & 11,1 & 10,9 & 0,2 & 15 & 15 & 0 \\
\hline 6 & 11,6 & 9,2 & 2,4 & 10,9 & 10,9 & 0 & 14,8 & 14,6 & 0,2 \\
\hline 7 & 13,1 & 9 & 4,1 & 10,6 & 10,7 & $-0,1$ & 15,4 & 14,6 & 0,8 \\
\hline 8 & 13 & 12,2 & 0,8 & 12,3 & 14,4 & $-2,1$ & 15,1 & 14,8 & 0,3 \\
\hline 9 & 16,1 & 16,3 & $-0,2$ & 14,4 & 16,7 & $-2,3$ & 14,6 & 15,2 & $-0,6$ \\
\hline 10 & 19,2 & 18,9 & 0,3 & 16 & 18,9 & $-2,9$ & 15,2 & 15,3 & $-0,1$ \\
\hline 11 & 21,1 & 20,3 & 0,8 & 19,3 & 21,9 & $-2,6$ & 14,9 & 15,3 & $-0,4$ \\
\hline 12 & 22,8 & 21,5 & 1,3 & 22,2 & 23,2 & -1 & 15,2 & 15,9 & $-0,7$ \\
\hline 13 & 23,7 & 22,8 & 0,9 & 25,8 & 25,2 & 0,6 & 15,7 & 17,2 & $-1,5$ \\
\hline 14 & 24,7 & 22,6 & 2,1 & 27,3 & 25,6 & 1,7 & 17 & 19 & -2 \\
\hline 15 & 25,5 & 23,7 & 1,8 & 28,1 & 26,4 & 1,7 & 19,1 & 19,9 & $-0,8$ \\
\hline 16 & 25,2 & 22,2 & 3 & 28,3 & 26,7 & 1,6 & 19,6 & 19,7 & $-0,1$ \\
\hline 17 & 23 & 19,1 & 3,9 & 27,6 & 24,1 & 3,5 & 19,6 & 19,1 & 0,5 \\
\hline 18 & 20 & 16,5 & 3,5 & 25,3 & 21,7 & 3,6 & 19,2 & 18,5 & 0,7 \\
\hline 19 & 17,8 & 15,4 & 2,4 & 22,7 & 19,2 & 3,5 & 18,7 & 16,8 & 1,9 \\
\hline 20 & 16 & 14,2 & 1,8 & 20,9 & 17 & 3,9 & 18,1 & 15,6 & 2,5 \\
\hline 21 & 15,4 & 13,1 & 2,3 & 19,4 & 14,8 & 4,6 & 15,8 & 15,1 & 0,7 \\
\hline 22 & 14,7 & 11,6 & 3,1 & 18,7 & 13,6 & 5,1 & 15,1 & 14,6 & 0,5 \\
\hline 23 & 14,4 & 11,4 & 3 & 17,2 & 12,7 & 4,5 & 14,8 & 13,9 & 0,9 \\
\hline 24 & 14 & 11,1 & 2,9 & 15,9 & 12 & 3,9 & 14,2 & 13,5 & 0,7 \\
\hline
\end{tabular}



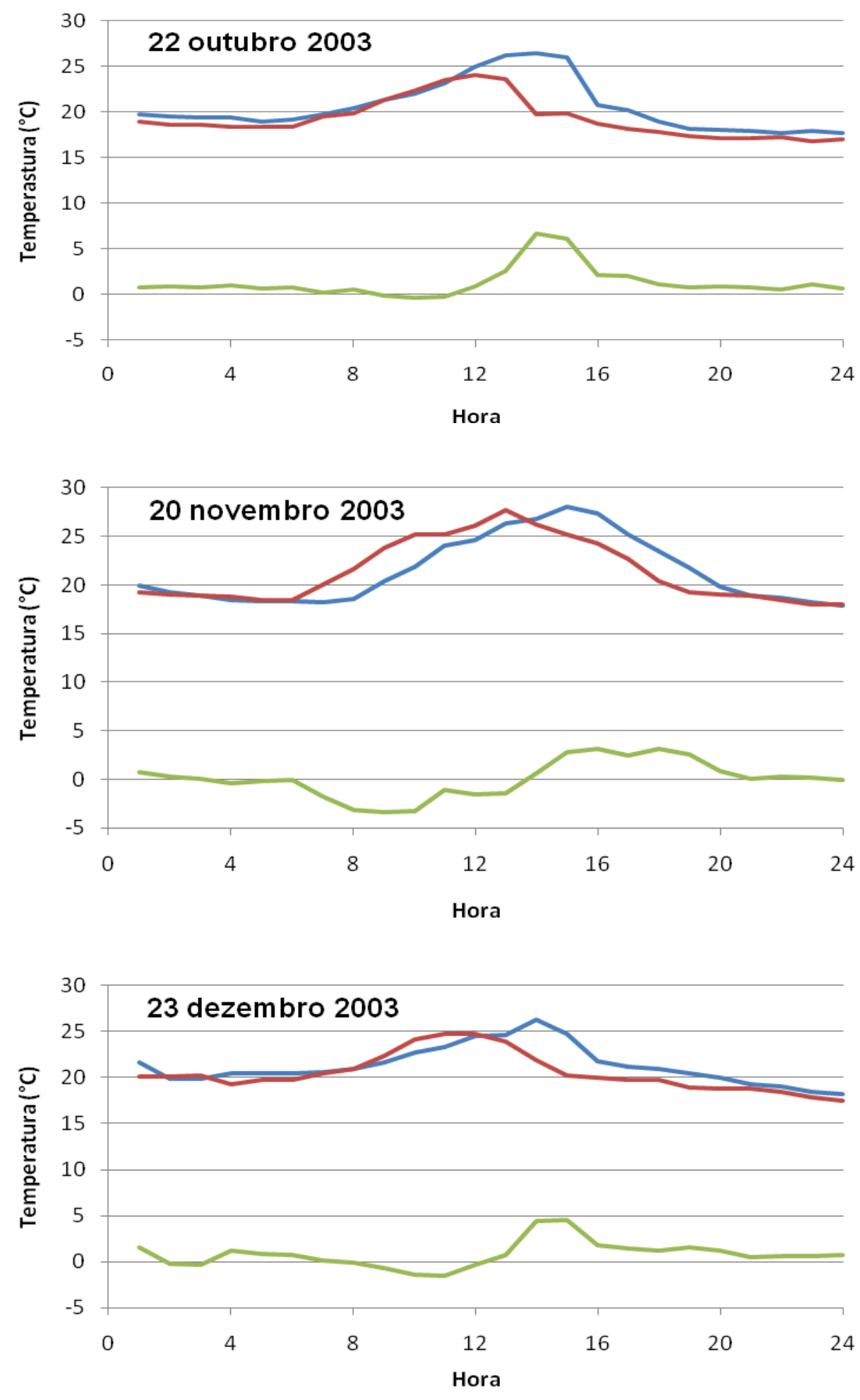

Pq. D. Pedro II — Pq. Estado Intensidade

FIGURA 80. Gráficos horários das temperaturas e da intensidade da ilha de Calor, nos dias 22 de outubro, 20 de novembro e 23 de dezembro de 2003, na Estação de Monitoramento do Pq. D. Pedro II, Estação Meteorológica do Parque Estadual Fontes do Ipiranga. Fonte: CETESB, 2004 e IAG, 2003. 
TABELA 38. Registros horários das temperaturas e da intensidade da ilha de Calor $\left({ }^{\circ} \mathrm{C}\right)$ nos dias 22 de outubro, 20 de novembro e 23 de dezembro de 2003, na Estação de Monitoramento do Pq. D. Pedro II, Estação Meteorológica do Parque Estadual Fontes do Ipiranga. Fonte: CETESB, 2004 e IAG, 2003.

\begin{tabular}{|c|c|c|c|c|c|c|c|c|c|}
\hline Mês & \multicolumn{3}{|c|}{22 Outubro 2003} & \multicolumn{3}{|c|}{20 Novembro 2003} & \multicolumn{3}{|c|}{23 Dezembro 2003} \\
\hline Hora & PDP & $P E$ & Int. & PDP & $\mathrm{PE}$ & Int. & PDP & $\mathrm{PE}$ & Int. \\
\hline 1 & 19,7 & 18,9 & 0,8 & 19,9 & 19,2 & 0,7 & 21,7 & 20,1 & 1,6 \\
\hline 2 & 19,5 & 18,6 & 0,9 & 19,3 & 19 & 0,3 & 19,9 & 20,1 & $-0,2$ \\
\hline 3 & 19,4 & 18,6 & 0,8 & 18,9 & 18,9 & 0 & 19,9 & 20,2 & $-0,3$ \\
\hline 4 & 19,4 & 18,4 & 1 & 18,4 & 18,8 & $-0,4$ & 20,5 & 19,3 & 1,2 \\
\hline 5 & 19 & 18,4 & 0,6 & 18,3 & 18,5 & $-0,2$ & 20,5 & 19,7 & 0,8 \\
\hline 6 & 19,2 & 18,4 & 0,8 & 18,3 & 18,4 & $-0,1$ & 20,5 & 19,8 & 0,7 \\
\hline 7 & 19,7 & 19,5 & 0,2 & 18,2 & 20 & $-1,8$ & 20,6 & 20,5 & 0,1 \\
\hline 8 & 20,4 & 19,9 & 0,5 & 18,6 & 21,7 & $-3,1$ & 20,9 & 21 & $-0,1$ \\
\hline 9 & 21,3 & 21,4 & $-0,1$ & 20,4 & 23,8 & $-3,4$ & 21,7 & 22,4 & $-0,7$ \\
\hline 10 & 22 & 22,4 & $-0,4$ & 21,9 & 25,2 & $-3,3$ & 22,7 & 24,1 & $-1,4$ \\
\hline 11 & 23,2 & 23,5 & $-0,3$ & 24,1 & 25,2 & $-1,1$ & 23,3 & 24,8 & $-1,5$ \\
\hline 12 & 25 & 24,1 & 0,9 & 24,6 & 26,1 & $-1,5$ & 24,5 & 24,8 & $-0,3$ \\
\hline 13 & 26,2 & 23,6 & 2,6 & 26,3 & 27,7 & $-1,4$ & 24,6 & 23,9 & 0,7 \\
\hline 14 & 26,5 & 19,8 & 6,7 & 26,8 & 26,2 & 0,6 & 26,3 & 21,9 & 4,4 \\
\hline 15 & 26 & 19,9 & 6,1 & 28 & 25,2 & 2,8 & 24,7 & 20,2 & 4,5 \\
\hline 16 & 20,8 & 18,7 & 2,1 & 27,4 & 24,3 & 3,1 & 21,8 & 20 & 1,8 \\
\hline 17 & 20,2 & 18,2 & 2 & 25,2 & 22,7 & 2,5 & 21,2 & 19,8 & 1,4 \\
\hline 18 & 18,9 & 17,8 & 1,1 & 23,5 & 20,4 & 3,1 & 20,9 & 19,7 & 1,2 \\
\hline 19 & 18,2 & 17,4 & 0,8 & 21,8 & 19,2 & 2,6 & 20,5 & 18,9 & 1,6 \\
\hline 20 & 18 & 17,1 & 0,9 & 19,8 & 19 & 0,8 & 20 & 18,8 & 1,2 \\
\hline 21 & 17,9 & 17,1 & 0,8 & 18,9 & 18,9 & 0 & 19,3 & 18,8 & 0,5 \\
\hline 22 & 17,7 & 17,2 & 0,5 & 18,7 & 18,4 & 0,3 & 19 & 18,4 & 0,6 \\
\hline 23 & 17,9 & 16,8 & 1,1 & 18,2 & 18 & 0,2 & 18,4 & 17,8 & 0,6 \\
\hline 24 & 17,7 & 17 & 0,7 & 17,9 & 18 & $-0,1$ & 18,2 & 17,5 & 0,7 \\
\hline
\end{tabular}




\section{APÊNDICE C - Gráficos e tabelas de umidade relativa do ar}
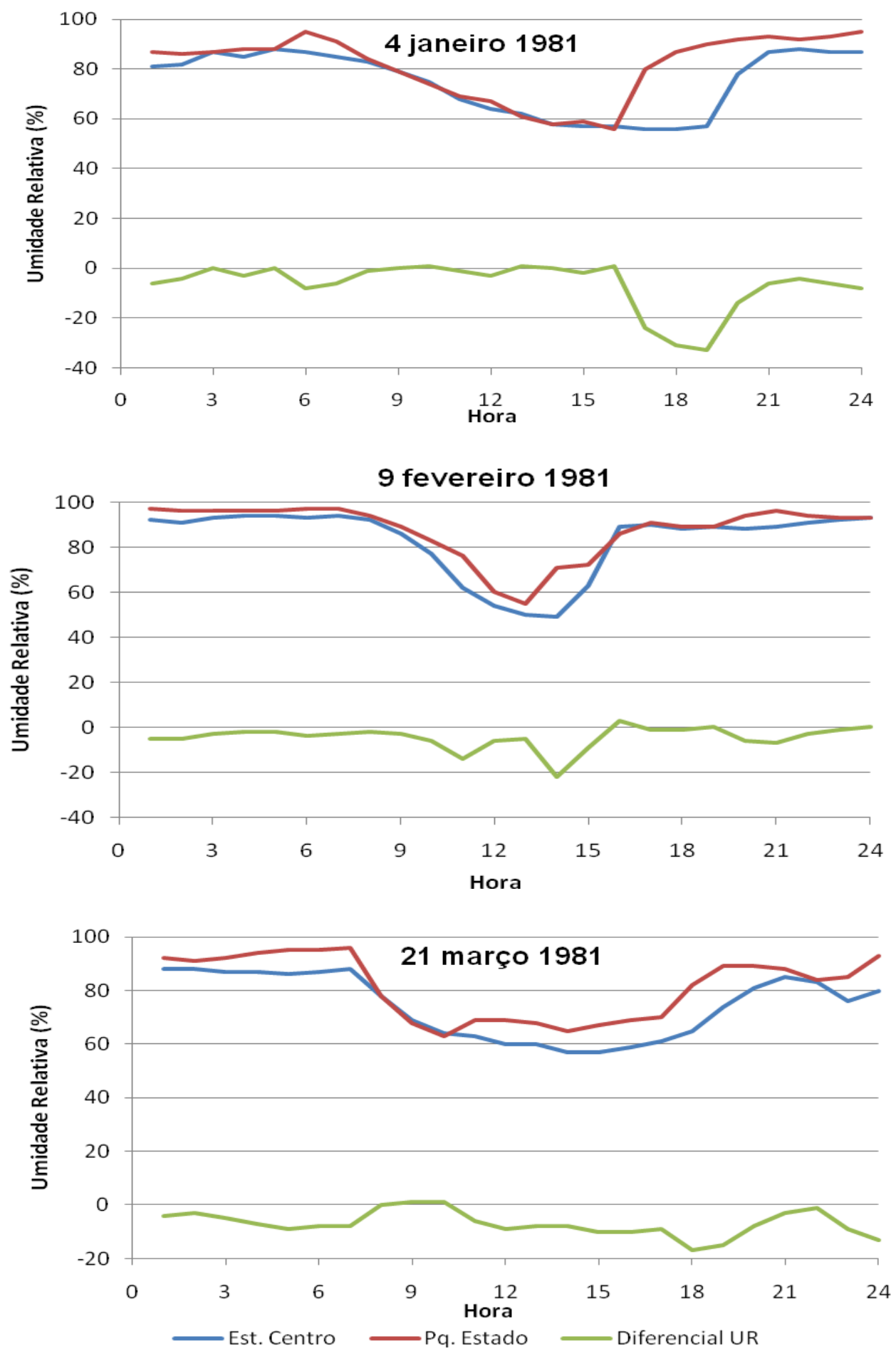

FIGURA 81. Gráficos horários da umidade relativa e do diferencial de umidade, dias 4 de janeiro, 9 de fevereiro e 21 de março de 1981, na Estação de Monitoramento Centro, Estação Meteorológica do Parque Estadual Fontes do Ipiranga. Fonte: CETESB, 1994 e IAG, 1981. 
TABELA 39. Registros horários da umidade relativa e do diferencial de umidade nos dias 9 de janeiro, 9 de fevereiro e 21 de março de 1981, na Estação de Monitoramento Centro, Estação Meteorológica do Parque Estadual Fontes do Ipiranga. Fonte: CETESB, 1994 e IAG, 1981.

\begin{tabular}{|c|c|c|c|c|c|c|c|c|c|}
\hline Mês & \multicolumn{3}{|c|}{4 Janeiro 1981} & \multicolumn{3}{|c|}{9 Fevereiro 1981} & \multicolumn{3}{|c|}{21 Março 1981} \\
\hline Hora & EC & $\mathrm{PE}$ & $\Delta$ & $\mathrm{EC}$ & $\mathrm{PE}$ & $\Delta$ & $\mathrm{EC}$ & $\mathrm{PE}$ & $\Delta$ \\
\hline 1 & 81 & 87 & -6 & 92 & 97 & -5 & 88 & 92 & -4 \\
\hline 2 & 82 & 86 & -4 & 91 & 96 & -5 & 88 & 91 & -3 \\
\hline 3 & 87 & 87 & 0 & 93 & 96 & -3 & 87 & 92 & -5 \\
\hline 4 & 85 & 88 & -3 & 94 & 96 & -2 & 87 & 94 & -7 \\
\hline 5 & 88 & 88 & 0 & 94 & 96 & -2 & 86 & 95 & -9 \\
\hline 6 & 87 & 95 & -8 & 93 & 97 & -4 & 87 & 95 & -8 \\
\hline 7 & 85 & 91 & -6 & 94 & 97 & -3 & 88 & 96 & -8 \\
\hline 8 & 83 & 84 & -1 & 92 & 94 & -2 & 78 & 78 & 0 \\
\hline 9 & 79 & 79 & 0 & 86 & 89 & -3 & 69 & 68 & 1 \\
\hline 10 & 75 & 74 & 1 & 77 & 83 & -6 & 64 & 63 & 1 \\
\hline 11 & 68 & 69 & -1 & 62 & 76 & -14 & 63 & 69 & -6 \\
\hline 12 & 64 & 67 & -3 & 54 & 60 & -6 & 60 & 69 & -9 \\
\hline 13 & 62 & 61 & 1 & 50 & 55 & -5 & 60 & 68 & -8 \\
\hline 14 & 58 & 58 & 0 & 49 & 71 & -22 & 57 & 65 & -8 \\
\hline 15 & 57 & 59 & -2 & 63 & 72 & -9 & 57 & 67 & -10 \\
\hline 16 & 57 & 56 & 1 & 89 & 86 & 3 & 59 & 69 & -10 \\
\hline 17 & 56 & 80 & -24 & 90 & 91 & -1 & 61 & 70 & -9 \\
\hline 18 & 56 & 87 & -31 & 88 & 89 & -1 & 65 & 82 & -17 \\
\hline 19 & 57 & 90 & -33 & 89 & 89 & 0 & 74 & 89 & -15 \\
\hline 20 & 78 & 92 & -14 & 88 & 94 & -6 & 81 & 89 & -8 \\
\hline 21 & 87 & 93 & -6 & 89 & 96 & -7 & 85 & 88 & -3 \\
\hline 22 & 88 & 92 & -4 & 91 & 94 & -3 & 83 & 84 & -1 \\
\hline 23 & 87 & 93 & -6 & 92 & 93 & -1 & 76 & 85 & -9 \\
\hline 24 & 87 & 95 & -8 & 93 & 93 & 0 & 80 & 93 & -13 \\
\hline
\end{tabular}



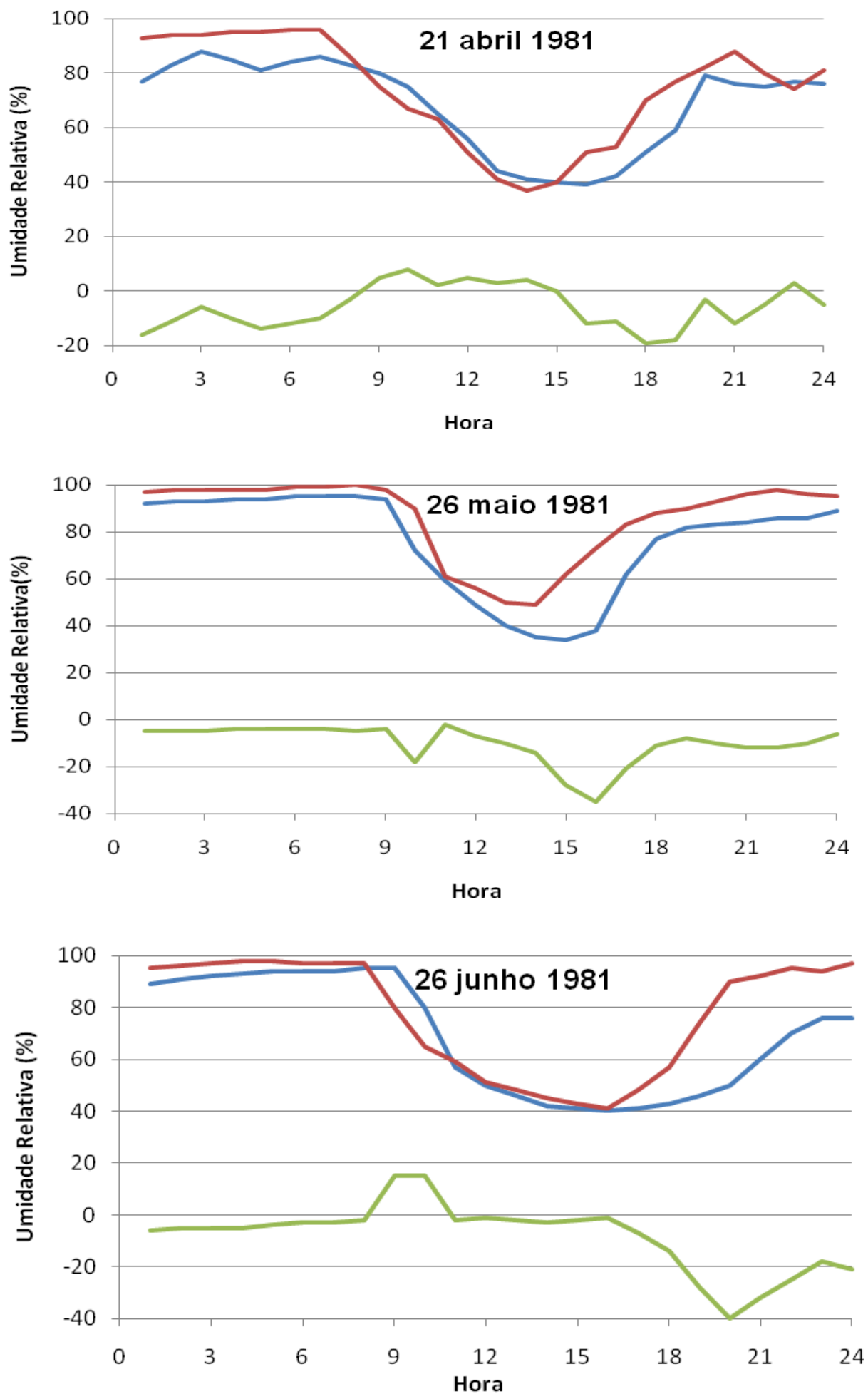

- Est. Centro —Pq. Estado Diferencial UR

FIGURA 82. Gráficos horários da umidade relativa e do diferencial de umidade, dias 21 de abril, 26 de maio e 26 de junho de 1981, na Estação de Monitoramento Centro, Estação Meteorológica do Parque Estadual Fontes do Ipiranga. Fonte: CETESB, 1994 e IAG, 1981. 
TABELA 40. Registros horários da umidade relativa e do diferencial de umidade nos dias 21 de abril, 26 de maio e 26 de junho de 1981, na Estação de Monitoramento Centro, Estação Meteorológica do Parque Estadual Fontes do Ipiranga. Fonte: CETESB, 1994 e IAG, 1981.

\begin{tabular}{|c|c|c|c|c|c|c|c|c|c|}
\hline Mês & \multicolumn{3}{|c|}{21 abril 1981} & \multicolumn{3}{|c|}{26 maio 1981} & \multicolumn{3}{|c|}{26 junho 1981} \\
\hline Hora & $E C$ & $\mathrm{PE}$ & $\Delta$ & $\mathrm{EC}$ & $\mathrm{PE}$ & $\Delta$ & EC & $\mathrm{PE}$ & $\Delta$ \\
\hline 1 & 77 & 93 & -16 & 92 & 97 & -5 & 89 & 95 & -6 \\
\hline 2 & 83 & 94 & -11 & 93 & 98 & -5 & 91 & 96 & -5 \\
\hline 3 & 88 & 94 & -6 & 93 & 98 & -5 & 92 & 97 & -5 \\
\hline 4 & 85 & 95 & -10 & 94 & 98 & -4 & 93 & 98 & -5 \\
\hline 5 & 81 & 95 & -14 & 94 & 98 & -4 & 94 & 98 & -4 \\
\hline 6 & 84 & 96 & -12 & 95 & 99 & -4 & 94 & 97 & -3 \\
\hline 7 & 86 & 96 & -10 & 95 & 99 & -4 & 94 & 97 & -3 \\
\hline 8 & 83 & 86 & -3 & 95 & 100 & -5 & 95 & 97 & -2 \\
\hline 9 & 80 & 75 & 5 & 94 & 98 & -4 & 95 & 80 & 15 \\
\hline 10 & 75 & 67 & 8 & 72 & 90 & -18 & 80 & 65 & 15 \\
\hline 11 & 65 & 63 & 2 & 59 & 61 & -2 & 57 & 59 & -2 \\
\hline 12 & 56 & 51 & 5 & 49 & 56 & -7 & 50 & 51 & -1 \\
\hline 13 & 44 & 41 & 3 & 40 & 50 & -10 & 46 & 48 & -2 \\
\hline 14 & 41 & 37 & 4 & 35 & 49 & -14 & 42 & 45 & -3 \\
\hline 15 & 40 & 40 & 0 & 34 & 62 & -28 & 41 & 43 & -2 \\
\hline 16 & 39 & 51 & -12 & 38 & 73 & -35 & 40 & 41 & -1 \\
\hline 17 & 42 & 53 & -11 & 62 & 83 & -21 & 41 & 48 & -7 \\
\hline 18 & 51 & 70 & -19 & 77 & 88 & -11 & 43 & 57 & -14 \\
\hline 19 & 59 & 77 & -18 & 82 & 90 & -8 & 46 & 74 & -28 \\
\hline 20 & 79 & 82 & -3 & 83 & 93 & -10 & 50 & 90 & -40 \\
\hline 21 & 76 & 88 & -12 & 84 & 96 & -12 & 60 & 92 & -32 \\
\hline 22 & 75 & 80 & -5 & 86 & 98 & -12 & 70 & 95 & -25 \\
\hline 23 & 77 & 74 & 3 & 86 & 96 & -10 & 76 & 94 & -18 \\
\hline 24 & 76 & 81 & -5 & 89 & 95 & -6 & 76 & 97 & -21 \\
\hline
\end{tabular}



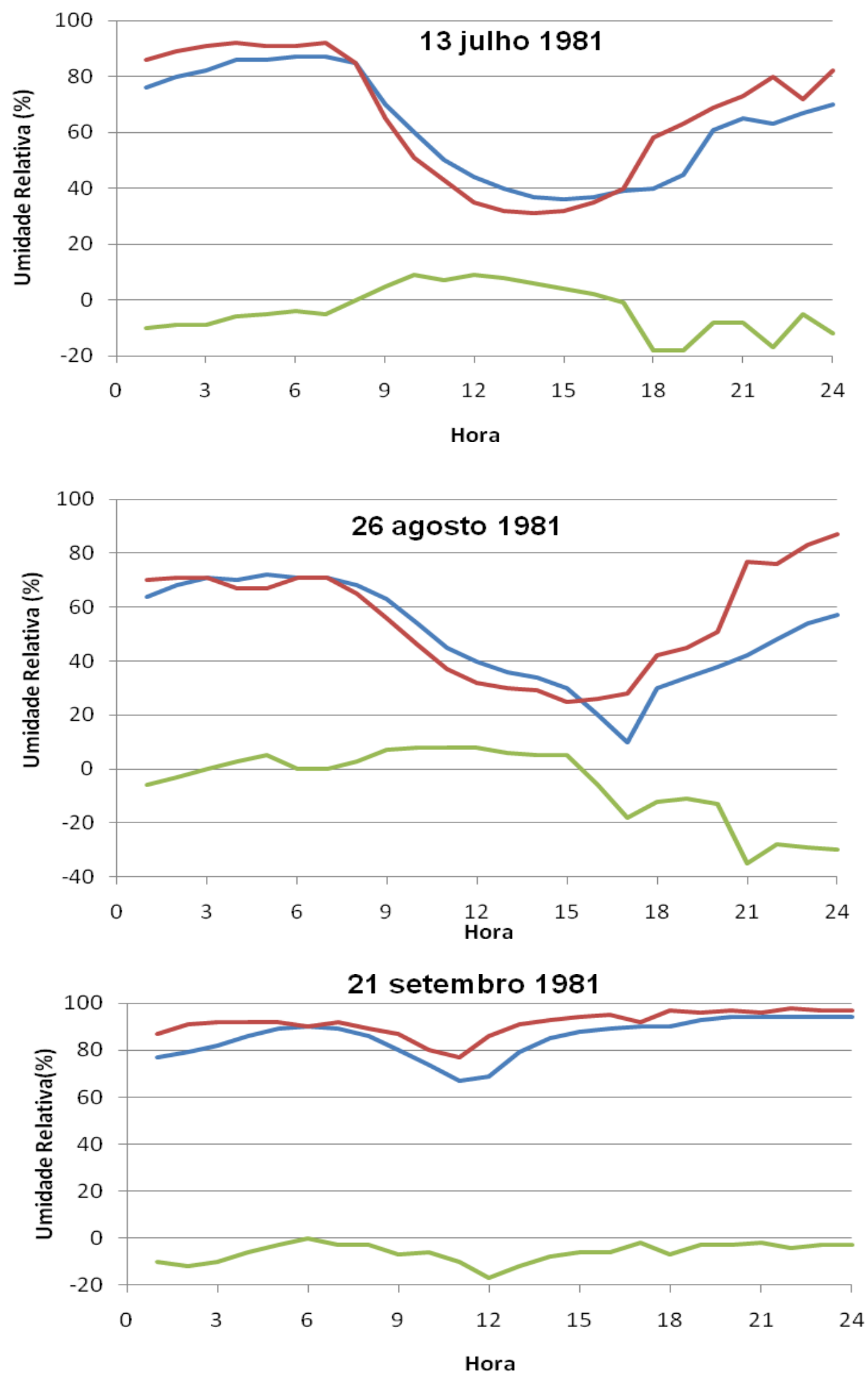

- Est. Centro $\longrightarrow$ Pq. Estado Diferencial UR

FIGURA 83. Gráficos horários da umidade relativa e do diferencial de umidade, dias 13 de julho, 26 de agosto e 21 de setembro de 1981, na Estação de Monitoramento Centro, Estação Meteorológica do Parque Estadual Fontes do Ipiranga. Fonte: CETESB, 1994 e IAG, 1981. 
TABELA 41. Registros horários da umidade relativa e do diferencial de umidade nos dias 13 de julho, 26 de agosto e 21 de setembro de 1981, na Estação de Monitoramento Centro, Estação Meteorológica do Parque Estadual Fontes do Ipiranga. Fonte: CETESB, 1994 e IAG, 1981.

\begin{tabular}{|c|c|c|c|c|c|c|c|c|c|}
\hline Mês & \multicolumn{3}{|c|}{13 julho 1981} & \multicolumn{3}{|c|}{26 agosto 1981} & \multicolumn{3}{|c|}{21 setembro 1981} \\
\hline Hora & EC & $\mathrm{PE}$ & $\Delta$ & $\mathrm{EC}$ & $\mathrm{PE}$ & $\Delta$ & $\mathrm{EC}$ & $\mathrm{PE}$ & $\Delta$ \\
\hline 1 & 76 & 86 & -10 & 64 & 70 & -6 & 77 & 87 & -10 \\
\hline 2 & 80 & 89 & -9 & 68 & 71 & -3 & 79 & 91 & -12 \\
\hline 3 & 82 & 91 & -9 & 71 & 71 & 0 & 82 & 92 & -10 \\
\hline 4 & 86 & 92 & -6 & 70 & 67 & 3 & 86 & 92 & -6 \\
\hline 5 & 86 & 91 & -5 & 72 & 67 & 5 & 89 & 92 & -3 \\
\hline 6 & 87 & 91 & -4 & 71 & 71 & 0 & 90 & 90 & 0 \\
\hline 7 & 87 & 92 & -5 & 71 & 71 & 0 & 89 & 92 & -3 \\
\hline 8 & 85 & 85 & 0 & 68 & 65 & 3 & 86 & 89 & -3 \\
\hline 9 & 70 & 65 & 5 & 63 & 56 & 7 & 80 & 87 & -7 \\
\hline 10 & 60 & 51 & 9 & 54 & 46 & 8 & 74 & 80 & -6 \\
\hline 11 & 50 & 43 & 7 & 45 & 37 & 8 & 67 & 77 & -10 \\
\hline 12 & 44 & 35 & 9 & 40 & 32 & 8 & 69 & 86 & -17 \\
\hline 13 & 40 & 32 & 8 & 36 & 30 & 6 & 79 & 91 & -12 \\
\hline 14 & 37 & 31 & 6 & 34 & 29 & 5 & 85 & 93 & -8 \\
\hline 15 & 36 & 32 & 4 & 30 & 25 & 5 & 88 & 94 & -6 \\
\hline 16 & 37 & 35 & 2 & 20 & 26 & -6 & 89 & 95 & -6 \\
\hline 17 & 39 & 40 & -1 & 10 & 28 & -18 & 90 & 92 & -2 \\
\hline 18 & 40 & 58 & -18 & 30 & 42 & -12 & 90 & 97 & -7 \\
\hline 19 & 45 & 63 & -18 & 34 & 45 & -11 & 93 & 96 & -3 \\
\hline 20 & 61 & 69 & -8 & 38 & 51 & -13 & 94 & 97 & -3 \\
\hline 21 & 65 & 73 & -8 & 42 & 77 & -35 & 94 & 96 & -2 \\
\hline 22 & 63 & 80 & -17 & 48 & 76 & -28 & 94 & 98 & -4 \\
\hline 23 & 67 & 72 & -5 & 54 & 83 & -29 & 94 & 97 & -3 \\
\hline 24 & 70 & 82 & -12 & 57 & 87 & -30 & 94 & 97 & -3 \\
\hline
\end{tabular}



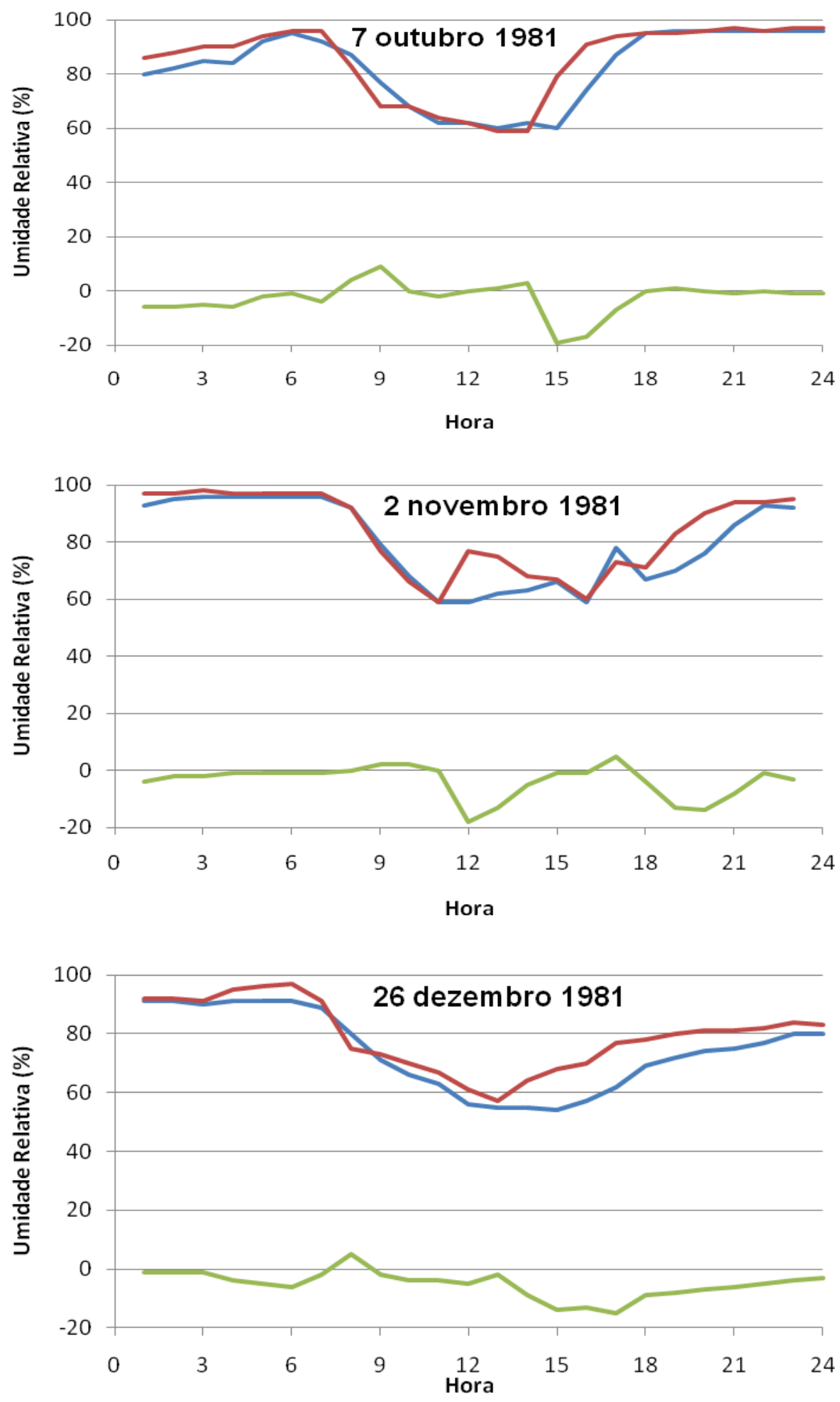

Est. Centro

Pq. Estado

Diferencial UR

FIGURA 84. Gráficos horários da umidade relativa e do diferencial de umidade, dias 7 de outubro, 2 de novembro e 26 de dezembro de 1981, na Estação de Monitoramento Centro, Estação Meteorológica do Parque Estadual Fontes do Ipiranga. Fonte: CETESB, 1994 e IAG, 1981. 
TABELA 42. Registros horários da umidade relativa e do diferencial de umidade nos dias 2 de outubro, 2 de novembro e 26 de dezembro de 1981, na Estação de Monitoramento Centro, Estação Meteorológica do Parque Estadual Fontes do Ipiranga. Fonte: CETESB, 1994 e IAG, 1981.

\begin{tabular}{|c|c|c|c|c|c|c|c|c|c|}
\hline Mês & \multicolumn{3}{|c|}{7 outubro 1981} & \multicolumn{3}{|c|}{2 novembro 1981} & \multicolumn{3}{|c|}{26 dezembro 1981} \\
\hline Hora & $\mathrm{EC}$ & $\mathrm{PE}$ & $\Delta$ & $\mathrm{EC}$ & $\mathrm{PE}$ & $\Delta$ & $\mathrm{EC}$ & $\mathrm{PE}$ & $\Delta$ \\
\hline 1 & 80 & 86 & -6 & 93 & 97 & -4 & 91 & 92 & -1 \\
\hline 2 & 82 & 88 & -6 & 95 & 97 & -2 & 91 & 92 & -1 \\
\hline 3 & 85 & 90 & -5 & 96 & 98 & -2 & 90 & 91 & -1 \\
\hline 4 & 84 & 90 & -6 & 96 & 97 & -1 & 91 & 95 & -4 \\
\hline 5 & 92 & 94 & -2 & 96 & 97 & -1 & 91 & 96 & -5 \\
\hline 6 & 95 & 96 & -1 & 96 & 97 & -1 & 91 & 97 & -6 \\
\hline 7 & 92 & 96 & -4 & 96 & 97 & -1 & 89 & 91 & -2 \\
\hline 8 & 87 & 83 & 4 & 92 & 92 & 0 & 80 & 75 & 5 \\
\hline 9 & 77 & 68 & 9 & 79 & 77 & 2 & 71 & 73 & -2 \\
\hline 10 & 68 & 68 & 0 & 68 & 66 & 2 & 66 & 70 & -4 \\
\hline 11 & 62 & 64 & -2 & 59 & 59 & 0 & 63 & 67 & -4 \\
\hline 12 & 62 & 62 & 0 & 59 & 77 & -18 & 56 & 61 & -5 \\
\hline 13 & 60 & 59 & 1 & 62 & 75 & -13 & 55 & 57 & -2 \\
\hline 14 & 62 & 59 & 3 & 63 & 68 & -5 & 55 & 64 & -9 \\
\hline 15 & 60 & 79 & -19 & 66 & 67 & -1 & 54 & 68 & -14 \\
\hline 16 & 74 & 91 & -17 & 59 & 60 & -1 & 57 & 70 & -13 \\
\hline 17 & 87 & 94 & -7 & 78 & 73 & 5 & 62 & 77 & -15 \\
\hline 18 & 95 & 95 & 0 & 67 & 71 & -4 & 69 & 78 & -9 \\
\hline 19 & 96 & 95 & 1 & 70 & 83 & -13 & 72 & 80 & -8 \\
\hline 20 & 96 & 96 & 0 & 76 & 90 & -14 & 74 & 81 & -7 \\
\hline 21 & 96 & 97 & -1 & 86 & 94 & -8 & 75 & 81 & -6 \\
\hline 22 & 96 & 96 & 0 & 93 & 94 & -1 & 77 & 82 & -5 \\
\hline 23 & 96 & 97 & -1 & 92 & 95 & -3 & 80 & 84 & -4 \\
\hline 24 & 96 & 97 & -1 & 89 & 93 & -4 & 80 & 83 & -3 \\
\hline
\end{tabular}



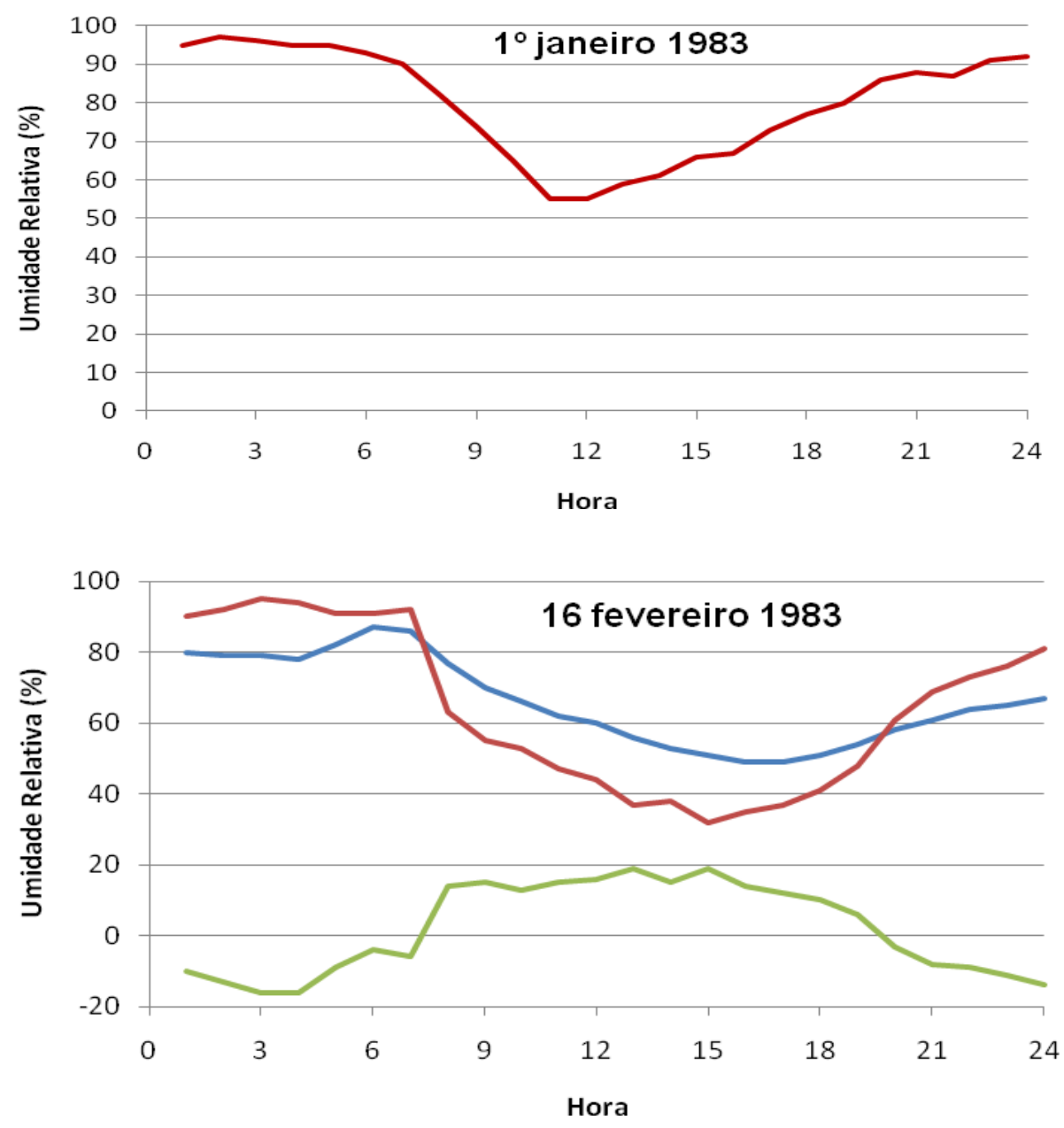

20 março 1983

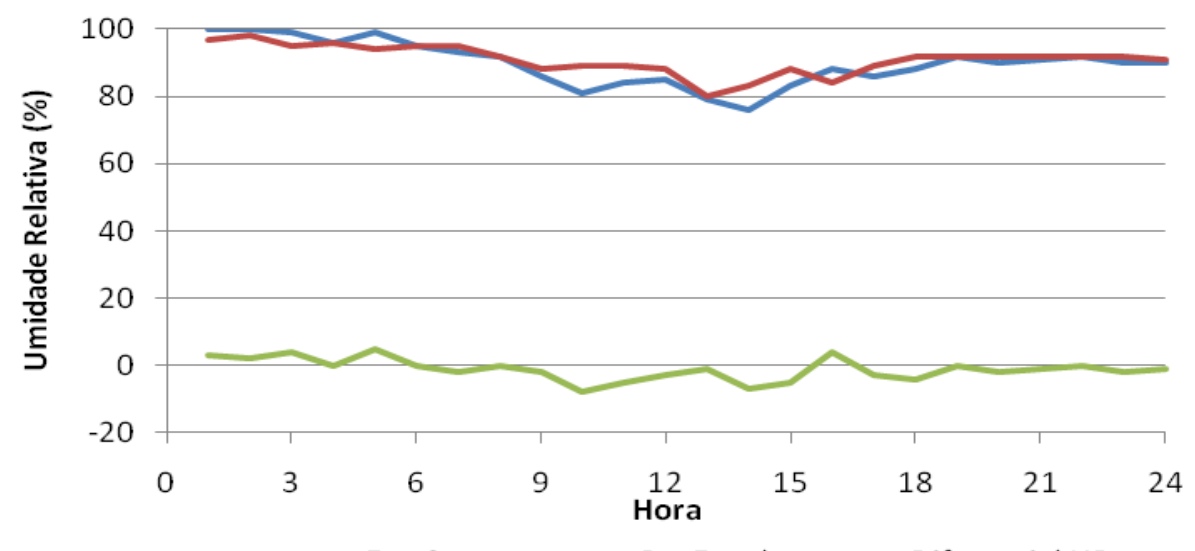

- Est. Centro $\longrightarrow$ Pq. Estado $\longrightarrow$ Diferencial UR

FIGURA 85. Gráficos horários da umidade relativa e do diferencial de umidade, dias $1^{\circ}$ de janeiro, 16 de fevereiro e 20 de março de 1983, na Estação de Monitoramento Centro, Estação Meteorológica do Parque Estadual Fontes do Ipiranga. Fonte: CETESB, 1994 e IAG, 1983. 
TABELA 43. Registros horários da umidade relativa e do diferencial de umidade nos dias $1^{\circ}$ de janeiro,16 de fevereiro e 20 de março de 1983 na Estação de Monitoramento Centro, Estação Meteorológica do Parque Estadual Fontes do Ipiranga. Fonte: CETESB, 1994 e IAG, 1983.

\begin{tabular}{|c|c|c|c|c|c|c|c|c|c|}
\hline Mês & \multicolumn{3}{|c|}{$1^{\circ}$ janeiro 1983} & \multicolumn{3}{|c|}{16 fevereiro 1983} & \multicolumn{3}{|c|}{20 março 1983} \\
\hline Hora & EC & $\mathrm{PE}$ & $\Delta$ & $\mathrm{EC}$ & $\mathrm{PE}$ & $\Delta$ & $\mathrm{EC}$ & $\mathrm{PE}$ & $\Delta$ \\
\hline 1 & ND & 95 & ND & 80 & 90 & -10 & 100 & 97 & 3 \\
\hline 2 & ND & 97 & ND & 79 & 92 & -13 & 100 & 98 & 2 \\
\hline 3 & ND & 96 & ND & 79 & 95 & -16 & 99 & 95 & 4 \\
\hline 4 & ND & 95 & ND & 78 & 94 & -16 & 96 & 96 & 0 \\
\hline 5 & ND & 95 & ND & 82 & 91 & -9 & 99 & 94 & 5 \\
\hline 6 & ND & 93 & ND & 87 & 91 & -4 & 95 & 95 & 0 \\
\hline 7 & ND & 90 & ND & 86 & 92 & -6 & 93 & 95 & -2 \\
\hline 8 & ND & 82 & ND & 77 & 63 & 14 & 92 & 92 & 0 \\
\hline 9 & ND & 74 & ND & 70 & 55 & 15 & 86 & 88 & -2 \\
\hline 10 & ND & 65 & ND & 66 & 53 & 13 & 81 & 89 & -8 \\
\hline 11 & ND & 55 & ND & 62 & 47 & 15 & 84 & 89 & -5 \\
\hline 12 & ND & 55 & ND & 60 & 44 & 16 & 85 & 88 & -3 \\
\hline 13 & ND & 59 & ND & 56 & 37 & 19 & 79 & 80 & -1 \\
\hline 14 & ND & 61 & ND & 53 & 38 & 15 & 76 & 83 & -7 \\
\hline 15 & ND & 66 & ND & 51 & 32 & 19 & 83 & 88 & -5 \\
\hline 16 & ND & 67 & ND & 49 & 35 & 14 & 88 & 84 & 4 \\
\hline 17 & ND & 73 & ND & 49 & 37 & 12 & 86 & 89 & -3 \\
\hline 18 & ND & 77 & ND & 51 & 41 & 10 & 88 & 92 & -4 \\
\hline 19 & ND & 80 & ND & 54 & 48 & 6 & 92 & 92 & 0 \\
\hline 20 & ND & 86 & ND & 58 & 61 & -3 & 90 & 92 & -2 \\
\hline 21 & ND & 88 & ND & 61 & 69 & -8 & 91 & 92 & -1 \\
\hline 22 & ND & 87 & ND & 64 & 73 & -9 & 92 & 92 & 0 \\
\hline 23 & ND & 91 & ND & 65 & 76 & -11 & 90 & 92 & -2 \\
\hline 24 & ND & 92 & ND & 67 & 81 & -14 & 90 & 91 & -1 \\
\hline
\end{tabular}

ND - Dados não disponíveis. 

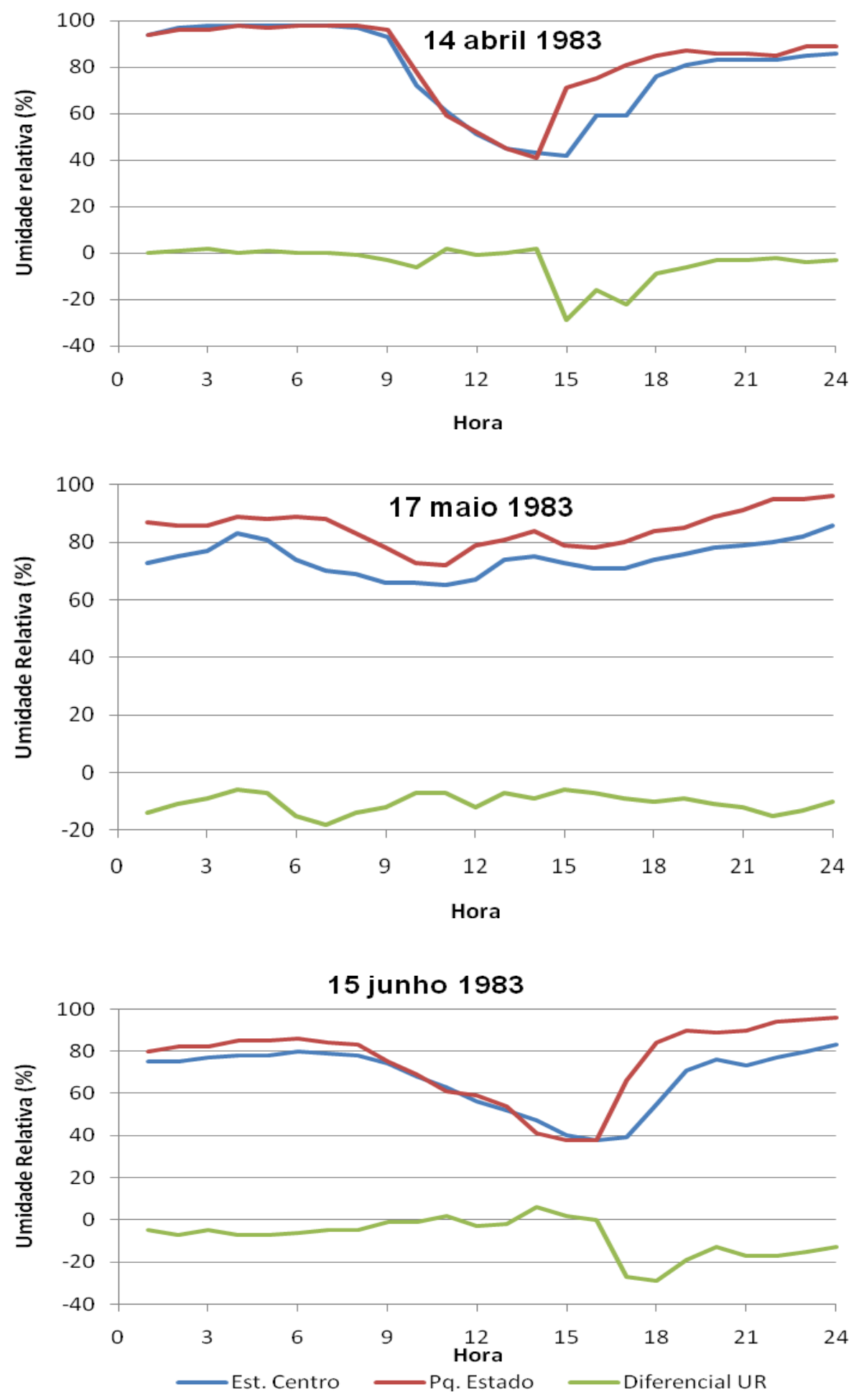

FIGURA 86. Gráficos horários da umidade relativa e do diferencial de umidade, dias 14 de abril, 17 de maio e 15 de junho de 1983, na Estação de Monitoramento Centro, Estação Meteorológica do Parque Estadual Fontes do Ipiranga. Fonte: CETESB, 1994 e IAG, 1983. 
TABELA 44. Registros horários da umidade relativa e do diferencial de umidade nos dias 14 de abril, 17 de maio e 15 de junho de 1983, na Estação de Monitoramento Centro, Estação Meteorológica do Parque Estadual Fontes do Ipiranga. Fonte: CETESB, 1994 e IAG, 1983.

\begin{tabular}{|c|c|c|c|c|c|c|c|c|c|}
\hline Mês & \multicolumn{3}{|c|}{14 abril 1983} & \multicolumn{3}{|c|}{17 maio 1983} & \multicolumn{3}{|c|}{15 junho 1983} \\
\hline Hora & $E C$ & $\mathrm{PE}$ & $\Delta$ & $\mathrm{EC}$ & $\mathrm{PE}$ & $\Delta$ & EC & $\mathrm{PE}$ & $\Delta$ \\
\hline 1 & 94 & 94 & 0 & 73 & 87 & -14 & 75 & 80 & -5 \\
\hline 2 & 97 & 96 & 1 & 75 & 86 & -11 & 75 & 82 & -7 \\
\hline 3 & 98 & 96 & 2 & 77 & 86 & -9 & 77 & 82 & -5 \\
\hline 4 & 98 & 98 & 0 & 83 & 89 & -6 & 78 & 85 & -7 \\
\hline 5 & 98 & 97 & 1 & 81 & 88 & -7 & 78 & 85 & -7 \\
\hline 6 & 98 & 98 & 0 & 74 & 89 & -15 & 80 & 86 & -6 \\
\hline 7 & 98 & 98 & 0 & 70 & 88 & -18 & 79 & 84 & -5 \\
\hline 8 & 97 & 98 & -1 & 69 & 83 & -14 & 78 & 83 & -5 \\
\hline 9 & 93 & 96 & -3 & 66 & 78 & -12 & 74 & 75 & -1 \\
\hline 10 & 72 & 78 & -6 & 66 & 73 & -7 & 68 & 69 & -1 \\
\hline 11 & 61 & 59 & 2 & 65 & 72 & -7 & 63 & 61 & 2 \\
\hline 12 & 51 & 52 & -1 & 67 & 79 & -12 & 56 & 59 & -3 \\
\hline 13 & 45 & 45 & 0 & 74 & 81 & -7 & 52 & 54 & -2 \\
\hline 14 & 43 & 41 & 2 & 75 & 84 & -9 & 47 & 41 & 6 \\
\hline 15 & 42 & 71 & -29 & 73 & 79 & -6 & 40 & 38 & 2 \\
\hline 16 & 59 & 75 & -16 & 71 & 78 & -7 & 38 & 38 & 0 \\
\hline 17 & 59 & 81 & -22 & 71 & 80 & -9 & 39 & 66 & -27 \\
\hline 18 & 76 & 85 & -9 & 74 & 84 & -10 & 55 & 84 & -29 \\
\hline 19 & 81 & 87 & -6 & 76 & 85 & -9 & 71 & 90 & -19 \\
\hline 20 & 83 & 86 & -3 & 78 & 89 & -11 & 76 & 89 & -13 \\
\hline 21 & 83 & 86 & -3 & 79 & 91 & -12 & 73 & 90 & -17 \\
\hline 22 & 83 & 85 & -2 & 80 & 95 & -15 & 77 & 94 & -17 \\
\hline 23 & 85 & 89 & -4 & 82 & 95 & -13 & 80 & 95 & -15 \\
\hline 24 & 86 & 89 & -3 & 86 & 96 & -10 & 83 & 96 & -13 \\
\hline
\end{tabular}



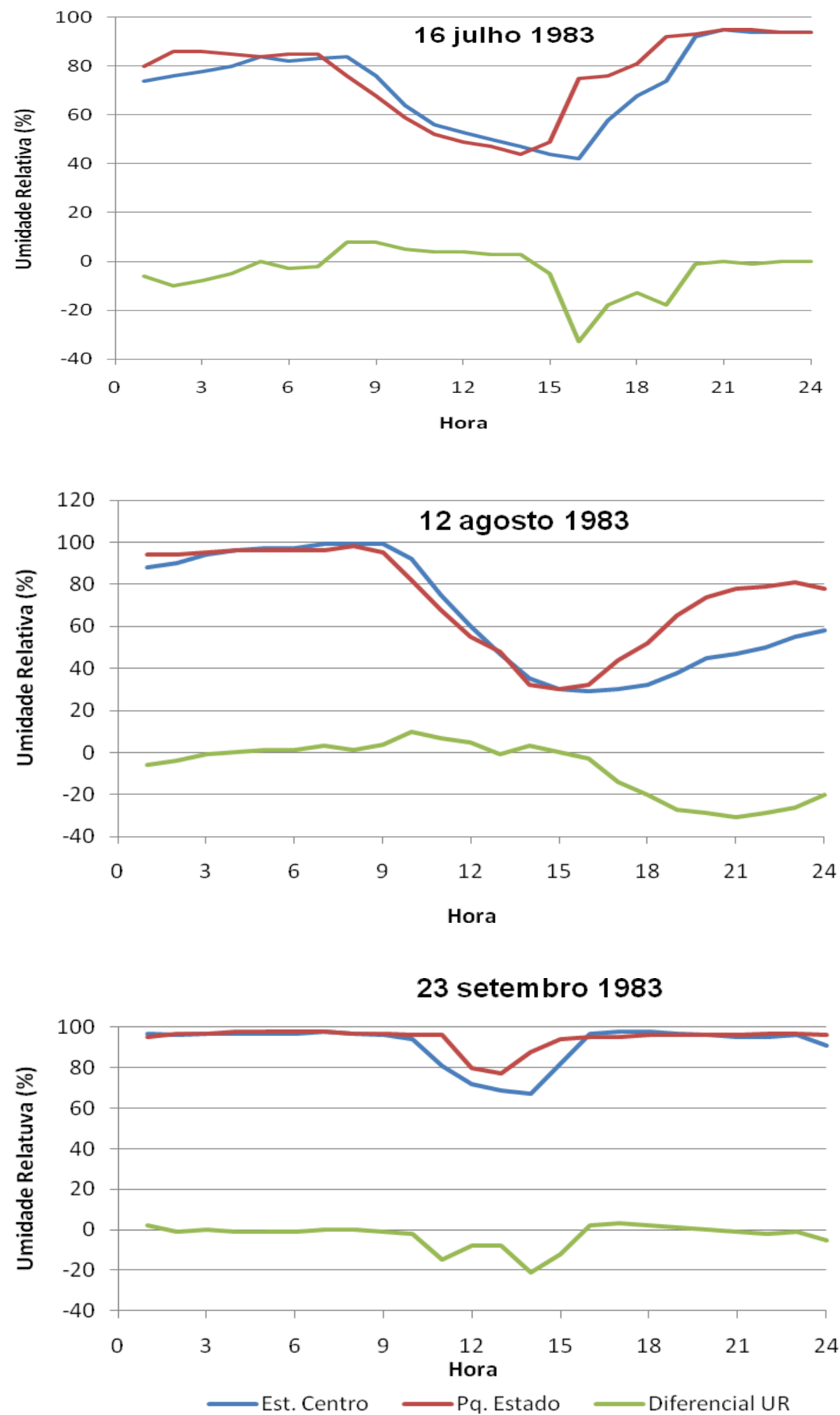

FIGURA 87. Gráficos horários da umidade relativa e do diferencial de umidade, dias 16 de julho, 12 de agosto e 23 de setembro de 1983, na Estação de Monitoramento Centro, Estação Meteorológica do Parque Estadual Fontes do Ipiranga. Fonte: CETESB, 1994 e IAG, 1983. 
TABELA 45. Registros horários da umidade relativa e do diferencial de umidade nos dias 16 de julho,12 de agosto e 23 de setembro de 1983 na Estação de Monitoramento Centro, Estação Meteorológica do Parque Estadual Fontes do Ipiranga. Fonte: CETESB, 1994 e IAG, 1983.

\begin{tabular}{|c|c|c|c|c|c|c|c|c|c|}
\hline Mês & \multicolumn{3}{|c|}{16 julho 1983} & \multicolumn{3}{|c|}{12 agosto 1983} & \multicolumn{3}{|c|}{23 setembro 1983} \\
\hline Hora & $\mathrm{EC}$ & $\mathrm{PE}$ & $\Delta$ & $\mathrm{EC}$ & $\mathrm{PE}$ & $\Delta$ & EC & $\mathrm{PE}$ & $\Delta$ \\
\hline 1 & 74 & 80 & -6 & 88 & 94 & -6 & 97 & 95 & 2 \\
\hline 2 & 76 & 86 & -10 & 90 & 94 & -4 & 96 & 97 & -1 \\
\hline 3 & 78 & 86 & -8 & 94 & 95 & -1 & 97 & 97 & 0 \\
\hline 4 & 80 & 85 & -5 & 96 & 96 & 0 & 97 & 98 & -1 \\
\hline 5 & 84 & 84 & 0 & 97 & 96 & 1 & 97 & 98 & -1 \\
\hline 6 & 82 & 85 & -3 & 97 & 96 & 1 & 97 & 98 & -1 \\
\hline 7 & 83 & 85 & -2 & 99 & 96 & 3 & 98 & 98 & 0 \\
\hline 8 & 84 & 76 & 8 & 99 & 98 & 1 & 97 & 97 & 0 \\
\hline 9 & 76 & 68 & 8 & 99 & 95 & 4 & 96 & 97 & -1 \\
\hline 10 & 64 & 59 & 5 & 92 & 82 & 10 & 94 & 96 & -2 \\
\hline 11 & 56 & 52 & 4 & 75 & 68 & 7 & 81 & 96 & -15 \\
\hline 12 & 53 & 49 & 4 & 60 & 55 & 5 & 72 & 80 & -8 \\
\hline 13 & 50 & 47 & 3 & 47 & 48 & -1 & 69 & 77 & -8 \\
\hline 14 & 47 & 44 & 3 & 35 & 32 & 3 & 67 & 88 & -21 \\
\hline 15 & 44 & 49 & -5 & 30 & 30 & 0 & 82 & 94 & -12 \\
\hline 16 & 42 & 75 & -33 & 29 & 32 & -3 & 97 & 95 & 2 \\
\hline 17 & 58 & 76 & -18 & 30 & 44 & -14 & 98 & 95 & 3 \\
\hline 18 & 68 & 81 & -13 & 32 & 52 & -20 & 98 & 96 & 2 \\
\hline 19 & 74 & 92 & -18 & 38 & 65 & -27 & 97 & 96 & 1 \\
\hline 20 & 92 & 93 & -1 & 45 & 74 & -29 & 96 & 96 & 0 \\
\hline 21 & 95 & 95 & 0 & 47 & 78 & -31 & 95 & 96 & -1 \\
\hline 22 & 94 & 95 & -1 & 50 & 79 & -29 & 95 & 97 & -2 \\
\hline 23 & 94 & 94 & 0 & 55 & 81 & -26 & 96 & 97 & -1 \\
\hline 24 & 94 & 94 & 0 & 58 & 78 & -20 & 91 & 96 & -5 \\
\hline
\end{tabular}



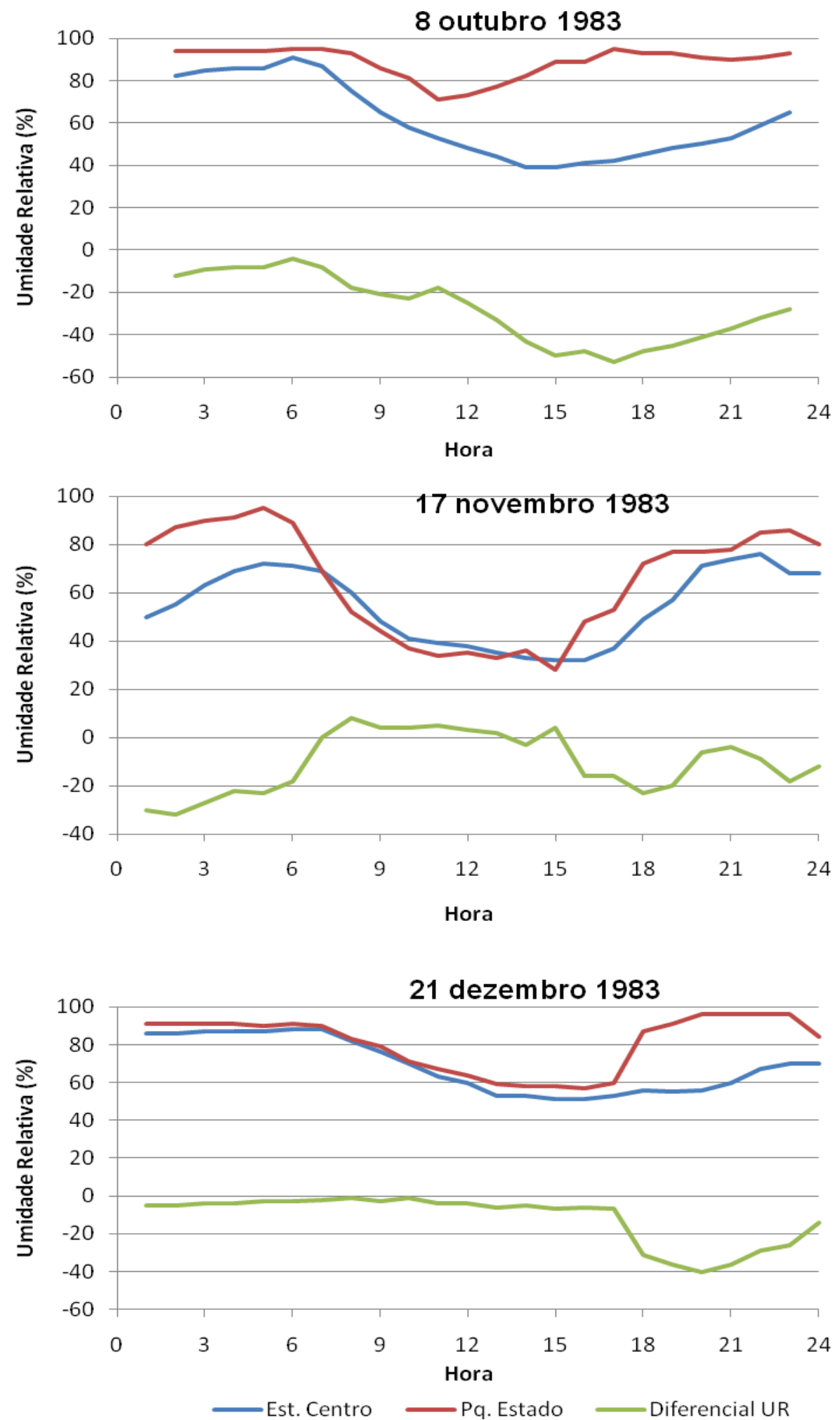

FIGURA 88. Gráficos horários da umidade relativa e do diferencial de umidade, dias 8 de outubro, 17 de novembro e 21 de dezembro de 1983, na Estação de Monitoramento Centro, Estação Meteorológica do Parque Estadual Fontes do Ipiranga. Fonte: CETESB, 1994 e IAG, 1983. 
TABELA 46. Registros horários da umidade relativa e do diferencial de umidade nos dias 8 de outubro, 17 de novembro e 21 de dezembro de 1983, na Estação de Monitoramento Centro, Estação Meteorológica do Parque Estadual Fontes do Ipiranga. Fonte: CETESB, 1994 e IAG, 1983.

\begin{tabular}{|c|c|c|c|c|c|c|c|c|c|}
\hline Mês & \multicolumn{3}{|c|}{8 outubro 1983} & \multicolumn{3}{|c|}{17 novembro 1983} & \multicolumn{3}{|c|}{21 dezembro 1983} \\
\hline Hora & $E C$ & $\mathrm{PE}$ & $\Delta$ & $\mathrm{EC}$ & $\mathrm{PE}$ & $\Delta$ & $\mathrm{EC}$ & $\mathrm{PE}$ & $\Delta$ \\
\hline 1 & 80 & 93 & -13 & 50 & 80 & -30 & 86 & 91 & -5 \\
\hline 2 & 82 & 94 & -12 & 55 & 87 & -32 & 86 & 91 & -5 \\
\hline 3 & 85 & 94 & -9 & 63 & 90 & -27 & 87 & 91 & -4 \\
\hline 4 & 86 & 94 & -8 & 69 & 91 & -22 & 87 & 91 & -4 \\
\hline 5 & 86 & 94 & -8 & 72 & 95 & -23 & 87 & 90 & -3 \\
\hline 6 & 91 & 95 & -4 & 71 & 89 & -18 & 88 & 91 & -3 \\
\hline 7 & 87 & 95 & -8 & 69 & 69 & 0 & 88 & 90 & -2 \\
\hline 8 & 75 & 93 & -18 & 60 & 52 & 8 & 82 & 83 & -1 \\
\hline 9 & 65 & 86 & -21 & 48 & 44 & 4 & 76 & 79 & -3 \\
\hline 10 & 58 & 81 & -23 & 41 & 37 & 4 & 70 & 71 & -1 \\
\hline 11 & 53 & 71 & -18 & 39 & 34 & 5 & 63 & 67 & -4 \\
\hline 12 & 48 & 73 & -25 & 38 & 35 & 3 & 60 & 64 & -4 \\
\hline 13 & 44 & 77 & -33 & 35 & 33 & 2 & 53 & 59 & -6 \\
\hline 14 & 39 & 82 & -43 & 33 & 36 & -3 & 53 & 58 & -5 \\
\hline 15 & 39 & 89 & -50 & 32 & 28 & 4 & 51 & 58 & -7 \\
\hline 16 & 41 & 89 & -48 & 32 & 48 & -16 & 51 & 57 & -6 \\
\hline 17 & 42 & 95 & -53 & 37 & 53 & -16 & 53 & 60 & -7 \\
\hline 18 & 45 & 93 & -48 & 49 & 72 & -23 & 56 & 87 & -31 \\
\hline 19 & 48 & 93 & -45 & 57 & 77 & -20 & 55 & 91 & -36 \\
\hline 20 & 50 & 91 & -41 & 71 & 77 & -6 & 56 & 96 & -40 \\
\hline 21 & 53 & 90 & -37 & 74 & 78 & -4 & 60 & 96 & -36 \\
\hline 22 & 59 & 91 & -32 & 76 & 85 & -9 & 67 & 96 & -29 \\
\hline 23 & 65 & 93 & -28 & 68 & 86 & -18 & 70 & 96 & -26 \\
\hline 24 & 68 & 93 & -25 & 68 & 80 & -12 & 70 & 84 & -14 \\
\hline
\end{tabular}




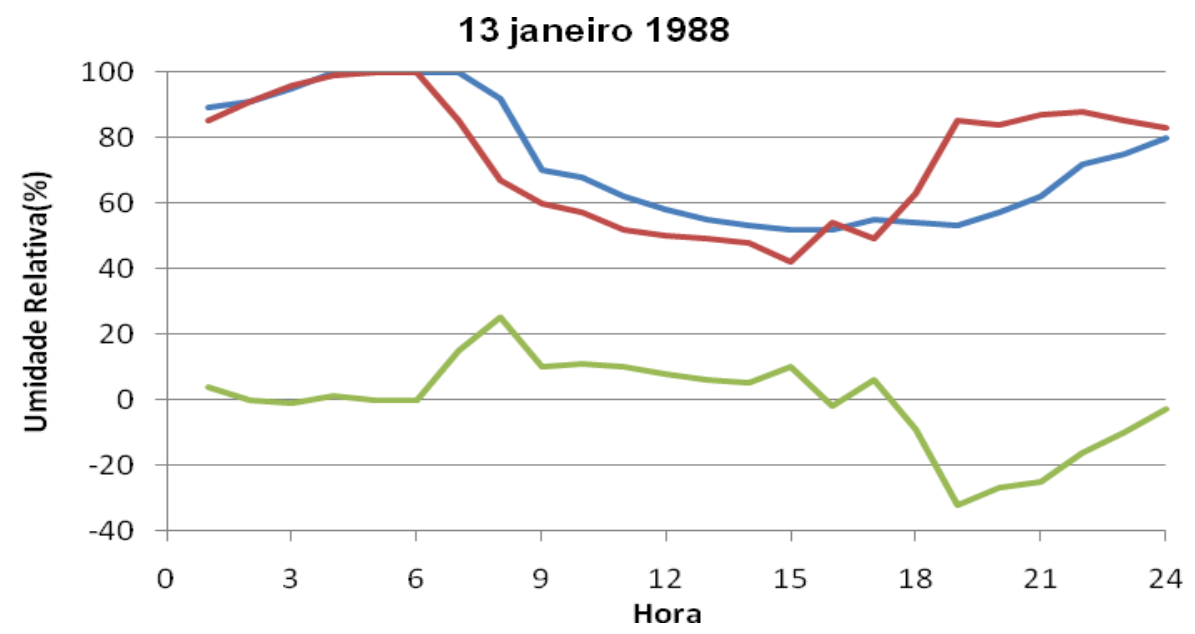

7 fevereiro 1988

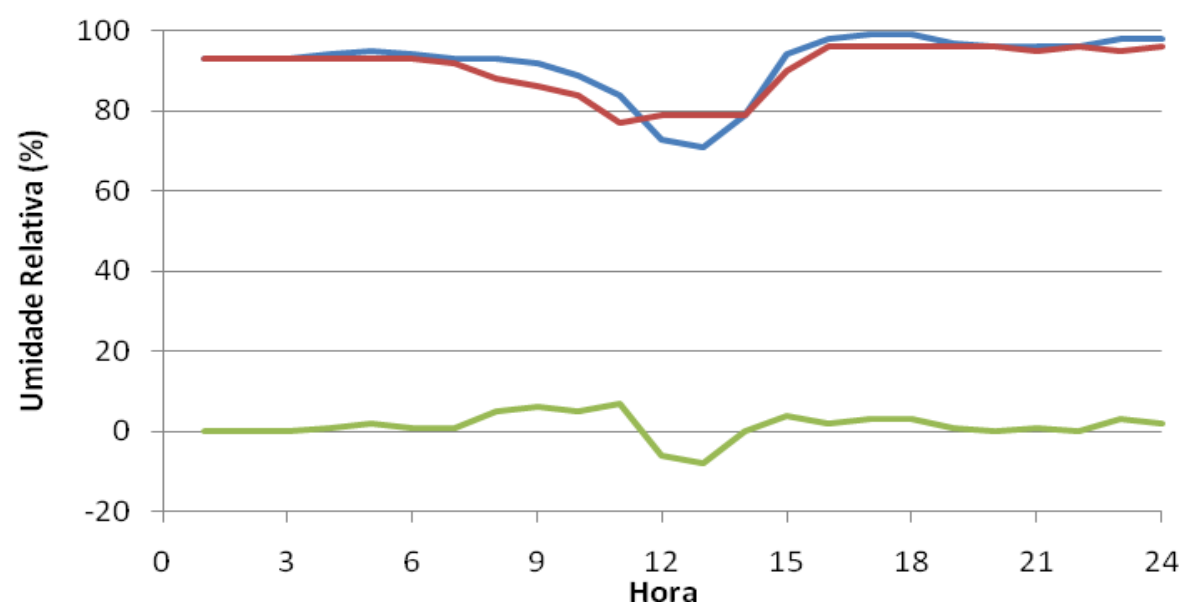

3 março 1988

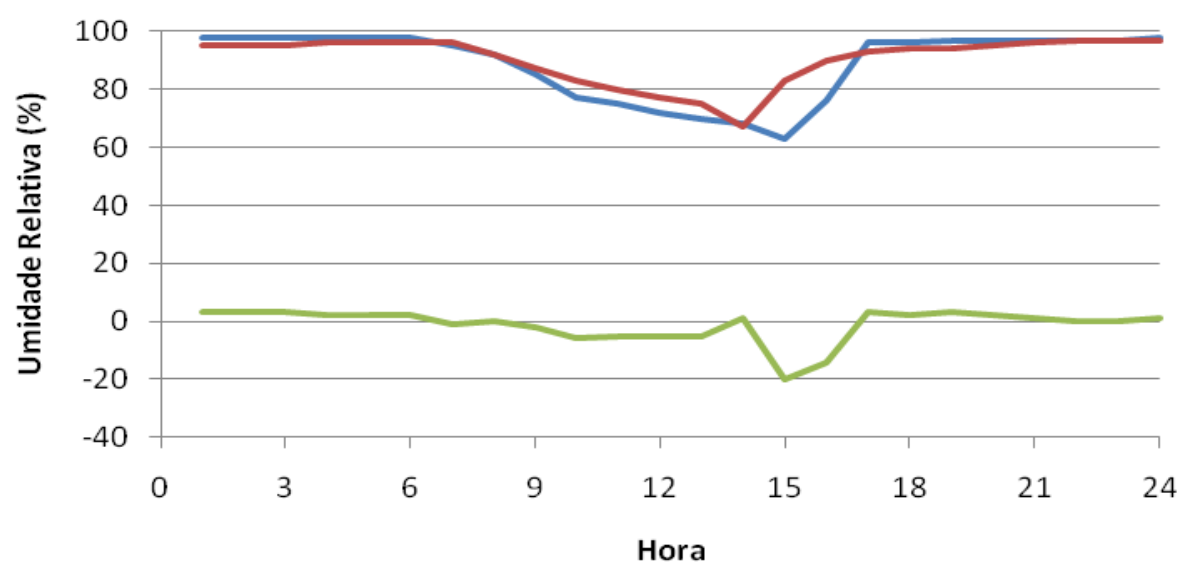

Est. Centro Pq. Estado Diferencial UR

FIGURA 89. Gráficos horários da umidade relativa e do diferencial de umidade, dias 13 de janeiro, 7 de fevereiro e 3 de março de 1988, na Estação de Monitoramento Centro, Estação Meteorológica do Parque Estadual Fontes do Ipiranga. Fonte: CETESB, 1994 e IAG, 1988. 
TABELA 47. Registros horários da umidade relativa e do diferencial de umidade nos dias 13 de janeiro, 7 de fevereiro e 3 de março de 1988, na Estação de Monitoramento Centro, Estação Meteorológica do Parque Estadual Fontes do Ipiranga. Fonte: CETESB, 1994 e IAG, 1988.

\begin{tabular}{|c|c|c|c|c|c|c|c|c|c|}
\hline Mês & \multicolumn{3}{|c|}{13 janeiro 1988} & \multicolumn{3}{|c|}{7 fevereiro 1988} & \multicolumn{3}{|c|}{3 março 1988} \\
\hline Hora & $\mathrm{EC}$ & $\mathrm{PE}$ & $\Delta$ & $\mathrm{EC}$ & $\mathrm{PE}$ & $\Delta$ & $\mathrm{EC}$ & $\mathrm{PE}$ & $\Delta$. \\
\hline 1 & 89 & 85 & 4 & 93 & 93 & 0 & 98 & 95 & 3 \\
\hline 2 & 91 & 91 & 0 & 93 & 93 & 0 & 98 & 95 & 3 \\
\hline 3 & 95 & 96 & -1 & 93 & 93 & 0 & 98 & 95 & 3 \\
\hline 4 & 100 & 99 & 1 & 94 & 93 & 1 & 98 & 96 & 2 \\
\hline 5 & 100 & 100 & 0 & 95 & 93 & 2 & 98 & 96 & 2 \\
\hline 6 & 100 & 100 & 0 & 94 & 93 & 1 & 98 & 96 & 2 \\
\hline 7 & 100 & 85 & 15 & 93 & 92 & 1 & 95 & 96 & -1 \\
\hline 8 & 92 & 67 & 25 & 93 & 88 & 5 & 92 & 92 & 0 \\
\hline 9 & 70 & 60 & 10 & 92 & 86 & 6 & 85 & 87 & -2 \\
\hline 10 & 68 & 57 & 11 & 89 & 84 & 5 & 77 & 83 & -6 \\
\hline 11 & 62 & 52 & 10 & 84 & 77 & 7 & 75 & 80 & -5 \\
\hline 12 & 58 & 50 & 8 & 73 & 79 & -6 & 72 & 77 & -5 \\
\hline 13 & 55 & 49 & 6 & 71 & 79 & -8 & 70 & 75 & -5 \\
\hline 14 & 53 & 48 & 5 & 79 & 79 & 0 & 68 & 67 & 1 \\
\hline 15 & 52 & 42 & 10 & 94 & 90 & 4 & 63 & 83 & -20 \\
\hline 16 & 52 & 54 & -2 & 98 & 96 & 2 & 76 & 90 & -14 \\
\hline 17 & 55 & 49 & 6 & 99 & 96 & 3 & 96 & 93 & 3 \\
\hline 18 & 54 & 63 & -9 & 99 & 96 & 3 & 96 & 94 & 2 \\
\hline 19 & 53 & 85 & -32 & 97 & 96 & 1 & 97 & 94 & 3 \\
\hline 20 & 57 & 84 & -27 & 96 & 96 & 0 & 97 & 95 & 2 \\
\hline 21 & 62 & 87 & -25 & 96 & 95 & 1 & 97 & 96 & 1 \\
\hline 22 & 72 & 88 & -16 & 96 & 96 & 0 & 97 & 97 & 0 \\
\hline 23 & 75 & 85 & -10 & 98 & 95 & 3 & 97 & 97 & 0 \\
\hline 24 & 80 & 83 & -3 & 98 & 96 & 2 & 98 & 97 & 1 \\
\hline
\end{tabular}



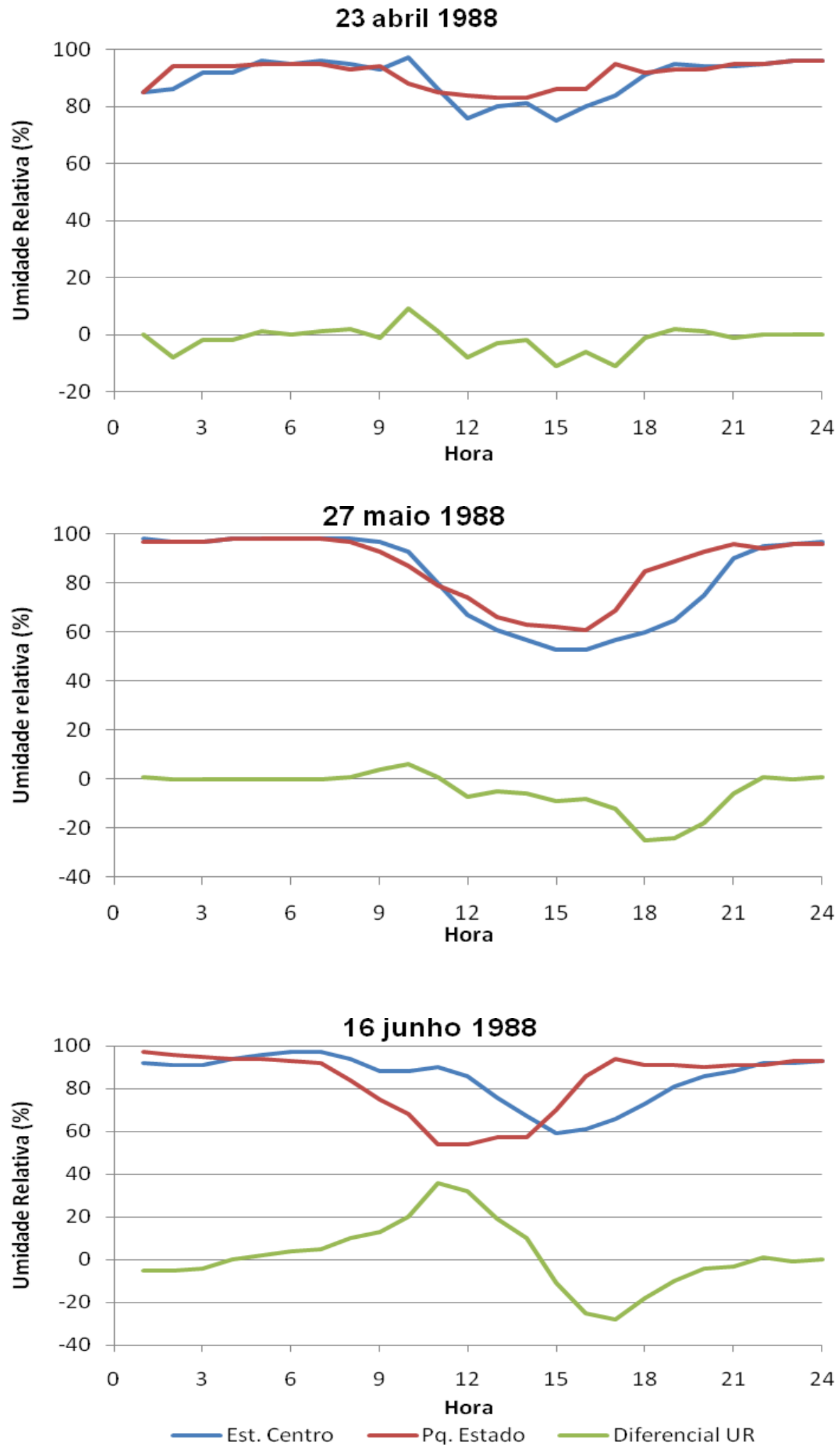

FIGURA 90. Gráficos horários da umidade relativa e do diferencial de umidade, dias 23 de abril, 19 de maio e 16 de junho de 1988, na Estação de Monitoramento Centro, Estação Meteorológica do Parque Estadual Fontes do Ipiranga. Fonte: CETESB, 1994 e IAG, 1988. 
TABELA 48. Registros horários da umidade relativa e do diferencial de umidade nos dias 23 de abril, 19 de maio e 16 de junho de 1988, na Estação de Monitoramento Centro, Estação Meteorológica do Parque Estadual Fontes do Ipiranga. Fonte: CETESB, 1994 e IAG, 1988.

\begin{tabular}{|c|c|c|c|c|c|c|c|c|c|}
\hline Mês & \multicolumn{3}{|c|}{23 abril 1988} & \multicolumn{3}{|c|}{19 maio 1988} & \multicolumn{3}{|c|}{16 junho 1988} \\
\hline Hora & $E C$ & $\mathrm{PE}$ & $\Delta$ & $\mathrm{EC}$ & $\mathrm{PE}$ & $\Delta$ & $\mathrm{EC}$ & $\mathrm{PE}$ & $\Delta$ \\
\hline 1 & 85 & 85 & 0 & 98 & 97 & 1 & 92 & 97 & -5 \\
\hline 2 & 86 & 94 & -8 & 97 & 97 & 0 & 91 & 96 & -5 \\
\hline 3 & 92 & 94 & -2 & 97 & 97 & 0 & 91 & 95 & -4 \\
\hline 4 & 92 & 94 & -2 & 98 & 98 & 0 & 94 & 94 & 0 \\
\hline 5 & 96 & 95 & 1 & 98 & 98 & 0 & 96 & 94 & 2 \\
\hline 6 & 95 & 95 & 0 & 98 & 98 & 0 & 97 & 93 & 4 \\
\hline 7 & 96 & 95 & 1 & 98 & 98 & 0 & 97 & 92 & 5 \\
\hline 8 & 95 & 93 & 2 & 98 & 97 & 1 & 94 & 84 & 10 \\
\hline 9 & 93 & 94 & -1 & 97 & 93 & 4 & 88 & 75 & 13 \\
\hline 10 & 97 & 88 & 9 & 93 & 87 & 6 & 88 & 68 & 20 \\
\hline 11 & 86 & 85 & 1 & 80 & 79 & 1 & 90 & 54 & 36 \\
\hline 12 & 76 & 84 & -8 & 67 & 74 & -7 & 86 & 54 & 32 \\
\hline 13 & 80 & 83 & -3 & 61 & 66 & -5 & 76 & 57 & 19 \\
\hline 14 & 81 & 83 & -2 & 57 & 63 & -6 & 67 & 57 & 10 \\
\hline 15 & 75 & 86 & -11 & 53 & 62 & -9 & 59 & 70 & -11 \\
\hline 16 & 80 & 86 & -6 & 53 & 61 & -8 & 61 & 86 & -25 \\
\hline 17 & 84 & 95 & -11 & 57 & 69 & -12 & 66 & 94 & -28 \\
\hline 18 & 91 & 92 & -1 & 60 & 85 & -25 & 73 & 91 & -18 \\
\hline 19 & 95 & 93 & 2 & 65 & 89 & -24 & 81 & 91 & -10 \\
\hline 20 & 94 & 93 & 1 & 75 & 93 & -18 & 86 & 90 & -4 \\
\hline 21 & 94 & 95 & -1 & 90 & 96 & -6 & 88 & 91 & -3 \\
\hline 22 & 95 & 95 & 0 & 95 & 94 & 1 & 92 & 91 & 1 \\
\hline 23 & 96 & 96 & 0 & 96 & 96 & 0 & 92 & 93 & -1 \\
\hline 24 & 96 & 96 & 0 & 97 & 96 & 1 & 93 & 93 & 0 \\
\hline
\end{tabular}




\section{7 julho 1988}

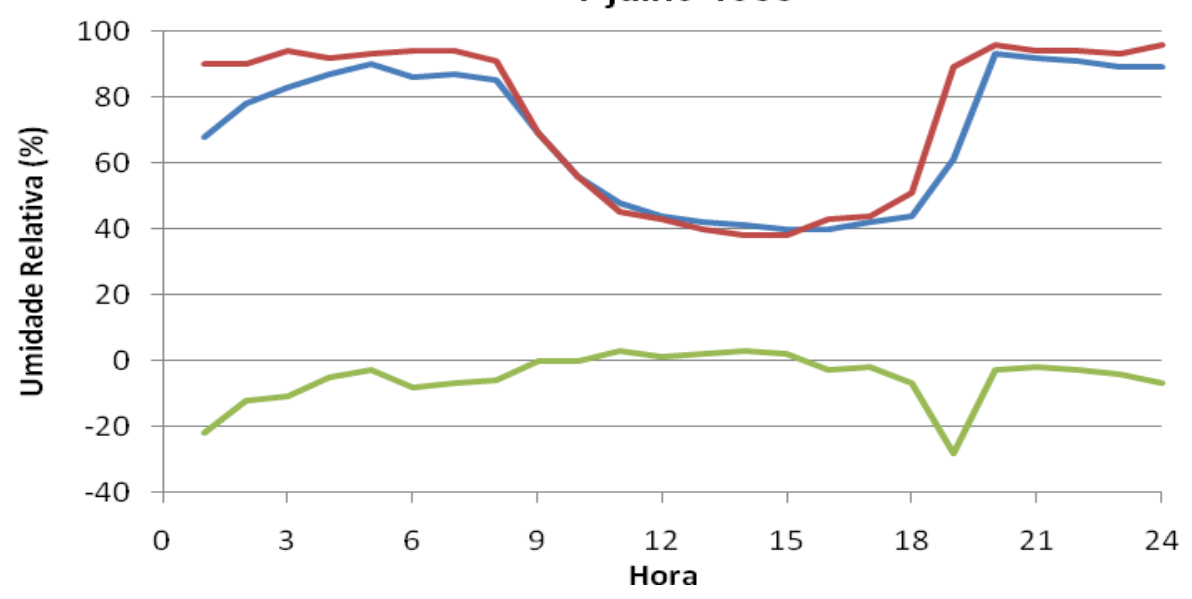

3 agosto 1988

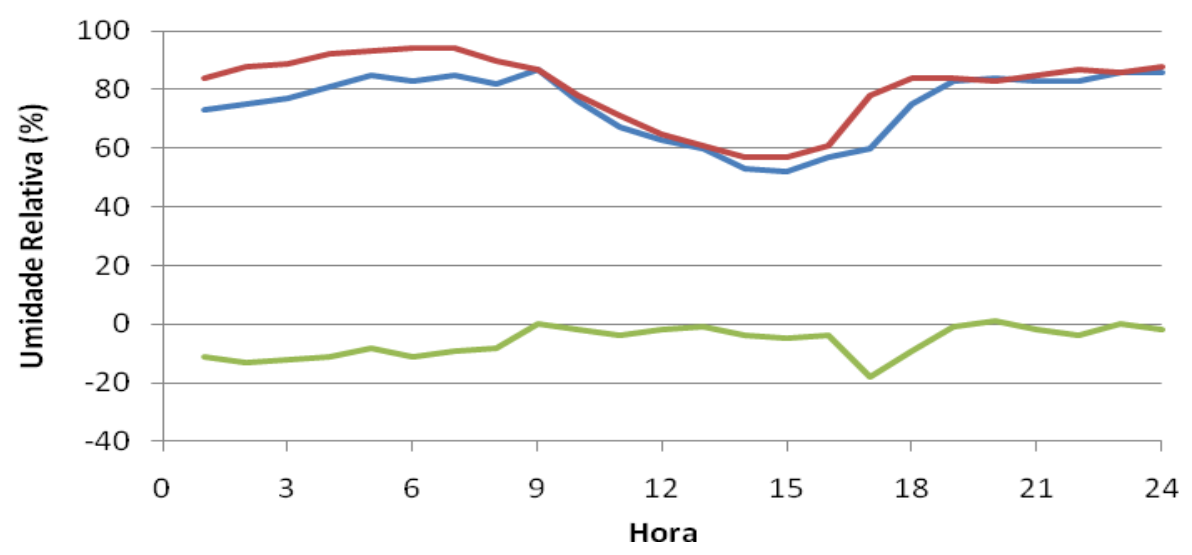

2 setembro 1988

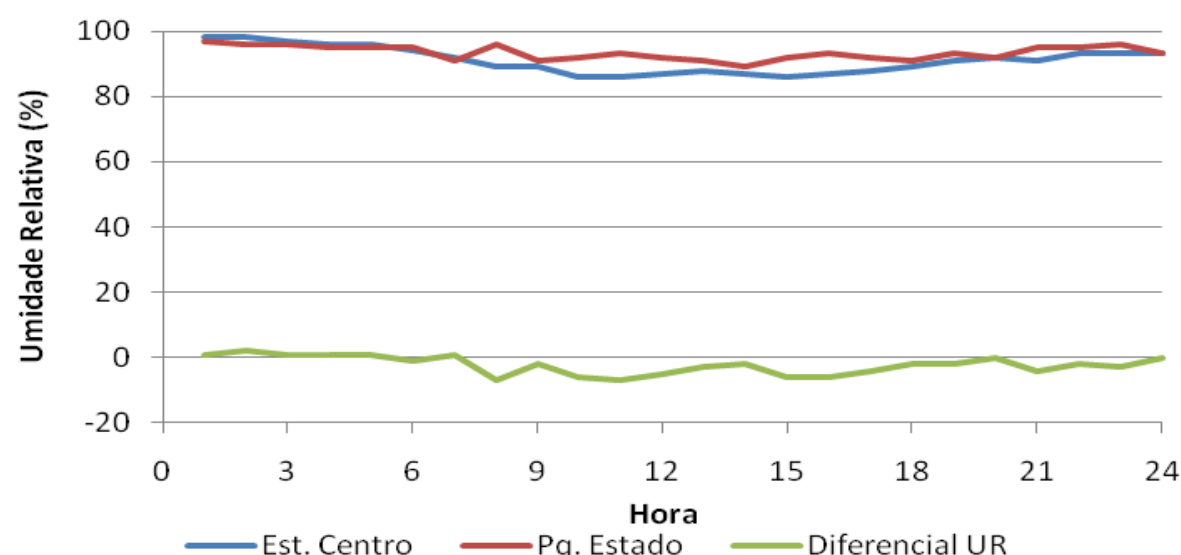

FIGURA 91. Gráficos horários da umidade relativa e do diferencial de umidade, dias 7 de julho, 3 de agosto e 2 de setembro de 1988, na Estação de Monitoramento Centro, Estação Meteorológica do Parque Estadual Fontes do Ipiranga. Fonte: CETESB, 1994 e IAG, 1988. 
TABELA 49. Registros horários da umidade relativa e do diferencial de umidade nos dias 7 de julho, 3 de agosto e 2 de setembro de 1988, na Estação de Monitoramento Centro, Estação Meteorológica do Parque Estadual Fontes do Ipiranga. Fonte: CETESB, 1994 e IAG, 1988.

\begin{tabular}{|c|c|c|c|c|c|c|c|c|c|}
\hline Mês & \multicolumn{3}{|c|}{7 julho 1988} & \multicolumn{3}{|c|}{3 agosto 1988} & \multicolumn{3}{|c|}{2 setembro 1988} \\
\hline Hora & $\mathrm{EC}$ & $\mathrm{PE}$ & $\Delta$ & $\mathrm{EC}$ & $\mathrm{PE}$ & $\Delta$ & $\mathrm{EC}$ & $\mathrm{PE}$ & $\Delta$ \\
\hline 1 & 68 & 90 & -22 & 73 & 84 & -11 & 98 & 97 & 1 \\
\hline 2 & 78 & 90 & -12 & 75 & 88 & -13 & 98 & 96 & 2 \\
\hline 3 & 83 & 94 & -11 & 77 & 89 & -12 & 97 & 96 & 1 \\
\hline 4 & 87 & 92 & -5 & 81 & 92 & -11 & 96 & 95 & 1 \\
\hline 5 & 90 & 93 & -3 & 85 & 93 & -8 & 96 & 95 & 1 \\
\hline 6 & 86 & 94 & -8 & 83 & 94 & -11 & 94 & 95 & -1 \\
\hline 7 & 87 & 94 & -7 & 85 & 94 & -9 & 92 & 91 & 1 \\
\hline 8 & 85 & 91 & -6 & 82 & 90 & -8 & 89 & 96 & -7 \\
\hline 9 & 69 & 69 & 0 & 87 & 87 & 0 & 89 & 91 & -2 \\
\hline 10 & 56 & 56 & 0 & 76 & 78 & -2 & 86 & 92 & -6 \\
\hline 11 & 48 & 45 & 3 & 67 & 71 & -4 & 86 & 93 & -7 \\
\hline 12 & 44 & 43 & 1 & 63 & 65 & -2 & 87 & 92 & -5 \\
\hline 13 & 42 & 40 & 2 & 60 & 61 & -1 & 88 & 91 & -3 \\
\hline 14 & 41 & 38 & 3 & 53 & 57 & -4 & 87 & 89 & -2 \\
\hline 15 & 40 & 38 & 2 & 52 & 57 & -5 & 86 & 92 & -6 \\
\hline 16 & 40 & 43 & -3 & 57 & 61 & -4 & 87 & 93 & -6 \\
\hline 17 & 42 & 44 & -2 & 60 & 78 & -18 & 88 & 92 & -4 \\
\hline 18 & 44 & 51 & -7 & 75 & 84 & -9 & 89 & 91 & -2 \\
\hline 19 & 61 & 89 & -28 & 83 & 84 & -1 & 91 & 93 & -2 \\
\hline 20 & 93 & 96 & -3 & 84 & 83 & 1 & 92 & 92 & 0 \\
\hline 21 & 92 & 94 & -2 & 83 & 85 & -2 & 91 & 95 & -4 \\
\hline 22 & 91 & 94 & -3 & 83 & 87 & -4 & 93 & 95 & -2 \\
\hline 23 & 89 & 93 & -4 & 86 & 86 & 0 & 93 & 96 & -3 \\
\hline 24 & 89 & 96 & -7 & 86 & 88 & -2 & 93 & 93 & 0 \\
\hline
\end{tabular}



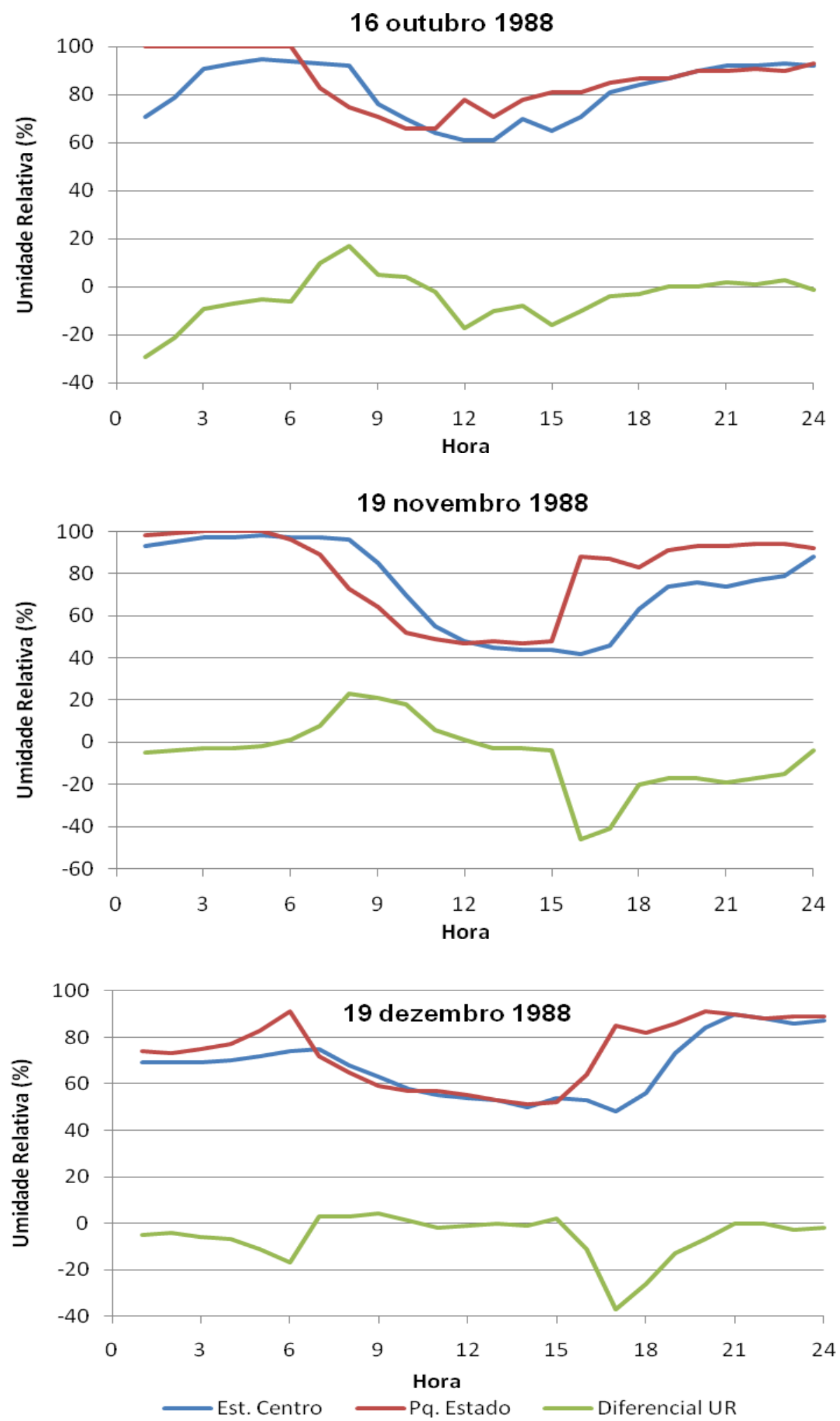

FIGURA 92. Gráficos horários da umidade relativa e do diferencial de umidade, dias 16 de outubro, 19 de novembro e 19 de dezembro de 1988, na Estação de Monitoramento Centro, Estação Meteorológica do Parque Estadual Fontes do Ipiranga. Fonte: CETESB, 1999 e IAG, 1988. 
TABELA 50. Registros horários da umidade relativa e do diferencial de umidade nos dias 16 de outubro, 19 de novembro e 19 de dezembro de 1988, na Estação de Monitoramento Centro, Estação Meteorológica do Parque Estadual Fontes do Ipiranga. Fonte: CETESB, 1994 e IAG, 1988.

\begin{tabular}{|c|c|c|c|c|c|c|c|c|c|}
\hline Mês & \multicolumn{3}{|c|}{16 outubro 1988} & \multicolumn{3}{|c|}{19 novembro 1988} & \multicolumn{3}{|c|}{19 dezembro 1988} \\
\hline Hora & $\mathrm{EC}$ & $\mathrm{PE}$ & $\Delta$ & $\mathrm{EC}$ & $\mathrm{PE}$ & $\Delta$ & $\mathrm{EC}$ & $\mathrm{PE}$ & $\Delta$ \\
\hline 1 & 71 & 100 & -29 & 93 & 98 & -5 & 69 & 74 & -5 \\
\hline 2 & 79 & 100 & -21 & 95 & 99 & -4 & 69 & 73 & -4 \\
\hline 3 & 91 & 100 & -9 & 97 & 100 & -3 & 69 & 75 & -6 \\
\hline 4 & 93 & 100 & -7 & 97 & 100 & -3 & 70 & 77 & -7 \\
\hline 5 & 95 & 100 & -5 & 98 & 100 & -2 & 72 & 83 & -11 \\
\hline 6 & 94 & 100 & -6 & 97 & 96 & 1 & 74 & 91 & -17 \\
\hline 7 & 93 & 83 & 10 & 97 & 89 & 8 & 75 & 72 & 3 \\
\hline 8 & 92 & 75 & 17 & 96 & 73 & 23 & 68 & 65 & 3 \\
\hline 9 & 76 & 71 & 5 & 85 & 64 & 21 & 63 & 59 & 4 \\
\hline 10 & 70 & 66 & 4 & 70 & 52 & 18 & 58 & 57 & 1 \\
\hline 11 & 64 & 66 & -2 & 55 & 49 & 6 & 55 & 57 & -2 \\
\hline 12 & 61 & 78 & -17 & 48 & 47 & 1 & 54 & 55 & -1 \\
\hline 13 & 61 & 71 & -10 & 45 & 48 & -3 & 53 & 53 & 0 \\
\hline 14 & 70 & 78 & -8 & 44 & 47 & -3 & 50 & 51 & -1 \\
\hline 15 & 65 & 81 & -16 & 44 & 48 & -4 & 54 & 52 & 2 \\
\hline 16 & 71 & 81 & -10 & 42 & 88 & -46 & 53 & 64 & -11 \\
\hline 17 & 81 & 85 & -4 & 46 & 87 & -41 & 48 & 85 & -37 \\
\hline 18 & 84 & 87 & -3 & 63 & 83 & -20 & 56 & 82 & -26 \\
\hline 19 & 87 & 87 & 0 & 74 & 91 & -17 & 73 & 86 & -13 \\
\hline 20 & 90 & 90 & 0 & 76 & 93 & -17 & 84 & 91 & -7 \\
\hline 21 & 92 & 90 & 2 & 74 & 93 & -19 & 90 & 90 & 0 \\
\hline 22 & 92 & 91 & 1 & 77 & 94 & -17 & 88 & 88 & 0 \\
\hline 23 & 93 & 90 & 3 & 79 & 94 & -15 & 86 & 89 & -3 \\
\hline 24 & 92 & 93 & -1 & 88 & 92 & -4 & 87 & 89 & -2 \\
\hline
\end{tabular}



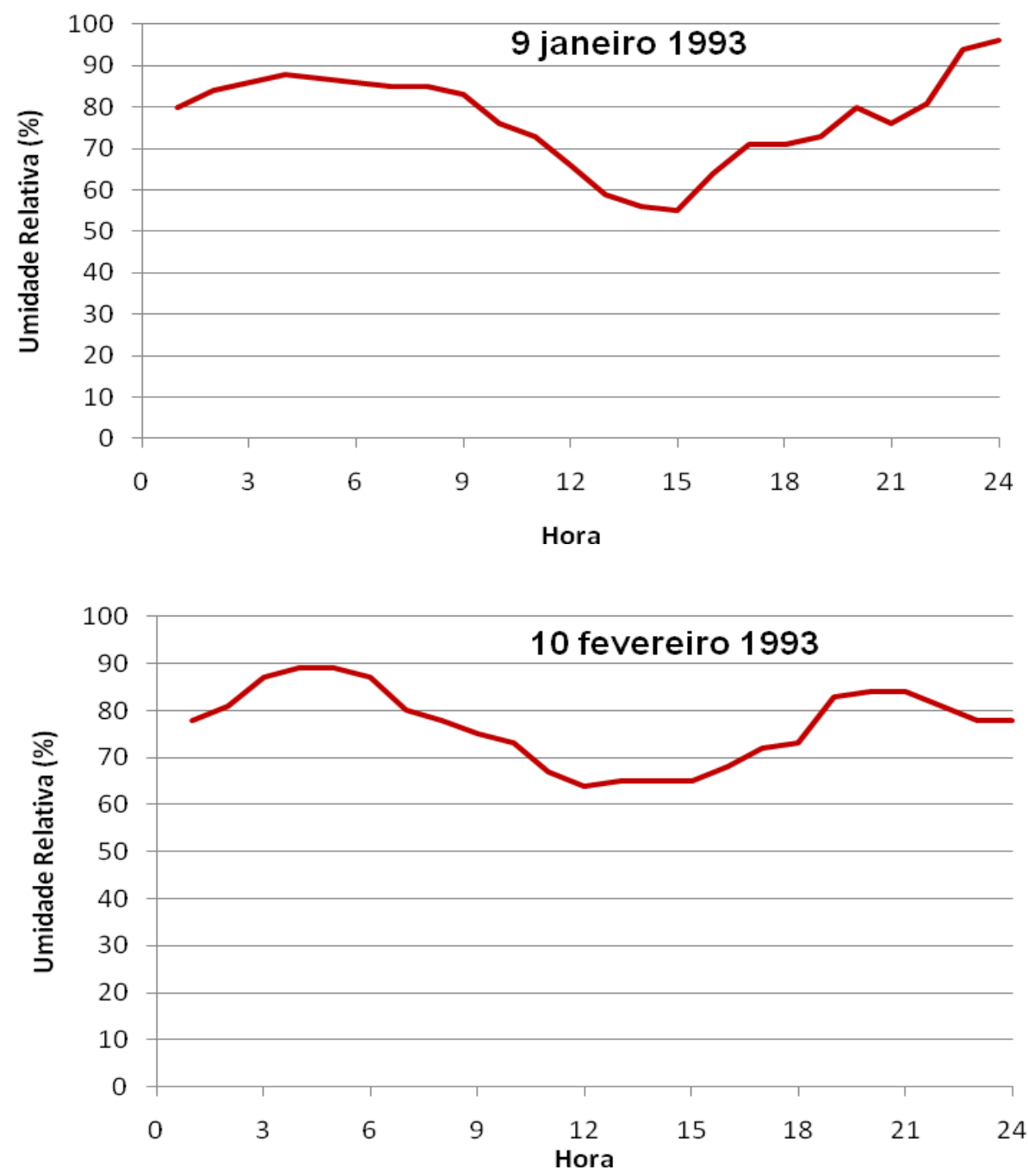

23 março 1993

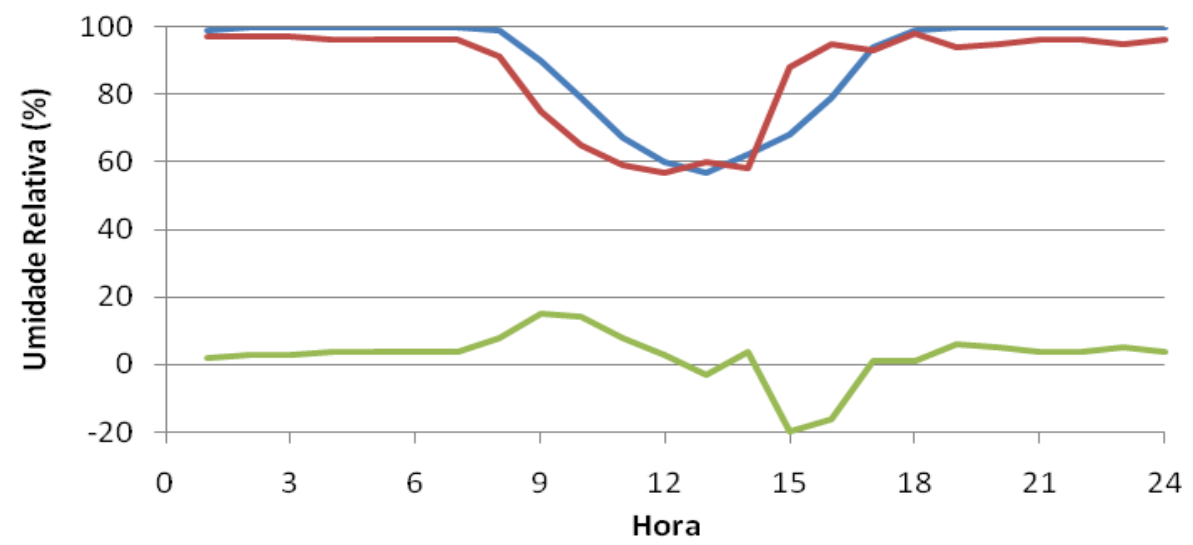

—Pq. D. Pedro II —Pq. Estado — Diferencial UR

FIGURA 93. Gráficos horários da umidade relativa e do diferencial de umidade, dias 9 de janeiro, 10 de fevereiro e 23 de março de 1993, na Estação de Monitoramento Pq. D. Pedro II, Estação Meteorológica do Parque Estadual Fontes do Ipiranga. Fonte: CETESB, 1994 e IAG, 1993. 
TABELA 51. Registros horários da umidade relativa e do diferencial de umidade nos dias 9 de janeiro, 10 de fevereiro e 23 de março de 1993, na Estação de Monitoramento Pq. D. Pedro II, Estação Meteorológica do Parque Estadual Fontes do Ipiranga. Fonte: CETESB, 1994 e IAG, 1993.

\begin{tabular}{|c|c|c|c|c|c|c|c|c|c|}
\hline \multirow{2}{*}{$\begin{array}{l}\text { Mês } \\
\text { Hora }\end{array}$} & \multicolumn{3}{|c|}{9 Janeiro 1993} & \multicolumn{3}{|c|}{10 Fevereiro 1993} & \multicolumn{3}{|c|}{23 Março 1993} \\
\hline & PDP & $\mathrm{PE}$ & $\Delta$ & PDP & $\mathrm{PE}$ & $\Delta$ & PDP & $\mathrm{PE}$ & $\Delta$ \\
\hline 1 & ND & 80 & ND & ND & 87 & ND & 99 & 97 & 2 \\
\hline 2 & ND & 84 & ND & ND & 89 & ND & 100 & 97 & 3 \\
\hline 3 & ND & 86 & ND & ND & 89 & ND & 100 & 97 & 3 \\
\hline 4 & ND & 88 & ND & ND & 87 & ND & 100 & 96 & 4 \\
\hline 5 & ND & 87 & ND & ND & 80 & ND & 100 & 96 & 4 \\
\hline 6 & ND & 86 & ND & ND & 78 & ND & 100 & 96 & 4 \\
\hline 7 & ND & 85 & ND & ND & 75 & ND & 100 & 96 & 4 \\
\hline 8 & ND & 85 & ND & ND & 73 & ND & 99 & 91 & 8 \\
\hline 9 & ND & 83 & ND & ND & 67 & ND & 90 & 75 & 15 \\
\hline 10 & ND & 76 & ND & ND & 64 & ND & 79 & 65 & 14 \\
\hline 11 & ND & 73 & ND & ND & 65 & ND & 67 & 59 & 8 \\
\hline 12 & ND & 66 & ND & ND & 65 & ND & 60 & 57 & 3 \\
\hline 13 & ND & 59 & ND & ND & 65 & ND & 57 & 60 & -3 \\
\hline 14 & ND & 56 & ND & ND & 68 & ND & 62 & 58 & 4 \\
\hline 15 & ND & 55 & ND & ND & 72 & ND & 68 & 88 & -20 \\
\hline 16 & ND & 64 & ND & ND & 73 & ND & 79 & 95 & -16 \\
\hline 17 & ND & 71 & ND & ND & 83 & ND & 94 & 93 & 1 \\
\hline 18 & ND & 71 & ND & ND & 84 & ND & 99 & 98 & 1 \\
\hline 19 & ND & 73 & ND & ND & 84 & ND & 100 & 94 & 6 \\
\hline 20 & ND & 80 & ND & ND & 81 & ND & 100 & 95 & 5 \\
\hline 21 & ND & 76 & ND & ND & 78 & ND & 100 & 96 & 4 \\
\hline 22 & ND & 81 & ND & ND & 78 & ND & 100 & 96 & 4 \\
\hline 23 & ND & 94 & ND & ND & 87 & ND & 100 & 95 & 5 \\
\hline 24 & ND & 96 & ND & ND & 89 & ND & 100 & 96 & 4 \\
\hline
\end{tabular}

ND - Dados não disponíveis. 

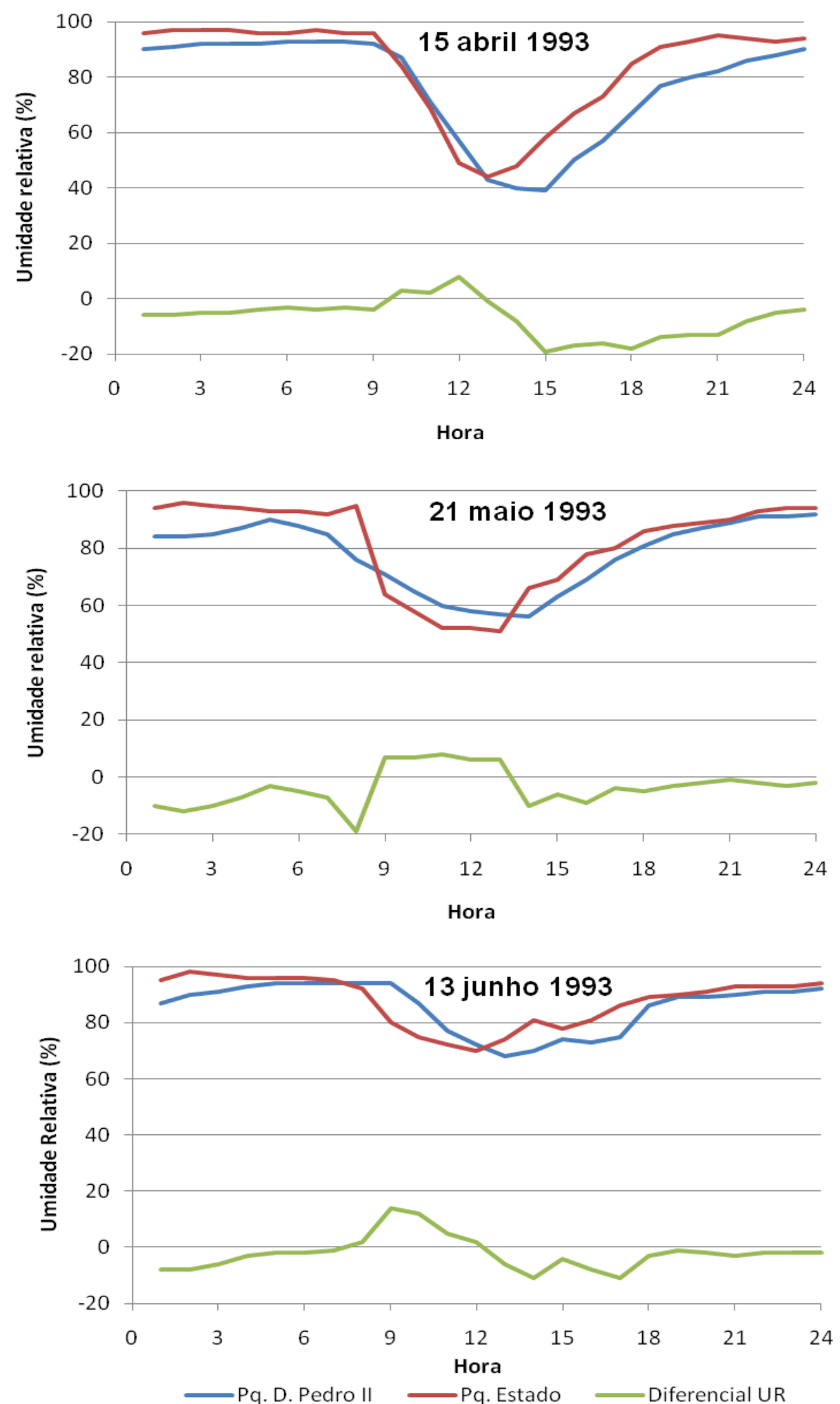

FIGURA 94. Gráficos horários da umidade relativa e do diferencial de umidade, dias 15 de abril, 21 de maio e 13 de junho de 1993, na Estação de Monitoramento Pq. D. Pedro II, Estação Meteorológica do Parque Estadual Fontes do Ipiranga. Fonte: CETESB, 1994 e IAG, 1993. 
TABELA 52. Registros horários da umidade relativa e do diferencial de umidade nos dias 15 de abril, 21 de maio e 16 de junho de 1993, na Estação de Monitoramento Pq. D. Pedro II, Estação Meteorológica do Parque Estadual Fontes do Ipiranga. Fonte: CETESB, 1994 e IAG, 1993.

\begin{tabular}{|c|c|c|c|c|c|c|c|c|c|}
\hline Mês & \multicolumn{3}{|c|}{15 de abril de 1993} & \multicolumn{3}{|c|}{21 de maio de 1993} & \multicolumn{3}{|c|}{13 de junho de 1993} \\
\hline Hora & PDP & $\mathrm{PE}$ & $\Delta$ & PDP & $\mathrm{PE}$ & $\Delta$ & PDP & $\mathrm{PE}$ & $\Delta$ \\
\hline 1 & 90 & 96 & -6 & 84 & 94 & -10 & 87 & 95 & -8 \\
\hline 2 & 91 & 97 & -6 & 84 & 96 & -12 & 90 & 98 & -8 \\
\hline 3 & 92 & 97 & -5 & 85 & 95 & -10 & 91 & 97 & -6 \\
\hline 4 & 92 & 97 & -5 & 87 & 94 & -7 & 93 & 96 & -3 \\
\hline 5 & 92 & 96 & -4 & 90 & 93 & -3 & 94 & 96 & -2 \\
\hline 6 & 93 & 96 & -3 & 88 & 93 & -5 & 94 & 96 & -2 \\
\hline 7 & 93 & 97 & -4 & 85 & 92 & -7 & 94 & 95 & -1 \\
\hline 8 & 93 & 96 & -3 & 76 & 95 & -19 & 94 & 92 & 2 \\
\hline 9 & 92 & 96 & -4 & 71 & 64 & 7 & 94 & 80 & 14 \\
\hline 10 & 87 & 84 & 3 & 65 & 58 & 7 & 87 & 75 & 12 \\
\hline 11 & 71 & 69 & 2 & 60 & 52 & 8 & 77 & 72 & 5 \\
\hline 12 & 57 & 49 & 8 & 58 & 52 & 6 & 72 & 70 & 2 \\
\hline 13 & 43 & 44 & -1 & 57 & 51 & 6 & 68 & 74 & -6 \\
\hline 14 & 40 & 48 & -8 & 56 & 66 & -10 & 70 & 81 & -11 \\
\hline 15 & 39 & 58 & -19 & 63 & 69 & -6 & 74 & 78 & -4 \\
\hline 16 & 50 & 67 & -17 & 69 & 78 & -9 & 73 & 81 & -8 \\
\hline 17 & 57 & 73 & -16 & 76 & 80 & -4 & 75 & 86 & -11 \\
\hline 18 & 67 & 85 & -18 & 81 & 86 & -5 & 86 & 89 & -3 \\
\hline 19 & 77 & 91 & -14 & 85 & 88 & -3 & 89 & 90 & -1 \\
\hline 20 & 80 & 93 & -13 & 87 & 89 & -2 & 89 & 91 & -2 \\
\hline 21 & 82 & 95 & -13 & 89 & 90 & -1 & 90 & 93 & -3 \\
\hline 22 & 86 & 94 & -8 & 91 & 93 & -2 & 91 & 93 & -2 \\
\hline 23 & 88 & 93 & -5 & 91 & 94 & -3 & 91 & 93 & -2 \\
\hline 24 & 90 & 94 & -4 & 92 & 94 & -2 & 92 & 94 & -2 \\
\hline
\end{tabular}



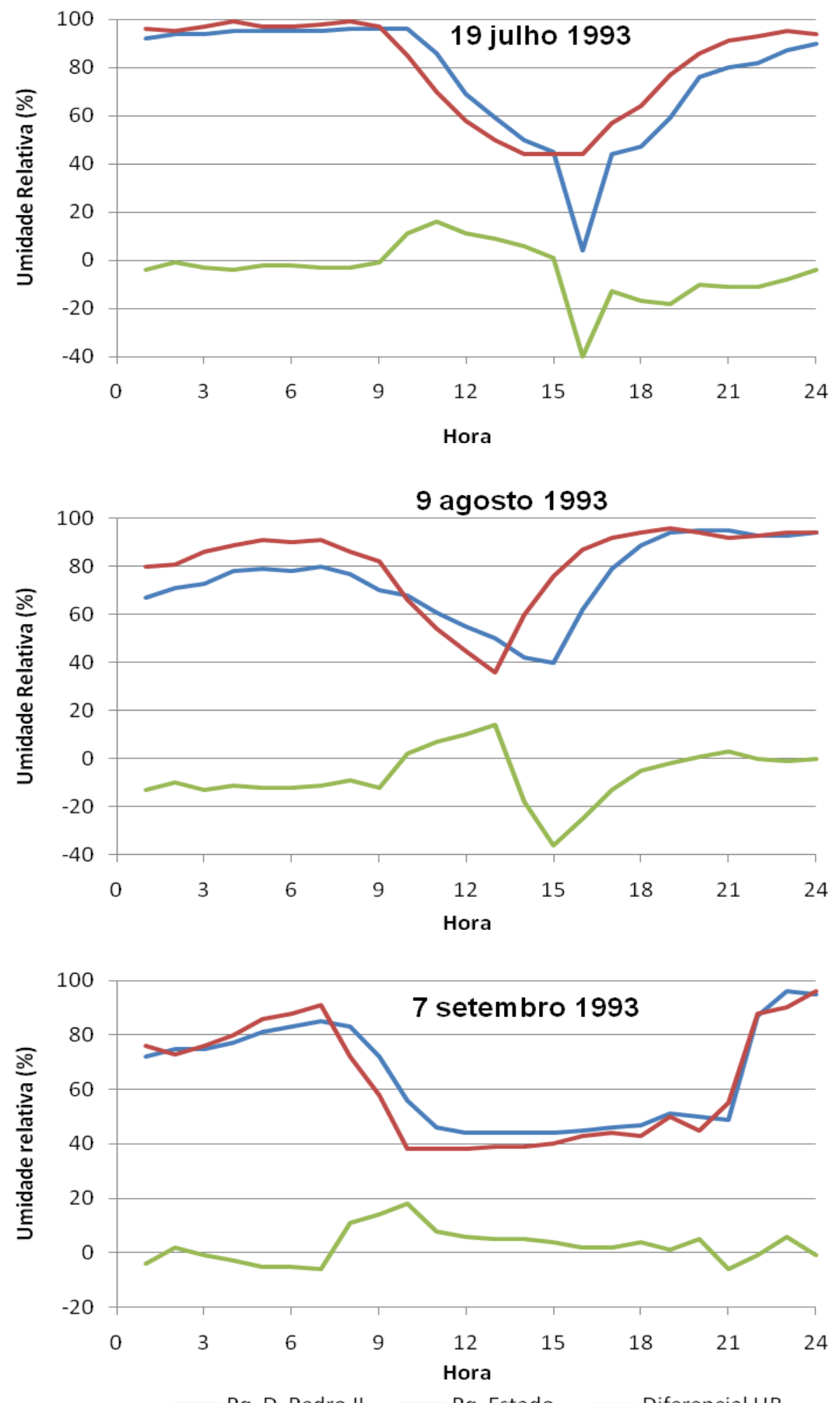

FIGURA 95. Gráficos horários da umidade relativa e do diferencial de umidade, dias 19 de julho, 9 de agosto e 7 de setembro de 1993, na Estação de Monitoramento P. D. Pedro II, Estação Meteorológica do Parque Estadual Fontes do Ipiranga. Fonte: CETESB, 1994 e IAG, 1993. 
TABELA 53. Registros horários da umidade relativa e do diferencial de umidade nos dias 19 de julho, 9 de agosto e 7 de setembro de 1993, na Estação de Monitoramento Pq. D. Pedro II, Estação Meteorológica do Parque Estadual Fontes do Ipiranga. Fonte: CETESB, 1994 e IAG, 1993.

\begin{tabular}{|c|c|c|c|c|c|c|c|c|c|}
\hline Mês & \multicolumn{3}{|c|}{19 de julho de 1993} & \multicolumn{3}{|c|}{9 de agosto de 1993} & \multicolumn{3}{|c|}{7 de setembro de 1993} \\
\hline Hora & PDP & $\mathrm{PE}$ & $\Delta$ & PDP & $\mathrm{PE}$ & $\Delta$ & PDP & $\mathrm{PE}$ & $\Delta$ \\
\hline 1 & 92 & 96 & -4 & 67 & 80 & -13 & 72 & 76 & -4 \\
\hline 2 & 94 & 95 & -1 & 71 & 81 & -10 & 75 & 73 & 2 \\
\hline 3 & 94 & 97 & -3 & 73 & 86 & -13 & 75 & 76 & -1 \\
\hline 4 & 95 & 99 & -4 & 78 & 89 & -11 & 77 & 80 & -3 \\
\hline 5 & 95 & 97 & -2 & 79 & 91 & -12 & 81 & 86 & -5 \\
\hline 6 & 95 & 97 & -2 & 78 & 90 & -12 & 83 & 88 & -5 \\
\hline 7 & 95 & 98 & -3 & 80 & 91 & -11 & 85 & 91 & -6 \\
\hline 8 & 96 & 99 & -3 & 77 & 86 & -9 & 83 & 72 & 11 \\
\hline 9 & 96 & 97 & -1 & 70 & 82 & -12 & 72 & 58 & 14 \\
\hline 10 & 96 & 85 & 11 & 68 & 66 & 2 & 56 & 38 & 18 \\
\hline 11 & 86 & 70 & 16 & 61 & 54 & 7 & 46 & 38 & 8 \\
\hline 12 & 69 & 58 & 11 & 55 & 45 & 10 & 44 & 38 & 6 \\
\hline 13 & 59 & 50 & 9 & 50 & 36 & 14 & 44 & 39 & 5 \\
\hline 14 & 50 & 44 & 6 & 42 & 60 & -18 & 44 & 39 & 5 \\
\hline 15 & 45 & 44 & 1 & 40 & 76 & -36 & 44 & 40 & 4 \\
\hline 16 & 4 & 44 & -40 & 62 & 87 & -25 & 45 & 43 & 2 \\
\hline 17 & 44 & 57 & -13 & 79 & 92 & -13 & 46 & 44 & 2 \\
\hline 18 & 47 & 64 & -17 & 89 & 94 & -5 & 47 & 43 & 4 \\
\hline 19 & 59 & 77 & -18 & 94 & 96 & -2 & 51 & 50 & 1 \\
\hline 20 & 76 & 86 & -10 & 95 & 94 & 1 & 50 & 45 & 5 \\
\hline 21 & 80 & 91 & -11 & 95 & 92 & 3 & 49 & 55 & -6 \\
\hline 22 & 82 & 93 & -11 & 93 & 93 & 0 & 87 & 88 & -1 \\
\hline 23 & 87 & 95 & -8 & 93 & 94 & -1 & 96 & 90 & 6 \\
\hline 24 & 90 & 94 & -4 & 94 & 94 & 0 & 95 & 96 & -1 \\
\hline
\end{tabular}



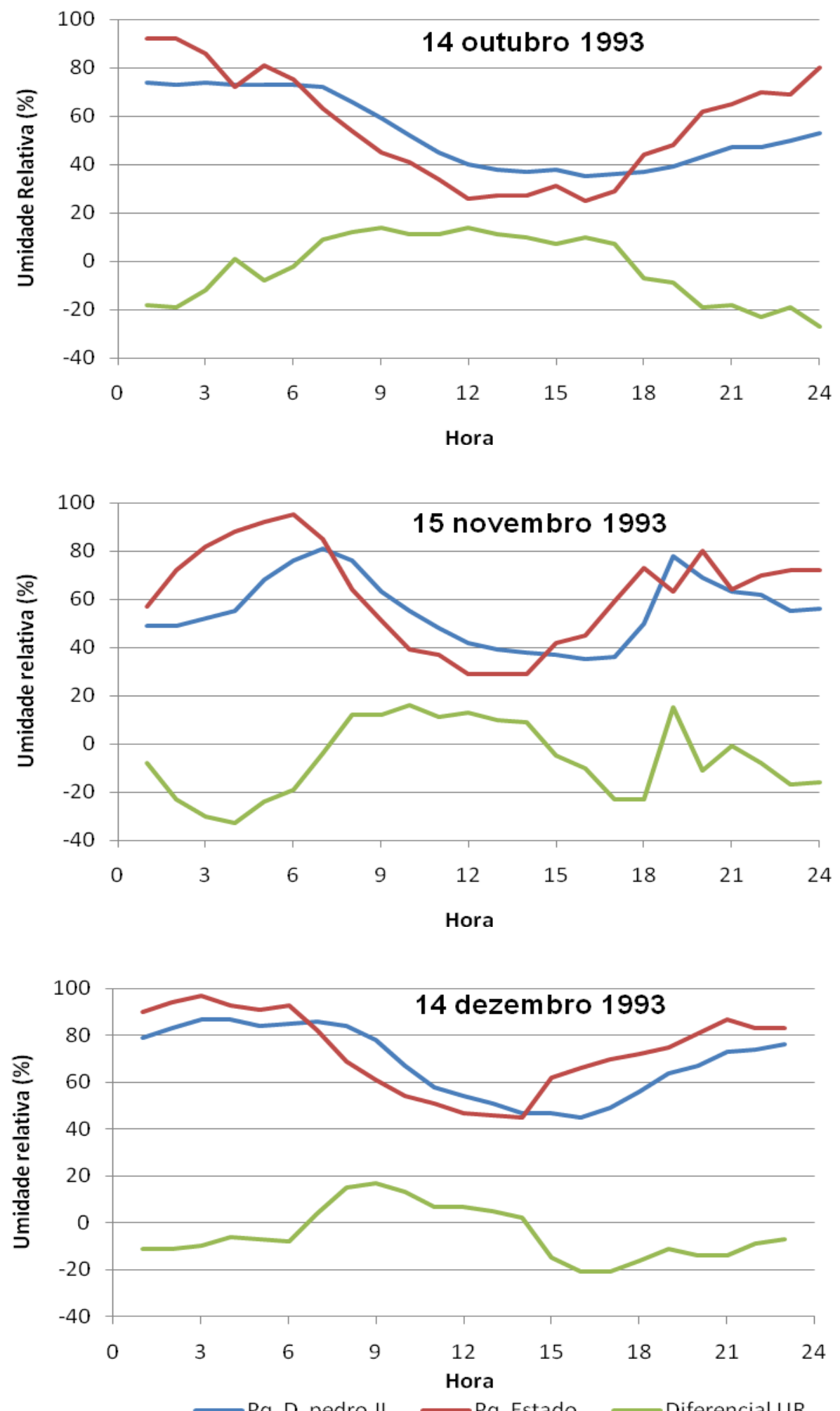

FIGURA 96. Gráficos horários da umidade relativa e do diferencial de umidade, dias 14 de outubro, 15 de novembro e 14 de dezembro de 1993, na Estação de Monitoramento Pq. D. Pedro II, Estação Meteorológica do Parque Estadual Fontes do Ipiranga. Fonte: CETESB, 1994 e IAG, 1993. 
TABELA 54. Registros horários da umidade relativa e do diferencial de umidade nos dias 14 de outubro, 15 de novembro e 14 de dezembro de 1993, na Estação de Monitoramento Pq. D. Pedro II, Estação Meteorológica do Parque Estadual Fontes do Ipiranga. Fonte: CETESB, 1994 e IAG, 1993.

\begin{tabular}{|c|c|c|c|c|c|c|c|c|c|}
\hline Mês & \multicolumn{3}{|c|}{14 de outubro de 1993} & \multicolumn{3}{|c|}{15 de novembro de 1993} & \multicolumn{3}{|c|}{14 de dezembro de 1993} \\
\hline Hora & PDP & $\mathrm{PE}$ & $\Delta$ & PDP & $\mathrm{PE}$ & $\Delta$ & PDP & $\mathrm{PE}$ & $\Delta$ \\
\hline 1 & 74 & 92 & -18 & 49 & 57 & -8 & 79 & 90 & -11 \\
\hline 2 & 73 & 92 & -19 & 49 & 72 & -23 & 83 & 94 & -11 \\
\hline 3 & 74 & 86 & -12 & 52 & 82 & -30 & 87 & 97 & -10 \\
\hline 4 & 73 & 72 & 1 & 55 & 88 & -33 & 87 & 93 & -6 \\
\hline 5 & 73 & 81 & -8 & 68 & 92 & -24 & 84 & 91 & -7 \\
\hline 6 & 73 & 75 & -2 & 76 & 95 & -19 & 85 & 93 & -8 \\
\hline 7 & 72 & 63 & 9 & 81 & 85 & -4 & 86 & 82 & 4 \\
\hline 8 & 66 & 54 & 12 & 76 & 64 & 12 & 84 & 69 & 15 \\
\hline 9 & 59 & 45 & 14 & 63 & 51 & 12 & 78 & 61 & 17 \\
\hline 10 & 52 & 41 & 11 & 55 & 39 & 16 & 67 & 54 & 13 \\
\hline 11 & 45 & 34 & 11 & 48 & 37 & 11 & 58 & 51 & 7 \\
\hline 12 & 40 & 26 & 14 & 42 & 29 & 13 & 54 & 47 & 7 \\
\hline 13 & 38 & 27 & 11 & 39 & 29 & 10 & 51 & 46 & 5 \\
\hline 14 & 37 & 27 & 10 & 38 & 29 & 9 & 47 & 45 & 2 \\
\hline 15 & 38 & 31 & 7 & 37 & 42 & -5 & 47 & 62 & -15 \\
\hline 16 & 35 & 25 & 10 & 35 & 45 & -10 & 45 & 66 & -21 \\
\hline 17 & 36 & 29 & 7 & 36 & 59 & -23 & 49 & 70 & -21 \\
\hline 18 & 37 & 44 & -7 & 50 & 73 & -23 & 56 & 72 & -16 \\
\hline 19 & 39 & 48 & -9 & 78 & 63 & 15 & 64 & 75 & -11 \\
\hline 20 & 43 & 62 & -19 & 69 & 80 & -11 & 67 & 81 & -14 \\
\hline 21 & 47 & 65 & -18 & 63 & 64 & -1 & 73 & 87 & -14 \\
\hline 22 & 47 & 70 & -23 & 62 & 70 & -8 & 74 & 83 & -9 \\
\hline 23 & 50 & 69 & -19 & 55 & 72 & -17 & 76 & 83 & -7 \\
\hline 24 & 53 & 80 & -27 & 56 & 72 & -16 & 75 & 82 & -7 \\
\hline
\end{tabular}



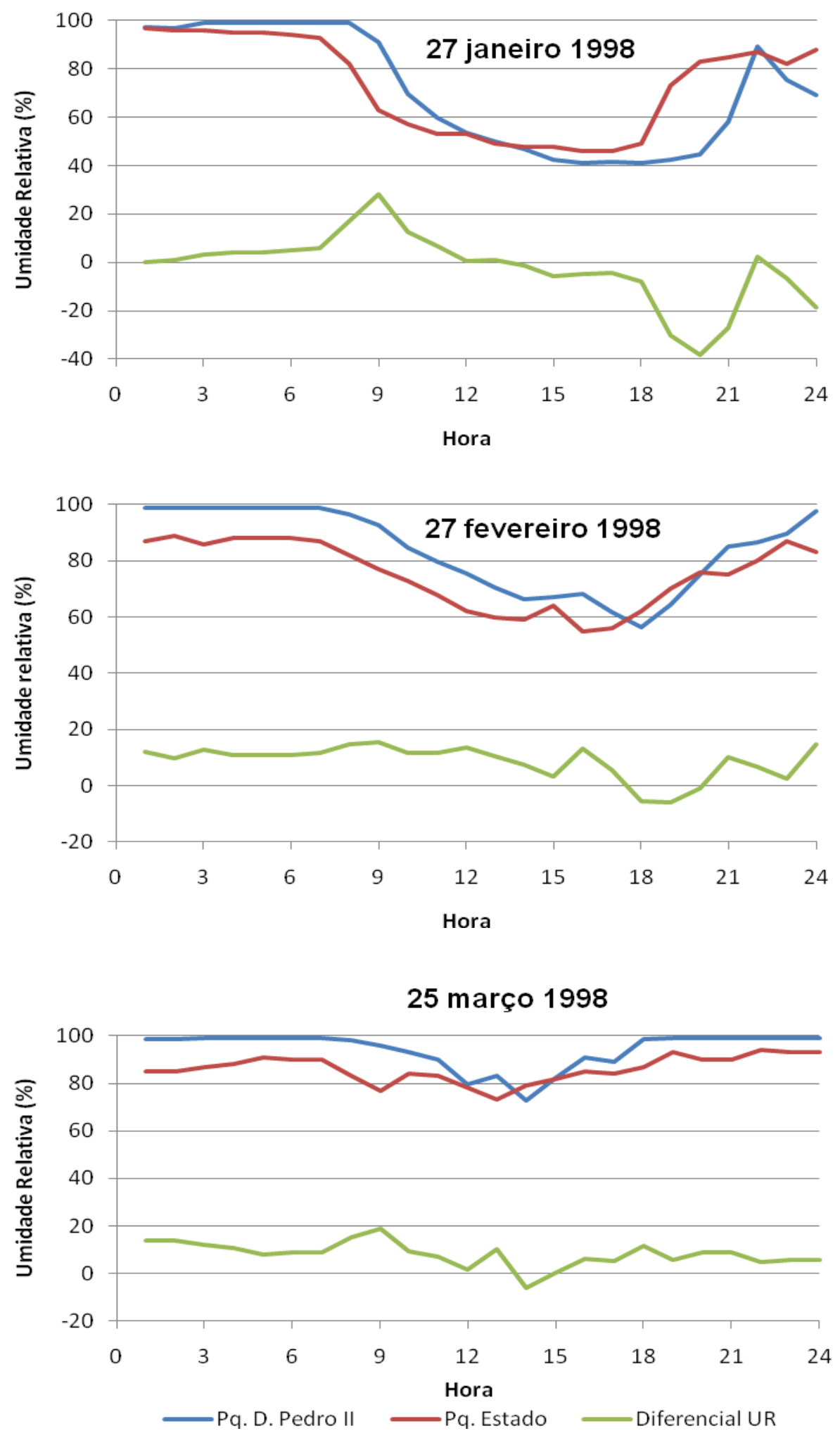

FIGURA 97. Gráficos horários da umidade relativa e do diferencial de umidade, dias 27 de janeiro, 27 de fevereiro e 25 de março de 1998, na Estação de Monitoramento Pq. D. Pedro II, Estação Meteorológica do Parque Estadual Fontes do Ipiranga. Fonte: CETESB, 1999 e IAG, 1998. 
TABELA 55. Registros horários da umidade relativa e do diferencial de umidade nos dias 27 de janeiro, 27 de fevereiro e 25 de março de 1998, na Estação de Monitoramento Pq. D. Pedro II, Estação Meteorológica do Parque Estadual Fontes do Ipiranga. Fonte: CETESB, 1999 e IAG, 1998.

\begin{tabular}{|c|c|c|c|c|c|c|c|c|c|}
\hline Mês & \multicolumn{3}{|c|}{27 Janeiro 1998} & \multicolumn{3}{|c|}{27 Fevereiro 1998} & \multicolumn{3}{|c|}{25 Março 1998} \\
\hline Hora & PDP & $\mathrm{PE}$ & $\Delta$ & PDP & $\mathrm{PE}$ & $\Delta$ & PDP & $\mathrm{PE}$ & $\Delta$. \\
\hline 1 & 97,3 & 97 & 0,3 & 98,9 & 87 & 11,9 & 98,8 & 85 & 13,8 \\
\hline 2 & 96,8 & 96 & 0,8 & 98,9 & 89 & 9,9 & 98,8 & 85 & 13,8 \\
\hline 3 & 99,1 & 96 & 3,1 & 98,9 & 86 & 12,9 & 98,9 & 87 & 11,9 \\
\hline 4 & 99,1 & 95 & 4,1 & 98,8 & 88 & 10,8 & 98,9 & 88 & 10,9 \\
\hline 5 & 99 & 95 & 4 & 98,8 & 88 & 10,8 & 98,9 & 91 & 7,9 \\
\hline 6 & 99 & 94 & 5 & 98,8 & 88 & 10,8 & 99 & 90 & 9 \\
\hline 7 & 99 & 93 & 6 & 98,8 & 87 & 11,8 & 98,9 & 90 & 8,9 \\
\hline 8 & 99 & 82 & 17 & 96,7 & 82 & 14,7 & 98,2 & 83 & 15,2 \\
\hline 9 & 91,2 & 63 & 28,2 & 92,7 & 77 & 15,7 & 96 & 77 & 19 \\
\hline 10 & 69,7 & 57 & 12,7 & 84,5 & 73 & 11,5 & 93,3 & 84 & 9,3 \\
\hline 11 & 59,8 & 53 & 6,8 & 79,8 & 68 & 11,8 & 89,9 & 83 & 6,9 \\
\hline 12 & 53,7 & 53 & 0,7 & 75,6 & 62 & 13,6 & 79,6 & 78 & 1,6 \\
\hline 13 & 50,1 & 49 & 1,1 & 70,7 & 60 & 10,7 & 83,3 & 73 & 10,3 \\
\hline 14 & 46,8 & 48 & $-1,2$ & 66,4 & 59 & 7,4 & 72,7 & 79 & $-6,3$ \\
\hline 15 & 42,4 & 48 & $-5,6$ & 67,1 & 64 & 3,1 & 82,2 & 82 & 0,2 \\
\hline 16 & 41,2 & 46 & $-4,8$ & 68,1 & 55 & 13,1 & 91,1 & 85 & 6,1 \\
\hline 17 & 41,5 & 46 & $-4,5$ & 61,6 & 56 & 5,6 & 89,2 & 84 & 5,2 \\
\hline 18 & 41,1 & 49 & $-7,9$ & 56,5 & 62 & $-5,5$ & 98,5 & 87 & 11,5 \\
\hline 19 & 42,6 & 73 & $-30,4$ & 64,3 & 70 & $-5,7$ & 98,9 & 93 & 5,9 \\
\hline 20 & 44,8 & 83 & $-38,2$ & 75,2 & 76 & $-0,8$ & 98,9 & 90 & 8,9 \\
\hline 21 & 58 & 85 & -27 & 85,1 & 75 & 10,1 & 98,9 & 90 & 8,9 \\
\hline 22 & 89,3 & 87 & 2,3 & 86,7 & 80 & 6,7 & 98,9 & 94 & 4,9 \\
\hline 23 & 75,4 & 82 & $-6,6$ & 89,6 & 87 & 2,6 & 98,9 & 93 & 5,9 \\
\hline 24 & 69,4 & 88 & $-18,6$ & 97,7 & 83 & 14,7 & 98,9 & 93 & 5,9 \\
\hline
\end{tabular}




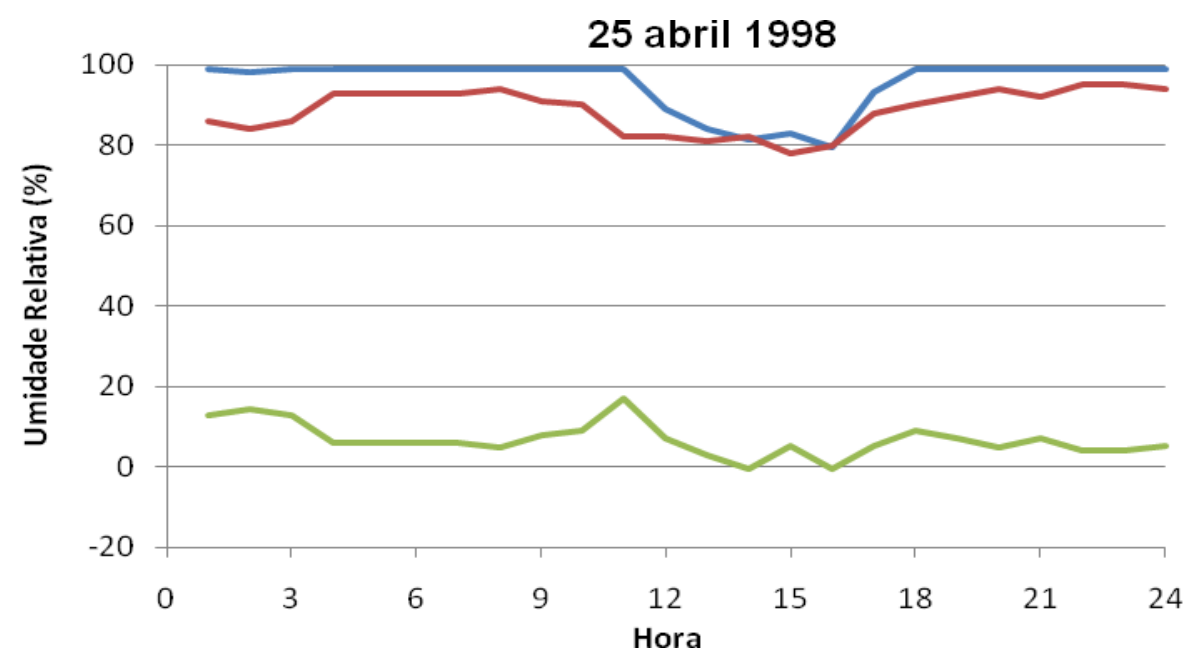

27 maio 1998

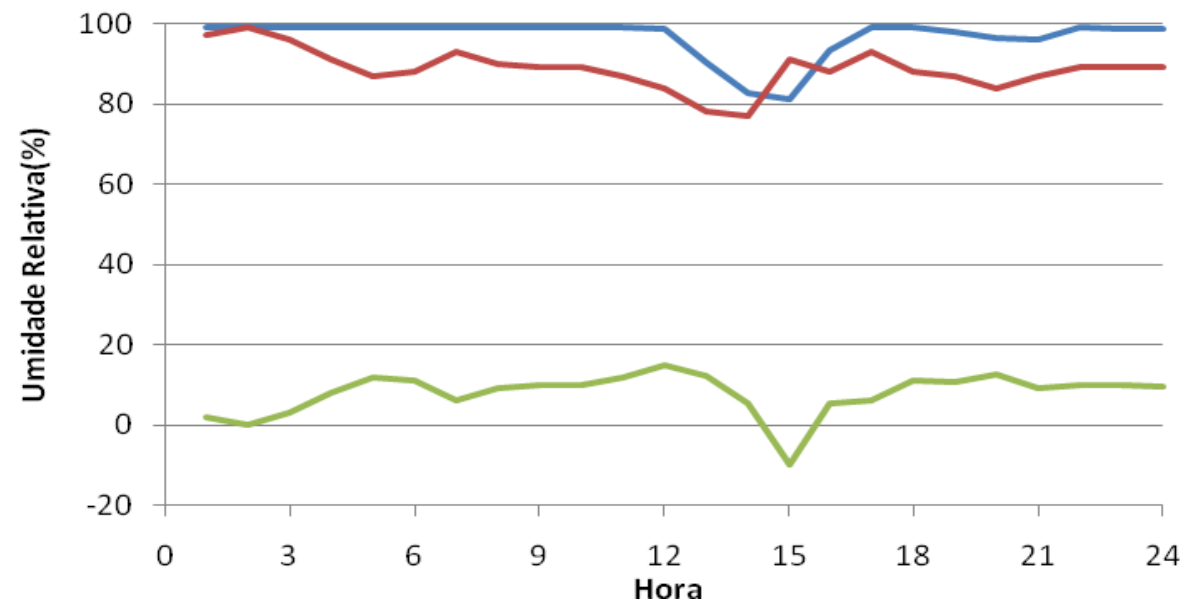

26 junho 1998

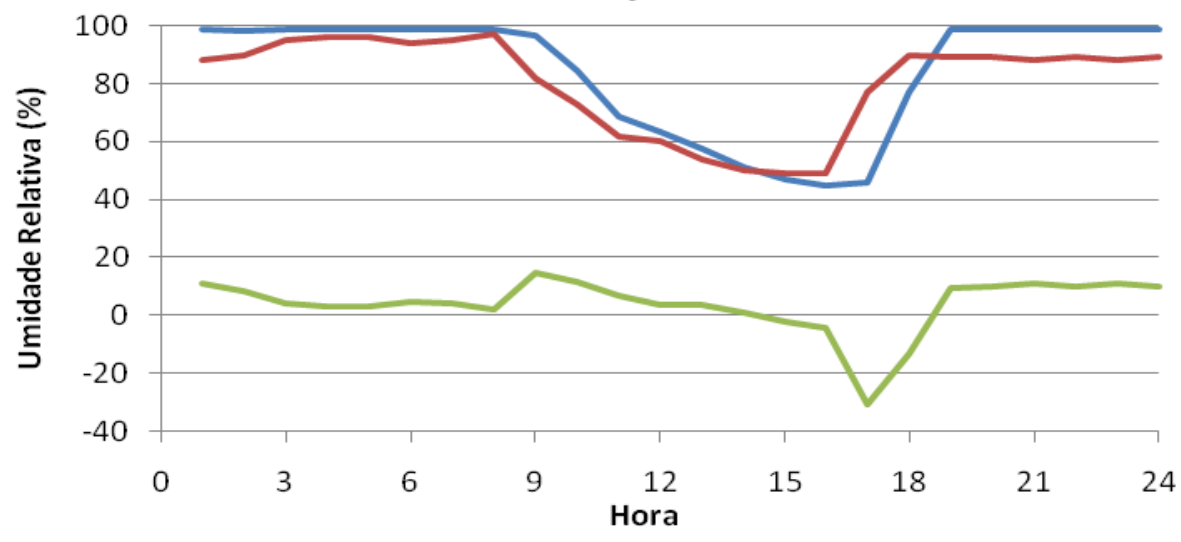

—Pq. D. Pedro II —Pq. Estado — Diferencial UR

FIGURA 98. Gráficos horários da umidade relativa e do diferencial de umidade, dias 25 de abril, 27 de maio e 26 de junho de 1998, na Estação de Monitoramento Pq. D. Pedro II, Estação Meteorológica do Parque Estadual Fontes do Ipiranga. Fonte: CETESB, 1999 e IAG, 1998. 
TABELA 56. Registros horários da umidade relativa e do diferencial de umidade nos dias 2,27 de fevereiro e 25 de março de 1998, na Estação de Monitoramento Pq. D. Pedro II, Estação Meteorológica do Parque Estadual Fontes do Ipiranga. Fonte: CETESB, 1999 e IAG, 1998.

\begin{tabular}{|c|c|c|c|c|c|c|c|c|c|}
\hline Mês & \multicolumn{3}{|c|}{25 abril 1998} & \multicolumn{3}{|c|}{27 maio 1998} & \multicolumn{3}{|c|}{26 junho 1998} \\
\hline Hora & PDP & $\mathrm{PE}$ & $\Delta$ & PDP & $\mathrm{PE}$ & $\Delta$ & PDP & $\mathrm{PE}$ & $\Delta$ \\
\hline 1 & 98,8 & 86 & 12,8 & 99 & 97 & 2 & 98,8 & 88 & 10,8 \\
\hline 2 & 98,2 & 84 & 14,2 & 99,1 & 99 & 0,1 & 98,4 & 90 & 8,4 \\
\hline 3 & 98,9 & 86 & 12,9 & 99,1 & 96 & 3,1 & 98,9 & 95 & 3,9 \\
\hline 4 & 98,9 & 93 & 5,9 & 99 & 91 & 8 & 98,9 & 96 & 2,9 \\
\hline 5 & 99 & 93 & 6 & 98,9 & 87 & 11,9 & 98,9 & 96 & 2,9 \\
\hline 6 & 99 & 93 & 6 & 98,9 & 88 & 10,9 & 98,9 & 94 & 4,9 \\
\hline 7 & 99 & 93 & 6 & 99 & 93 & 6 & 99 & 95 & 4 \\
\hline 8 & 99 & 94 & 5 & 99 & 90 & 9 & 99 & 97 & 2 \\
\hline 9 & 99 & 91 & 8 & 98,9 & 89 & 9,9 & 96,6 & 82 & 14,6 \\
\hline 10 & 99 & 90 & 9 & 98,9 & 89 & 9,9 & 84,3 & 73 & 11,3 \\
\hline 11 & 98,9 & 82 & 16,9 & 98,9 & 87 & 11,9 & 68,7 & 62 & 6,7 \\
\hline 12 & 89 & 82 & 7 & 98,8 & 84 & 14,8 & 63,4 & 60 & 3,4 \\
\hline 13 & 84 & 81 & 3 & 90,3 & 78 & 12,3 & 57,6 & 54 & 3,6 \\
\hline 14 & 81,5 & 82 & $-0,5$ & 82,5 & 77 & 5,5 & 51 & 50 & 1 \\
\hline 15 & 83,1 & 78 & 5,1 & 81 & 91 & -10 & 46,9 & 49 & $-2,1$ \\
\hline 16 & 79,7 & 80 & $-0,3$ & 93,5 & 88 & 5,5 & 44,9 & 49 & $-4,1$ \\
\hline 17 & 93,1 & 88 & 5,1 & 99 & 93 & 6 & 46,1 & 77 & $-30,9$ \\
\hline 18 & 98,9 & 90 & 8,9 & 99,1 & 88 & 11,1 & 76,9 & 90 & $-13,1$ \\
\hline 19 & 99 & 92 & 7 & 97,8 & 87 & 10,8 & 98,6 & 89 & 9,6 \\
\hline 20 & 99 & 94 & 5 & 96,5 & 84 & 12,5 & 99 & 89 & 10 \\
\hline 21 & 99 & 92 & 7 & 96,1 & 87 & 9,1 & 99 & 88 & 11 \\
\hline 22 & 99 & 95 & 4 & 98,9 & 89 & 9,9 & 98,9 & 89 & 9,9 \\
\hline 23 & 99 & 95 & 4 & 98,8 & 89 & 9,8 & 98,9 & 88 & 10,9 \\
\hline 24 & 99,1 & 94 & 5,1 & 98,7 & 89 & 9,7 & 98,8 & 89 & 9,8 \\
\hline
\end{tabular}



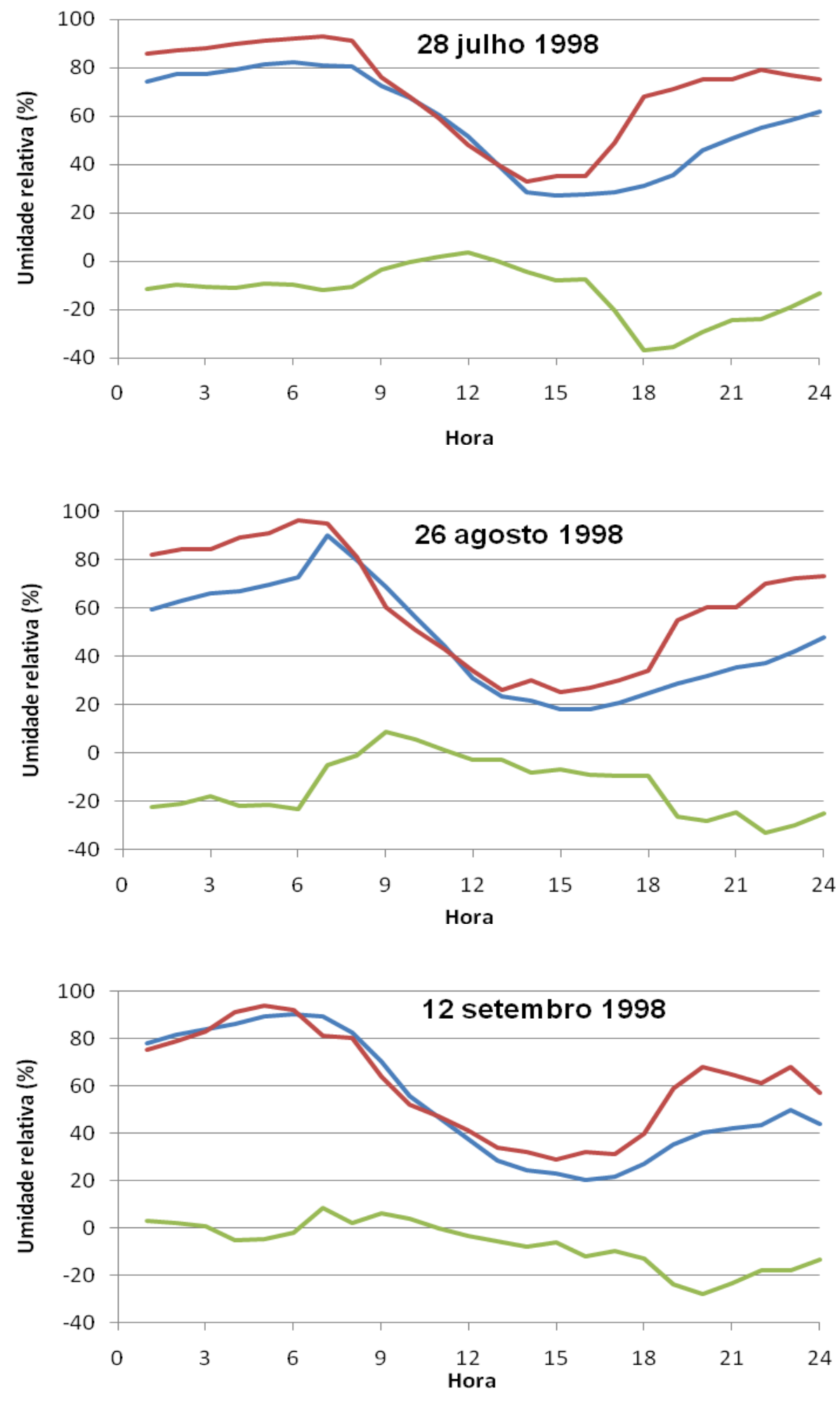

- Pq. D. Pedro II —Pq. Estado —Dfiferencial UR

FIGURA 99. Gráficos horários da umidade relativa e do diferencial de umidade, dias 28 de julho, 26 de agosto e 12 de setembro de 1998, na Estação de Monitoramento Pq. D. Pedro II, Estação Meteorológica do Parque Estadual Fontes do Ipiranga. Fonte: CETESB, 1999 e IAG, 1998. 
TABELA 57. Registros horários da umidade relativa e do diferencial de umidade nos dias 28 de julho, 26 de agosto e 12 de setembro de 1998, na Estação de Monitoramento Pq. D. Pedro II, Estação Meteorológica do Parque Estadual Fontes do Ipiranga. Fonte: CETESB, 1999 e IAG, 1998.

\begin{tabular}{|c|c|c|c|c|c|c|c|c|c|}
\hline Mês & \multicolumn{3}{|c|}{28 de julho 1998} & \multicolumn{3}{|c|}{26 de agosto de 1998} & \multicolumn{3}{|c|}{12 de setembro de 1998} \\
\hline Hora & PDP & $\mathrm{PE}$ & $\Delta$ & PDP & $\mathrm{PE}$ & $\Delta$ & PDP & $\mathrm{PE}$ & $\Delta$ \\
\hline 1 & 74,3 & 86 & $-11,7$ & 59,5 & 82 & $-22,5$ & 77,9 & 75 & 2,9 \\
\hline 2 & 77,2 & 87 & $-9,8$ & 63 & 84 & -21 & 81,4 & 79 & 2,4 \\
\hline 3 & 77,6 & 88 & $-10,4$ & 66 & 84 & -18 & 83,7 & 83 & 0,7 \\
\hline 4 & 79,1 & 90 & $-10,9$ & 67 & 89 & -22 & 86 & 91 & -5 \\
\hline 5 & 81,6 & 91 & $-9,4$ & 69,6 & 91 & $-21,4$ & 89,5 & 94 & $-4,5$ \\
\hline 6 & 82,2 & 92 & $-9,8$ & 72,8 & 96 & $-23,2$ & 90,3 & 92 & $-1,7$ \\
\hline 7 & 81,1 & 93 & $-11,9$ & 89,9 & 95 & $-5,1$ & 89,4 & 81 & 8,4 \\
\hline 8 & 80,4 & 91 & $-10,6$ & 79,8 & 81 & $-1,2$ & 82,3 & 80 & 2,3 \\
\hline 9 & 72,6 & 76 & $-3,4$ & 68,6 & 60 & 8,6 & 70,3 & 64 & 6,3 \\
\hline 10 & 67,6 & 68 & $-0,4$ & 56,4 & 51 & 5,4 & 55,8 & 52 & 3,8 \\
\hline 11 & 60,7 & 59 & 1,7 & 44,2 & 43 & 1,2 & 46,8 & 47 & $-0,2$ \\
\hline 12 & 51,6 & 48 & 3,6 & 31 & 34 & -3 & 37,6 & 41 & $-3,4$ \\
\hline 13 & 40,1 & 40 & 0,1 & 23,3 & 26 & $-2,7$ & 28,4 & 34 & $-5,6$ \\
\hline 14 & 28,6 & 33 & $-4,4$ & 21,6 & 30 & $-8,4$ & 24,2 & 32 & $-7,8$ \\
\hline 15 & 27,1 & 35 & $-7,9$ & 18,2 & 25 & $-6,8$ & 23,1 & 29 & $-5,9$ \\
\hline 16 & 27,6 & 35 & $-7,4$ & 18,1 & 27 & $-8,9$ & 20,3 & 32 & $-11,7$ \\
\hline 17 & 28,7 & 49 & $-20,3$ & 20,6 & 30 & $-9,4$ & 21,5 & 31 & $-9,5$ \\
\hline 18 & 31,1 & 68 & $-36,9$ & 24,6 & 34 & $-9,4$ & 27,1 & 40 & $-12,9$ \\
\hline 19 & 35,4 & 71 & $-35,6$ & 28,5 & 55 & $-26,5$ & 35,1 & 59 & $-23,9$ \\
\hline 20 & 45,7 & 75 & $-29,3$ & 31,9 & 60 & $-28,1$ & 40,2 & 68 & $-27,8$ \\
\hline 21 & 50,7 & 75 & $-24,3$ & 35,5 & 60 & $-24,5$ & 41,9 & 65 & $-23,1$ \\
\hline 22 & 55,1 & 79 & $-23,9$ & 37,1 & 70 & $-32,9$ & 43,3 & 61 & $-17,7$ \\
\hline 23 & 58,1 & 77 & $-18,9$ & 42,2 & 72 & $-29,8$ & 50 & 68 & -18 \\
\hline 24 & 61,8 & 75 & $-13,2$ & 59,5 & 82 & $-22,5$ & 43,8 & 57 & $-13,2$ \\
\hline
\end{tabular}



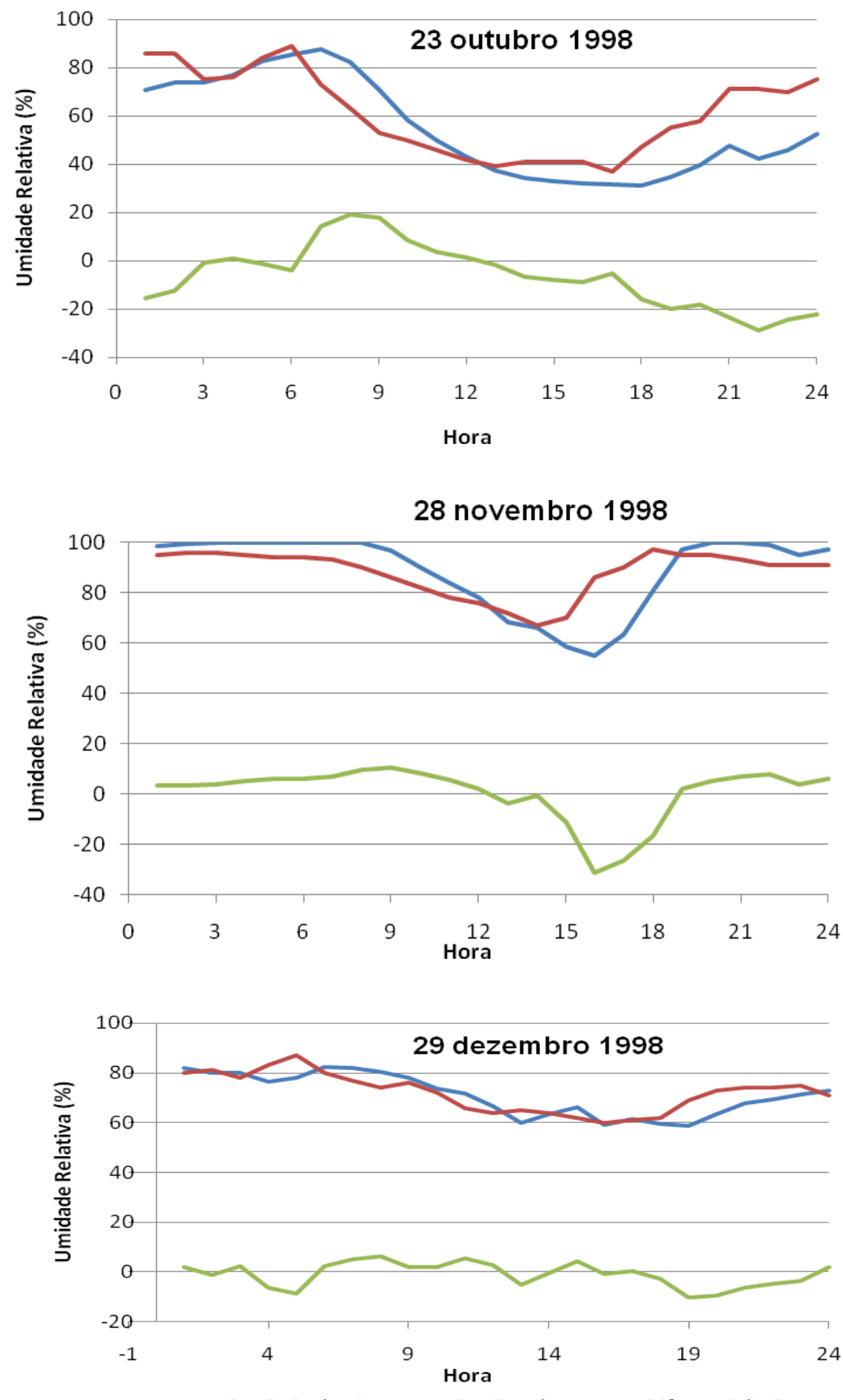

FIGURA 100. Gráficos horários da umidade relativa e do diferencial de umidade, dias 23 de outubro, 28 de novembro e 29 de dezembro de 1998, na Estação de Monitoramento Pq. D. Pedro II, Estação Meteorológica do Parque Estadual Fontes do Ipiranga. Fonte: CETESB, 1999 e IAG, 1998. 
TABELA 58. Registros horários da umidade relativa e do diferencial de umidade nos dias 23 de outubro, 28 novembro e 29 de dezembro de 1998, na Estação de Monitoramento Pq. D. Pedro II, Estação Meteorológica do Parque Estadual Fontes do Ipiranga. Fonte: CETESB, 1999 e IAG, 1998.

\begin{tabular}{|c|c|c|c|c|c|c|c|c|c|}
\hline Mês & \multicolumn{3}{|c|}{23 de outubro de 1998} & \multicolumn{3}{|c|}{28 de novembro de 1998} & \multicolumn{3}{|c|}{29 de dezembro de 1998} \\
\hline Hora & PDP & $\mathrm{PE}$ & $\Delta$ & PDP & $\mathrm{PE}$ & $\Delta$ & PDP & $\mathrm{PE}$ & $\Delta$ \\
\hline 1 & 70,7 & 86 & $-15,3$ & 98,4 & 95 & 3,4 & 82 & 80 & 2 \\
\hline 2 & 73,8 & 86 & $-12,2$ & 99,4 & 96 & 3,4 & 80 & 81 & -1 \\
\hline 3 & 74 & 75 & -1 & 100 & 96 & 4 & 80,2 & 78 & 2,2 \\
\hline 4 & 76,9 & 76 & 0,9 & 100 & 95 & 5 & 76,5 & 83 & $-6,5$ \\
\hline 5 & 82,7 & 84 & $-1,3$ & 100 & 94 & 6 & 78,2 & 87 & $-8,8$ \\
\hline 6 & 85,2 & 89 & $-3,8$ & 100 & 94 & 6 & 82,2 & 80 & 2,2 \\
\hline 7 & 87,4 & 73 & 14,4 & 100 & 93 & 7 & 82,1 & 77 & 5,1 \\
\hline 8 & 82,2 & 63 & 19,2 & 99,7 & 90 & 9,7 & 80,5 & 74 & 6,5 \\
\hline 9 & 70,9 & 53 & 17,9 & 96,6 & 86 & 10,6 & 77,9 & 76 & 1,9 \\
\hline 10 & 58,5 & 50 & 8,5 & 90,1 & 82 & 8,1 & 73,8 & 72 & 1,8 \\
\hline 11 & 49,7 & 46 & 3,7 & 83,8 & 78 & 5,8 & 71,7 & 66 & 5,7 \\
\hline 12 & 43,3 & 42 & 1,3 & 78 & 76 & 2 & 66,7 & 64 & 2,7 \\
\hline 13 & 37,5 & 39 & $-1,5$ & 68,4 & 72 & $-3,6$ & 59,9 & 65 & $-5,1$ \\
\hline 14 & 34,4 & 41 & $-6,6$ & 66,2 & 67 & $-0,8$ & 63,6 & 64 & $-0,4$ \\
\hline 15 & 33,1 & 41 & $-7,9$ & 58,5 & 70 & $-11,5$ & 66,4 & 62 & 4,4 \\
\hline 16 & 32,2 & 41 & $-8,8$ & 54,7 & 86 & $-31,3$ & 59,1 & 60 & $-0,9$ \\
\hline 17 & 31,7 & 37 & $-5,3$ & 63,4 & 90 & $-26,6$ & 61,5 & 61 & 0,5 \\
\hline 18 & 31 & 47 & -16 & 80,5 & 97 & $-16,5$ & 59,4 & 62 & $-2,6$ \\
\hline 19 & 34,9 & 55 & $-20,1$ & 97 & 95 & 2 & 58,9 & 69 & $-10,1$ \\
\hline 20 & 39,8 & 58 & $-18,2$ & 100 & 95 & 5 & 63,6 & 73 & $-9,4$ \\
\hline 21 & 47,5 & 71 & $-23,5$ & 100 & 93 & 7 & 67,8 & 74 & $-6,2$ \\
\hline 22 & 42,4 & 71 & $-28,6$ & 98,7 & 91 & 7,7 & 69,4 & 74 & $-4,6$ \\
\hline 23 & 45,8 & 70 & $-24,2$ & 94,7 & 91 & 3,7 & 71,5 & 75 & $-3,5$ \\
\hline 24 & 52,7 & 75 & $-22,3$ & 97,1 & 91 & 6,1 & 72,8 & 71 & 1,8 \\
\hline
\end{tabular}



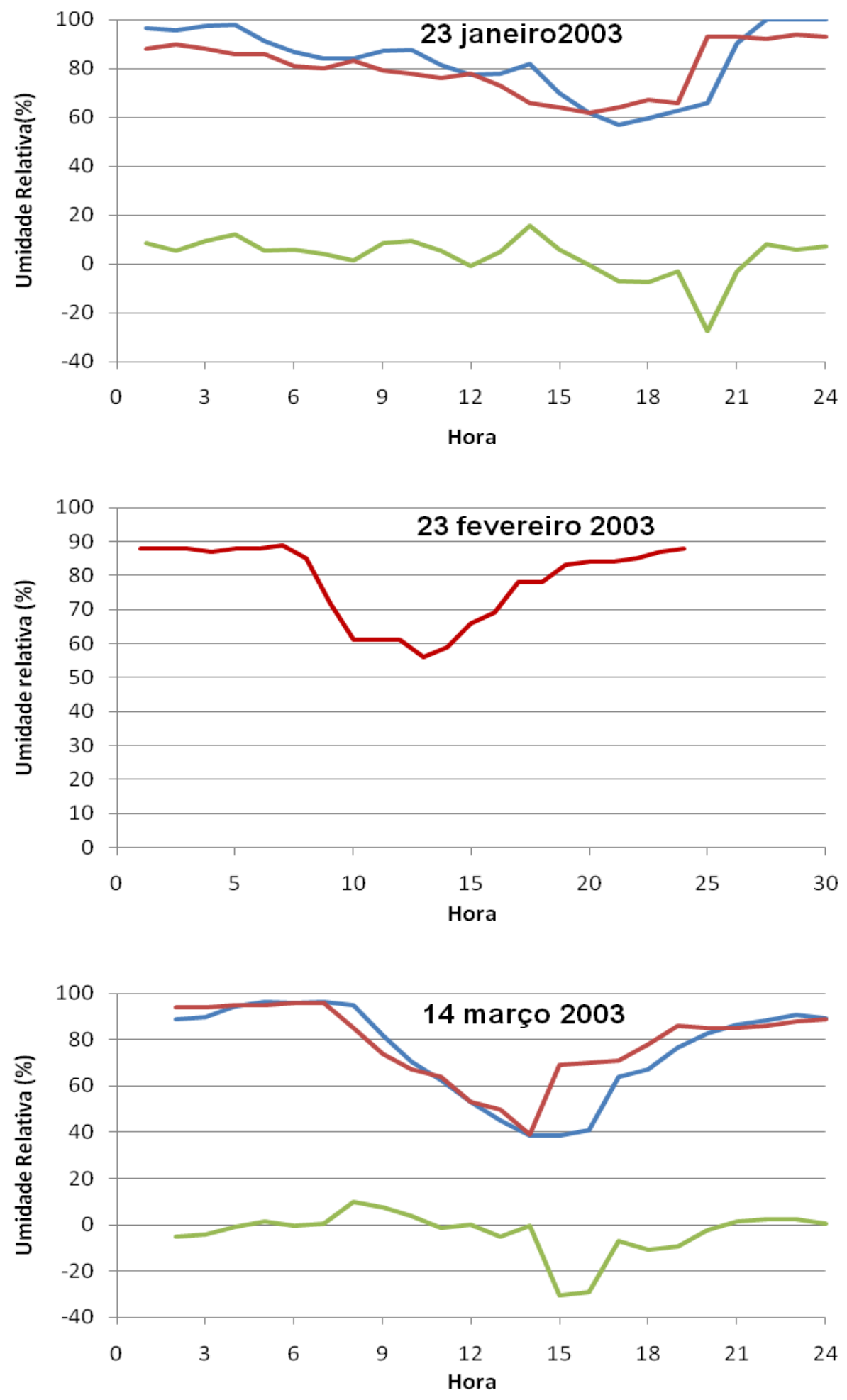

Pq. D. Pedro II

Pq. Estado Diferencial UR

FIGURA 101. Gráficos horários da umidade relativa e do diferencial de umidade, dias 23 de janeiro, 23 de fevereiro e 14 de março de 2003, na Estação de Monitoramento Pq. D. Pedro II, Estação Meteorológica do Parque Estadual Fontes do Ipiranga. Fonte: CETESB, 2004 e IAG, 2003. 
TABELA 59. Registros horários da umidade relativa e do diferencial de umidade nos dias 23 de janeiro, 23 de fevereiro e 14 de março de 2003, na Estação de Monitoramento Pq. D. Pedro II, Estação Meteorológica do Parque Estadual Fontes do Ipiranga. Fonte: CETESB, 2004 e IAG, 2003.

\begin{tabular}{|c|c|c|c|c|c|c|c|c|c|}
\hline Mês & \multicolumn{3}{|c|}{23 Janeiro 2003} & \multicolumn{3}{|c|}{23 Fevereiro 2003} & \multicolumn{3}{|c|}{14 Março 2003} \\
\hline Hora & PDP & $\mathrm{PE}$ & $\Delta$ & PDP & $\mathrm{PE}$ & $\Delta$ & PDP & $\mathrm{PE}$ & $\Delta$. \\
\hline 1 & 96,5 & 88 & 8,5 & ND & 88 & ND & 86,7 & 92 & $-5,3$ \\
\hline 2 & 95,4 & 90 & 5,4 & ND & 88 & ND & 88,8 & 94 & $-5,2$ \\
\hline 3 & 97,2 & 88 & 9,2 & ND & 88 & ND & 89,7 & 94 & $-4,3$ \\
\hline 4 & 97,9 & 86 & 11,9 & ND & 87 & ND & 94,2 & 95 & $-0,8$ \\
\hline 5 & 91,3 & 86 & 5,3 & ND & 88 & ND & 96,3 & 95 & 1,3 \\
\hline 6 & 86,7 & 81 & 5,7 & ND & 88 & ND & 95,8 & 96 & $-0,2$ \\
\hline 7 & 84,2 & 80 & 4,2 & ND & 89 & ND & 96,5 & 96 & 0,5 \\
\hline 8 & 84,2 & 83 & 1,2 & ND & 85 & ND & 95,1 & 85 & 10,1 \\
\hline 9 & 87,3 & 79 & 8,3 & ND & 72 & ND & 81,7 & 74 & 7,7 \\
\hline 10 & 87,6 & 78 & 9,6 & ND & 61 & ND & 70,6 & 67 & 3,6 \\
\hline 11 & 81,4 & 76 & 5,4 & ND & 61 & ND & 62,7 & 64 & $-1,3$ \\
\hline 12 & 77,2 & 78 & $-0,8$ & ND & 61 & ND & 53 & 53 & 0 \\
\hline 13 & 77,8 & 73 & 4,8 & ND & 56 & ND & 45,1 & 50 & $-4,9$ \\
\hline 14 & 81,8 & 66 & 15,8 & ND & 59 & ND & 38,6 & 39 & $-0,4$ \\
\hline 15 & 69,7 & 64 & 5,7 & ND & 66 & ND & 38,4 & 69 & $-30,6$ \\
\hline 16 & 61,7 & 62 & $-0,3$ & ND & 69 & ND & 41,1 & 70 & $-28,9$ \\
\hline 17 & 57,1 & 64 & $-6,9$ & ND & 78 & ND & 63,9 & 71 & $-7,1$ \\
\hline 18 & 59,7 & 67 & $-7,3$ & ND & 78 & ND & 67,1 & 78 & $-10,9$ \\
\hline 19 & 62,9 & 66 & $-3,1$ & ND & 83 & ND & 76,8 & 86 & $-9,2$ \\
\hline 20 & 65,7 & 93 & $-27,3$ & ND & 84 & ND & 82,7 & 85 & $-2,3$ \\
\hline 21 & 90,1 & 93 & $-2,9$ & ND & 84 & ND & 86,4 & 85 & 1,4 \\
\hline 22 & 100 & 92 & 8 & ND & 85 & ND & 88,5 & 86 & 2,5 \\
\hline 23 & 100 & 94 & 6 & ND & 87 & ND & 90,6 & 88 & 2,6 \\
\hline 24 & 100 & 93 & 7 & ND & 88 & ND & 89,3 & 89 & 0,3 \\
\hline
\end{tabular}

ND - Dados não disponíveis. 

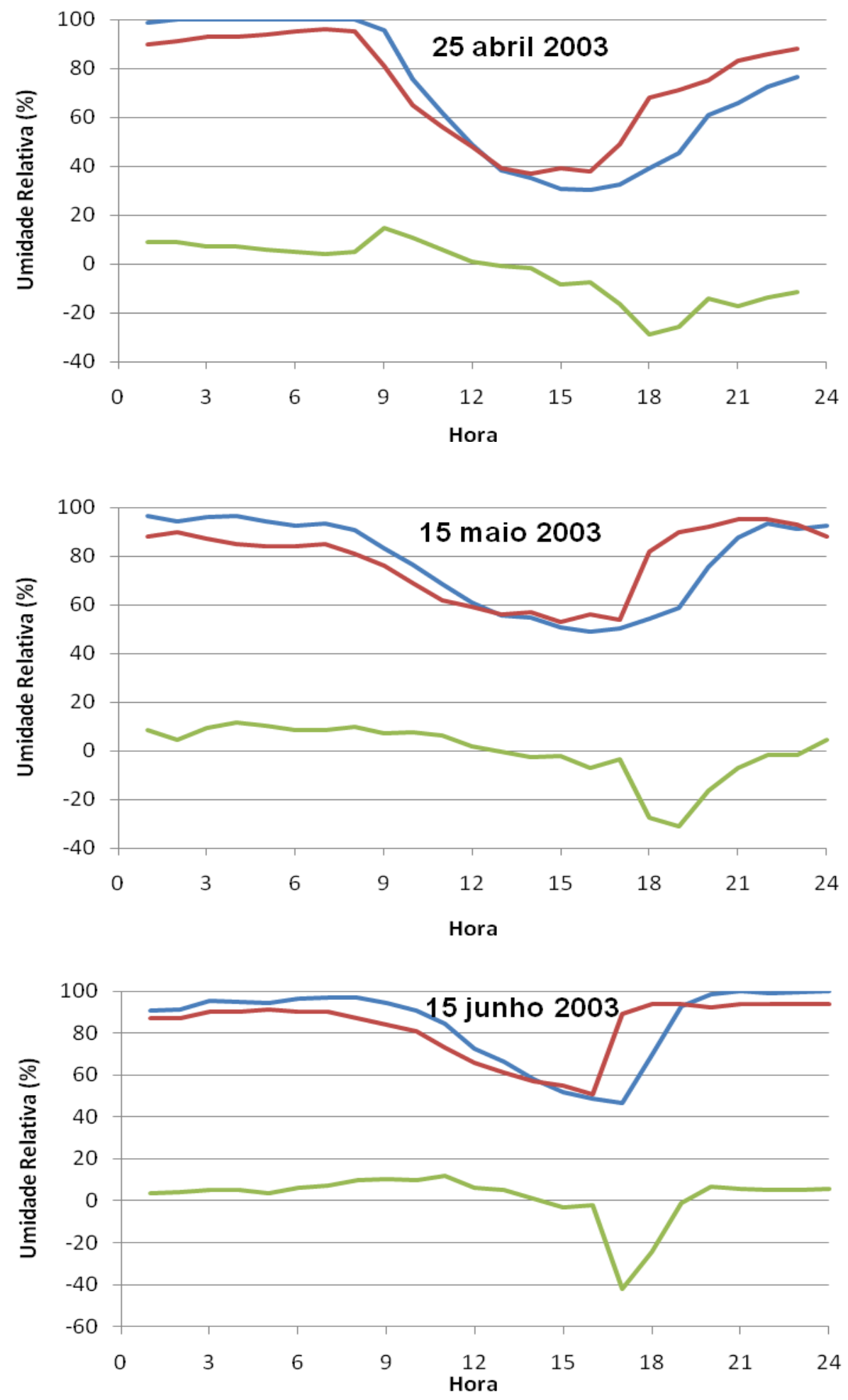

Pq. D. Pedro II $\longrightarrow$ Pq. Estado Diferencial UR

FIGURA 102. Gráficos horários da umidade relativa e do diferencial de umidade, dias 25 de abril, 15 de maio e 15 de junho de 2003, na Estação de Monitoramento Pq. D. Pedro II, Estação Meteorológica do Parque Estadual Fontes do Ipiranga. Fonte: CETESB, 2004 e IAG, 2003. 
TABELA 60. Registros horários da umidade relativa e do diferencial de umidade nos dias 25 de abril, 15 de maio e 15 de junho de 2003, na Estação de Monitoramento Pq. D. Pedro II, Estação Meteorológica do Parque Estadual Fontes do Ipiranga. Fonte: CETESB, 2004 e IAG, 2003.

\begin{tabular}{|c|c|c|c|c|c|c|c|c|c|}
\hline Mês & \multicolumn{3}{|c|}{25 Abril 2003} & \multicolumn{3}{|c|}{15 Maio 2003} & \multicolumn{3}{|c|}{15 Junho 2003} \\
\hline Hora & PDP & $\mathrm{PE}$ & $\Delta$ & PDP & $\mathrm{PE}$ & $\Delta$ & PDP & $\mathrm{PE}$ & $\Delta$ \\
\hline 1 & 98,8 & 90 & 8,8 & 96,3 & 88 & 8,3 & 90,6 & 87 & 3,6 \\
\hline 2 & 99,9 & 91 & 8,9 & 94,4 & 90 & 4,4 & 91,2 & 87 & 4,2 \\
\hline 3 & 100 & 93 & 7 & 96,2 & 87 & 9,2 & 95,3 & 90 & 5,3 \\
\hline 4 & 100 & 93 & 7 & 96,4 & 85 & 11,4 & 94,9 & 90 & 4,9 \\
\hline 5 & 100 & 94 & 6 & 94,4 & 84 & 10,4 & 94,5 & 91 & 3,5 \\
\hline 6 & 100 & 95 & 5 & 92,7 & 84 & 8,7 & 96,4 & 90 & 6,4 \\
\hline 7 & 100 & 96 & 4 & 93,4 & 85 & 8,4 & 97,1 & 90 & 7,1 \\
\hline 8 & 100 & 95 & 5 & 90,9 & 81 & 9,9 & 96,8 & 87 & 9,8 \\
\hline 9 & 95,7 & 81 & 14,7 & 83,3 & 76 & 7,3 & 94,3 & 84 & 10,3 \\
\hline 10 & 75,6 & 65 & 10,6 & 76,5 & 69 & 7,5 & 90,9 & 81 & 9,9 \\
\hline 11 & 62 & 56 & 6 & 68,3 & 62 & 6,3 & 84,7 & 73 & 11,7 \\
\hline 12 & 49,1 & 48 & 1,1 & 60,9 & 59 & 1,9 & 72,4 & 66 & 6,4 \\
\hline 13 & 38,1 & 39 & $-0,9$ & 55,8 & 56 & $-0,2$ & 66,1 & 61 & 5,1 \\
\hline 14 & 35,2 & 37 & $-1,8$ & 54,6 & 57 & $-2,4$ & 57,8 & 57 & 0,8 \\
\hline 15 & 30,8 & 39 & $-8,2$ & 50,8 & 53 & $-2,2$ & 52 & 55 & -3 \\
\hline 16 & 30,5 & 38 & $-7,5$ & 49 & 56 & -7 & 48,9 & 51 & $-2,1$ \\
\hline 17 & 32,5 & 49 & $-16,5$ & 50,3 & 54 & $-3,7$ & 46,8 & 89 & $-42,2$ \\
\hline 18 & 39,3 & 68 & $-28,7$ & 54,4 & 82 & $-27,6$ & 69,6 & 94 & $-24,4$ \\
\hline 19 & 45,5 & 71 & $-25,5$ & 58,9 & 90 & $-31,1$ & 92,7 & 94 & $-1,3$ \\
\hline 20 & 60,9 & 75 & $-14,1$ & 75,6 & 92 & $-16,4$ & 98,5 & 92 & 6,5 \\
\hline 21 & 65,7 & 83 & $-17,3$ & 87,8 & 95 & $-7,2$ & 99,8 & 94 & 5,8 \\
\hline 22 & 72,5 & 86 & $-13,5$ & 93,2 & 95 & $-1,8$ & 99,2 & 94 & 5,2 \\
\hline 23 & 76,4 & 88 & $-11,6$ & 91,1 & 93 & $-1,9$ & 99,4 & 94 & 5,4 \\
\hline 24 & 74,7 & 91 & $-16,3$ & 92,5 & 88 & 4,5 & 99,8 & 94 & 5,8 \\
\hline
\end{tabular}



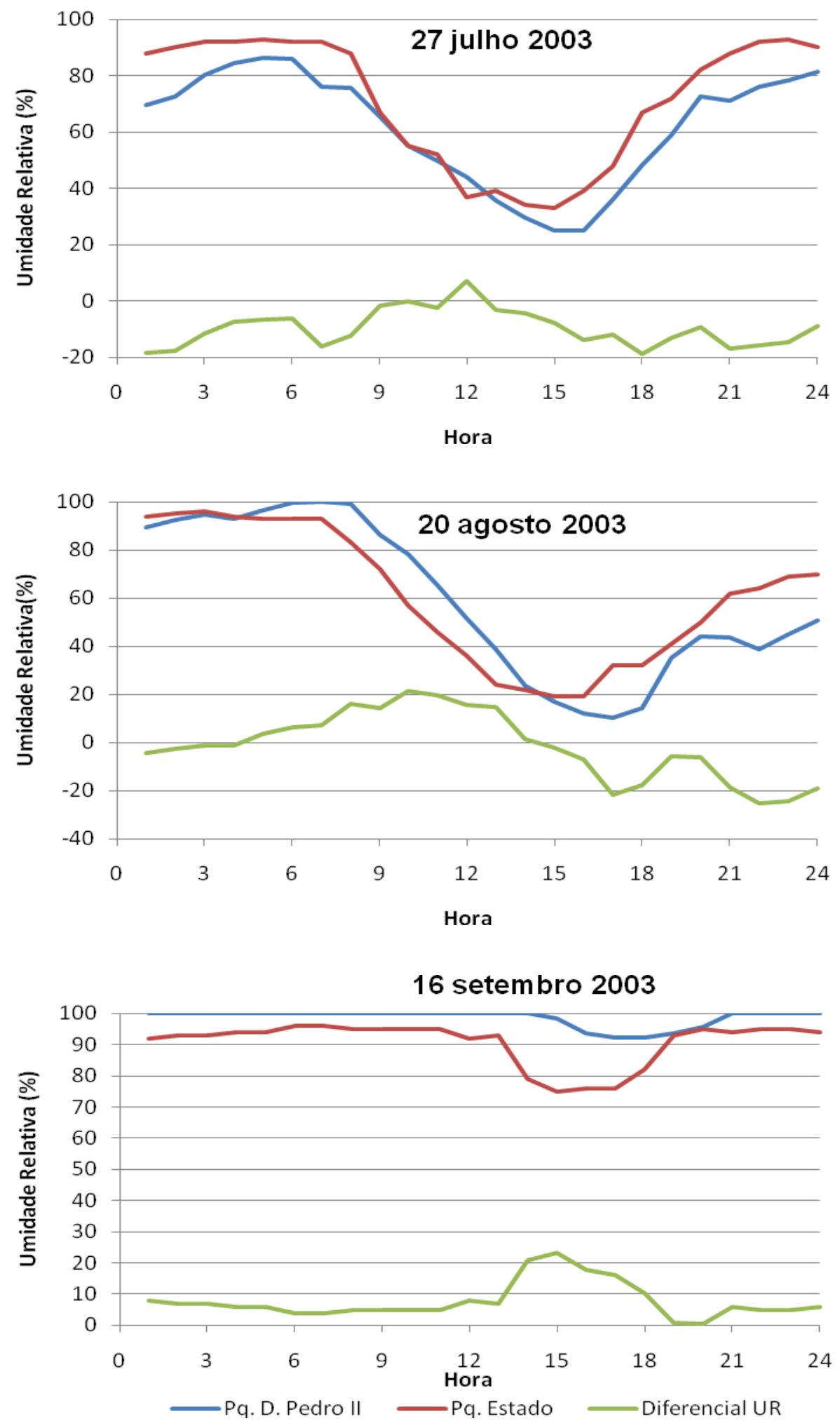

FIGURA 103. Gráficos horários da umidade relativa e do diferencial de umidade, dias 27 de julho, 20 de agosto e 16 de setembro de 2003, na Estação de Monitoramento Pq. D. Pedro II, Estação Meteorológica do Parque Estadual Fontes do Ipiranga. Fonte: CETESB, 2004 e IAG, 2003. 
TABELA 61. Registros horários da umidade relativa e do diferencial de umidade nos dias 27 de julho, 20 de agosto e 16 de setembro de 2003, na Estação de Monitoramento Pq. D. Pedro II, Estação Meteorológica do Parque Estadual Fontes do Ipiranga. Fonte: CETESB, 2004 e IAG, 2003.

\begin{tabular}{|c|c|c|c|c|c|c|c|c|c|}
\hline Mês & \multicolumn{3}{|c|}{27 Julho 2003} & \multicolumn{3}{|c|}{20 Agosto 2003} & \multicolumn{3}{|c|}{16 Setembro 2003} \\
\hline Hora & PDP & $\mathrm{PE}$ & $\Delta$ & PDP & $\mathrm{PE}$ & $\Delta$ & PDP & $\mathrm{PE}$ & $\Delta$ \\
\hline 1 & 69,5 & 88 & $-18,5$ & 89,6 & 94 & $-4,4$ & 100 & 92 & 8 \\
\hline 2 & 72,5 & 90 & $-17,5$ & 92,3 & 95 & $-2,7$ & 100 & 93 & 7 \\
\hline 3 & 80,3 & 92 & $-11,7$ & 94,7 & 96 & $-1,3$ & 100 & 93 & 7 \\
\hline 4 & 84,6 & 92 & $-7,4$ & 92,9 & 94 & $-1,1$ & 100 & 94 & 6 \\
\hline 5 & 86,4 & 93 & $-6,6$ & 96,4 & 93 & 3,4 & 100 & 94 & 6 \\
\hline 6 & 85,8 & 92 & $-6,2$ & 99,5 & 93 & 6,5 & 100 & 96 & 4 \\
\hline 7 & 75,9 & 92 & $-16,1$ & 100 & 93 & 7 & 100 & 96 & 4 \\
\hline 8 & 75,7 & 88 & $-12,3$ & 99,1 & 83 & 16,1 & 100 & 95 & 5 \\
\hline 9 & 65,2 & 67 & $-1,8$ & 86,5 & 72 & 14,5 & 100 & 95 & 5 \\
\hline 10 & 55 & 55 & 0 & 78,3 & 57 & 21,3 & 100 & 95 & 5 \\
\hline 11 & 49,6 & 52 & $-2,4$ & 65,5 & 46 & 19,5 & 100 & 95 & 5 \\
\hline 12 & 44 & 37 & 7 & 51,6 & 36 & 15,6 & 100 & 92 & 8 \\
\hline 13 & 35,7 & 39 & $-3,3$ & 38,8 & 24 & 14,8 & 100 & 93 & 7 \\
\hline 14 & 29,5 & 34 & $-4,5$ & 23,4 & 22 & 1,4 & 100 & 79 & 21 \\
\hline 15 & 25,1 & 33 & $-7,9$ & 16,8 & 19 & $-2,2$ & 98,4 & 75 & 23,4 \\
\hline 16 & 25 & 39 & -14 & 12 & 19 & -7 & 93,7 & 76 & 17,7 \\
\hline 17 & 36 & 48 & -12 & 10,4 & 32 & $-21,6$ & 92,2 & 76 & 16,2 \\
\hline 18 & 48,2 & 67 & $-18,8$ & 14,5 & 32 & $-17,5$ & 92,3 & 82 & 10,3 \\
\hline 19 & 58,8 & 72 & $-13,2$ & 35,1 & 41 & $-5,9$ & 93,8 & 93 & 0,8 \\
\hline 20 & 72,6 & 82 & $-9,4$ & 43,9 & 50 & $-6,1$ & 95,6 & 95 & 0,6 \\
\hline 21 & 71,1 & 88 & $-16,9$ & 43,4 & 62 & $-18,6$ & 100 & 94 & 6 \\
\hline 22 & 76,1 & 92 & $-15,9$ & 38,7 & 64 & $-25,3$ & 100 & 95 & 5 \\
\hline 23 & 78,4 & 93 & $-14,6$ & 44,8 & 69 & $-24,2$ & 100 & 95 & 5 \\
\hline 24 & 81,2 & 90 & $-8,8$ & 50,8 & 70 & $-19,2$ & 100 & 94 & 6 \\
\hline
\end{tabular}



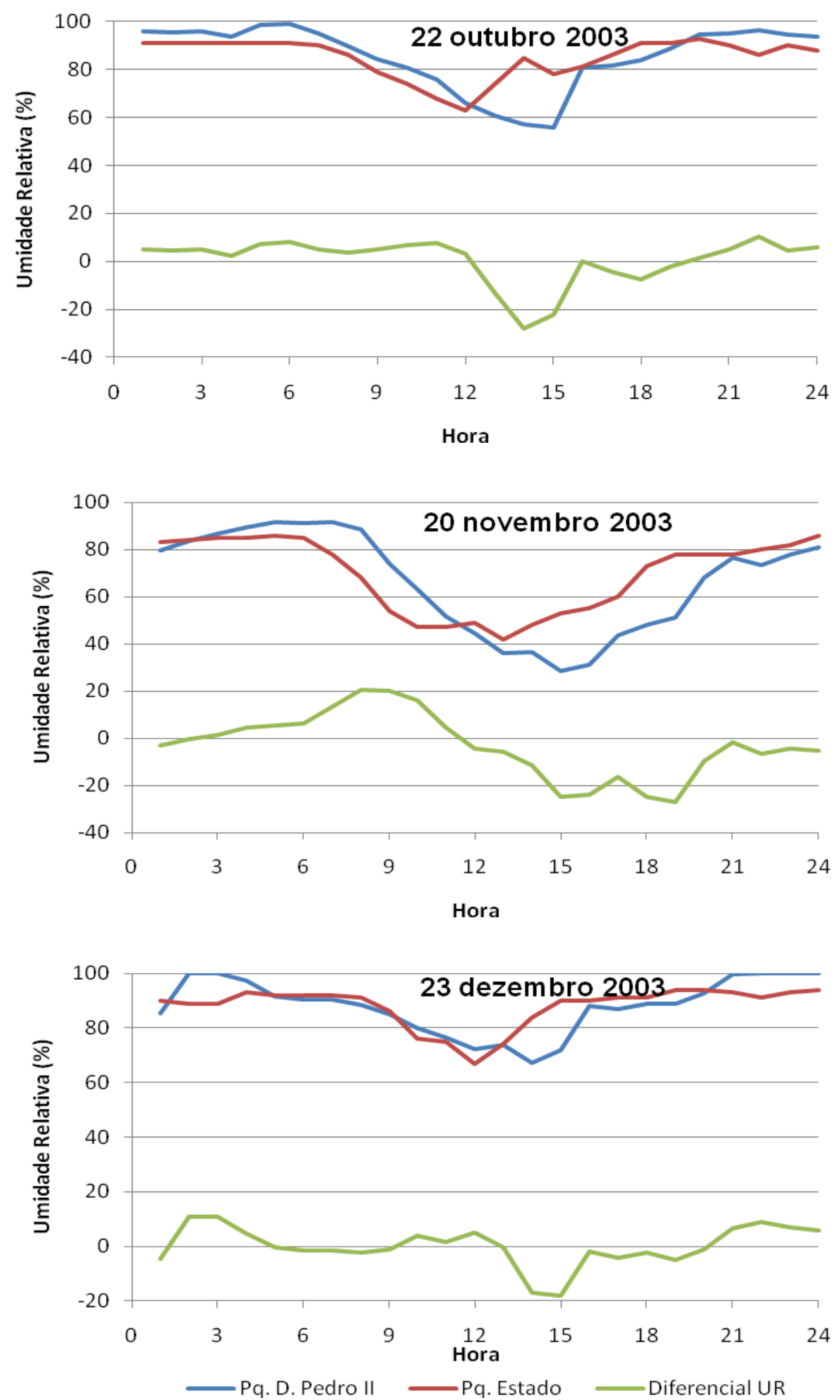

FIGURA 104. Gráficos horários da umidade relativa e do diferencial de umidade, dias 22 de outubro, 20 de novembro e 23 de dezembro de 2003, na Estação de Monitoramento Pq. D. Pedro II, Estação Meteorológica do Parque Estadual Fontes do Ipiranga. Fonte: CETESB, 2004 e IAG, 2003. 
TABELA 62. Registros horários da umidade relativa e do diferencial de umidade nos dias 22 de outubro, 20 de novembro e 23 de dezembro de 2003, na Estação de Monitoramento Pq. D. Pedro II, Estação Meteorológica do Parque Estadual Fontes do Ipiranga. Fonte: CETESB, 2004 e IAG, 2003.

\begin{tabular}{|c|c|c|c|c|c|c|c|c|c|}
\hline Mês & \multicolumn{3}{|c|}{22 Outubro 2003} & \multicolumn{3}{|c|}{20 Novembro 2003} & \multicolumn{3}{|c|}{23 Dezembro 2003} \\
\hline Hora & PDP & $\mathrm{PE}$ & $\Delta$ & PDP & $\mathrm{PE}$ & $\Delta$ & PDP & $\mathrm{PE}$ & $\Delta$ \\
\hline 1 & 95,8 & 91 & 4,8 & 79,8 & 83 & $-3,2$ & 85,3 & 90 & $-4,7$ \\
\hline 2 & 95,6 & 91 & 4,6 & 83,8 & 84 & $-0,2$ & 100 & 89 & 11 \\
\hline 3 & 95,8 & 91 & 4,8 & 86,6 & 85 & 1,6 & 100 & 89 & 11 \\
\hline 4 & 93,5 & 91 & 2,5 & 89,5 & 85 & 4,5 & 97,5 & 93 & 4,5 \\
\hline 5 & 98,4 & 91 & 7,4 & 91,5 & 86 & 5,5 & 91,6 & 92 & $-0,4$ \\
\hline 6 & 99,1 & 91 & 8,1 & 91,3 & 85 & 6,3 & 90,3 & 92 & $-1,7$ \\
\hline 7 & 94,9 & 90 & 4,9 & 91,6 & 78 & 13,6 & 90,4 & 92 & $-1,6$ \\
\hline 8 & 89,8 & 86 & 3,8 & 88,3 & 68 & 20,3 & 88,6 & 91 & $-2,4$ \\
\hline 9 & 84,2 & 79 & 5,2 & 73,9 & 54 & 19,9 & 84,8 & 86 & $-1,2$ \\
\hline 10 & 80,6 & 74 & 6,6 & 63,1 & 47 & 16,1 & 79,8 & 76 & 3,8 \\
\hline 11 & 75,7 & 68 & 7,7 & 51,5 & 47 & 4,5 & 76,4 & 75 & 1,4 \\
\hline 12 & 66,1 & 63 & 3,1 & 44,5 & 49 & $-4,5$ & 72,1 & 67 & 5,1 \\
\hline 13 & 60,9 & 74 & $-13,1$ & 36,2 & 42 & $-5,8$ & 73,7 & 74 & $-0,3$ \\
\hline 14 & 57,1 & 85 & $-27,9$ & 36,4 & 48 & $-11,6$ & 67,2 & 84 & $-16,8$ \\
\hline 15 & 56 & 78 & -22 & 28,3 & 53 & $-24,7$ & 71,9 & 90 & $-18,1$ \\
\hline 16 & 80,9 & 81 & $-0,1$ & 31,2 & 55 & $-23,8$ & 88 & 90 & -2 \\
\hline 17 & 81,8 & 86 & $-4,2$ & 43,7 & 60 & $-16,3$ & 86,9 & 91 & $-4,1$ \\
\hline 18 & 83,7 & 91 & $-7,3$ & 48,2 & 73 & $-24,8$ & 88,8 & 91 & $-2,2$ \\
\hline 19 & 89 & 91 & -2 & 51 & 78 & -27 & 89 & 94 & -5 \\
\hline 20 & 94,5 & 93 & 1,5 & 68,1 & 78 & $-9,9$ & 92,8 & 94 & $-1,2$ \\
\hline 21 & 95 & 90 & 5 & 76,5 & 78 & $-1,5$ & 99,7 & 93 & 6,7 \\
\hline 22 & 96,4 & 86 & 10,4 & 73,6 & 80 & $-6,4$ & 100 & 91 & 9 \\
\hline 23 & 94,6 & 90 & 4,6 & 77,7 & 82 & $-4,3$ & 100 & 93 & 7 \\
\hline 24 & 93,9 & 88 & 5,9 & 80,9 & 86 & $-5,1$ & 100 & 94 & 6 \\
\hline
\end{tabular}




\section{APÊNDICE D - Ações de revitalização do Procentro}

\section{Projeto Nova Luz}

O objetivo deste projeto é a requalificação e recuperação da área de $362.000 \mathrm{~m}^{2}$, definida pela Lei № 14.918/09, delimitada pelo perímetro da Avenida Cásper Líbero, Avenida Ipiranga, Avenida São João, Rua Duque de Caxias e Rua Mauá (JORNAL DA TARDE, 2010).

Região com atividade econômica geradora de 2.500 empregos formais, apresenta acentuado processo de degradação, evidenciado pelo êxodo dos moradores do distrito da República.

Enquanto em 1996 a região apresentava 54.274 habitantes, em 2008 contava com apenas 44.770 habitantes (IBGE, 2008).

O projeto define a região por áreas com baixo potencial de transformação e áreas com possibilidades imediatas de transformação. As áreas com baixo potencial de transformação são aquelas que apresentam edifícios com quatro ou mais pavimentos, imóveis tombados, ocupados por comércio especializado e imóveis ocupados por outros usos consolidados. As demais áreas, não qualificadas com estas características, são definidas como com possibilidades imediatas de transformação pelo projeto Nova Luz (FIG. 105 e 106).

O estudo inicial, que limitava o perímetro do projeto Nova Luz até a Avenida Rio Branco, ilustra a magnitude da preservação e da intervenção prevista (FIG. 105 e 106) (SÃO PAULO [Cidade] - EMURB, 2007).

A Lei № 14.918/09, de 7 de maio de 2009, no Artigo 2o, define como diretrizes da intervenção a preservação e a recuperação do patrimônio histórico e cultural, o equilíbrio entre habitação e atividade econômica, implantação de unidades habitacionais destinadas à população de baixa renda e incentivo à expansão da atividade econômica ligada à tecnologia (FOLHA DE SÃO PAULO, 2010). 
No parágrafo $3^{\circ}$, estipula que a compatibilidade dos imóveis preservados com o entorno previsto deverá ser estabelecida pelo projeto urbanístico (FIG. 107) (LEI № 14.918/09, 2009).

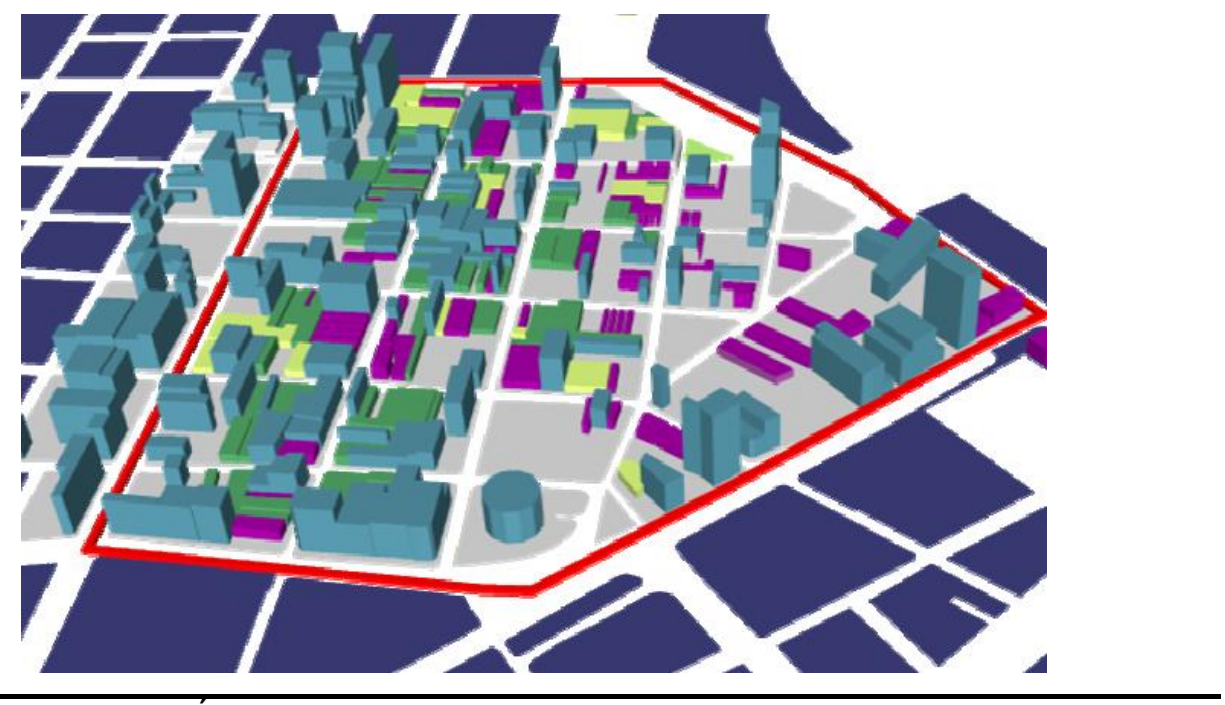

\begin{tabular}{|l|l|}
\hline \multicolumn{2}{|c|}{ Áreas com baixo potencial de transformação } \\
\hline \begin{tabular}{l|l} 
Edifícios com 4 ou mais pavimentos & Comércio especializado \\
Imóveis tombados & Outros usos consolidados \\
\hline Área com possibilidade de transformação imediata
\end{tabular} \\
\hline
\end{tabular}

FIGURA 105. Áreas com baixo potencial de transformação dentro do perímetro do Programa Nova Luz. Fonte: São Paulo [Cidade] - EMURB, 2007.

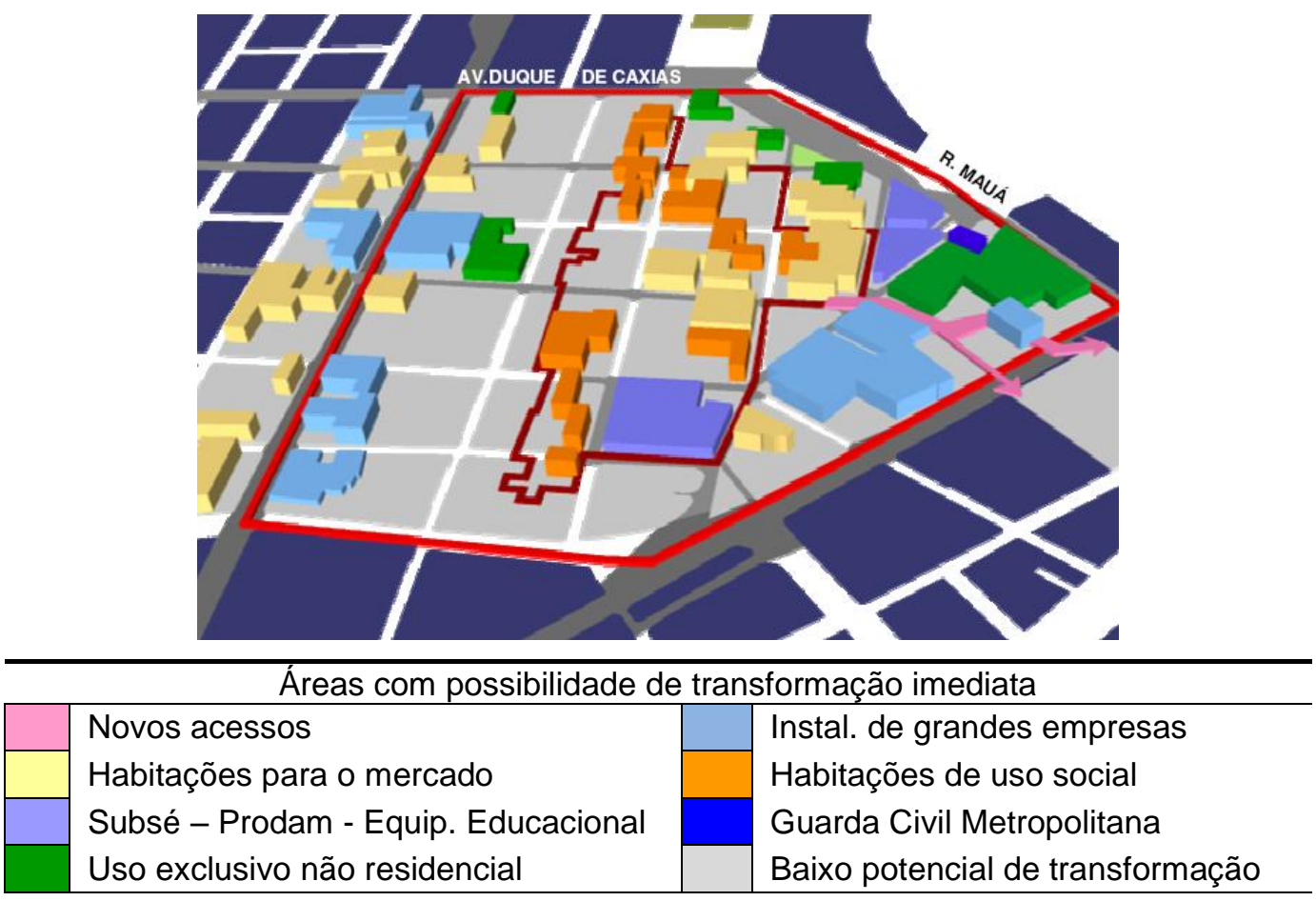

FIGURA 106. Áreas com possibilidade de transformação imediata dentro do perímetro do Programa Nova Luz. Fonte: Programa Procentro. São Paulo [Cidade] - EMURB, 2007. 


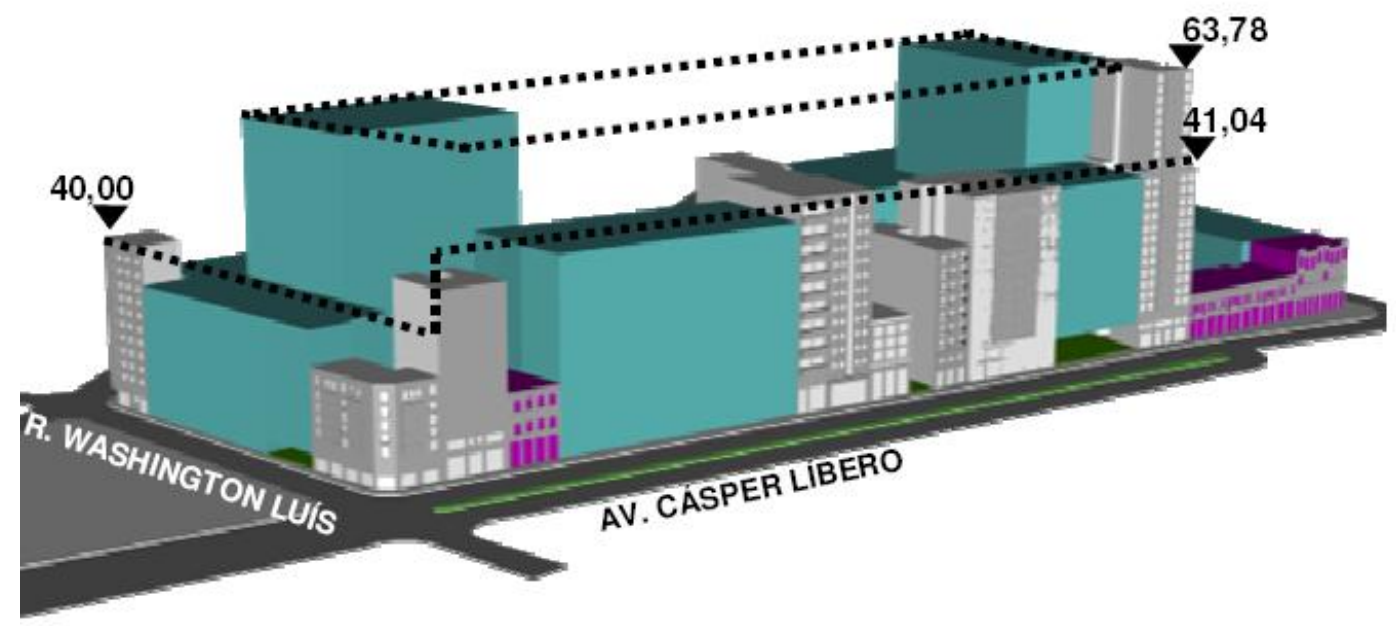

FIGURA 107. Volumetria máxima proposta na Quadra 19. Fonte: Programa Procentro. São Paulo [Cidade] - EMURB 2007.

O projeto prevê o aumento dos índices de permeabilidade do solo, de áreas verdes por habitante, intensificação do uso habitacional (utilizando densidade de 350 hab./ha) e compatibilização com as necessidades apontadas no EIA/Rima. Define a instalação de quatro edifícios públicos (Prodam, SUBSÉ, GCM e Escola Técnica Estadual Centro Paula Souza) (TERMO DE REFERÊNCIA NOVA LUZ, 2009).

Foram habilitadas 23 empresas privadas para receberem incentivos fiscais e se instalarem no distrito da República que não apresentam atividades poluidoras (12 empresas de sistemas, três call centers, uma empresa de publicidade, uma empresa que desenvolve atividades culturais, uma empresa gráfica e cinco investidores imobiliários).

\section{Residencial Olarias}

Localizado no distrito do Pari, com 137 unidades residenciais, concluído em 2004 pela Secretaria Municipal de Urbanização (Sehab) (CANTERO; GHOUBAR, 2008). 


\section{Edifício residencial na Rua Riachuelo}

Recuperação e requalificação de edifício comercial degradado, na Rua Riachuelo, criando-se 120 unidades residenciais. Obra concluída em 2008, pela Sehab (FIG. 108) (PROCENTRO, 2010);
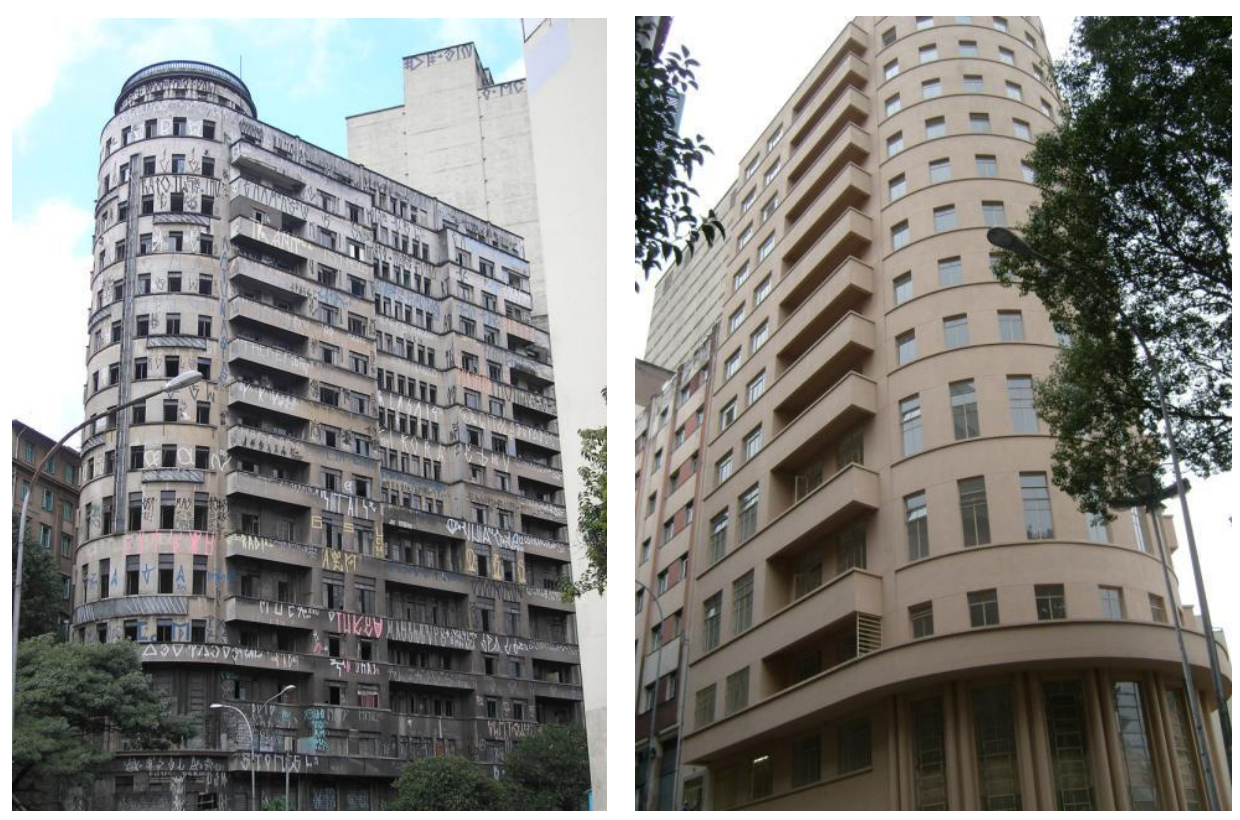

FIGURA 108. Conjunto Residencial da Rua Riachuelo. Fonte: Procentro/Galeria de imagens. Disponível em: <http://www.procentro.com.br/site/Galerialmagens.aspx>. Acesso em: 19 maio 2010.

Este tipo de ação, por reutilizar a estrutura da edificação, atende ao conceito de sustentabilidade e não agrava a questão da temperatura ambiente.

\section{Conjunto Residencial Parque do Gato}

Localizado junto à foz do Rio Tamanduateí, composto por nove edifícios com cinco pavimentos e 486 unidades residenciais, obra concluída em 2004 pela Sehab. A construção deste conjunto se deu removendo-se a Favela do Gato, anteriormente existente no local (FIG. 109) (CANTERO, 2008); 

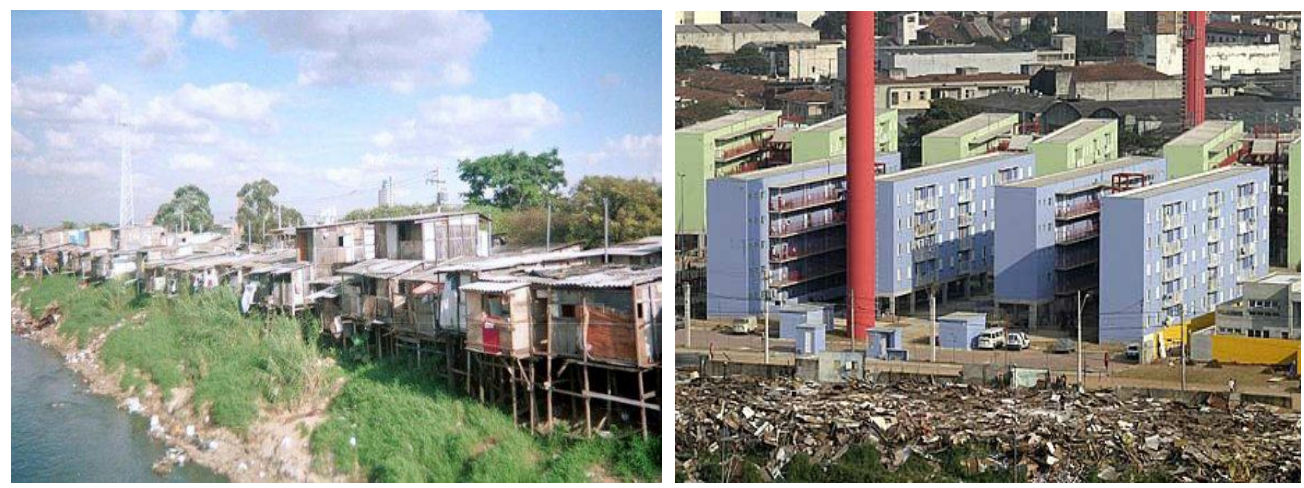

FIGURA 109. Favela do Gato e Conjunto Residencial Parque do Gato. Foto da Favela do Gato Disponível em: <http://www.google.com.br/images?hl=pt-BR\&q=favela+do+gato\&um=1\&ie=UTF$8 \&$ source=univ\&ei=s0TOS-

fXFMK88gavsPyrDg\&sa=X\&oi=image result group\&ct=title\&resnum=4\&ved=0CDIQsAQwAw>. Acesso em: 20 set. 2010.

Foto do Conjunto Residencial Parque do Gato: Marcos Issa/Argos Foto. Disponível em: $<$ http://bbs. keyhole.com/ubb/ubbthreads. php?ubb=showthreaded\&Number=80736\&site id=1\#import $>$. Acesso em: Acesso em: 20 set. 2010.

\section{Reurbanização da Praça Roosevelt}

Ação em andamento. Estão previstas demolições, recuperação e reforço estrutural, requalificação arquitetônica e paisagística (FIG. 110) (ALCALDE, 2010);
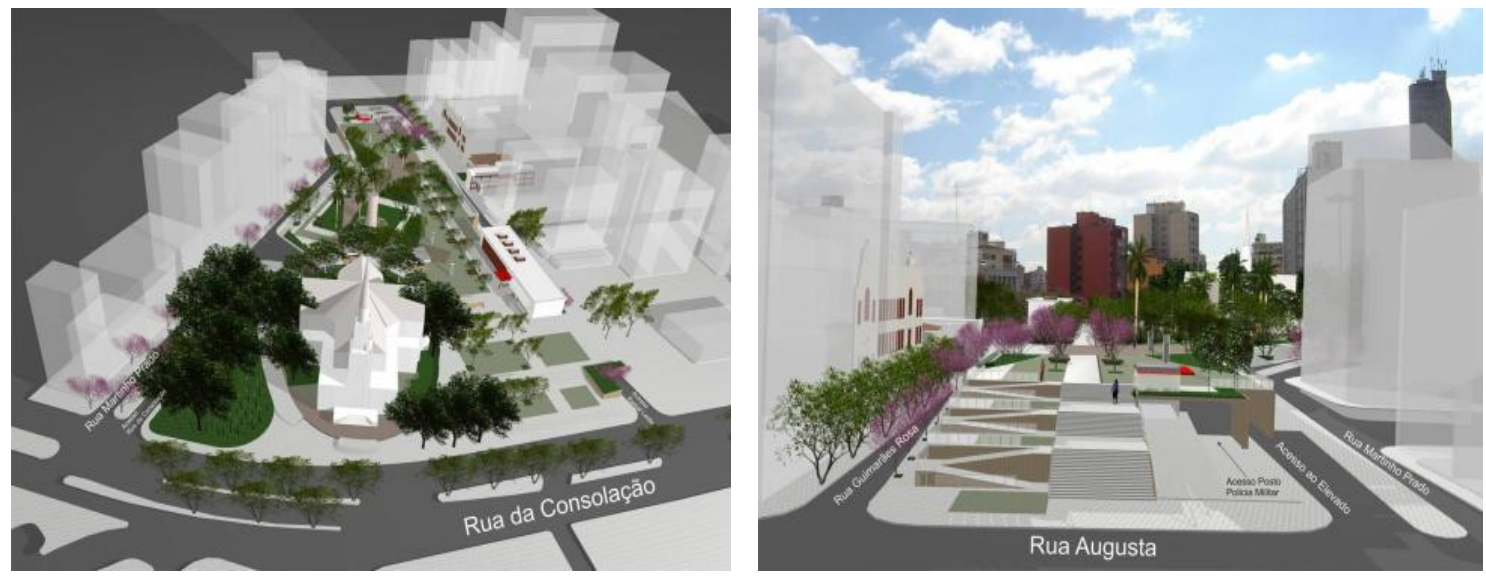

FIGURA 110. Reurbanização da Praça Roosevelt. Fonte: Procentro/Galeria de imagens. Disponível em: <http://www.procentro,com.br/site/Obra.aspx?ld=63>. Acesso em: 19 maio 2010.

\section{Reurbanização da Praça da Sé}

Criação de circulação transversal integrando espaços através de pontes metálicas sobre espelho d'água e fosso de ventilação do Metrô. Liberação dos acessos confinados do Metrô. Ampliação da área permeável de 8.754 para $9.804 \mathrm{~m}^{2}$ (acréscimo de 12\%). Relocação das esculturas. Incremento do mobiliário urbano. Redimensionamento da iluminação. Reestruturação e manutenção dos componentes 
vegetais. Plantação de novas 234 árvores (96 novas árvores na praça e 138 árvores no entorno, por compensação ambiental). Rebaixamento de jardineiras proporcionando maior visibilidade e segurança para os usuários. Implantação de rampas para portadores de deficiências físicas. Ação concluída em 2007 (FIG. 111) (SÃO PAULO [Cidade] -EMURB, 2004).
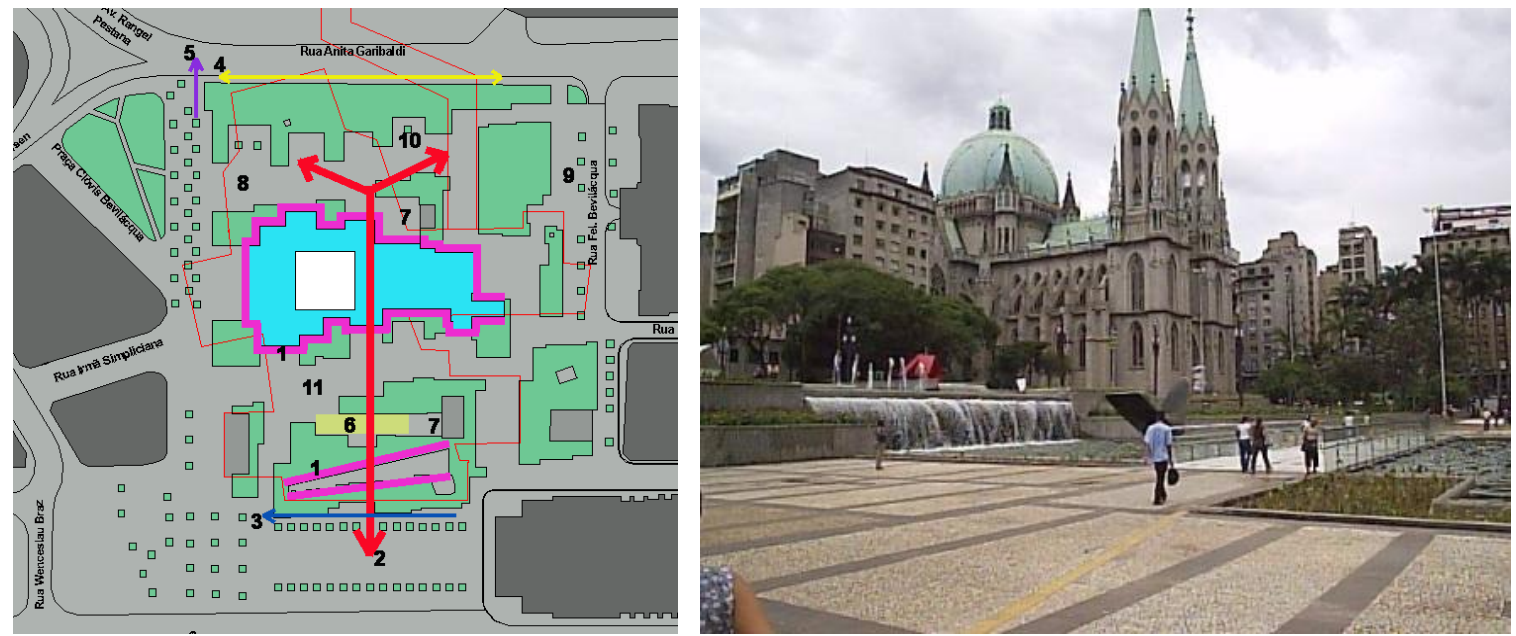

FIGURA 111. Praça da Sé - Análise e diagnóstico - Requalificação e instalação de ponte sobre o espelho d'água. Fontes: Fernando Chacel e Procentro/Galeria de imagens. Disponível em: $<$ http://www.procentro,com.br/site/Obra.aspx?ld=65\#>. Acesso em 19 maio 2010.

\section{Reurbanização da Praça da República}

Por se tratar de área tombada, as diretrizes do projeto foram determinadas pelo Departamento do Patrimônio Histórico (DPH). Resgate do traçado original. Manutenção integral dos bens paisagísticos de interesse histórico. Criação de novo sub-bosque compatível com o extrato arbóreo preservado. Resgate das características originais dos canteiros com remoção de muretas, reconstituição das orlas e sarjetas em elemento cerâmico, instalação de cerca baixa metálica em arco. Substituição do pavimento asfáltico dos caminhos por elemento cerâmico. Ajuste das interfaces entre a praça, passagem de pedestres e o prédio da Secretaria Estadual da Educação (antigo Colégio Caetano de Campos), resgatando o eixo entre a Rua do Arouche e a Rua 7 de Abril (FIG. 113). Reimplantação, recuperação e limpeza das esculturas. Restauração da impermeabilização do lago. Ação concluída em 2007 (FIG. 112 e 114) (SÃO PAULO [Cidade] - EMURB, 2005). 

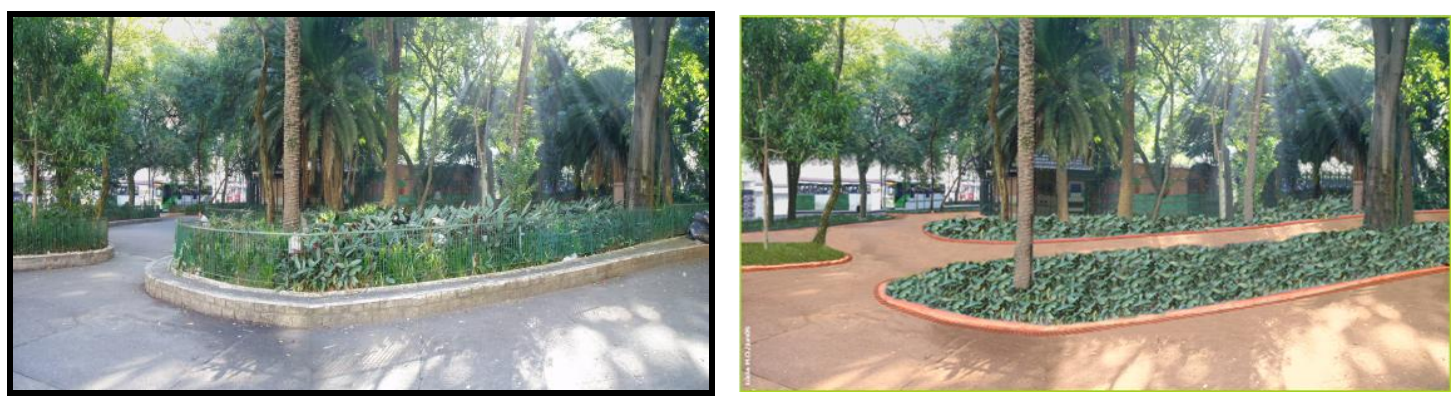

FIGURA 112. Resgate das características originais dos canteiros, remoção de muretas, reconstituição das orlas, sarjetas e substituição do pavimento por elemento cerâmico. Fonte: São Paulo [Cidade] EMURB, 2005.
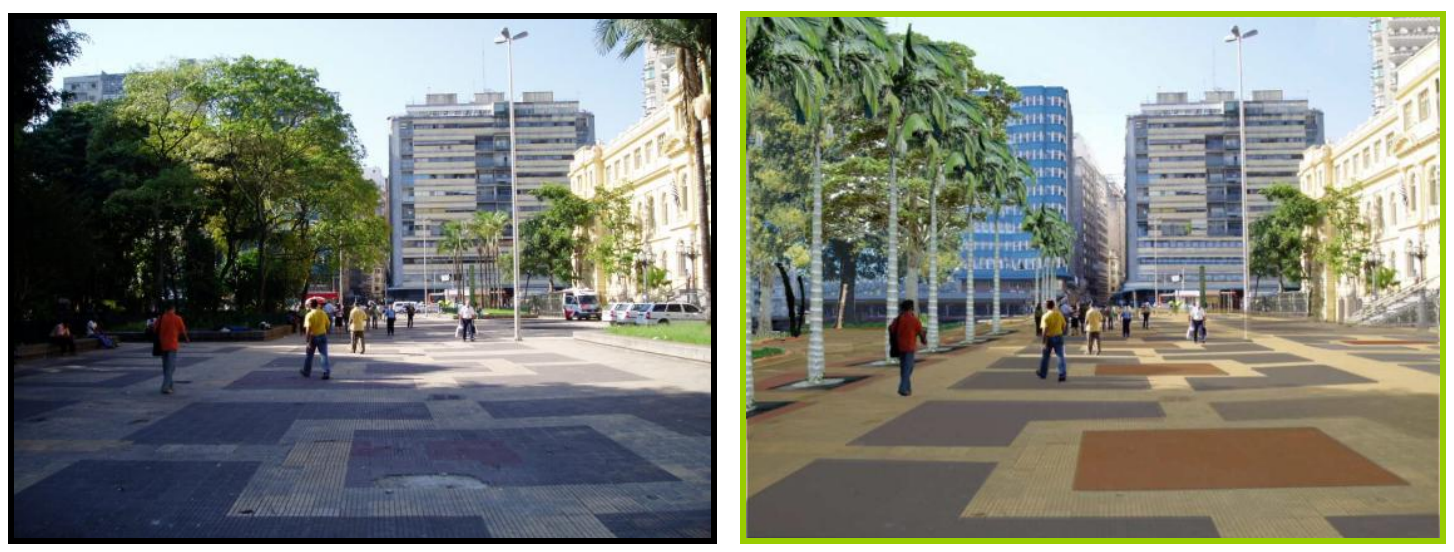

FIGURA 113. Resgate do eixo da Rua do Arouche com a 7 de Abril. Fonte: São Paulo [Cidade] EMURB, 2005.
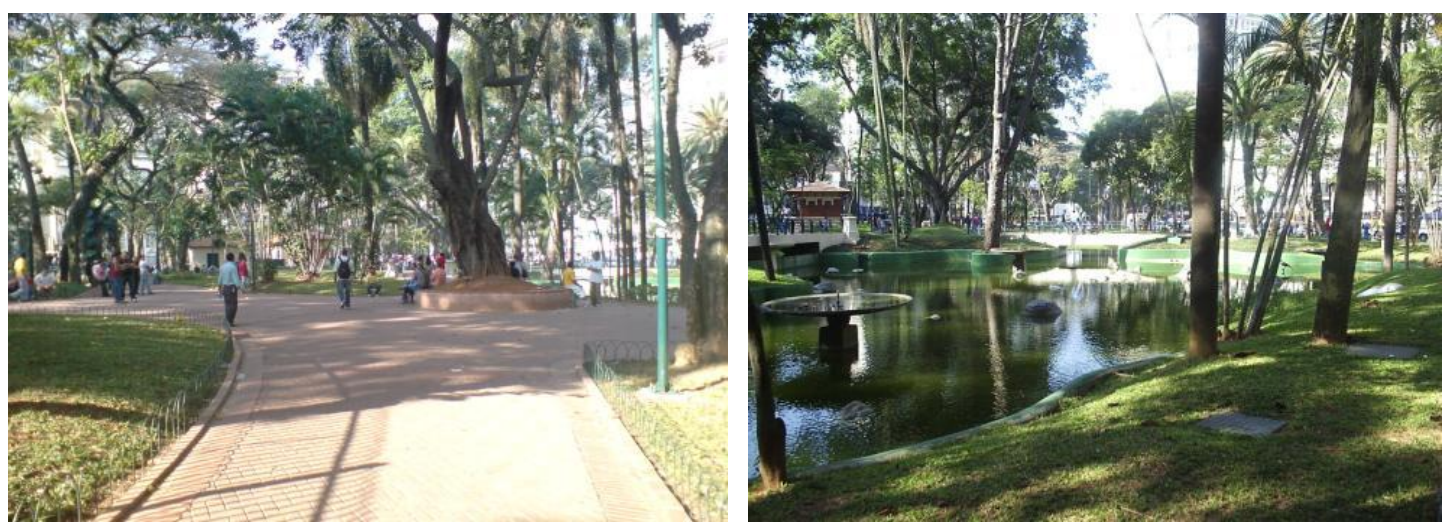

FIGURA 114. Reurbanização da Praça da República. Fonte: Procentro/Galeria de imagens. Disponível em: <http://www.procentro,com.br/site/Obra.aspx?ld=64\#>. Acesso em: 19 maio 2010. 


\section{Requalificação Urbana da Praça Dom José Gaspar}

Manutenção da característica original do bosque. Saneamento fitossanitário. Valorização das espécies remanescentes significativas. Introdução de 69 novas árvores. Melhoria da iluminação. Novo traçado dos passeios. Nova paginação do piso. Aumento da área permeável do solo e implantação de "poços" para aumentar o volume da captação de águas pluviais. Ação concluída em 2008 (FIG. 115) (SÃO PAULO [Cidade] - EMURB, 2004).
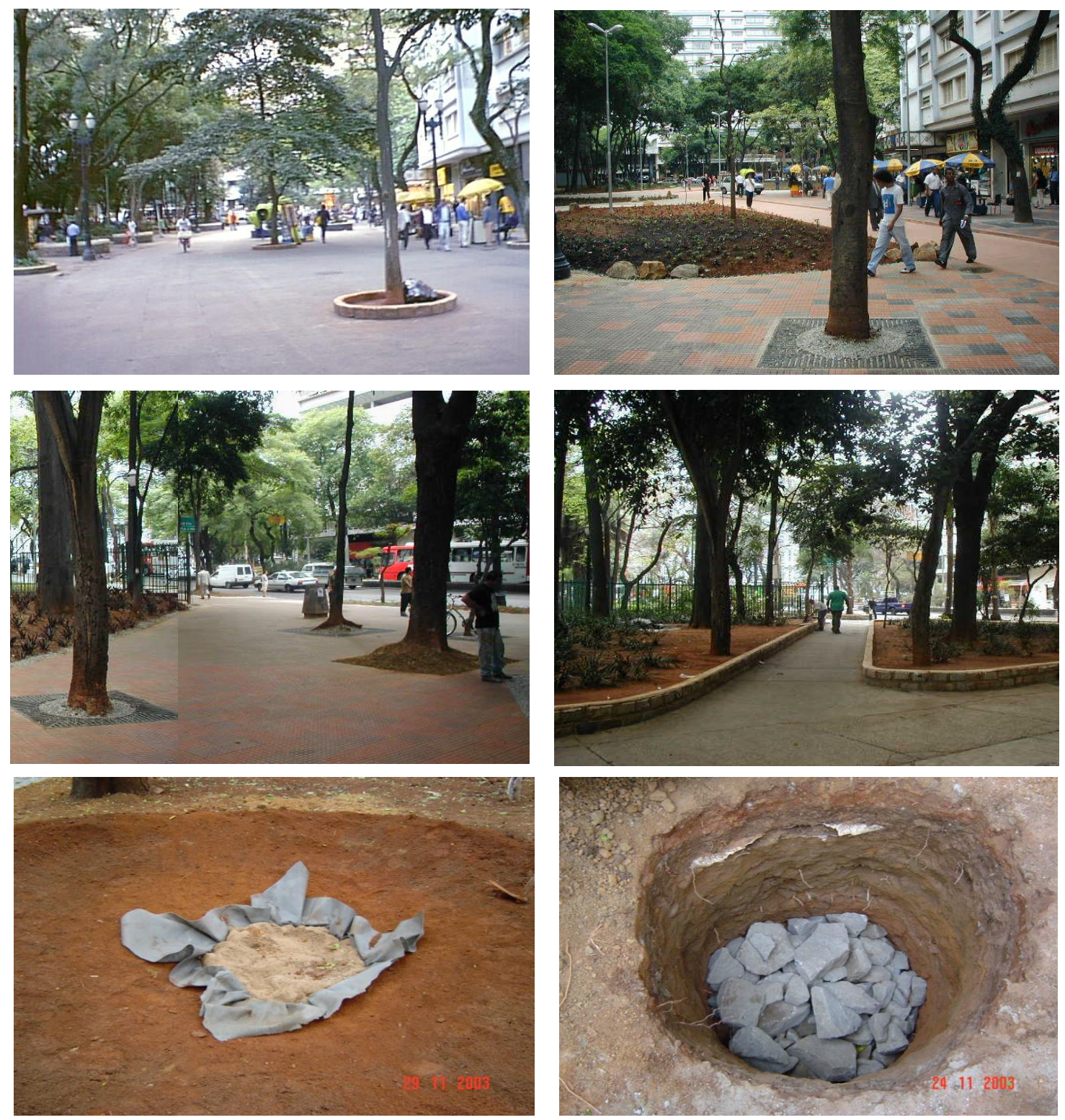

FIGURA 115. Reurbanização da Praça Dom José Gaspar, aumento da área permeável do solo, novo traçado dos passeios e nova paginação do piso. Fonte: SÃO PAULO [Cidade] - EMURB, 2004. 


\section{Requalificação do Mercado Municipal}

Instalação de mezzanino com $2.000 \mathrm{~m}^{2}$, dois elevadores e duas escadas rolantes. Refeitas instalações hidráulicas e elétricas. Ação concluída em 2004 pela Secretaria Municipal do Abastecimento (Semab) (FIG. 116) (RUBIES, 2010);

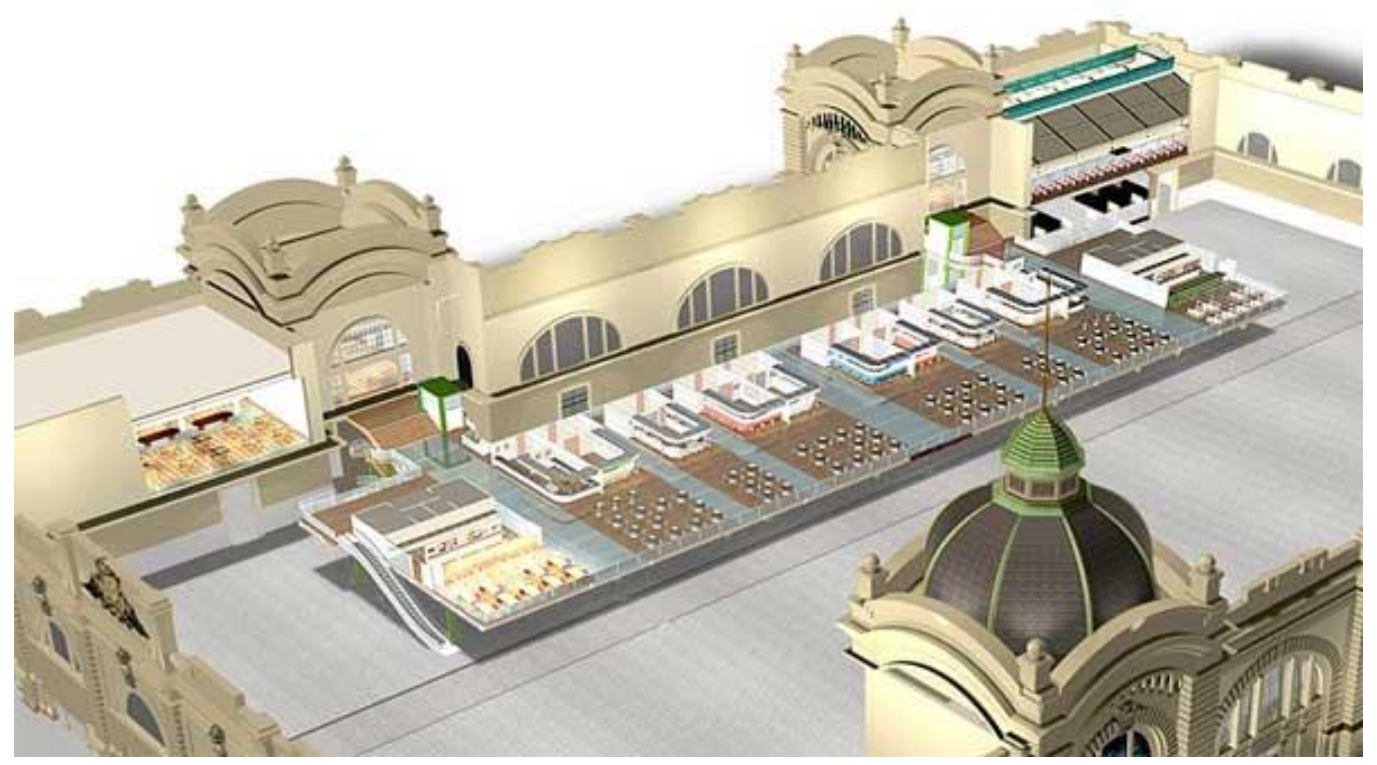

FIGURA 116. Requalificação do Mercado Municipal. Fonte: PPMS - Pedro Paulo de Mello Saraiva Arquitetos Associados S/C Ltda. Disponível em: <http://www.piratininga,org/mercado municipal.htm>. Acesso em: 23 maio 2010.

\section{Restauro do Theatro Municipal}

Recuperação das pinturas encontradas na intervenção realizada de 1987 a 1991 nas dependências do café e do antigo restaurante. Fixação das áreas com descolamento das pinturas artísticas (CALIL, 2010). Tratamento de fissuras e rachaduras. Restauro de piso de madeira, urdimento, esquadrias de madeira e de ferro, vitrais, fachadas, ornatos, cobertura e esculturas. Ação em andamento com término previsto por ocasião das festividades do centenário do Theatro Municipal em 12 de setembro de 2011 (FIG. 117) (JAHA, 2009/2010). 

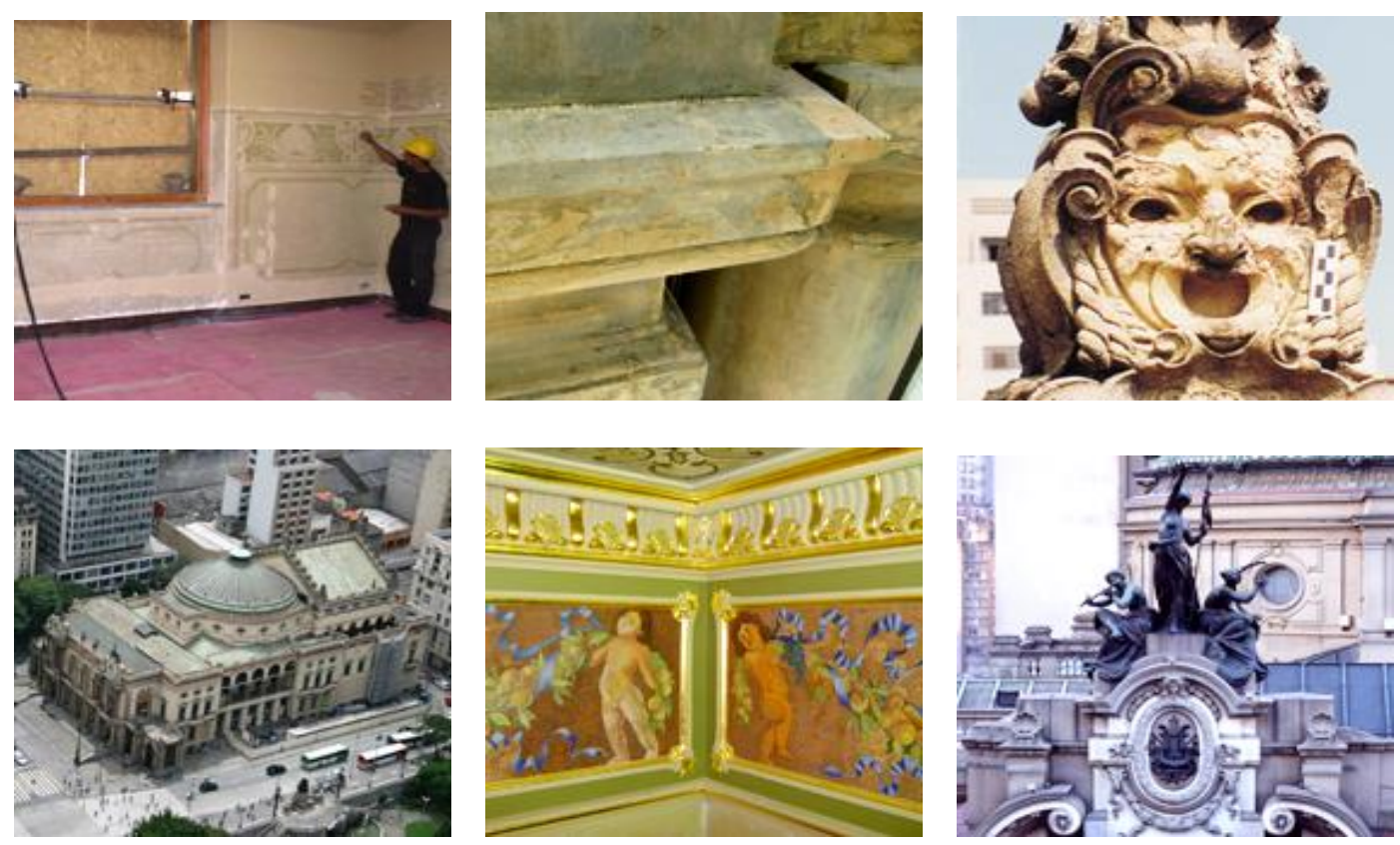

FIGURA 117. Recuperação do Theatro Municipal. Fonte: JAHA, 2009/2010. Disponível em: $<$ http://www.prefeitura.sp.gov.br/cidade/secretarias/cultura/teatromunicipal/notícias $>$. Acesso em: 23 maio 2010.

\section{Recuperação da Casa no 1 e do Beco do Pinto}

Ação em andamento com previsão para término em 2010 (FIG.118) (PROCENTRO, 2010);
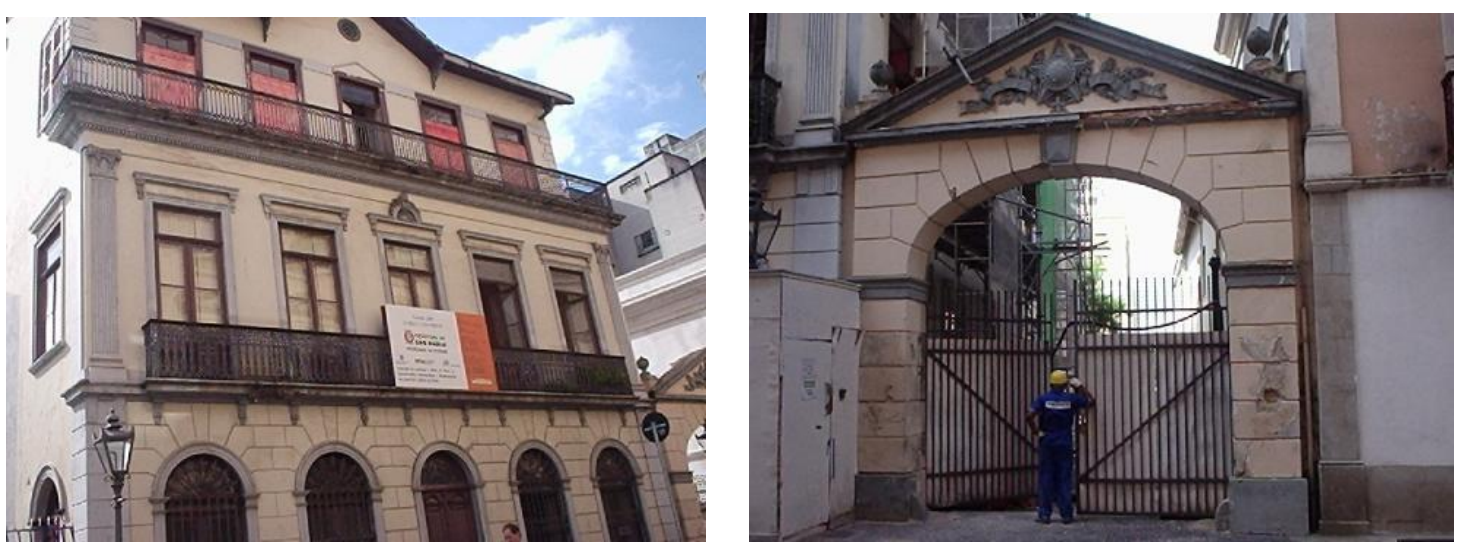

FIGURA 118. Recuperação da Casa oำ e do Beco do Pinto. Fonte: Procentro/Galeria de imagens. Disponível em: <http://www.procentro,com.br/site/Obra.aspx?ld=78\#>. Acesso em: 19 maio 2010.

\section{Reforma da Biblioteca Mário de Andrade}

Ampliação das instalações. Modernização das instalações elétricas. Tratamento dos vidros para filtragem de raios solares. Incorporação das instalações do antigo prédio do Instituto de Pagamentos Especiais de São Paulo (Ipesp), situado 
na Rua Bráulio Gomes nํ 139, onde será alocada a Coleção de Periódicos, com 2,8 milhões de fascículos (FIG. 120). Ação concluída em 21 de julho de 2010 (FIG. 119) (CALIL, 2010).
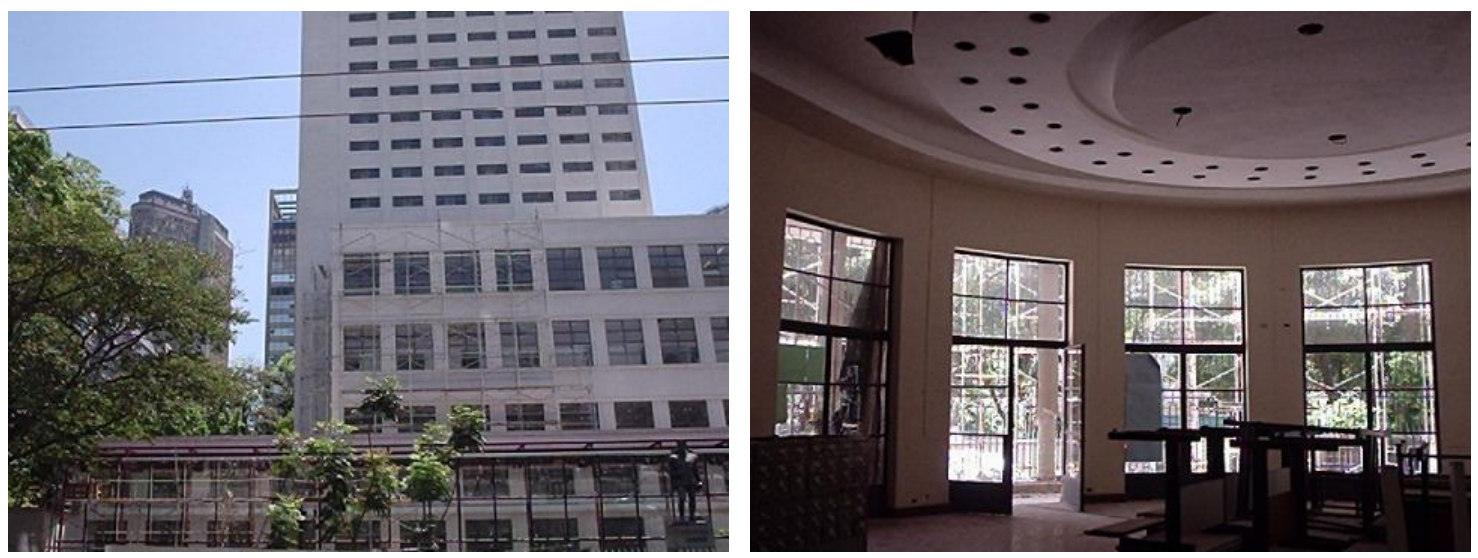

FIGURA 119. Recuperação da Biblioteca Mário de Andrade. Fonte: Procentro/Galeria de imagens. Disponível em: <http://www.procentro,com.br/site/Obra.aspx?ld=79\#>.Acesso em 19 maio 2010.

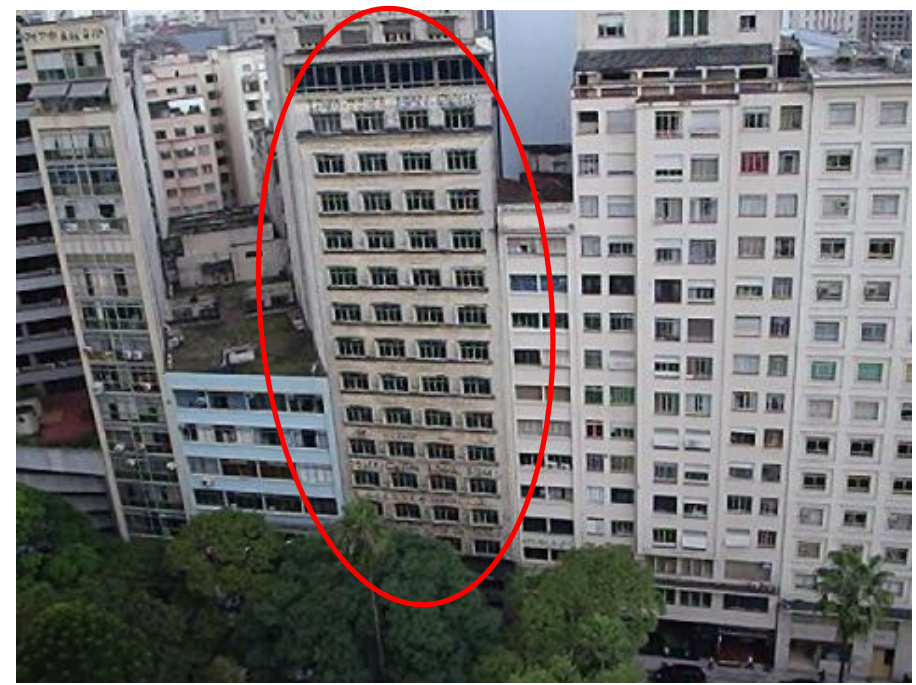

FIGURA 120. Incorporação do antigo prédio do Ipesp como anexo da biblioteca. Fonte: Procentro/Galeria de imagens.

Disponível em: <http://www.procentro,com.br/site/Obra.aspx?ld=76\#>. Acesso em: 19 maio 2010.

\section{Recuperação do Solar da Marquesa}

Situado na Rua Roberto Simonsen № 136A. Recuperação de pinturas decorativas do forro de madeira. Escavação arqueológica com posterior análise de objetos dos séculos XVIII e XIX. Ação em andamento com previsão de término para 2010 (FIG.121) (CALIL, 2010). 

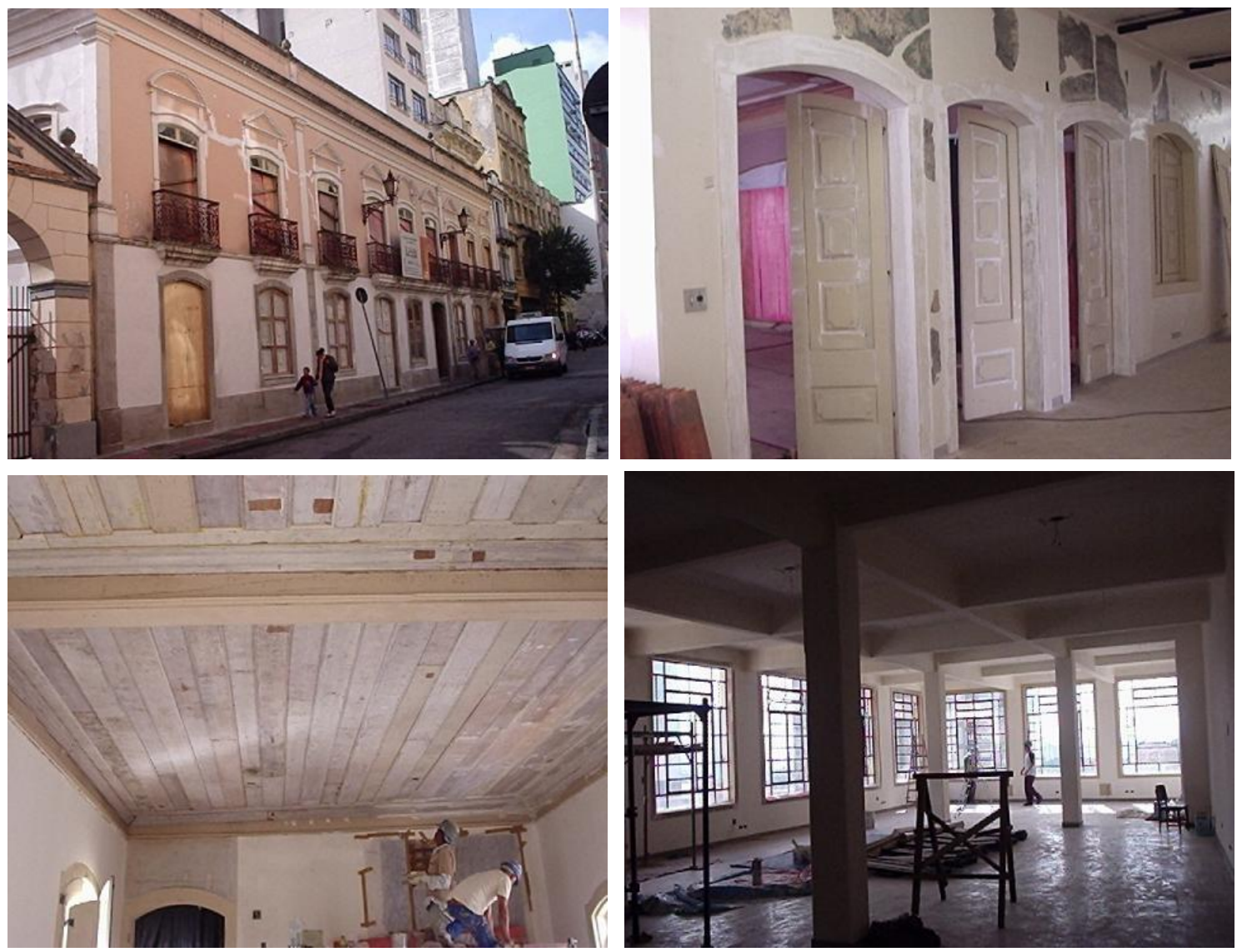

FIGURA 121. Recuperação do Solar da Marquesa. Fonte: Procentro/Galeria de imagens. Disponível em: <http://www.procentro,com.br/site/Obra.aspx?ld=83\#>. Acesso em: 19 maio 2010.

\section{Praça das Artes}

Ação em andamento, situada na esquina do Vale do Anhangabaú com a Avenida São João, compreende a construção e adequação de edifícios para as Escolas Municipais de Música e Dança, Orquestras Sinfônica Municipal e Experimental de Repertório, Centro de Documentação Artística e Museu do Theatro (FIG. 122 e 123). 

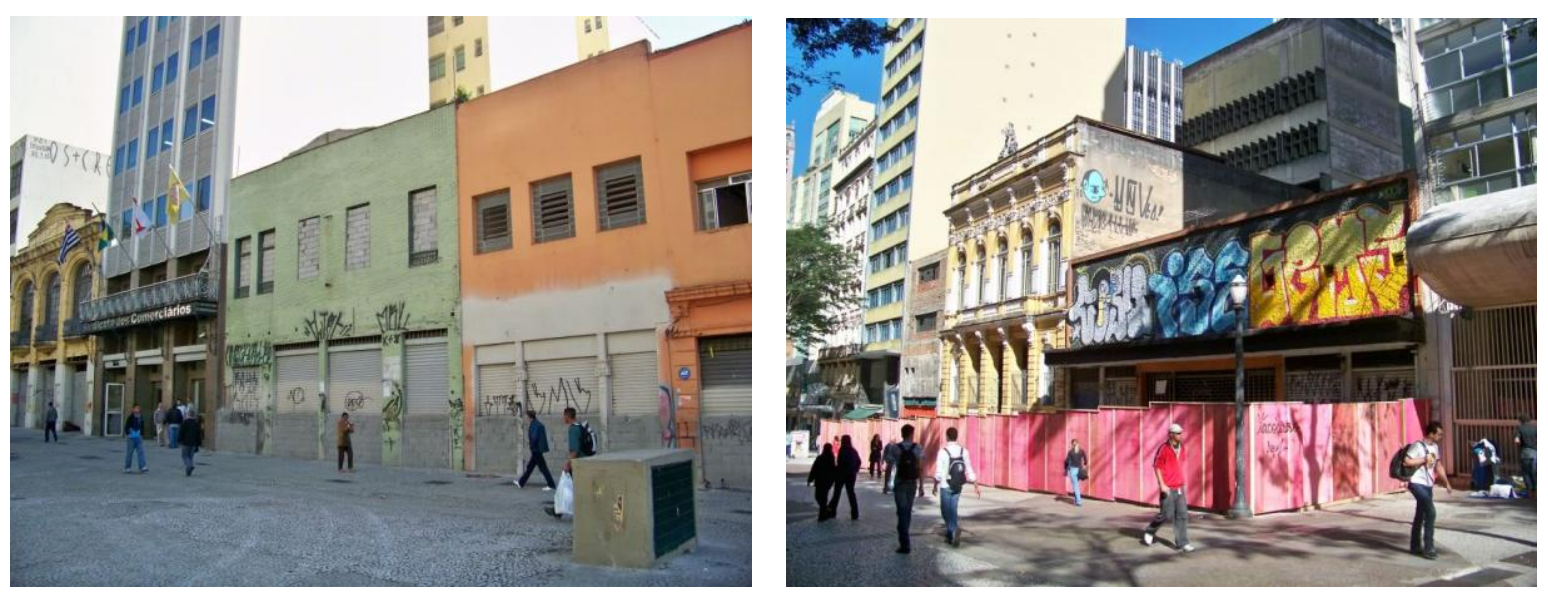

FIGURA 122. Fachadas do Vale do Anhangabaú e Avenida São João referentes ao período de início das obras da Praça das Artes. Disponível em:

<http://www.skyscrapercity.com/showthread.php?t=910554>. Acesso em: 20 set. 2010.
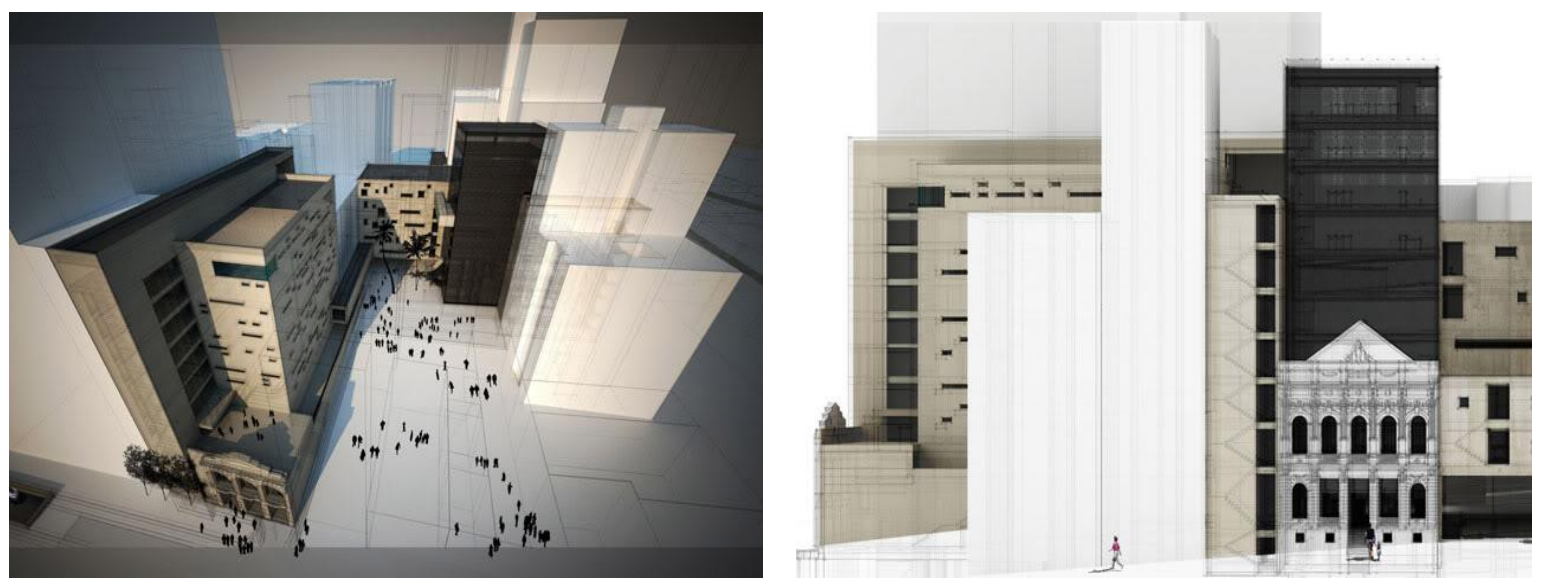

FIGURA 123. Maquetes do projeto da Praça das Artes com vistas do Vale do Anhangabaú e Avenida São João. Disponível em: <http://www.skyscrapercity.com/showthread.php?t=910554>. Acesso em: 20 set. 2010.

\section{Demolição dos Edifícios S. Vito, Mercúrio e Francisco Herrerias}

Ação em andamento que consiste na demolição dos imóveis localizados no quarteirão formado pelas Avenidas do Estado e Mercúrio e pelas Ruas Carlos Garcia e Luis de Camões (FIG. 124).

Tais demolições serão realizadas manualmente para que não seja comprometida a integridade dos 32 vitrais do Mercado Municipal, que fica localizado do outro lado da Avenida do Estado.

No terreno será construído um parque com $5.400 \mathrm{~m}^{2}$, interligado ao parque do Palácio das Indústrias, já existente. 


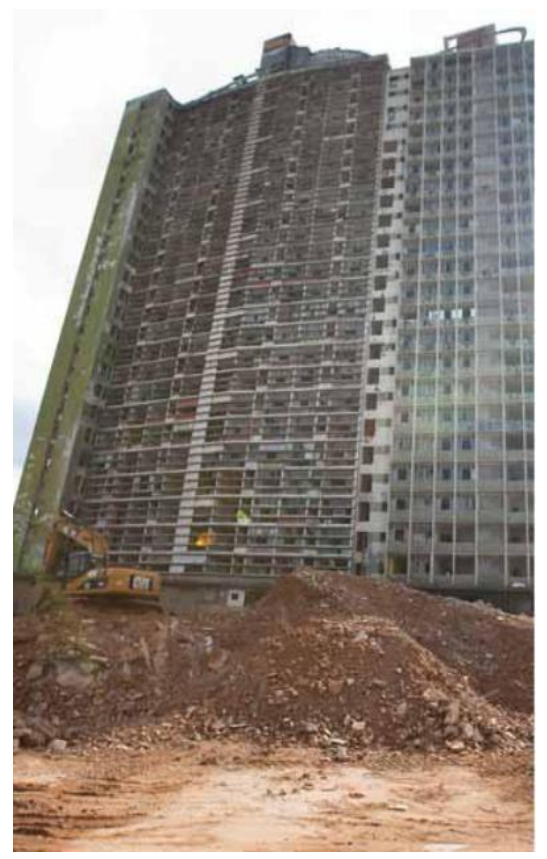

FIGURA 124. Edifícios S. Vito, Mercúrio e Francisco Herrerias. Fonte: André Porto/Metrô. Disponível em: http://www.band.com.br/jornalismo/cidades/conteudo.asp?ID=1000000343960. Acesso em: 10 set. 2010.

\section{Análise das ações de revitalização}

As ações de revitalização previstas no programa Procentro promovem mais moradias para o centro, recuperação do ambiente urbano e requalificação de edifícios utilizando o conceito de reuso da estrutura das edificações que atendem ao conceito de sustentabilidade e não agravam o problema da temperatura ambiente com novas construções.

São ações realizadas com objetivo de atrair novos moradores. Atrair frequentadores à procura de lazer, cultura e comércio. Incentivar a instalação de empresas não poluidoras, resgatando postos de trabalho perdidos pela desindustrialização do centro promovida a partir de 1960.

Contudo, tais ações implicam no aumento do número de veículos automotores para esta região e elevação da poluição, sendo necessária a implantação das ações de controle da poluição que integram o programa.

Para melhorar a qualidade de vida e diminuir os teores de poluição (que colaboram para a elevação da temperatura ambiente), o programa deve implantar a programação prevista de aumento de áreas verdes. 
Os cálculos das áreas verdes devem considerar densidade demográfica de 420 habitantes por hectare (índice que permite o aproveitamento máximo da infraestrutura instalada sem comprometer o meio ambiente, conforme estudos de 1996) e $12 \mathrm{~m}^{2}$ de área verde por habitante (recomendação da OMS).

Para não haver elevação da temperatura ambiente noturna, o projeto Nova Luz deve limitar as construções civis previstas a quatro pavimentos. 


\section{APÊNDICE E - Ações de drenagem do Procentro}

As ações referentes à drenagem da região central, promovidas pelo programa Procentro, estão concentradas no controle das inundações do Vale do Anhangabaú (FIG. 125) e da Avenida Nove de Julho (FIG. 126).

Estas inundações são provocadas pelo Córrego Anhangabaú (canalizado sob o Vale do Anhangabaú e Avenida Tiradentes), que deságua no Rio Tamanduateí. Este córrego é formado pelo encontro das vazões dos Córregos Saracura (canalizado sob a Avenida Nove de Julho), Bixiga (canalizado sob as Ruas Humaitá e Japurá) e Itororó (canalizado sob a Avenida 23 de Maio) (FIG. 128).

O programa Procentro prevê a recuperação das galerias dos córregos Saracura e Bixiga sob a Avenida Nove de Julho e a construção de reservatórios de captação de águas pluviais (piscinões) na Praça 14 Bis (FIG. 126 a 128). Ação em andamento (HIDROSTUDIO ENG, 2004).

Como o sistema de captação do Córrego Itororó possui $40 \%$ da capacidade da demanda e parte da sua vazão deságua na galeria do Córrego do Moringuinho (FIG. 128), está previsto, para os $800 \mathrm{~m}$ de canalização do Córrego do Moringuinho, aumento da capacidade de vazão de 8 para $17 \mathrm{~m} 3 / \mathrm{s}$. Este acréscimo de vazão será alcançado com a construção de duas galerias: uma de $150 \mathrm{~m}$ de comprimento, $2 \mathrm{~m}$ de largura por $2 \mathrm{~m}$ de altura, sob a Avenida 23 de Maio, entre os Viadutos Jaceguai e Dona Paulina, e outra de $250 \mathrm{~m}$ de comprimento, 2,50 m de largura por $2 \mathrm{~m}$ de altura, ampliando a capacidade da galeria existente sob a Rua dos Estudantes (de 1,60 m por 1,90 m), da Rua Tomás de Lima até as proximidades do Rio Tamanduateí.

Estas ampliações têm por objetivo desviar 15\% da vazão do Córrego Itororó do Vale do Anhangabaú. Ação concluída em 2009 (SÃO PAULO [Cidade] CENTROSP, 2007).

Serão construídos reservatórios de captação de águas pluviais (piscinões) na Praça da Bandeira (capacidade de 46.000 m³$^{3}$ ) (FIG. 127 e 128). Ação em andamento (HIDROSTUDIO ENG, 2004). 

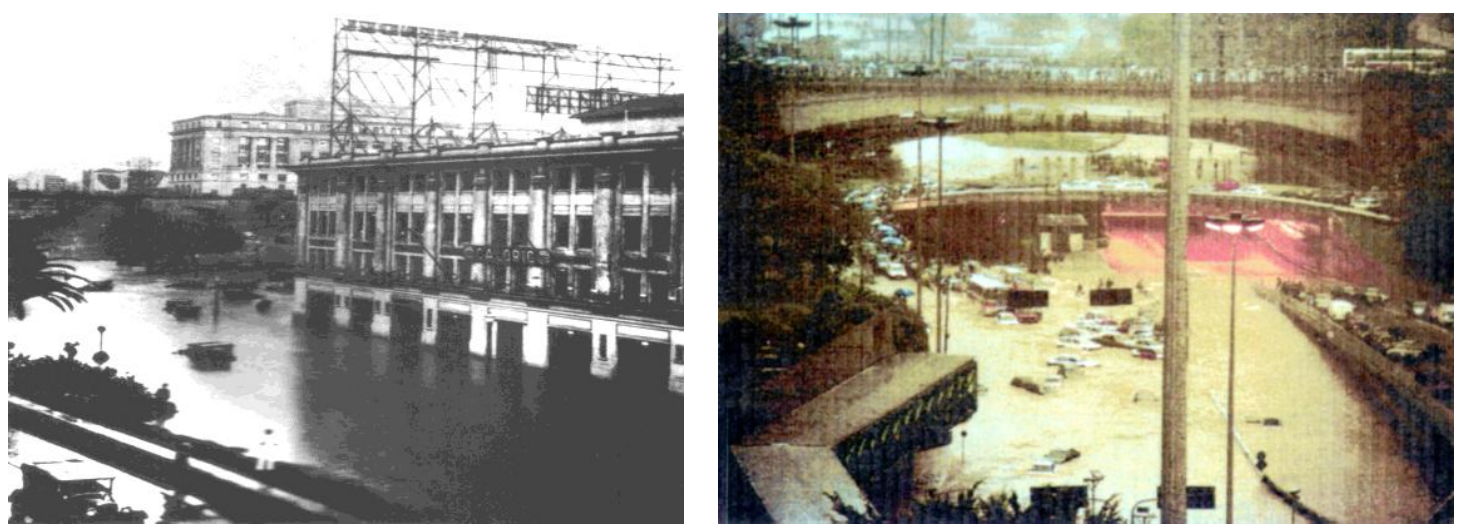

FIGURA 125- Inundações do Vale do Anhangabaú, 1929 e 1999. Fonte: Hidrostudio Engenharia.
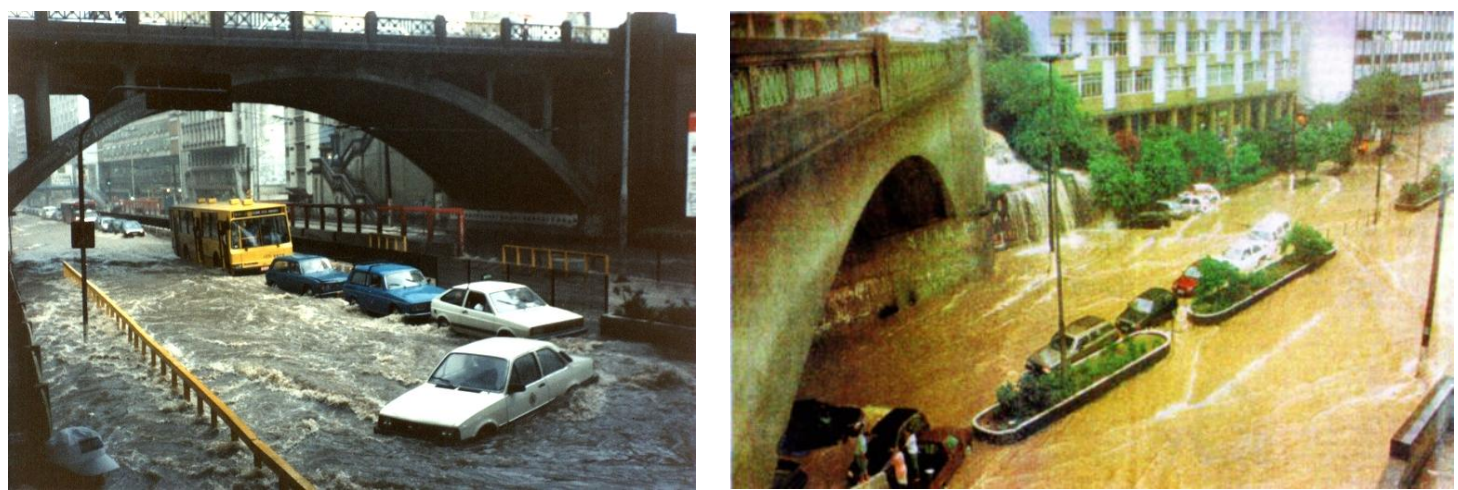

FIGURA 126. Inundações da Avenida Nove de Julho. Fonte: Hidrostudio Engenharia.
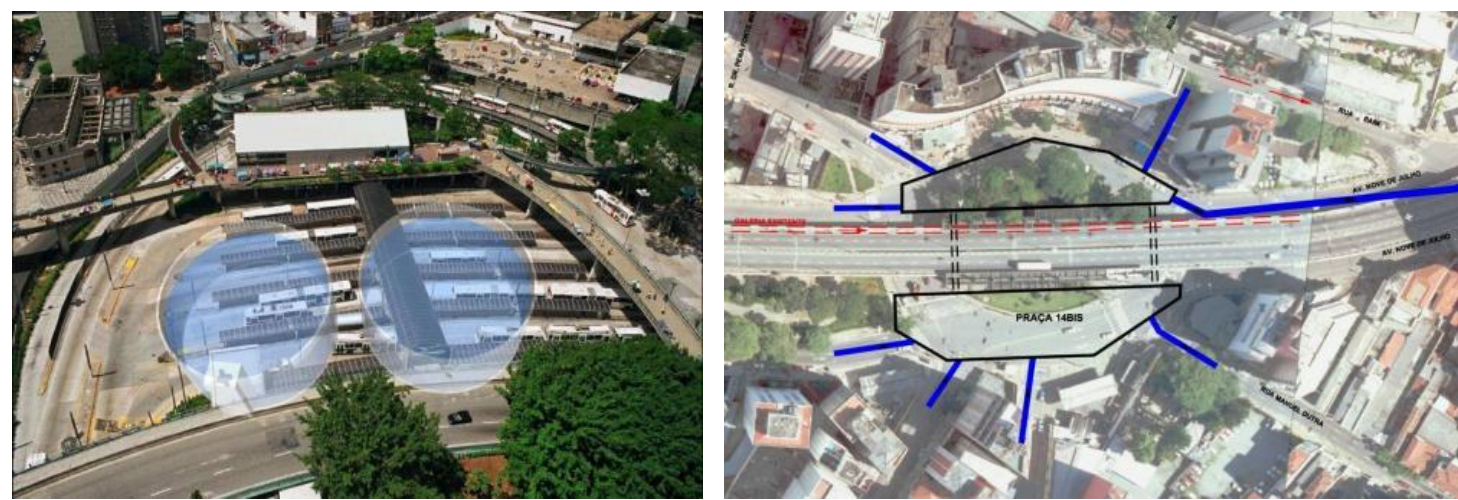

FIGURA 127. Reservatórios de retenção de enchentes na Praça da Bandeira e Praça 14 Bis. Fonte: Procentro/Galeria de imagens. Disponível em:

<http://www.procentro,com.br/site/Obra.aspx?ld=87\#>. Acesso em 19 maio 2010, 


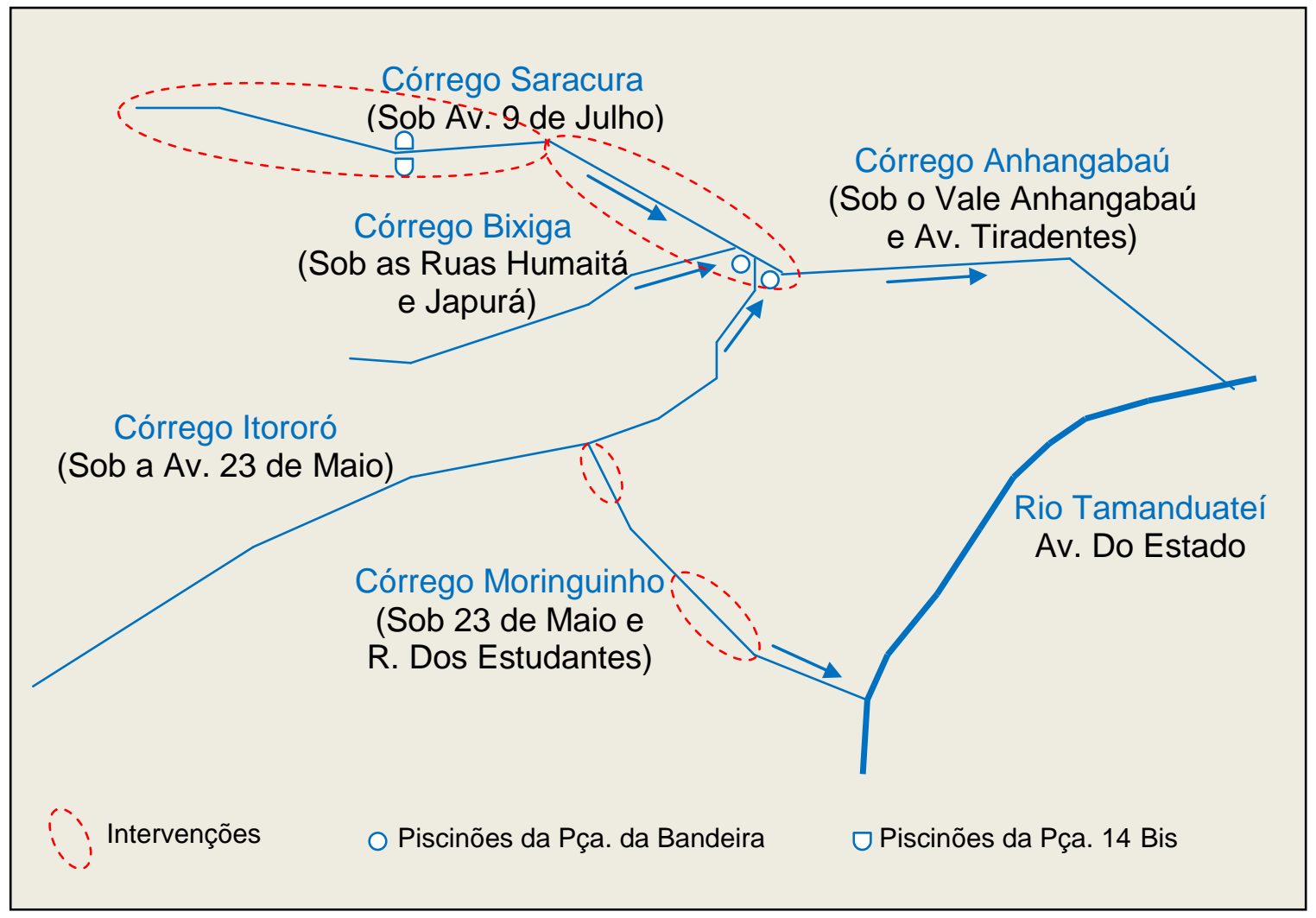

FIGURA 128. Córregos Saracura, Itororó, Bixiga, Moringuinho e Anhangabaú, intervenções no Córrego Moringuinho e Saracura, reservatórios de retenção de enchentes na Praça da Bandeira e Praça 14 Bis. Fonte: Adaptado de Procentro/Galeria de imagens e Hidrostudio Engenharia.

\section{Análise das ações de drenagem}

As ações de drenagem do Procentro não apresentam como objetivos a preservação do meio ambiente ou a elevação da permeabilidade do solo. Têm como meta eliminar as enchentes do Vale do Anhangabaú, que trazem inúmeros transtornos para a população. 


\section{APÊNDICE F - Ações de controle da poluição do ar do Procentro}

\section{Arborização de vias públicas}

No Procentro está prevista a implantação do Plano Diretor de Arborização de Vias Públicas, com a identificação das espécies existentes, levantamento da situação fitossanitária e arborização dos distritos Sé e República. Ação em andamento.

Entre os projetos em andamento estão o plano de arborização das ruas da Nova Luz. O plano inclui projeto paisagístico com plantação de 154 árvores nas Ruas General Osório e Vitória (FIG. 129).

Inclui ainda, dentro da requalificação da Avenida Duque de Caxias, Rua Mauá, Avenida Cásper Líbero, Praça Alfredo Issa, Ruas General Couto de Magalhães e dos Protestantes, plantação de 158 novas árvores (FIG. 130) SÃO PAULO [Cidade] - EMURB, 2009).

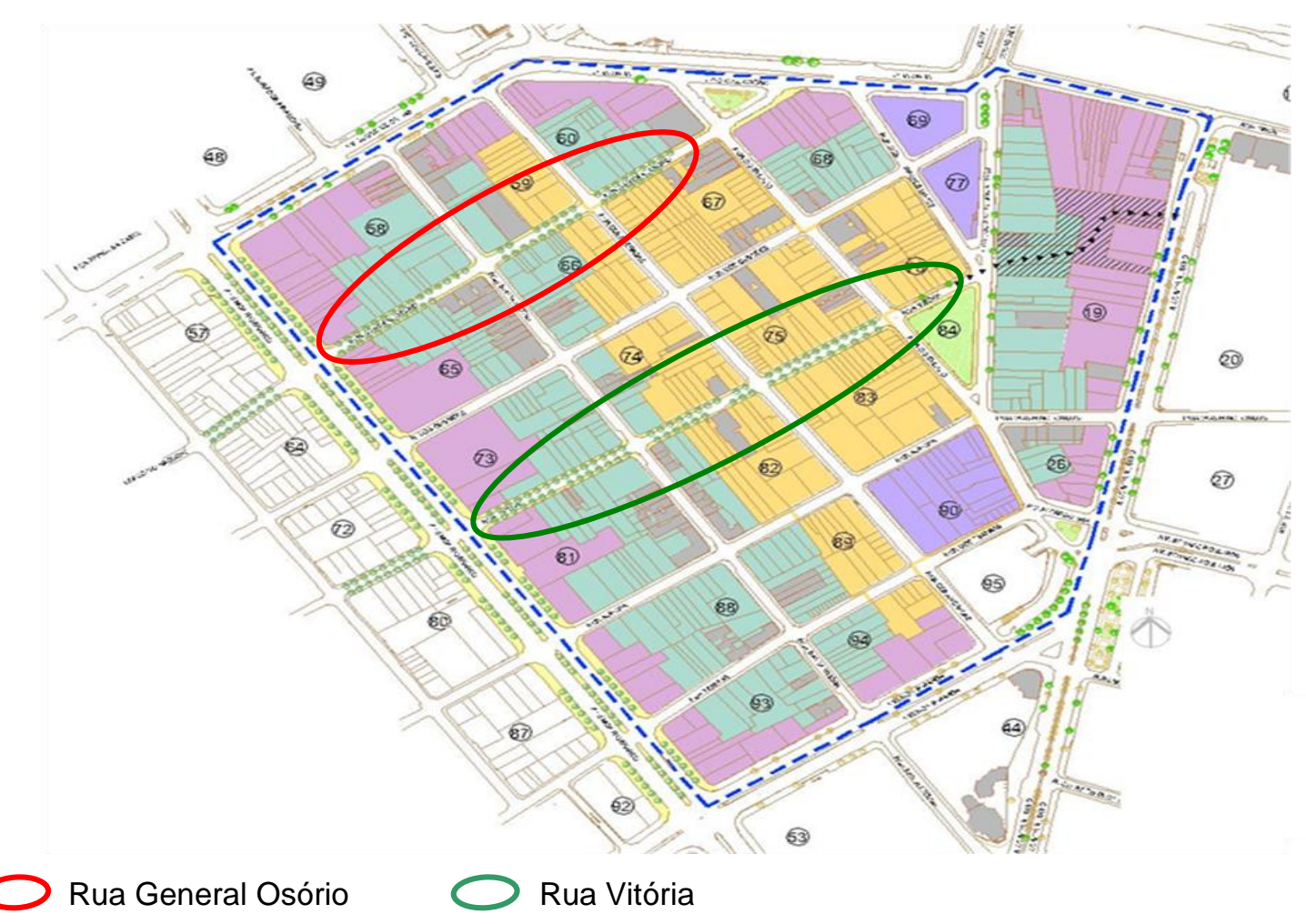

FIGURA 129. Requalificação das ruas da Nova Luz. Fonte: São Paulo [Cidade] - EMURB, 2009. 


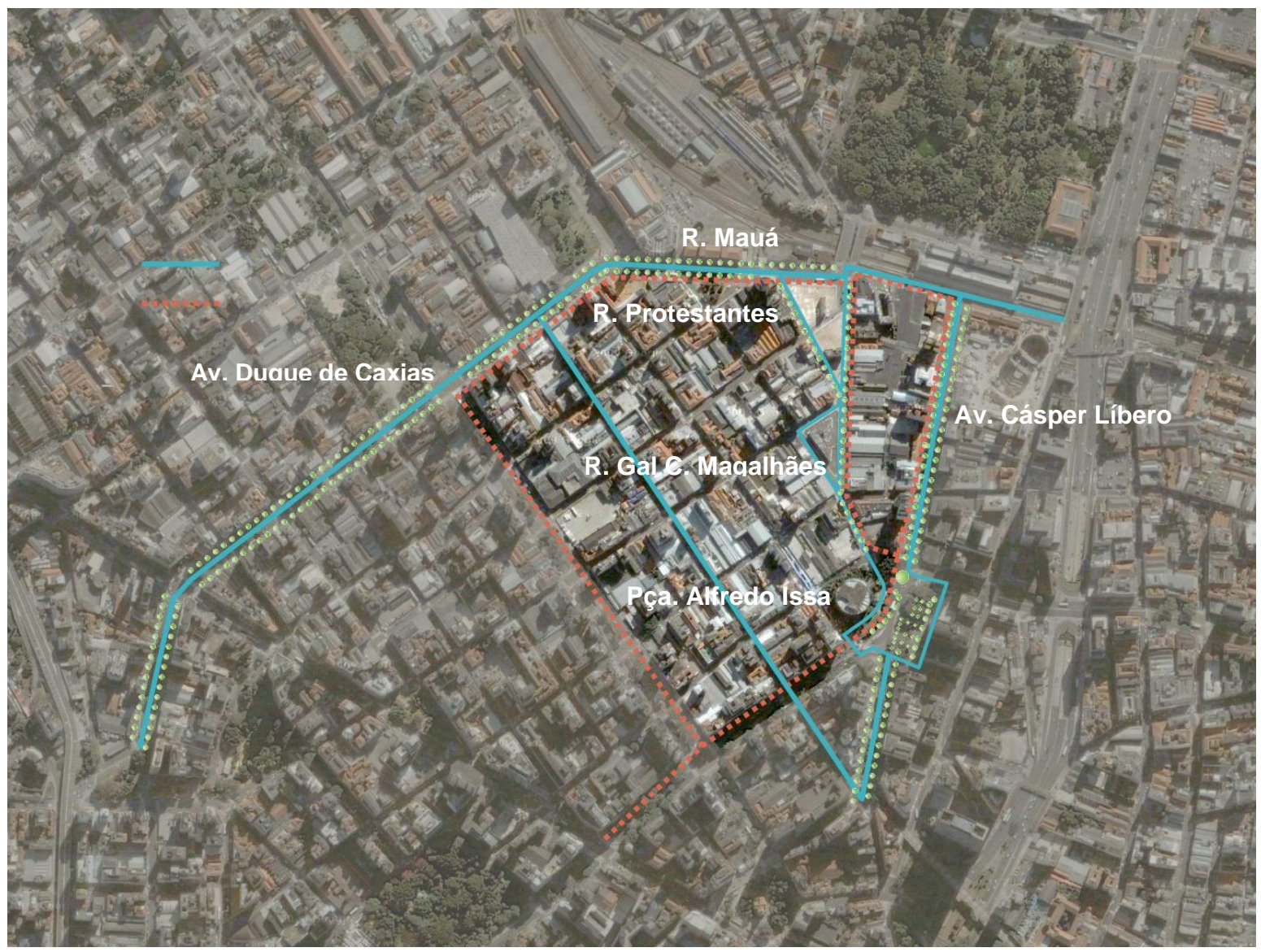

- Novas árvores - Vala técnica — Ruas abrangidas

FIGURA 130. Requalificação dos espaços públicos. Fonte: São Paulo [Cidade] - EMURB, 2009.

\section{Rótula e contrarrótula}

Ação ainda não implantada que tem por objetivo a introdução de melhorias nas operações de trânsito na área central. Prevê a substituição do controle de transporte limitado à fiscalização pela operação de trânsito assistida (SCARINGELLA, 2001).

Este sistema possibilita intervenção e correção dos problemas operacionais em tempo real e aumento da velocidade média dos veículos no centro em $20 \%$.

O projeto consiste da implantação do SIM, composto por controle centralizado de semáforos, câmeras de circuito fechado de televisão, painéis de mensagens variáveis e estação de coleta de dados na rótula e contrarrótula. 
A rótula é o anel interno ao conjunto dos distritos Sé e República, com circulação de veículos no sentido anti-horário, formado pelas Avenidas Senador Queiroz, Ipiranga, São Luís, Viaduto Maria Paula, Praça João Mendes, Avenidas Rangel Pestana e Mercúrio (FIG.131).

Contrarrótula é o anel formado pelo perímetro externo do conjunto dos distritos Sé e República, com circulação de veículos no sentido horário, constituído pelas Ruas Ribeiro de Lima, João Teodoro, Avenida do Estado, Ruas Teixeira Leite, Barão de Iguape, Condessa de São Joaquim, Elevado Costa e Silva, Avenidas Amaral Gurgel, Duque de Caxias, Ruas Mauá e Prates (FIG. 131) (PROCENTRO, 2010).

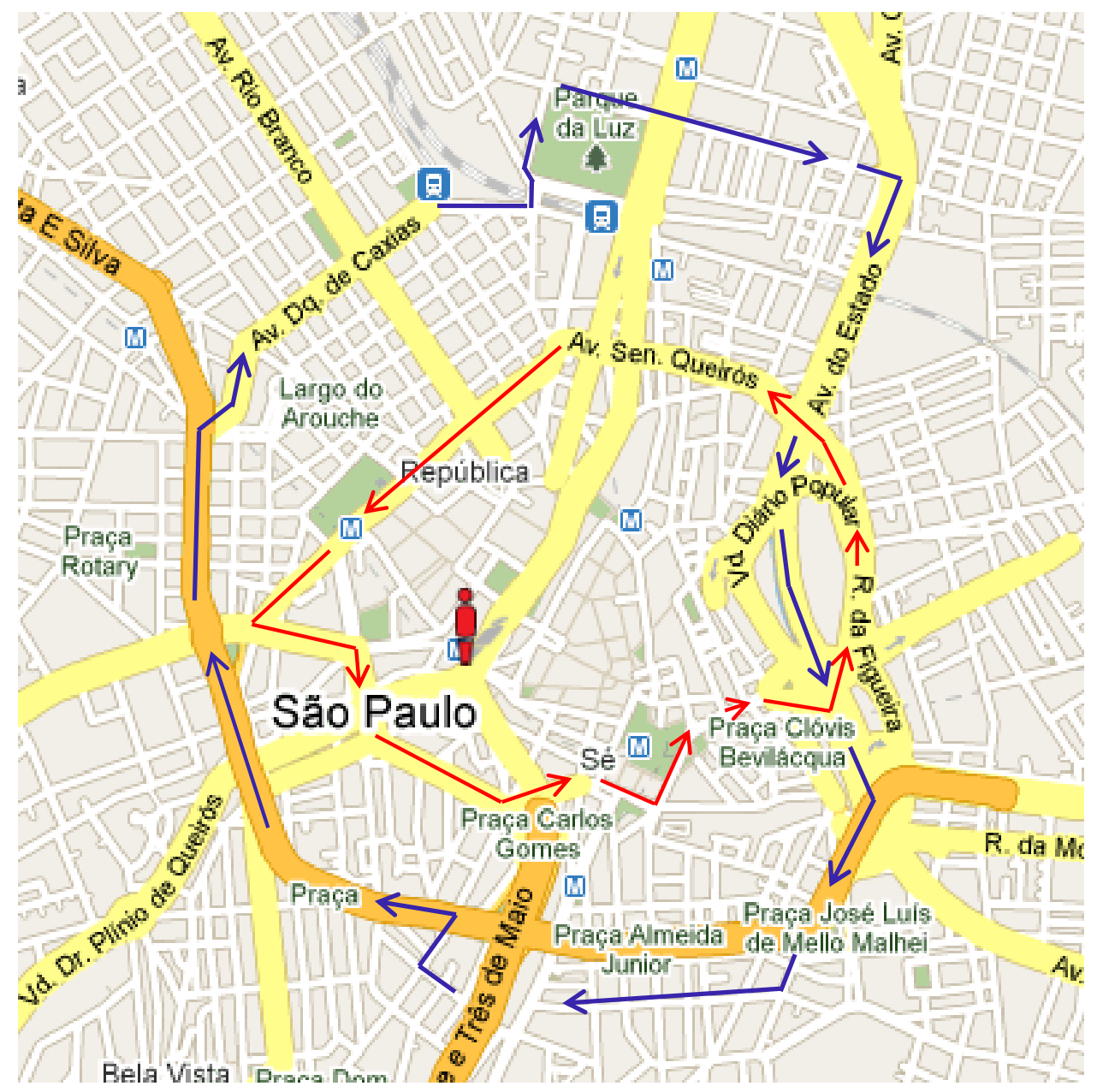

_ Rótula (Fluxo no sentido anti-horário)

- Contrarrótula (Fluxo no sentido horário)

FIGURA 131. Circuitos da rótula e da contrarrótula na região central da cidade de São Paulo. Fonte: Adaptado de Guiamais. Disponível em: <http://mapas.guiamais.com.br/>. 


\section{Terminal de compras}

Ação não iniciada. Consiste na implantação de terminal para ônibus provenientes de outras cidades, cujos ocupantes se destinam ao setor de compras do centro.

Este terminal se localizará na região da foz do Rio Tamanduateí, junto à Avenida do Estado, diminuindo o número de ônibus que cruzam o centro e fazendo com que o acesso dos compradores que vêm de outras cidades seja realizado através da rede de transporte coletivo do Metrô.

\section{Centrais de triagem}

Das três centrais de triagem de material reciclável previstas na Subprefeitura da Sé está em operação somente a da Avenida do Estado № 300, distrito Bom Retiro, que comercializa 12 t de materiais recicláveis por mês.

Dos três locais previstos para entrega voluntária de volumes com capacidade de até um metro cúbico, somente está em operação o ecoponto dos baixos do Viaduto Glicério.

\section{Análise das ações de controle da poluição do ar}

As ações de controle da poluição do ar do Procentro têm por objetivo desviar o tráfego de veículos automotores da região central, aumentar a área verde e o percentual de resíduos recicláveis.

Para melhorar a qualidade de vida e diminuir os teores de poluição (que colaboram para a elevação da temperatura ambiente) deve ser implantada a programação prevista de aumento de áreas verdes, desvio dos veículos do centro e implantação das centrais de triagem.

Tais medidas são necessárias uma vez que o processo de revitalização do Procentro aumentará a quantidade de veículos que se dirigirá ao centro e elevará os índices de poluição. 


\section{REFERÊNCIAS BIBLIOGRÁFICAS}

ABASCAL, E.H.S. São Paulo e a cidade do México: espaço e transformações econômico-sociais, um enfoque comparativo. Disponível em: <http://www.vitruvius.com.br>. Acesso em: 15 maio 2008.

ALCALDE, L. Revitalização. Após 4 anos, sai edital da Roosevelt. Jornal da Tarde, São Paulo, 13 jan. 2010.

AMBIENTEBRASIL. Energia eólica. Disponível em: $<$ http://www.ambientebrasil.com.br>. Acesso em: 16 nov. 2007.

ARAUJO, M. de F.I. Reestruturação produtiva e transformações econômicas, região metropolitana de São Paulo. São Paulo em perspectiva, v. 15, n. 1, p. 20 - 30, 2001.

BAENINGER, R. São Paulo e suas migrações no final do século XX. São Paulo em perspectiva, v. 19, n. 3, p. $84-96,2005$.

BIDONE, E.D. Relatório de avaliação ambiental. Programa de reabilitação da área central de São Paulo - RAA. São Paulo: Emurb, 2003. Versão preliminar.

BOAVENTURA, M. Política e planejamento dos resíduos sólidos. In: ENCONTRO TÉCNICO: resíduos sólidos e meio ambiente no Estado de São Paulo, 10-11 nov. 1992, São Paulo.

CALIL, T. Obras sem fim. Diário de São Paulo, 19 maio 2010.

CAMPOS, A. et al. Prevenção e controle de risco em máquinas, equipamentos e instalações. São Paulo: Senac, 2006.

CAMPOS, C.M. et al. São Paulo: metrópole em trânsito: percursos urbanos e culturais. São Paulo: Senac, 2004.

CANTERO, J. A. O Conjunto Habitacional "Parque do Gato" do programa de locação social da Cohab-SP. São Paulo: 2008. Disponível em:

$<$ http://www.usp.br/fau/cursos/graduacao/arq urbanismo/disciplinas/aut0583/2o. Se mestre de 2009/03. Aula 03 Setembro/02 o Conj. Habitacional Parque do Gato da Cohab-sp/02 o Conj. Habitacional Parque do Gato.pdf>. Acesso em: 20 maio 2010. 
CANTERO, J. A.; GHOUBAR, K. Sobre a sustentabilidade da produção pública de habitações populares para a "locação social" na cidade de São Paulo. São Paulo: 2008. Disponível em: <http://www.usp.br/nutau/CD/130.pdf>. Acesso em: 20 maio 2010.

CARSON, R. Primavera silenciosa. São Paulo: Gaia, 2010.

CARVALHO, A.R.; OLIVEIRA, M.V.C. Princípios básicos do saneamento do meio. 5. ed..São Paulo: Senac, 2005.

CARVALHO B. de. Ecologia e arquitetura. Rio de Janeiro: Globo, 1984.

CASEIRO A.H. Proteção do meio ambiente. São Paulo: Centro Universitário Nove de Julho (Uninove), 2006. Curso de especialização em engenharia de segurança do trabalho.

CETESB. Estudo do comportamento do ozônio na Região Metropolitana de São Paulo. 2000. Disponível em: <www.cetesb.sp.gov.br/relatóriosepublicações/ar>. Acesso em: 20 dez. 2009.

- Caracterização da rede automática de monitoramento da qualidade do ar na região metropolitana de São Paulo: Estação Cerqueira César, 2005. Disponível em: <www.cetesb.sp.gov.br/relatóriosepublicações/ar>. Acesso em: 20 de nov. 2009.

Relatório de qualidade do ar no Estado de São Paulo, 2008. Companhia de Tecnologia de Saneamento Ambiental. 2009. Disponível em: $<$ http://www.cetesb.sp.gov.br/Ar/publicacoes.asp>. Acesso em: 22 nov. 2009.

- Dados horários de temperatura do ar na Região Metropolitana de São Paulo e Cubatão. São Paulo: 1999.

Dados horários de temperatura do ar na Região Metropolitana de São Paulo, Interior e Cubatão. São Paulo: 2004.

Dados horários de umidade relativa do ar na Região Metropolitana de São Paulo e Cubatão. São Paulo: 1994.

Dados horários de umidade relativa do ar na Região Metropolitana de São Paulo e Cubatão. São Paulo: 1999. 
Dados horários de umidade relativa do ar na Região Metropolitana de São Paulo, Interior e Cubatão. São Paulo: 2004.

COMIN, A.A. Caminhos para o centro: estratégias de desenvolvimento para a região central de São Paulo. Introdução. Diagnósticos, oportunidades e diretrizes de ação. São Paulo: Emurb, 2004.

DEL RIO, V. Em busca do tempo perdido: o renascimento dos centros urbanos. Disponível em <http://www.vitruvius.com.br/arquitextos/arq000/esp028.asp $>$. Acesso em: 28 jun. 2008.

FOLHA DE SÃO PAULO. Um novo centro. 25 de maio de 2010.

FOLHA.COM. Buraco na camada de ozônio sobre a Antártida é o menor em cinco anos. 2010. Disponível em http://www1.folha.uol.com.br/ambiente/840159-buraco-dacamada-de-ozonio-sobre-a-antartida-e-o-menor-em-5-anos.shtml. Acesso em: 3 dez. 2010.

GALDINO, M.A.; SILVA, P.C. Perguntas mais frequentes sobre energia eólica. 2004. Disponível em <http://cresesb.cepel.br/faq/faq eolica.htm>. Acesso em: 19 out. 2007.

GARAY, A.M. Creación de una agencia de desarollo del centro. Relatório da assessoria técnica desenvolvido pelo centro de estudos Polis para o Procentro. São Paulo: 2002.

GROSTEIN, M.D. Metrópole e expansão urbana: a persistência de processos insustentáveis. São Paulo em perspectiva, v. 17, n.1, p. 13 - 19, 2001.

HIDROSTUDIO ENGENHARIA. Sistema de controle das inundações do Vale do Anhangabaú e da Avenida Nove de Julho. São Paulo: 2004.

IACOCCA, A. A conquista da Paulista: Conjunto Nacional. São Paulo: Peirópolis, 1998.

IGAMI, M.P.Z. Guia para elaboração de dissertações e teses. São Paulo: Ipen, 2002.

INSTITUTO DE ASTRONOMIA, GEOFÍSICA E CIÊNCIAS ATMOSFÉRICAS DA UNIVERSIDADE DE SÃO PAULO - IAG. Relatório anual de registro das temperaturas horárias no Parque Fontes do Ipiranga. São Paulo: 1981. 
Relatório anual de registro das temperaturas horárias no Parque Fontes do Ipiranga. São Paulo: 1983.

. Relatório anual de registro das temperaturas horárias no Parque Fontes do Ipiranga. São Paulo: 1988.

Relatório anual de registro das temperaturas horárias no Parque Fontes do Ipiranga. São Paulo: 1993.

. Relatório anual de registro das temperaturas horárias no Parque Fontes do Ipiranga. São Paulo: 1998.

Relatório anual de registro das temperaturas horárias no Parque Fontes do Ipiranga. São Paulo: 2003.

. Relatório anual de registro das umidades relativas horárias no Parque Fontes do Ipiranga. São Paulo: 1981.

. Relatório anual de registro das umidades relativas horárias no Parque Fontes do Ipiranga. São Paulo: 1983.

. Relatório anual de registro das umidades relativas horárias no Parque Fontes do Ipiranga. São Paulo: 1988.

Relatório anual de registro das umidades relativas horárias no Parque Fontes do Ipiranga. São Paulo: 1993.

. Relatório anual de registro das umidades relativas horárias no Parque Fontes do Ipiranga. São Paulo: 1998.

. Relatório anual de registro das umidades relativas horárias no Parque Fontes do Ipiranga. São Paulo: 2003.

INSTITUTO NACIONAL DE GEOGRAFIA E ESTATÍSTICA - IBGE. Dados demográficos dos distritos pertencentes às subprefeituras, 2000. Disponível em: $<$ www.prefeitura.sp.gov.br/cidade/secretarias/subprefeituras/subprefeituras/dados de mográficos>. Acesso em: 14 maio 2010.

Dados demográficos dos distritos pertencentes às subprefeituras, 1960.

Disponível em:

http://sempla.prefeitura.sp.gov.br/infocidade/htmls/7 populacao recenseada e proje tada 1950 530.html. Acesso em: 30 setembro 2010.

Pesquisa Nacional de Saneamento Básico 2000. Tabela 110 - Quantidade diária de lixo coletado, por destino final de lixo coletado, segundo as grandes regiões, 
unidades da federação, regiões metropolitanas e municípios das capitais. Disponível em:

$<$ http://www.ibge.gov.br/home/estatistica/populacao/condicaodevida/pnsb//lixo coleta dolixo coletado110.shtm>. Acesso em: 21 set. 2009.

JAHA, L. Conheça os detalhes das obras de restauro do Teatro Municipal . São Paulo: 2009. Disponível em:

$<$ http://www.prefeitura.sp.gov.br/cidade/secretarias/cultura/teatromunicipal/notícias $>$. Acesso em: 23 maio 2010.

JARDIM, N.S; WELLS, C; PRANDINI, F.L; D'ALMEIDA, M.L.O; MANO, V.G.T. (Coord). Lixo municipal: manual de gerenciamento integrado. Instituto de Pesquisas Tecnológicas (IPT) e Compromisso Empresarial para Reciclagem (Cempre). IPT no 2.163, São Paulo, 1996.

JOLY, C.A. Desenvolvimento sustentável: a utopia possível? 2003. Disponível em: $<$ http://www.biotaneotropica.org.br/v3n2/pt/editorial >. Acesso em: 6 set. 2009.

Biodiversidade e mudanças climáticas: contexto evolutivo, histórico e político. Ambiente \& sociedade, v. 10, n. 1, p. 169 - 172, 2007.

JORNAL DA TARDE. Reurbanização do Centro. São Paulo, 12 maio 2010.

LANDSBERG, H.E. The climate of the towns. In: THOMAS JR. (Ed.). Man's role in changing the face of the earth. Un. Chicago Press, 1956.

LEI № 14918/09. Concessão urbanística na área da Nova Luz. Disponível em: <http://www.jusbrasil.com.br/legislação >. Acesso em: 12 maio 2010.

LUZ, R.R. da. Centro velho de São Paulo: memória-momento. São Paulo: Lis Gráfica, 1999.

MASCARÓ, J. Infraestrutura e densificação. Porto Alegre: UFRGS; PMPA, 1996.

MAYER, R.M.P. Atributos da metrópole moderna. São Paulo em perspectiva, v. 14, n. 4 , p. $3-9,2000$.

MOTAVALLI, J. A carne na mesa. Com Ciência Ambiental, n. 20, p. 52 - 73, 2008. 
OKE, T.R. Boundary layer climates. London: Methuen, 1970.

PEREIRA FILHO, A.J., SANTOS, P.M. dos, CAMARGO, R. de, FESTA, M., FUNARI, F.L., SALUM, S.T., OLIVEIRA, C.T. de, SANTOS, E. M. dos, LOURENÇO, P.R, SILVA, E.G. da, GRACIA, W., FIALHO, M.A. Impactos antrópicos no clima da região metropolitana de São Paulo. Instituto de Astronomia, Geofísica e Ciências Atmosféricas. Departamento de Ciências Atmosféricas. São Paulo: 2007. Disponível em: $<$ http://www.nossasaopaulo.org.br/portal/files/impactos antropicos clima.pdf>. Acesso em: 14 jan. 2010.

PROCENTRO. Componentes do programa. São Paulo: 2010. Disponível em: <http://www.procentro.com.br>. Acesso em: 19 maio 2010.

RIBEIRO, H. Ilha de calor na cidade de São Paulo: sua dinâmica e efeitos na saúde da população. 1996. Tese (Livre-docência, área de gerenciamento ambiental) Faculdade Pública da Universidade de São Paulo, São Paulo.

ROCHA, A.A. A história do lixo. In: ENCONTRO TÉCNICO: resíduos sólidos e meio ambiente no estado de São Paulo, 10-11 nov. 1992, São Paulo.

RUBIES, J.E. Mercado Municipal da Cantareira. São Paulo 2004. Disponível em: $<$ http://www.piratininga,org/mercado municipal.htm>. Acesso em: 23 maio 2010.

SÃO PAULO [Cidade] - EMURB. Departamento de Paisagismo. Resumo do Projeto da Praça da Sé. São Paulo: 2004.

SÃO PAULO [Cidade] - EMURB. Diretoria de meio ambiente e paisagem urbana. Requalificação urbana da Praça da República. São Paulo: 2005.

SÃO PAULO [Cidade] - EMURB. Diretoria de Desenvolvimento e Intervenções Urbanas. Programa Procentro. São Paulo: 2007.

SÃO PAULO [Cidade] - NOVOS DISTRITOS. Lei 10.932/91. Disponível em: $<$ www.lidas.org.br/novasp/mapa20.htm >. Acesso em: 14 jul. 2008.

SÃO PAULO [Cidade] - SEMPLA. Atlas ambiental do município de São Paulo. Disponível em: <http://atlasambiental.prefeitura.sp.gov.br/>. Acesso em: 19 jul. 2008.

SÃO PAULO [Cidade] - SUBSÉ. Varrição de ruas. Disponível em: $<$ http://portal.prefeitura.sp.gov.br/subprefeituras/spse>. Acesso em: 20 set. 2009. 
SÃO PAULO [Cidade] - SVMA. Panorama do meio ambiente urbano. Geo, cidade de São Paulo. Prefeitura do Município de São Paulo. Coordenação: Patrícia Marra Sepe e Tânia de Oliveira Braga. Secretaria Municipal do Verde e do Meio Ambiente e Instituto de Pesquisas Tecnológicas do Estado de São Paulo. Programa das Nações Unidas para o Meio Ambiente. Brasília: 2004.

SÃO PAULO [Cidade] - SVMA. Termo de referência para contratação de plano de referência objetivando subsidiar o Plano Diretor de Arborização de Vias Públicas dos distritos da Sé e República. São Paulo: 2010.

SCARIGELLA, R.S. A crise da mobilidade urbana em São Paulo. São Paulo em perspectiva, v. 15, n. 1, p. $55-59,2001$.

SCHUTZER, J.G. Paisagem, paisagismo e meio ambiente: os arquétipos naturais e a intervenção paisagística. Caderno de textos de apoio do curso de pós-graduação em desenho ambiental e arquitetura da paisagem. São Paulo: Universidade Presbiteriana Mackenzie, 2005.

SEPE P.M; GOMES S. Indicadores ambientais e gestão urbana: desafios para a construção da sustentabilidade na cidade de São Paulo. São Paulo: Imprensa Oficial, 2008.

SEWELL H.G. Administração e controle da qualidade ambiental. São Paulo: Edusp, 1978.

TARIFA, J.R.; ARMANI, G. Unidades climáticas urbanas da cidade de São Paulo. In: SÃO PAULO [Cidade]. Atlas ambiental do município de São Paulo, Fase I. São

Paulo: 2000.

TASCHNER, S.P; BÓGUS, L.M.M. São Paulo, o caleidoscópio humano. São Paulo em perspectiva, v. 15, n. 1, p. 31 - 44, 2001.

UNEP. As conquistas do regime do ozônio. Programa das Nações Unidas para o Meio Ambiente / Filial de Informação e Questões Públicas - Unep. 1996. Disponível em: <http://homologa.ambiente.sp.gov.br/prozonesp/default.asp>.

Acesso em: 27 dez. 2009.

VESPUCCI, A.C. Recursos internacionais para o Centro. Urbs, n. 33, p. 8 - 14, 2004. 